


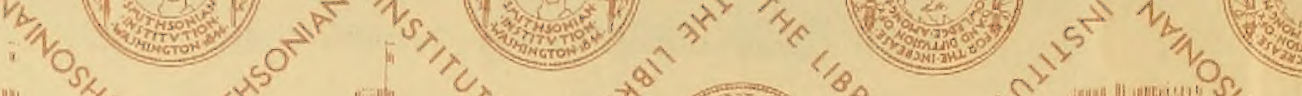

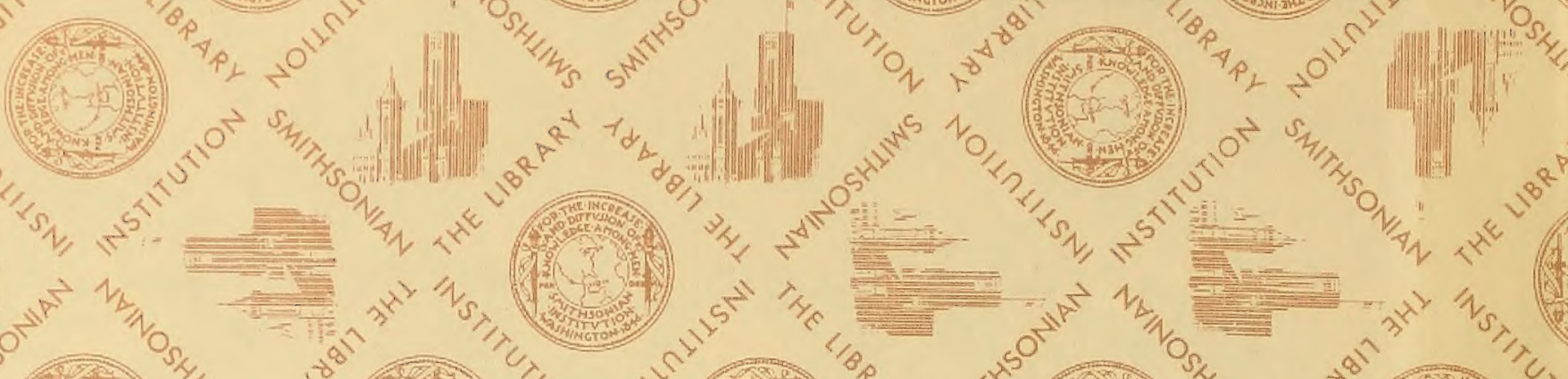

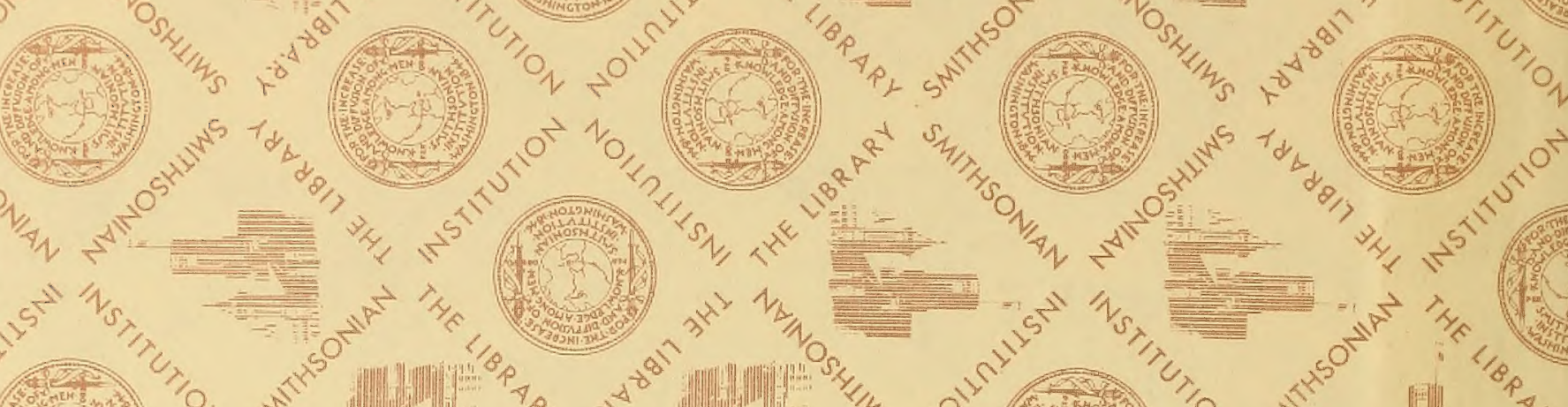

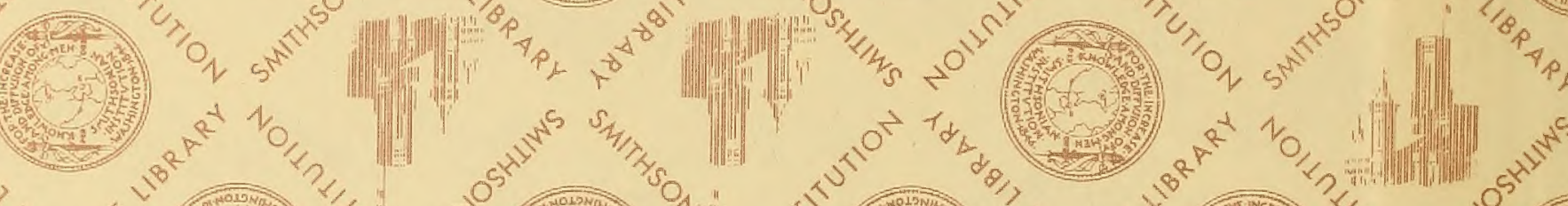

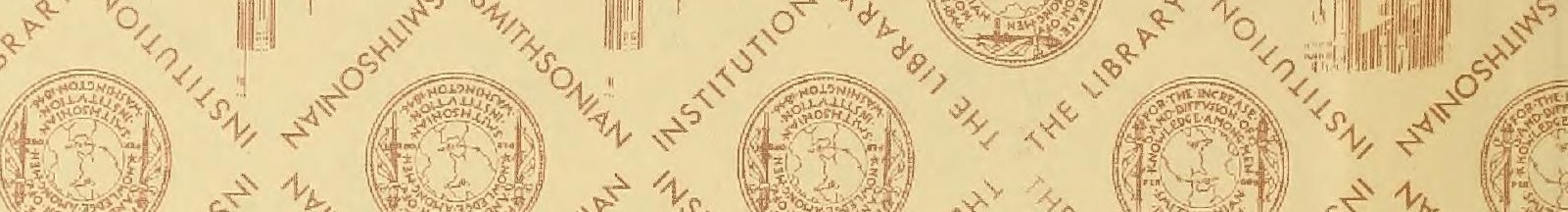
(i)
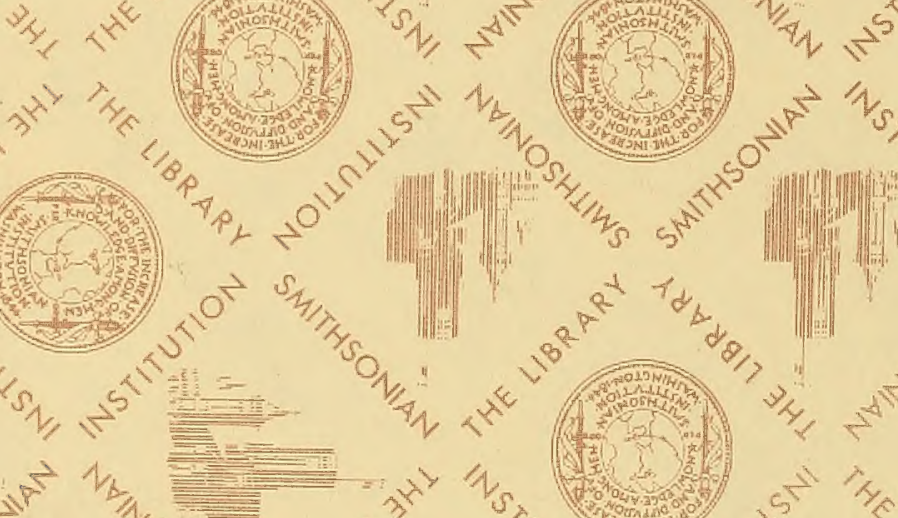

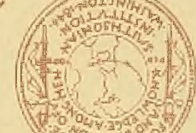

$(1250$

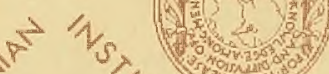

st $\frac{1}{b} v_{0}$

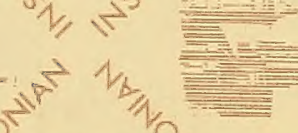

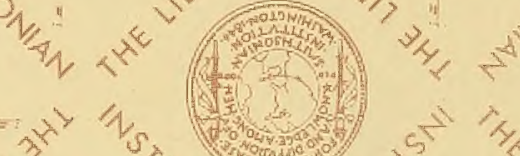

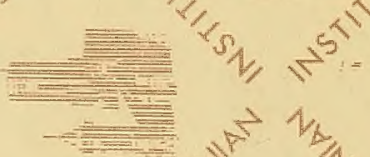
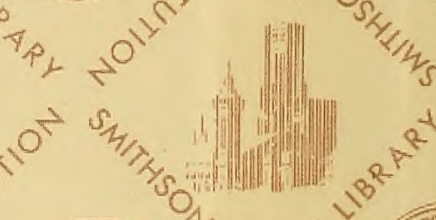

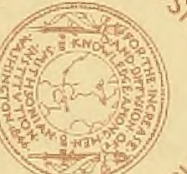

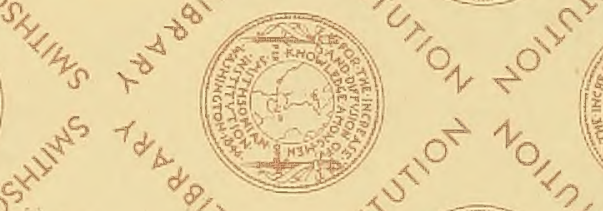

政

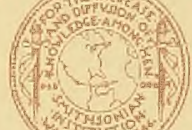

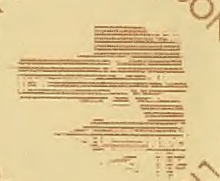

IIIf $s^{p^{2}}$
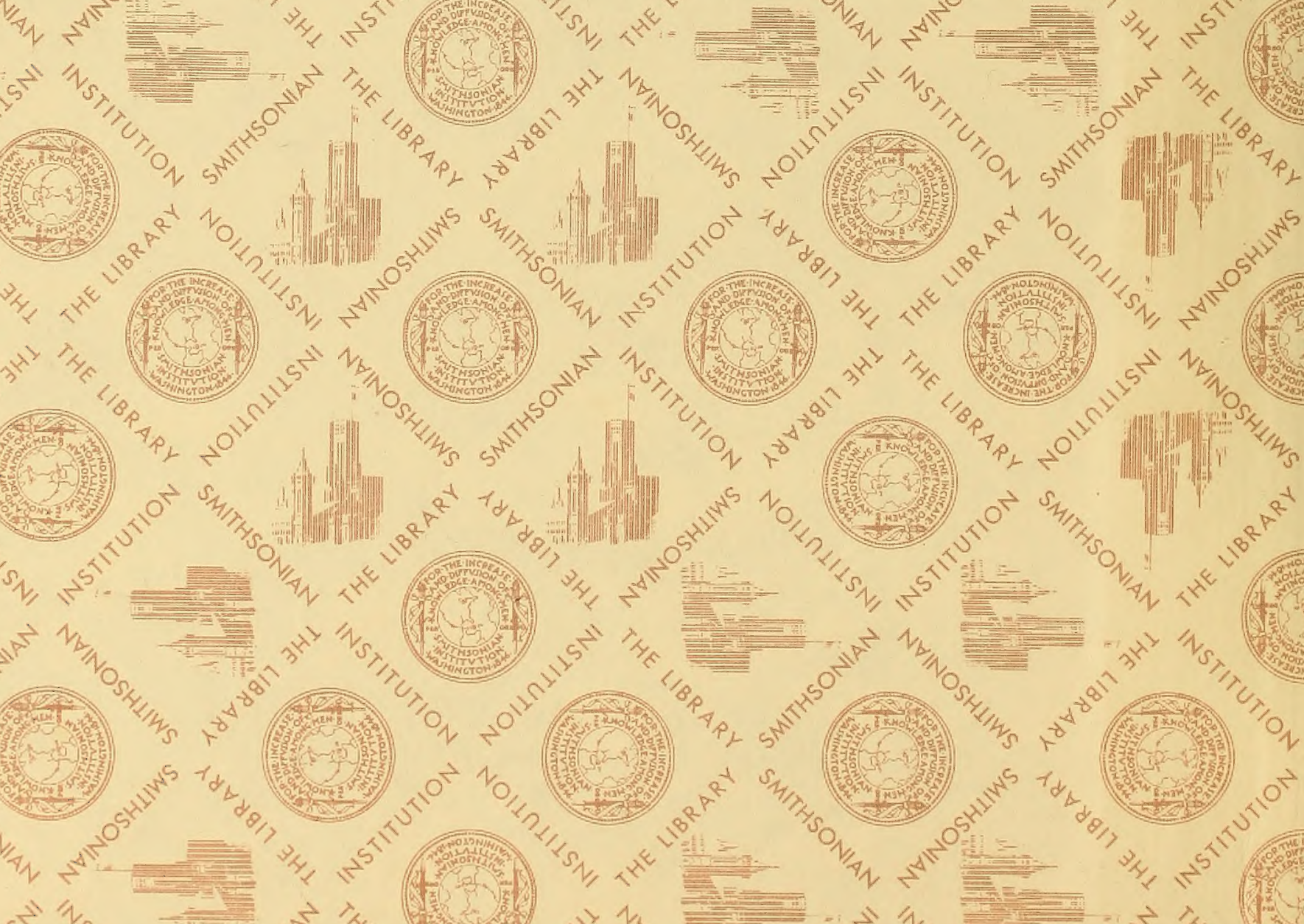

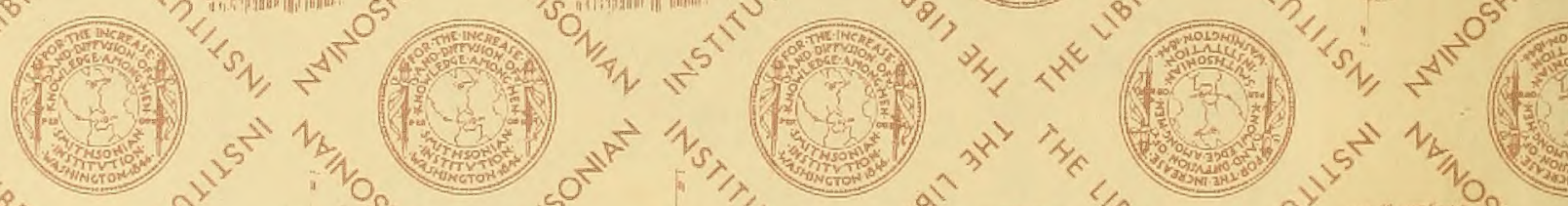
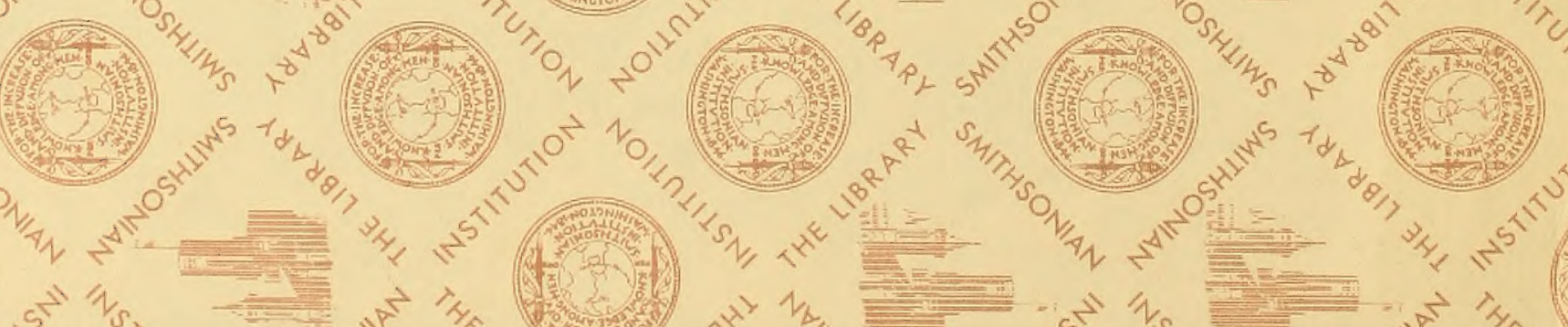

is

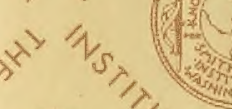

(2) $\mathrm{O}^{2}$ 








\section{Die Kriechthiere}

\section{Deutsch-Ost-Afrikas.}

Beiträge zur Systematik und Descendenzlehre

\section{Dr. Gustav Tornier}

Kustos am Kgl, Museum für Naturkunde zu Berlin.

Mit 5 Tafeln und 11 Textfiguren nach der Natur gezeichnet

von

Euald H. Rüibsaamen.

\section{BERLIN 1897}

Geographische Verlagsbuchhandlung Dietrich Reimer 


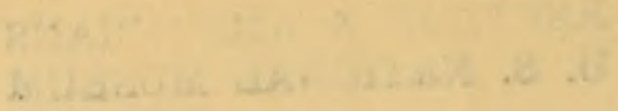

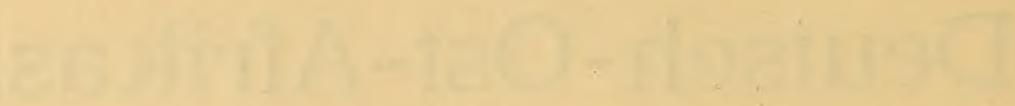

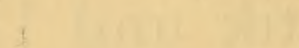




\section{VORWORT.}

Ueber dem grössten Theil des Kriechthier-Materials, welches im Verlauf der letzten 12 Jahre in Deutsch-Ost-Afrika gesammelt worden ist, schwebte bisher ein eigenthümliches Missgeschick. Da es von deutschen Forschern, vorwiegend auf Anregung von Peters, dem früheren Direktor des Berliner zoologischen Museums, zusammengebracht worden war, wurde es natürlicher Weise ihm zur Bearbeitung anvertraut, was um so berechtigter war, da Peters, wie bekannt, eine erste Autorität in der Herpetologie gewesen ist. Gerade zur Zeit nun, als die bedeutendsten dieser von ihm sehnlichst erwarteten Sendungen hier einliefen, starb Peters, und seitdem ruhten sie unbearbeitet in den Vorräthen des zoologischen Museums in Berlin, weil die wenigen wissenschaftlichen Beamten, welche dieses Institut zu Peters' Zeiten besass, durch andere gleich wichtige Arbeiten voll in Anspruch genommen wurden. So blieb dieses Material und vieles andere, das später hinzukam, liegen bis zum Jahre I 895, wo ich seine Bearbeitung übernahm.

Ursprünglich war ich nicht zum Mitarbeiter an diesem Werk ausersehen.

Emin Pascha und Stuhlmann hatten bestimmt, dass Herr Dr. Pfeffer, wie bekannt der Bearbeiter ihrer »ersten "Kriechthiersendung, auch ihre ferneren Sendungen verwerthen solle, und damit fiel ihm naturgemäss die Bearbeitung der vorliegenden Abtheilung dieses Reisewerkes zu. Leider sah sich Herr Dr. Pfeffer genöthigt, ein Jahr später den ehrenvollen Auftrag krankheitshalber abzulehnen, und so musste ich, als Verwalter der Reptilien- und Amphibiensammlung des Berliner Museums, an seine Stelle treten.

Die Arbeit, welche mir auf diese Weise zufiel, war sehr umfangreich. Dass ich sie relativ schnell erledigen konnte, verdanke ich erstens dem ausgezeichneten Vergleichsmaterial der Berliner zoologischen Sammlung, das in Folge der unermüdlichen Forscherthätigkeit eines Peters an Verlässlichkeit nichts zu wünschen uibrig lässt; dann dem Umstand, dass ein Theil der »zweiten « Stuhlmann-Sendung durch Dr. Pfeffer bereits bestimmt war, als er die Bearbeitung derselben abzulehnen gezwungen wurde.

Obgleich ich dem mir befreundeten Hamburger Gelehrten für diese sehr werthvolle und vorzügliche Vorarbeit zu grossem Dank verpflichtet bin, habe ich dieselbe doch nur als Kontrolle für meine eigenen Bestimmungen verwerthet, und in einigen zweifelhaften Fällen bin ich ausserdem nur meiner Ansicht gefolgt, übernehme deshalb auch allein die Verantwortung für Alles, was in diesem Abschnitt des Stuhlmann-IVerkes an Artbestimmungen enthalten ist. Andererseits fügte es sich für diese Arbeit sehr günstig, dass Herr Oscar Neumann, welcher dem Museum eine grossc Sammlung ostafrikanischer Kriechthicre übergeben hatte, 
als fast alle Eidechsen und Frösche und ein Theil seiner Schlangen von mir bestimmt worden waren, sich plötzlich entschloss, seine gesammte herpetologische Ausbeute Herrn Boulenger zur Durchsicht vorzulegen. In Folge dessen ist auch dieses Material bereits doppelt bearbeitet worden. Im Text dieses Buches findet man gewissenhaft angegeben, welche von Neumann's Exemplaren Herr Boulenger zuerst bestimmt hat und wo ich mich ihm angeschlossen habe. An anderen Stellen habe ich meine gegentheilige Ansicht $\mathrm{zu}$ begründen gesucht. - $\mathrm{Zu}$ grossem Dank verpflichtete mich ausserdem Herr Boulenger durch die Bestimmung der in dieser Arbeit beschriebenen Coecilienart, die ich deshalb nach ihm benenne. - Dadurch aber, dass bereits mehrere Forscher grosse Theile des von mir untersuchten Materials vor und neben mir bearbeitet haben, dürften die in dieser Schrift enthaltenen »Bestimmungen « an Sicherheit kaum etwas zu wünschen übrig lassen.

Sehr eingehend habe ich dann ausserdem die mir vorliegenden Individuen auf Varietätenbildung untersucht. Schon Peters und Fischer haben darauf hingewiesen, dass die Variabilität der afrikanischen Kriechthierarten eine sehr grosse ist, und Boulenger wies später an dem Beispiel von Chalcides ocellatus nach, dass die zahlreichen, sehr voneinander abweichenden Varietäten dieser Art zwar örtlich getrennt sind, aber doch eine lückenlose, geschlossene Entwicklungsreihe bilden. Ich selbst bin nunmehr in der Lage, in den Individuen von Chamaeleon bitaeniatus eine ebenso grosse, lückenlose Varietätenreihe nachzuweisen, deren Glieder wahrscheinlich auch örtlich getrennt sind. Aus alledem aber folgt: Kaum ein anderes zoologisches Material dürfte für die Lösung von Descendenzfragen so geeignet sein, wie die afrikanische Kriechthierfauna. Auch noch andere Stellen dieser Schrift lassen das erkennen. Woraus dann weiter folgt: Diese Schrift selbst ist keine rein systematische Arbeit und ... sie soll es auch gar nicht sein. -

Das mir vorliegende, an Individuen sehr reiche Untersuchungsmaterial hat mich in mehreren Fällen vor die Frage gestellt: Entsprechen die von anderen Autoren aufgestellten Artbegriffe wirklichen Naturarten? Ich habe jedoch nur solche Artbegriffe zusammengezogen, deren Vertreter nachweisbar in ihren sämmtlichen Charakteren durch Uebergänge verbunden sind. Wo ich diesen Nachweis nicht ganz führen konnte, und selbst dann, wenn vielleicht nur noch ein Divergenzcharakter zweifelhafter Werthigkeit den als Arten beschriebenen Individuen eine gewisse Selbstständigkeit gegeneinander garantirte, habe ich nur durch eingehende Besprechung ein Fragezeichen an die betreffende Art gesetzt. Mit einem kühnen Satz über die Hindernisse hinwegspringen wollte ich nicht.

Das führt mich nun zu der Auffassung, die ich vom Artbegriff überhaupt habe. Ich bin Gegner der Ansicht, dass jedes Individuum, welches von dem nächst verwandten in irgend einem Merkmal abweicht, zu einer neuen Art gehört. Auch stimme ich darin Boulenger bei, dass Farbendivergenzen, wie gross sie auch seien, nur Varietätscharaktere sind. Eine »Arte ist nämlich für mich, wie für die meisten Zoologen, eine Gruppe von Individuen, welche unter normalen Verhältnissen Nachkommen erzeugen können, die durch mehrere Generationen hindurch fortpflanzungsfähig sind. Dieser "physiologische" Artbegriff ist natüricher Weise für den »Morphologen nicht anwendbar, und so erkläre ich als Morphologe in Uebereinstimmung mit Boulenger und Pfeffer die Art als Individuen von sehr ähnlichem, aber durchaus nicht kongruentem Bau, welche auf gemeinsame Abstammung schliessen lassen, weil sie so angeordnet werden können, dass sie in Ruicksicht auf ihre Divergenzcharaktere lickenlose Entwicklungsreihen bilden.

$\mathrm{Ob}$ der physiologische und morphologische Artbegriff sich decken, kann hier nicht untersucht werden, es genuigt, wenn darauf hingewiesen wird, dass es annähernd der Fall ist, da bei Individuen, welche sich fruchtbar begatten, bis zu einem gewissen Grade eine Mischung der Charaktere möglich ist, die Kreuzung also für die Entstehung der Zwischenformen Sorge trägt. 
Thiergeographische Spekulationen sind in dieser Abhandlung nicht enthalten, erstens fehlte die Zeit dazu, zweitens ist das herpetologische Material für derartige Arbeiten nicht ausreichend, denn einem oder wenigen Individuen, die von anderen nur wenig abweichen, ist es nicht anzusehen, ob sie $»$ Lokalformen oder nur "Varietäten«, ob sie "vikarirende" oder "gemischt lebende" Arten sind. Und wenn bestimmte Arten bisher nur in bestimmten Gegenden gefunden worden sind, ist damit noch keineswegs bewiesen, dass sie nirgend anders gefunden werden können oder gar gefunden werden dürfen. Dagegen enthält die vorliegende Arbeit Alles, was mir bisher über die Kriechthierfauna DeutschOst-Afrika's entweder aus der Litteratur oder durch eigene Arbeit bekannt geworden ist, daneben sind noch einige Arten berücksichtigt, welche aus der Nachbarschaft dieses Gebietes von Sammlern herruhren, die vorwiegend in Deutsch-Ost-Afrika thätig gewesen sind. Es wäre ein Unrecht gewesen, wenn hier nur der Haupttheil ihrer Forscherthätigkeit Beruicksichtigung gefunden hätte.

Da uiber die meisten dieser Sammler, weil sie nicht nur Kriechthiere, sondern auch andere Wirbelthiere gesammelt haben, in diesem Werk schon zweimal eingehend berichtet worden ist, halte ich es für überfluissig, noch einmal auf ihre Reisen zurückzukommen und verweise deshalb auf die Abhandlung meiner Vorgänger in dieser Schrift. Sehr reiches Kriechthiermaterial aus DeutschOst-Afrika sandten nach Berlin: Dr. Richard Böhm, Dr. Gustav Fischer, Johann Maria Hildebrandt, Dr. Stuhlmann, Oscar Neumann, ganz vorzüglich waren auch die drei kleineren Sendungen aus Usambara, welche Gustav Eismann, L. Conradt und Reimer einsandten. (Auch die Thiere, welche Franz Werner aus Usambara beschrieben hat, gehörten übrigens ursprünglich der Reimer'schen Sammlung an.) Einzelne Kriechthiere aus Deutsch-Ost-Afrika sandten nach Europa und zum Theil nach Berlin: Prof. Dr. Volkens, Abott, Graf Teleki, von Höhnel, Dr. J. Kirk, H. Johnston, Révoil, J. Thomson, F. J. Jackson, Scott Elliot, Lieutenant Elpons, Forstassessor Krüger und mancher andere, dessen Namen man unter der betreffenden Artbezeichnung finden wird. -

Die Abbildungen, welche dieser Arbeit im Text und als Tafeln beigegeben werden, sind mit Ausnahme der ausdrücklich als schematisirt bezeichneten so peinlich genau nach der Natur gezeichnet, dass selbst die Hautbilder kleinschuppiger Reptilien bis in's Detail den Objekten entsprechen. Um diese Genauigkeit überall, wo es nöthig war, zum Extrem zu steigern, wurden die Objekte von meinem Kollegen Dr. Wandolleck vergrössert photographirt, und dann unter Benutzung der Photographien gezeichnet; so entstanden z. B. die Figuren auf Tafel II. Ich danke daher ausser Dr. Wandolleck hier noch besonders dem Verfertiser dieser Abbildunsen, dem als Entomologen wohlbekannten Herrn Ewald H. Rübsaamen zu Berlin für den grossen Fleiss und für das Verständniss, mit dem er sich bei Ausführung der Zeichnungen in die vielen Anforderungen, welche ich an ihn gestellt habe, und in ein ihm bisher fremdes wissenschaftliches Gebiet hineingearbeitet hat. Ausserdem bin ich auch Herrn Prof. Dr. Karsch in Berlin für die Liebenswürdigkeit zu Dank verpflichtet, mit. welcher er mich bei der Benennung der Rappienfarbkleider unterstützt hat. 


\section{Vorwiegend benutzte Litteratur.}

Ballowitz: Die Nerven der Chromatophoren. Anatomischer Anzeiger, Ergänzungsheft I 893, S. 72.

Beddard, F. E.: Animal Coloration. London, I 892.

Bocage: Herpétologie d'Angola et du Congo. Lisbonne, I 895.

- Melanges erpétologiques. Jornal de Lisboa (IV), I873, S. 201.

Böhm, R.: Handschriftliche Mittheilungen.

Böttger: Uebersicht der von Professor Dr. Keller anlässlich der Ruspoli'schen Expedition nach den Somaliländern gesammelten Reptilien und Amphibien. Zoologischer Anzeiger I893, S. II 3,129 und I93.

Boulenger: Catalogue of Lizards, Bd. I-III. London, I885 und I887.

- Catalogue of Batrachia salientia. London, I882.

- Catalogue of Chelonia and Crocodilia. London, I889.

- Catalogue of Snakes, Bd. I und II. London, I893-94.

- On newly discovered East-Afrikan Chameleons. Ann. NH (i6) IX, I892, S. 72 und 74 .

- On two new East-Afrikan snakes. Ann. Mag. nat. hist., I895, S. I7 I.

- On the reptiles collected by Brichetti Robecchi in Somalia. Annali del. Mus. Scienc. nat. Genova, (2) XII, I 89I, S. 5.

- Description of new Species of Coeciliae. Proceed zool. Soc., I890, S. 80.

- Zoological Record, I889 (Reptilia and Amphibia).

- A Synopsis of the Genera and Species of Apodal Batrachians, with Description of a new Genus and Species (Bdellophis vittatus) Proceed. zool. Soc., 1895, S. 401 .

Bronn: Klassen und Ordnungen des Thierreichs, Bd. VI und VII (Amphibien und Reptilien von C. K. Hoffmann).

Brücke: Ueber den Farbwechsel der Chamaeleonen. Sitzungsber. Wiener Acad. Mat.-nat. Klasse, I851, S. 802.

- Ueber den Farbwechsel der Chamaeleonen. Abhandlungen der Wiener Acad. Mat.-nat. Klasse, Bd. IV, 1852 , S. 58.

- Vergleichende Bemerkungen über Farben und Farbwechsel der Cephalopoden und Chamaeleonen. Sitzungsber. Wiener Acad. Mat.-nat. Klasse, I852, S. 196.

- Ueber die Farben, welche tribe Medien in auffallendem oder durchfallendem Lichte zeigen. Sitzungsber. Wiener Acad. Mat.-nat. Klasse, I8 52 , S. 530.

Cunningham: An experiment concerning the absence of color from the lower side of Flatfishes. Zoologischer Anzeiger I89I, S. 27.

von der Decken: Reisen in Ostafrika. Leipzig, I 869. (Abtheil. Säugethiere und Amphibien bearb. von Peters.) 
Disse, J.: Die Haut. Referat in den Ergebnissen der Anatomie und Entwicklungsgeschichte von Merkel und Bonnet, I892, S. 229.

Eberth, Jos.: Untersuchungen zur normalen und pathologischen Anatomie der Froschhaut. Leipzig, I869.

- Die Nerven der Chromatophoren. Anatomischer Anzeiger, Ergänzungsheft I893, S. 70 .

Ecker, Alex.: Anatomịe des Frosches. Braunschweig, 1887.

Ehrmann: Zur Kenntniss von der Entwicklung und Wanderung des Pigments bei den Amphibien. Archiv für Dermatologie und Syphilis, Jahrgang 24, I 892 , S. 195.

Eimer, Theodor: Zoologische Studien auf Capri II: Lacerta muralis coerulea. Leipzig, I 874 .

- Ueber das Variiren der Mauereidechse. Troschel's Archiv I88I.

- Ueber die Zeichnung der Thiere, I. Säugethiere a) Raubthiere. Zoologischer Anzeiger I882, 1883 und 1884 .

- Ueber die Zeichnung der Vögel und Säugethiere. Württembergische Jahreshefte 1883 .

- Bruchstücke aus Eidechsenstudien. Humboldt, I883.

- Ueber die Zeichnung der Thiere I-VI. Humboldt, I885-88 und I 890.

- Die Verwandtschaftsbeziehungen der Raubthiere. Humboldt, 1890.

- Die Artbildung und Verwandtschaft bei den Schmetterlingen. Jena, I889.

- Das Entstehen der Arten. Jena, 1888.

Elsässer: Studien über Pigmentflecken der Haut. Berlin, 1886. Diss.

Emin Pascha und Stuhlmann: Lebensweise des Krokodils. Zoologische Jahrbücher, Abth. für System., Bd. 5 (1890), S. 546.

Flemming: Ueber die Theilung der Pigmentzellen und Capillarwandzellen. Archiv f. mikrosk. Anatomie I890, Bd. I, S. 275.

Fischer, J. G.: Ueber einige afrikanische Reptilien, Amphibien und Fische. Jahresberichte naturhist. Mus. Hamburg 1884.

Guinther: Report on the Collection of Reptiles and Batrachians transmitted from Nyassaland. Proceed. zool. Soc. London I892, S. 553.

- Notice of Reptiles and Batrachians collected in the Eastern Half of Tropical Africa. Ann. Mag. I 895, S. 523.

Häcker, V.: Ueber die Färbung der Vogelfedern. Archiv für mikroskopische Anatomie I 890 , S. 79.

Harless: Ueber die Chromatophoren des Frosches. Münchener Gelehrten-Anzeigen I 853, N. 35 .

Jarisch: Ueber die Anatomie und Entwicklung des Oberhautpigments beim Frosch. Archiv f. Dermatologie und Syphilis, Jahrg. 23 (I89I), S. 559.

- Ueber die Bildung des Pigments in den Oberhautzellen. Archiv für Dermatologie und Syphilis, Jahrg. XXIV (1892), S. 223.

Kaposi: Ueber die Pathogenese der Pigmentirungen und Entfärbungen der Haut. Wiener Medizinische Blätter, Jahrg. I4, Nr. I3, S. I93.

Kromeyer: Oberhautpigment der Säugethiere. Archiv f. mikroskop. Anatomie, Bd. 42 , S. I.

- Lymphbahnen und Lymphcirkulation der Haut. Monatshefte für praktische Dermatologie, Bd. XIII, Nr. 9, S. 359.

Krukenberg und Ewald: Ueber das Guanin, besonders über sein Vorkommen in der Haut von Amphibien und Reptilien. Untersuchungen aus dem physikalischen Institut zu Heidelberg, Bd. IV, Heft 3, I882.

Lewin: Ueber Morbus Addisoni. Charité-Annalen X.

- Ueber die halbseitigen Atrophien und Hypertrophien mit besonderer Bericksichtigung des Pigments. Charité-Annalen IX 
Leydig: Integument und Hautsinnesorgane der Knochenfische. Zoologische Jahrbücher, Abth. für Anatomie, Bd. VIII (I894/95), S. I.

- Allgemeine Bedeckung der Amphibien. Archiv f. mikroskop. Anatomie I 896.

- Blaufarbiger Wasserfrosch, Leuchtflecken der. Ellritze. Zoologischer Garten, 1892 , S. . 1 .

- Ueber das Blau in der Farbe der Thiere. Zoologischer Anzeiger 1885, S. 752.

- Pigment der Haut und Iris. Verhandl. der physik.-mediz. Gesellsch. zu Würzburg I 888.

Lode, Aloys: Beiträge zur Anatomie und Physiologie des Farbwechsels der Fische. Sitzungsber. Akad. Wien I890, S. I30.

Matschie: Ueber eine kleine Sammlung von Säugethieren und Reptilien, welche Herr L. Conradt aus Usambara (Deutsch - Ost - Afrika) heimgebracht hat. Sitzber. Gesellsch. nat. Freunde zu Berlin I 892, S. I04.

Mertsching: Histologische Studien über Keratohyalin und Pigment. Archiv für pathol. Anatomie und Physiologie I889, S. I I6.

Mocquard: Sur une Collection de Reptiles et de Batrachiens rapportés des Pays Çomalis et de Zanzibar par M. G. Révoil. Mém. soc. Philom. I\$88, S. IO3.

Nathusius, W. v.: Die Fibrillen oder Hornzellen der Haare und die Beziehungen der Pigmentkörperchen zu denselben. Archiv f. mikrosk. Anat. I 894, S. 148 .

Neumann, E.: Beiträge zur Kenntniss der pathologischen Pigmente.'Archiv für pathologische Anat. und Physiol. I 888 (III), S. 25.

Peters: Naturwissenschaftliche Reise nach Mossambique, I 882, Bd. III.

- Zahlreiche Abhandlungen über ostafrikanische Kriechthiere in den Berichten der Berliner Akad. der Wiss. und in den Sitzungsber. Gesellsch. nat. Freunde zu Berlin, Jahre I $868,-70,-74,-78, .82,-86$.

Pfeffer: Uebersicht der von Stuhlmann in Aegypten, Zanzibar und dem gegenüberliegenden Festlande gesammelten Reptilien, Amphibien und Fische. Mittheilungen aus dem naturhistor. Museum in Hamburg, Bd. VI (I 889), N. 4, S. I.

- Ostafrikanische Reptilien und Amphibien, gesammelt von Herrn Dr. F. Stuhlmann im Jahre I 888 und I 889. Jahrbuch Hamburger gelehrter Anstalten X, I893, S. 7 I.

Poulton, Bayn: Colours of animals. London, I890.

Rathke, Heinr.: Entwicklungsgeschichte der Natter (Coluber natrix), Königsberg, I839.

Reichenow: Neue Wirbelthiere des zoologischen Museums zu Berlin. Zoologischer Anzeiger I 887 , S. 369.

Schenkling-Prevôt: Farbenwechselnde Fische des Berliner Aquariums. Der zoologische Garten, I 893.

Schmidt, Martin: Ueber die Verwandtschaft der haematogenen und autochthonen Pigmente und deren Stellung zur sogenannten Haemosiderie. Archiv für pathol. Anat, und Physiologie I 889 , S. I I5.

Schwalbe: Ueber den Farbenwechsel winterweisser Thiere. Morphologische Arbeiten, Bd. II, H. 3, I 893, S. 483 .

Steindachner, F.: Bericht über die von Herrn Linienschiffslieutenant Ritter von Höhnel während der Graf Telecki'schen ostafrikanischen Expedition gesammelten Reptilien. Sitzungsber. Akad. Wien, I89I, S. 307.

Stejneger: On some Collections of Reptiles and Batrachians from East Africa and the adjacent Islands recently received from Dr. W. L. Abott. Proceed. United states national Museum, I 1894, S. 709.

- Description of a new scincoid Lizard from East Afrika. Proceed. Nat. Mus. Philad. vol. XIV, S, 405. 
Stuhlmann: Handschriftliche Mittheilungen.

Tylor, Alfred: In F. E. Beddard S. 30 citirt.

Unna: Dermatologische Studien, I892, S. I4.

Voeltzkow, A.: Ein Beitrag zur Kenntniss der Eiablage bei Krokodilen. Zoologischer Anzeiger I890, S. 190.

- Ueber die Eiablage und Embryonalanlage der Krokodile. Sitzungsber. der Berliner Akad. d. Wissensch. I89I, S. II 5.

Werner, Franz: Untersuchungen über die Zeichnung der Schlangen. Wien, I890.

- Untersuchungen über die Zeichnung der Wirbelthiere. Zoologische Jahrb. Bd. VI (I892/93), S. I 55 und Bd. VII (1893/94), S. 365.

- Kriechthiere aus Usambara (Deutsch-Ost-Afrika. Verhandl. d. K. K. zool.-bot. Gesellsch., Wien, I895.

- Biologische Notizen aus der Reptilienwelt. Der zoologische Garten, I892, S. 367 .

- Thierleben in Ost-Algerien. Der zoologische Garten, . I892, S. 264.

Wurm: Ueber die Farben der Vogelfedern (Referat). Der zoologische Garten, I 89 I, S. 212.

Zacher: Der Farbenwechsel der Frösche und Tintenfische. Der zoologische Garten, I 894 , S. I 57.

Zenneck: Die Anlage der Zeichnung und deren physiologische Ursachen bei Ringelnatterembryonen. Archiv für mikroskop. Anatomie I 894, S. 364. Zimmermann: Ueber die Kontraktion der Pigmentzellen der Knochenfische. Anatomischer Anzeiger, Ergänzungsheft 1893, S. 76.

- Studien über Pigmentzellen I. Ueber die Anordnung des Archiplasmas in den Pigmentzellen der Knochenfische. Archiv für mikroskop. Anat. 1893, S. 367 . 


\title{
Das Sammeln der Kriechthiere.
}

\author{
Welche Reptilien und Amphibien braucht das Museum für Naturkunde \\ zu Berlin jetzt noch aus Ost-Afrika? \\ Fast alle Sammler, welche aus Afrika Kriechthiere nach Berlin sandten,
} haben den Fehler gemacht, dass sie recht viele Arten zu sammeln bestrebt waren, aber möglichst wenige Vertreter dieser Arten einschickten. Der Grundsatz, nach welchem sie sammelten, lautete demnach: Viele Arten, wenig Exemplare! Ferner berücksichtigten sie »gemeine" Arten nur wenig, denn, so überlegten sie, »die wird das Museum schon haben". Beide Methoden des Sammelns sind falsch. Gewiss ist es gut, wenn viele Arten gesammelt werden, aber es darf nie auf Kosten der Artexemplare geschehen. Und gemeine Arten sind ebenso werthvoll wie seltene Arten und müssen in recht vielen Exemplaren gesammelt werden; aus folgenden Gründen:

Kein Exemplar einer thierischen Art stimmt mit seinen Artgenossen in allen Charakteren genau überein; jedes weicht vom anderen in etwas ab. Es besteht demnach jede Art aus einer Gruppe von sehr ähnlichen, aber doch durch kleine Unterschiede voneinander getrennten Individuen. Je häufiger eine Art ist, desto häufiger sind natürlicher Weise derartige Verschiedenheiten unter ihren Vertretern, und daraus folgt dann: Da selbst von den allergemeinsten ausländischen Kriechthier-Arten noch lange nicht genügendes Material in europäischen Museen ist, sind gerade viele ihrer Varietäten für selbstständige Arten beschrieben worden. Der Zoologe in Europa aber muss trotz innerem Widerstreben diese "Bucharten « so lange in seinen Verzeichnissen führen, bis er durch mehr Vergleichsmaterial beweisen kann, dass sie nur »Varietäten « einer "Naturart « sind. Nun kann man aber ausserdem ohne Uebertreibung sagen, von keiner der ostafrikanischen Kriechthierarten wissen wir genug und von den gemeinsten thatsächlich am wenigsten. Wieviel Arten der ganz gemeinen grünen Baumschlangen giebt es in Afrika? Wir wissen es nicht! - Bis zu welchem Grade variirt die gemeinste Eidechse Ost-Afrikas, der in jedem Negerdorf in vielen hundert Exemplaren vorkommende Streifenskink? Nichts ist davon bekannt! - In allen niederen Buischen Ost-Afrikas hausen Laubfrösche in zahllosen Mengen. Gerade über sie sind wir aber am schlechtesten unterrichtet, und es werden noch Tausende von ihnen nach Europa gesandt werden müssen, ehe es besser damit wird. Man sammle also viele Arten, wenn es geht; schicke aber von allen Arten, und wenn es die gemeinsten sind, sehr viele Exemplare. Bei kleinen Kriechthieren, besonders Laubfröschen, 30-40 Stück einer Art, selbst wenn sie aus einer Gegend stammen. Findet man aber in einer Gegend Exemplare einer Art, die sclbst im Farbkleid nur ganz wenig voneinander abweichen, dann schicke 
man sie alle ein. Auch ganz junge und halberwachsene Exemplare der Art lege man bei.

Ferner mache man ganz besonders Jagd auf Kriechthiere, welche in der Begattung sind. Glückt es, solche zu fangen, so binde man sie nach dem Abtödten mit den Hinterfüssen zusammen und bringe sie so in die Versandtflaschen. Man kann im Allgemeinen sagen: Was sich in Freiheit miteinander begattet, gehört zu einer Art. Daher werfen Thiere, welche in der Begattung gefangen werden, ein helles Licht auf viele sehr schwierige Fragen der Systematik. Sie sind für den Zoologen von unschätzbarem Werth.

Ferner achte man auf Junge, welche aus einem Nest stammen. Diese schicke man sämmtlich ein. Auch an ihnen kann man oft einen grossen Theil des Variationskreises einer Art studiren; denn Weibchen, welche in Freiheit mehrere Junge werfen, begatten sich öfter mit mehreren Männchen, und sind diese verschieden, so sind es gewöhnlich auch die von ihnen erzeugten Jungen, wie ich an Hunden in Europa und auch bereits an einer ostafrikanischen Art (Chamaesaura tenuior) beobachten konnte.

Dass ich mit meinen Vorschlägen nicht allein stehe, beweist der Ausspruch des in diesem Buch so oft erwähnten J. G. Fischer, dass die afrikanischen Kriechthiere die grösste Veränderlichkeit der Arten zeigen und die Notiz, welche der zu seiner Zeit grösste Kriechthierkenner Prof. Peters am II. August I 870 in die Sitzungsberichte der Berliner Akademie der Wissenschaften einrücken liess. Er schreibt dort:

》Wiederholt habe ich auf die Veränderlichkeit in der Pholidosis (Kopfbeschuppung) der Schlangen aufmerksam gemacht, wodurch nicht allein die Zahl der Arten, sondern sogar der Gattungen unnatürlich vermehrt worden ist. In vielen Fällen ist es schwer, die Variation als solche nachzuweisen, da hierzu oft ganze Reihen (von Exemplaren der Art) gehören, und es kann daher den Reisenden in fernen Ländern nicht genug empfohlen werden, von derselben. Art möglichst viele Exemplare zu sammeln. «

Was das Museum für Naturkunde aus Deutsch-Ost-Afrika - und Afrika überhaupt - besonders wünscht, sind sehr viele Vertreter der grünen Baumschlangen, der Streifenskinke (Mabuia striata) und ganz besonders viele Laubfrösche.

\section{Wie fängt man Kriechthiere?}

Die Fangmethoden richten sich natülicher Weise nach der Beschaffenheit der Orte, in welchen gesammelt wird.

Kriechthiere des Wassers (Frösche z. B.) sind am besten durch Kätscher zu fangen, indem man am Wasser stehend so lange wartet, bis die Thiere, welche vor dem herannahenden Feinde auf den Grund des Wassers flohen, zum Athemholen wieder hervorkommen. Jedes vierfüssige Thier muss, weil es Lungenathmer ist, nach kurzem Verharren im Wasser zum Luftschöpfen an dessen Oberfläche erscheinen.

Alle Thiere, welche im Blattwerk der Bäume und Sträucher verweilen, I aubfrösche, Geckonen, Chamaeleonen und andere fängt man folgendermaassen: Unter den wagerecht stehenden Ast oder die leise seitwärts gebogene Baumkrone hält man einen grossen ausgespannten Schirm mit der Höhlung nach oben. Ein kurzer kräftiger Schlag mit einem starken Stock auf die Baumäste wirft die auf ihnen befindlichen Thiere in den Schirm.

Man sei anwesend, wenn hohe Bäume gefällt werden, hierbei erhält man oft sehr seltene Arten in vielen Exemplaren.

Um Thiere, die im Boden leben, zu erlangen, umgräbt man morsche Baumstämme mit Spaten oder Hacken und dreht grössere Steine um. Unter 
Steinen findet man sehr viele Kriechthiere, selbst grosse Eidechsen und Schlangen; wird der Stein schnell umgeworfen, so bleiben die darunter sitzenden Thiere erschreckt so lange sitzen, dass man sie mit einer Gabel oder durch Betäuben bequem fangen kann.

Man sei zugegen bei Plantagenbearbeitung und wenn Gräben aufgeworfen werden; hierbei erhält man stets sehr seltene Arten.

Eine besonders feine Methode, um Thiere, welche in Bodenlöcher flüchteten, zu erlangen, beschreibt Dr. Franz Werner, ein bekannter Kriechthierkenner und erfahrener Sammler, in der Zeitschrift: Der zoologische Garten I 893, S. 27I.. "Mein arabischer Führer", so berichtet er, "hatte eine vortreffliche Methode, die im Sand sich verkriechenden, sehr schnellen Eidechsen zu fangen. Er merkte sich ungefähr die Stelle, wo die Eidechse untergetaucht war und bearbeitete die Stelle längere Zeit kräftig mit einem Stock, dann räumte er den Sand weg und nach einigem Suchen fanden wir regelmässig den gänzlich besinnungslosen oder wenigstens sehr mürbe gewordenen Sandbewohner. Auf diese Weise habe ich die meisten meiner Exemplare unbeschädigt und noch ganz lebensfähig erhalten.«

Sehr schnelle Eidechsen, welche Mauern oder Felsspalten, sowie Baumstämme bewohnen und die Annäherung des Menschen gerade noch gestatten, fängt man am besten mit der bekannten »Fliegenklatsche «. Der Apparat besteht aus einem mässig langen, drehrunden Stock, an dessen freies Ende eine rundliche Lederscheibe so befestigt ist, dass sie bei jedem Schlag in der Schlagrichtung über das Stockende hinaus eine Art Gelenkbewegung ausführt. Die bei vorsichtiger Anwendung dieser Klatsche nicht zu heftig getroffenen Individuen werden betäubt und können durch schnelles Zufassen mühelos erbeutet werden. So fing ich in Tyrol und Italien fast alle jene Exemplare der äusserst flinken und sonst kaum zu erwischenden Mauereidechse, auf welche ich es abgesehen hatte.

Schlangen, auch Giftschlangen, die auf dem Boden liegen, fängt man am besten, indem man sie zuerst mit einer zweizinkigen Gabel auf den Boden drückt, dann packt man sie mit einer grösseren Pincette kurz hinter dem Kopf und wirft sie in die Sammelflasche mit $75 \%$ Alkohol. Ein sehr einfaches Mittel, Schlangen zu fangen, das ich selbst sehr oft bei Giftschlangen erprobt habe, ist folgendes: Man versetzt dem Thier mit einer langen geschmeidigen Ruthe (mit spanischem Rohr.z. B.) einen kurzen kräftigen Schlag auf den Vordertheil des Rückens, dadurch wird seine Wirbelsäule zerschlagen, es kann nicht mehr fort und wird leicht gefangen; doch hüte man sich vor den Bissen des zwar nicht mehr fortbewegungsfähigen, aber sonst noch völlig intakten Thieres. Mit einer Pincette kann man übrigens auch viele Eidechsen, die sich in Ritzen und Löcher zurückziehen, fangen, da die meisten von ihnen vorn in den Löchern liegen bleiben, damit sie ins Freie blicken können.

Grössere Eidechsen und Schlangen oder äusserst scheue Thiere schiesst man mit Vogeldunst.

\section{Konservirungsmethoden.}

Frösche und alle Thiere mit weicher Haut werden nach dem Fang durch Einlegen in eine Sammelflasche abgetödtet. Die Flasche enthält $75 \%$ Alkohol. Die Thiere sind dann nach einiger Zeit in Versandtflaschen mit derselben Flüssigkeitsmischung zu übertragen. (Nicht Formol anwenden!)

Eidechsen und Schlangen (Thiere mit Schuppen) werden nach dem Fang in derselben Sammelflasche abgetödtet; in den nächsten Tagen am Bauch nahe dem After durch einen kurzen Scheerenschnitt geöfnet; ihr Maul wird aufgesperrt, nöthigenfalls durch ein hineingestecktes Hölzchen. So vorbereitet 
kommen sie in die Versandtbiichsen mit $75 \%$ Alkohol. Schlangen- und Eidechsenhäute haben wenig Werth. Von sehr grossen Thieren sendet man nur den Kopf und alle vier Beine, am Körpergelenk abgelöst.

Schildkröten öfnet man nach dem Tode, indem man die Haut zwischen den beiden Schalen eine Strecke weit durchschneidet, worauf man die Thiere in Spiritus legt. Grössere Schildkröten öffnet man ganz, entfernt das Fleisch vorsichtig so weit wie möglich von den Knochen und trocknet Schalen und Skelett. Gegen Insektenfrass versieht man sie mit Naphtalin oder Insektenpulver, oder man legt sie einige Stunden in eine starke Salzlösung.

Allen Stücken sind Angaben über Ort und Zeit des Fanges, womöglich auch über Lebensweise und Farbkleid beizufügen. Wenn diese Angaben mit Tinte auf Pergament geschrieben und an die einzelnen Thiere angebunden werden, bleiben sie auch in Spiritus leserlich. Statt des Pergaments kann auch starkes Papier benutzt werden, das man mit Bleistift (nicht mit Tinte) beschreibt.

$\mathrm{Zu}$ jeder weiteren Auskunft in Sammelangelegenheiten ist der Verfasser dieser Anleitung gern bereit. Adresse: Berlin N., Museum für Naturkunde, Invalidenstrasse 43 . 

Reptilien. 



\title{
Ordnung: Hydrosauria.
}

\author{
Familie: Crocodilidae.
}

\section{Crocodilus vulgaris Cuv.}

Tanga in Usambara; erwachsenes Individ.; Oscar Neumann S.

Bach, der vom Kilima-Ndjaro hinabfliesst; ein Junges.; G. A. Fischer S.; I. G. Fischer, Jahresb. Hamburg. Mus. I884, S. I 8.

Im Victoria Nyansa zwischen Mwansa und Bukoba wurden auf einer kleinen unbewohnten Sandinsel von Oscar Neumann zwei Krokodilnester gefunden. "Die Eier waren im Sande verscharrt, die obersten herausschauend, die tiefsten circa I Fuss tief unter der Oberfläche des Sandes. Das eine enthielt 64 frische, das andere 7 I stark angebrütete Eier. - Aufbewahrte Embryonen aus diesen Eiern erwiesen sich als Individuen von Crocodilus vulgaris.

Böhm schreibt über die Verbreitung von Crocodilus vulgaris in DeutschOstafrika folgendes: "Crocodilus vulgaris ist in allen Flüssen, besonders im Wala- und Ugallafluss häufig und kolossale Dimensionen erreichend. Merkwürdiger Weise watet man in hiesiger Gegend (Kakoma) unbesorgt in den von Krokodilen bevölkerten Gewässern umher, während sie z. B. am Kingani und Ta nganyika ihrer Angriffe wegen gefürchtet werden. Als wir auf den Sumpfinseln im Ugallaflusse lagerten, kam ein grosses Exemplar nachts häufig auf den kleinen, unmittelbar aus dem Wasser sich erhebenden Hügel, der unser Zelt trug, und schleppte von hier einmal ein Antilopengehörn fort. Ein anderes hatte sich unweit unserer Jagdhütte an demselben Flusse auf einer Sandbank postirt, um die in's Wasser fallenden Jungen einer Cormoran-Colonie (Phalacrocorax africanus) wegzuschnappen.

"Das Krokodil ist hier unverletzlich, da es von den Wanyamwesi für zauberhaft und fürchterlich giftig gehalten wird, sein Blut das ganze Wasser vergiften, und, wie man behauptet, der Mtemi die Tödtung eines solchen auf das furchtbarste bestrafen würde, weil derselbe besorgt, durch Theile des Getödteten vergiftet zu werden. In Kawende kennt man diesen unsinnigen Aberglauben nicht, dafür sind dort die Pythonen geheiligt. «

Emin Pascha und F. Stuhlmann berichten über die Lebensweise des Krokodils in Ostafrika Folgendes (Zool. Jahrb., Abth. f. Syst. B 5, S. 545-548): Die Eiablage findet in Ostafrika einmal im Jahre statt, doch ist die Zeit für verschiedene Orte verschieden. In Zwischenräumen von etwa zwei Tagen legt das Weibchen bis hundert Eier in vier bis fünf selbstgescharrte Gruben. Die Dauer der Eientwicklung beträgt 40 Tage. Von einer Brutpflege des Weibchen ist keine Rede. Im Innern von Ostafrika halten die Krokodile in trockenem Schlamm einen Sommerschlaf. 
Sehr interessante Beobachtungen veröffentlicht auch A. Voeltzkow über denselben Gegenstand aus Madagascar. Nach ihm ist auch hier die Eiablage des Krokodils in verschiedenen Gegenden verschieden. Das Nest besteht aus einer etwa $\mathrm{I}^{1} / 2-2$ Fuss tiefen Grube mit theilweise steilen Wänden, die am Grunde unterhöhlt sind. Da der Boden der Grube in der Mitte etwas erhöht ist, rollen die Eier beim Legen von selbst an die unterhöhlten Stellen. Die Grube wird dann vom Weibchen so zugescharrt, dass sie von aussen nicht kenntlich ist. Das alte Krokodil schläft auf dem Nest, daher finden die Eingeborenen die Eier, indem sie den Spuren des Thieres vom Wasser aus nachgehen.

Kurz vor dem Auskriechen aus den Eiern stossen die Jungen lebhafte Töne aus, die durch die Nestdecke auf Zimmerlänge zu vernehmen sind. Diese Töne veranlassen die Mutter, welche auf dem Neste schläft, die Eier auszuscharren. Sind darauf die jungen Thiere ausgeschlüpft, indem sie die Eischale mit ihrem Eizahn durchbrechen, dann wandert das alte Krokodil mit ihnen zum Wasser. (Zool. Anzeiger 1890, S. I90-I92 u. Sitzungsber. Berl. Acad. I89I, S. I I5).

\title{
Ordnung: Chelonia.
}

\section{Subordnung: Cryptodira.}

\author{
Familie: Testudinidae.
}

\section{Cinicys belliana Gray}

Tanga in Usambara; I Individ., jung; Oscar Neumann S.

Tanga in Usambara; I Individ., alt; Oscar Neumann S.

Kissrawe am Kingani; I Individ.; Stuhlmann S.

Kakoma; 3 Individ.; Böhm S.

Bussisi am Victoria Nyansa S.-O.-Ecke; I Individ.; Stuhlmann S.

Bukome, Landschaft am Victoria Nyansa S.-Ufer; 2 Individ.; Stuhlmann S.

Victoria-Nyansa; I Individ.; G. A. Fischer S.; Mus.-No. 10776.

Nyangesi in Ussukuma (S.-O.-Ufer des Victoria-Nyansa); I Individ., jung; Stuhlmann S.

Nach Böhm »häufig zur Regenzeit an feuchten Stellen im Walde«. Dazu passt Stuhlmann's Bemerkung: »Gefunden am Papyrus-Sumpf zu Bukome«.

Das sehr grosse, durchaus erwachsene Individuum aus Bussisi zeigt höchst eigenthümliche Pathologie: Seine Schale ist papierdünn und flach zusammendrükkbar, nach dem Aufhören des Drucks nimmt sie ihre bisherige Form wieder an. Der Grund dafür ist: Die Knochenplatten der Schale sind fast gar nicht von Kalksalzen imprägnirt und von den Platten selbst sind grössere Partien durch einfache Bindegewebspartien derartig ersetzt, dass die Beschalung des Thieres den Eindruck erweckt, als sei sie auf einer jugendlichen Entwicklungsstufe stehen geblieben; womit aber nicht gesagt sein soll, dass dies wirklich der Fall ist. 
Die Vertreter der Art zeigen in der Form des Oberkiefers individuelle Variabilität. Bei den meisten Individuen ist der papageischnabelartige Oberkiefer einfach von den Seiten dreieckig zusammengedruickt, besteht also aus zwei glatten Seitenwänden, die in einer scharfen Kante kielförmig zusammenstossen. Diese Schnabelfirste hängt ausserdem zahnartig über den Oberkieferrand hinab. Bei einem anderen Individuum aber hängen ausser dieser hakenartigen Schnabelfirste noch zwei Nebenhaken über den Oberkieferrand hinab; sie sind so angeordnet, dass die Schnabelfirste zwischen ihnen liegt. Bei diesem Schnabel sind also eigentlich drei Firsten in erster Andeutung. Bei dem weichschaligen Thier erscheint die Schnabelkante, da hier die Nebenfirsten auffällig vergrössert sind, nicht mehr kielförmig zugespitzt, sondern abgestumpft, oder, besser gesagt, plattgedrückt. Als Fortsätze dieser Schnabelplatte hängen dann drei Haken über den Oberkiefer hinab, von denen nunmehr die seitlichen die grösseren sind.

Auch in Bezug auf die Beschilderung der Hinterfüsse zeigt die Art eine geringe individuelle Variabilität. Gemeinsam ist allen Thieren, dass an ihren Unterschenkeln zwischen kleinere Schuppen viel stärker entwickelte Schuppen vertheilt sind; ihre Zahl und Vertheilung stimmt bei allen Individuen annähernd uberein. Die Individuen aus Kakoma zeichnen sich nun aber vor den anderen Artvertretern dadurch aus, dass bei ihnen hinten am Unterschenkel, in der Nähe des Fussansatzes, eine der grossen Schuppen wie ein starker Sporn schwanzwärts aus dem Schuppenpanzer herausragt, also eine eigenartige Form auszubilden beginnt, während bei den anderen Individuen die ihr homologe Schuppe von den ubrigen grossen Unterschenkelschuppen nicht wesentlich verschieden ist.

\section{Testudo pardalis Bell.}

Usambara; I Individ.; Oscar Neumann S.

Mkaramo am Pangani; I Individ.; Stuhlmann S.; 24. Mai I893.

Massai-Nyika; 2 Individ.; Oscar Neumann $\mathrm{S}$.

Umgegend des Djipe-Sees; 2 Individ,; v. d. Decken S.; Peters;

Decken III, S. IO.

Wembere Steppe; I Individ.; Stuhlmann S.; Mai I892.

Ngoma; I Individ.; Stuhlmann S.; 2I. Oktober I890.

Mwansa in Ussukuma am Victoria Nyansa S.-O.-Ecke; I Individ.; StuhlmannS.; April r892.

Bussisi am Victoria-Nyansa S.-Ufer; I Individ.; Stuhlmann S.

Erreicht nach Böhm eine beträchtliche Grösse und hat im Mai hühnereigrosse, legereife Eier.

\section{[Testudo radiata Shaw}

Sansibarküste; I Individ.; v. d. Decken S.; Peters, Decken III, S. IO. Peters.?

"Wahrscheinlich von Madagascar, wo diese Art heimisch ist, importirt».

\section{Familie: Chelonidae.}

\section{Chelone imbricata L.}

Tanga; I Individ.; Oscar Neumann S.

Junge Exemplare dieser Art erhielt das Museum auch aus Mombas durch Hildebrandt. 


\section{Subordnung: Pleurodira.}

\section{Familie: Pelomedusidae.}

\section{Sternothaerus sinuatus Smith}

Tanga; mehrere Individ., jung und alt; Oscar Neumann S.

Umgebung des Djipe-Sees; 2 Individ.; v. d. Decken S.; Peters, Decken III, S. 2 I.

Bukoba am Victoria Nyansa-Westufer; 2 Individ.; Stuhlmann S.

Uganda, Insel Ussi; 3 Individ.; $\sigma^{7}$ u. 우; Stuhlmann S.

\section{Sternothaerus nigricans Donn.}

Tanga in Usambara; 3 Individ., jung und alt; Oscar Neumann S.

Dar es Salaam; I Individ.; Stuhlmann S.

Karagwe, Landschaft am Victoria Nyansa S.-W.-Ufer; I Individ.; Stuhlmann S.

Wawamba-Fähre zwischen Victoria Nyansa und Albert-Edward-See; Schale; Stuhlmann S.

Böhm macht über Sternothaerus folgende Bemerkungen, von denen aber nicht festzustellen ist, auf welche Arten oder Varietäten einer Art sie zu beziehen sind. Er unterscheidet zwei Arten. Eine Art: "Bei Konko in Ugogo häufig, wo Wasser nur sehr spärlich vorhanden war; gräbt sich schnell in Sand ein". - Zweite Art: "In Unyamwesi, wie alle anderen Schildkröten nur zur Regenzeit zum Vorschein kommend. - Am Tschaia-See fand ich einen sehr grossen und schweren Sternothaerus, welcher mir Sternothaerus emarginata zu sein schien, leider fehlte es an Gelegenheit, ein Exemplar weiter zu transportiren. «

Sehr grosse Sternothaerus sinuatus sind auch die erwähnten vom Djipe-See, wie schon Peters mit folgenden Worten berichtete: „Zwei sehr grosse und alte Exemplare vom Djipe-See, welche von den jüngeren durch die grössere Verlängerung der Vertebralplatten besonders ausgezeichnet sind. Die Länge des Panzers des grössten Exemplars ist $0,385 \mathrm{~m}$, die Breite desselben $0,26 \mathrm{~m}$. Der Schädel hat (vom Condylus occipitalis bis zur Schnauzenspitze) eine Länge von $0,70 \mathrm{~m}$ bei einer Breite von $0,60 \mathrm{~m}$.

Sternothaerus nigricans und sinuatus unterscheiden sich nach Boulenger folgendermaassen:

Charaktere des Sternothaerus sinuatus: Die Oberschnabelfirste hat vorn an Stelle einer scharfen Kante eine schwache Grube, die durch zwei schwache Wülste begrenzt wird, welche ausserdem, wie zwei stumpfe Zähne, über die Maulöffnung hinüberhängen. Die Interorbitalbreite des Thieres ist beträchtlich kürzer als die Längsnaht zwischen den Frontalschildern. Zweites und drittes Vertebralschild beim erwachsenen Thier annähernd so lang wie breit. Intergularschild mehr als zweimal so lang als breit. Kopf blassbraun mit dunklen wurmförmigen Zeichnungen.

Bei jungen Thieren ist die Oberschale am hinteren Rand mehr oder weniger gesägt oder eingebuchtet, bei älteren Thieren ist ihr Rand glatt.

Bei Sternothaerus nigricans ist nach Boulenger die Schnabelspitze weder scharf dreieckig zugespitzt, noch an der Firste eingedrückt und mit stumpfen Zähnchen versehen, ihr Rand erscheint vielmehr scharf gegen den Unterkiefer umgeschlagen. Die Längsnaht zwischen den Frontalen übertrifft nicht oder nur schwach die Breite des Interorbitalraums. Das Intergularschild ist nicht zwei- 
mal so lang wie breit. Beim erwachsenen Thier ist das zweite und dritte Vertebralschild ein wenig breiter als lang. Kopf oben ohne Flecken oder wurmförmige Zeichnung.

Bei jungen Thieren ist die Oberschale gekielt und hat hinten glatten Rand.-

Stejneger schreibt in seiner Abhandlung über afrikanische Reptilien und Batrachier (Proceed. of the national Mus. Philad. I 893, S. 7 I3), dass es für ihn sehr schwierig gewesen sei, Sternothaerus nigricans und sinuatus zu unterscheiden, da er kein Vergleichsmaterial gehabt habe, und die Litteraturangaben nur zum Theil auf die von ihm untersuchten Thiere zu beziehen waren. Das Berliner Museum für Naturkunde hat von beiden Arten »typische " Exemplare d. h. solche Exemplare, die mit Boulenger's Beschreibung genau übereinstimmen. Alle diese Individuen sind von Peters bestimmt oder nachbestimmt, einige von ihnen gelangten durch die Zoological Society of London mit Namen versehen in den Besitz des Museums. Aus diesen Angaben könnte man schliessen, dass bei Benutzung dieser Vergleichsobjekte die Bestimmung des neu hinzugekommenen Materials mir selbst gar keine Schwierigkeiten gemacht habe; würde damit aber sehr falsch geschlossen haben, denn ich fand wie Stejneger, dass die Charaktere der beiden angeblichen Arten bei vielen Individuen gemischt vorkommen; ja, dies ist bei so vielen der Fall, dass ich ohne Uebertreibung angeben kann: kaum eins der neu hinzugekommenen Individuen erwies sich als typischer Vertreter der einen oder anderen Art; so fand ich, wie beigefügte Tabelle ergiebt, Individuen mit Schädelcharakteren der einen und Schalencharakteren der anderen Art, und dazu fand ich ausserdem bei den mir vorliegenden, hierhergehörigen erwachsenen Individuen alle Uebergänge von den typischen Oberkiefercharakteren der einen Art zu den typischen Oberkiefercharakteren der anderen. Die Frage, ob sich bei dieser Sachlage die beiden Arten getrennt aufrecht erhalten lassen werden, bezweifle ich um so entschiedener, weil bereits Individuen beider Arten an denselben Fundorten, ja in demselben Teich gefunden worden sind, und ich vermuthe, dass die angeblichen Arten nur Varietäten einer Art sind, die sich ausbilden, je nachdem die Jungen der Art in stark fliessendem oder stagnirendem Wasser heranwachsen; ein mässig fliessendes Wasser würde dann zur Entstehung der Zwischenformen Veranlassung geben, doch kann auch die eine Varietät mehr an das Land-, die andere mehr an das Wasserleben angepasst sein, wie folgende Betrachtung ergiebt:

Zuerst etwas über die Jungen der beiden Arten: Mir liegen 4 recht junge Sternothaerus vor, die entweder zu sinuatus oder nigricans gehören. Von diesen 4 Individuen hat nur eins die typischen Charactere eines jungen Sternothaerus sinuatus, d. h. im Hornbelag der Oberkieferspitze eine Grube, begrenzt von zwei Wülsten, die ausserdem zahnartig über die Mundöffnung hinabhängen; ferner hat es eine flachgedrückte, gekielte Oberschale, die im Querschnitt dreieckig ist und an ihrem ganzen Rand starke Sägezähne und Ausbuchtungen zeigt. Das Individuum stammt aus dem Panganifluss, wo es Oscar Neumann gesammelt hat.

Ein anderes von diesen jungen Individuen wird unter allen Umständen als Sternothaerus nigricans bestimmt werden müssen, es hat den für diese Art typischen Oberkiefer-Hornbelag ohne Grube an der Spitze und Grenzwülste, ferner besitzt es eine Oberschale mit durchaus glattem Rand, die fast kuglig gewölbt ist. Doch ist diese Schale nicht gekielt, was nach Boulenger's Angaben bei jungen Thieren dieser Art der Fall sein soll. Das Individuum stammt aus dem Victoria Nyassa-See, wo es Stuhlmann gefangen hat. Vergleicht man diese beiden Individuen, so ergiebt sich, dass jenes mit kugliger Schale seinen Kopf und seine Gliedmaassen am tiefsten in die Schale hineingezogen hat und hineinziehen kann. Indirect wird dies auch durch folgenden Versuch bestätigt: Drückt man das Individuum mit kugliger Schale so weit zusammen, dass seine noch weiche Schale die Form der flachen Sternothaerus sinuatus-Schale annimmt, so 
werden durch den Druck Kopf und Gliedmaassen des Thieres aus der Schale herausgetrieben und es ist nicht mehr möglich, sie in der bisherigen Weise in der Schale unterzubringen, lässt der Druck nach, so treten Kopf und Gliedmaassen des Thieres in die Schale zurück. - Durch die Befähigung, Kopf und Gliedmaassen in der Schale gut verbergen zu können, erinnert das Individuum mit kugliger Schale an die echten Landschildkröten, die diese Fähigkeit im Maximum besitzen, während das flachschalige Individuum mehr den echten Wasserschildkröten ähnelt, bei welchen jene Fähigkeit wenig oder garnicht ausgebildet ist; und wir können uns denken, dass deshalb das eine Individuum einer Land-, das andere einer Wasservarietät einer Art angehören. Andererseits ist es aber auch nicht unmöglich, dass die Form der Schale bei anfänglich gleichen Individuen sich ändert, je nach der Intensität, mit welcher sie ihre Schwimmbewegungen ausführen, ganz abgesehen davon, dass eine flache, auf ein Minimum reducirte (an den Rändern ausgebuchtete) Schale die Fortbewegung im Wasser sehr erleichtert und daher für Thiere des fliessenden Wassers sehr geeignet ist, da hier die Fortbewegung eine viel grössere Anstrengung erfordert und grössere Hindernisse zu überwinden hat, als das Schwimmen in stehendem Wasser.

Die letzten beiden, von mir untersuchten und hierher gehörigen, jungen Sternothaerus stimmen in all' ihren Schalencharacteren bis in die feinsten Details mit dem als Sternothaerus sinuatus erwähnten Individuum überein: Ihre Oberschale ist flach gedrückt, gekielt, im Querschnitt dreieckig und am Rande tief ausgebuchtet, dagegen haben sie den typischen Oberkiefer des Sternothaerus nigricans, d. h. keine Grube an der Oberkieferspitze und keine Spur von den wulstigen Rändern derselben. Sie gehören also, wenn man auf die Oberkieferbildung das Hauptgewicht legt zu Sternothaerus nigricans, beweisen dann aber, dass auch bei dieser Art junge Individuen vorkommen können, deren Schalen flach gedrückt, gekielt und am Rande vielfach ausgebuchtet sind; legt man aber beim Bestimmen das Hauptgewicht auf die Schalencharactere, so gehören die beiden Individuen zu Sternothaerus sinuatus, was dann beweist, dass Sternothaerus sinuatus in frühester Jugend keine Oberkieferzähnchen besitzt, oder, was dasselbe besagt, dass beide Arten in fruhester Jugend dieselbe Kopfbildung haben, und sich nur in der Schalenbildung unterscheiden. Das Letztere ist das Wahrscheinlichste, denn die beiden soeben beschriebenen Individuen lebten mit dem, welches als typischer Sternothaerus sinuatus juv. erkannt wurde in demselben Gebiet und unterscheiden sich von ihm nur wenig dem Alter nach, so dass sie jedenfalls zu derselben Begattungsperiode erzeugt sind; alle drei Individuen wurden von Herrn Oscar Neumann an demselben Tag im Pangani gesammelt und in einer Sendung mit der Bezeichnung ,Flussschildkröten“ an das Museum eingeschickt.

In der Schnabelbildung zeigen, wie schon erwähnt, die erwachsenen Individuen, welche ich als Sternothaerus nigricans und sinuatus bestimmen muss, alle Uebergänge von einem Artextrem zum anderen, ein besonderer systematischer Werth wird auch deshalb diesen Schnabelbildungen nicht beigelegt werden dürfen.

Welche äusseren Ursachen mitbetheiligt sind an der Ausbildung gerade dieser Schnabelformen und ihrer Extreme und welche Wichtigkeit besonders die Extreme derselben für die Lebensweise der damit versehenen Individuen besitzen, dürfte, wenn es überhaupt zu constatiren ist, nur durch ein genaues Studium der Lebensweise der betreffenden Individuen festzustellen sein. Sicher ist allerdings, dass die Form eines Oberschnabels nicht aus der Ortsbewegung ihres Trägers erklärt werden kann. Für die divergente und individuell verschiedene Ausbildung der Schnabelform der vorliegenden beiden Arten oder Varietäten, deren Extreme, wie es scheint, gewöhnlich mit den Extremen der Schalenbildung zusammenfallen, ist das Wahrscheinlichste, dass die Thiergruppen, welche 
die beiden Arten gebildet haben oder zu bilden streben, indem sie sich in gewissem Sinn räumlich sonderten oder sondern, deshalb auch gewöhnlich auf verschiedene Nahrung angewiesen sind und im Zusammenhang damit eine mehr oder weniger verschiedene Schnabelausbildung erfahren, welche dann, wie leicht einzusehen ist, in den meisten Fällen annähernd parallel der Schalenausbildung verlaufen wird, so dass gewöhnlich ein Extrem der Schalenbildung von dem entsprechenden Extrem der Schnabelbildung begleitet wird.

Beifolgende Tabelle liefert einen weiteren Beweis dafür, dass die meisten der mir vorliegenden Sternothaerus-Vertreter durchaus nicht genau den Anforderungen entsprechen, welche Boulenger an die Arten Sternothaerus nigricans und sinuatus stellt, die meisten von ihnen zeigen eine Mischung der beiden Artcharactere.

\begin{tabular}{|c|c|c|c|c|c|c|c|}
\hline $\begin{array}{l}\text { Art (nach der } \\
\text { Schnauze) }\end{array}$ & $\begin{array}{r}\text { Länge } \\
\mathrm{cm}\end{array}$ & $\begin{array}{c}\text { Zweite } \\
\text { Vertebral- } \\
\text { platte } \\
\mathrm{cm} \\
\end{array}$ & $\begin{array}{c}\text { Dritte } \\
\text { Vertebral- } \\
\text { platte } \\
\mathrm{cm} \\
\end{array}$ & $\begin{array}{c}\begin{array}{c}\text { Augen- } \\
\text { zwischenraum } \\
\mathrm{cm}\end{array} \\
\end{array}$ & $\begin{array}{c}\text { Intergular- } \\
\text { platte } \\
\mathbf{c m}\end{array}$ & Schnauze & Kopffärbung \\
\hline $\begin{array}{l}\text { St. nigricans } \\
\text { nach Boul. }\end{array}$ & & $\begin{array}{l}\text { beim } \\
\text { Alten ein } \\
\text { wenig } \\
\text { breiter als } \\
\text { lang }\end{array}$ & $\begin{array}{l}\text { ein wenig } \\
\text { breiter } \\
\text { als lang }\end{array}$ & $\begin{array}{l}\text { die Frontal- } \\
\text { länge nicht } \\
\text { oder wenig } \\
\text { länger als der } \\
\text { Augen- } \\
\text { zwischenraum }\end{array}$ & $\begin{array}{l}\text { nicht } \\
\text { zweimal } \\
\text { so lang } \\
\text { als breit }\end{array}$ & $\begin{array}{l}\text { Rand gegen } \\
\text { den Unterkiefer } \\
\text { umgeschlagen }\end{array}$ & $\begin{array}{l}\text { ohne } \\
\text { wurmförmige } \\
\text { Flecke }\end{array}$ \\
\hline $\begin{array}{l}\text { St. nigricans, } \\
\text { Type ent- } \\
\text { sprechend; } \\
\text { Mesuril }\end{array}$ & 12.7 & $\begin{array}{l}\text { lang } 1,9 \\
\text { breit } 2,5\end{array}$ & $\begin{array}{l}\text { lang } 2,0 \\
\text { breit } 2,7\end{array}$ & $\begin{array}{c}\text { Frontal- } \\
\text { länge } 0,9 \\
\text { Augen- } \\
\text { zwischenr. } 0,8\end{array}$ & $\begin{array}{l}\text { lang } 2,4 \\
\text { breit } 1,6\end{array}$ & $\begin{array}{c}\text { Schnauzenrand } \\
\text { fast rechtwinklig } \\
\text { umgeschlagen, } \\
\text { Zähne angedeutet, } \\
\text { ebenso die seichte } \\
\text { Einbuchtung }\end{array}$ & $\begin{array}{l}\text { dunkelbraun, } \\
\text { wurmförmige } \\
\text { Flecke } \\
\text { angedeutet }\end{array}$ \\
\hline $\begin{array}{c}\text { nigricans } f \\
\text { Mus. } 55 \text { I9 }\end{array}$ & 17,0 & $\begin{array}{l}\text { lang } 2,75 \\
\text { breit } 3,35\end{array}$ & $\begin{array}{l}\text { lang } 3,0 \\
\text { breit } 3,4\end{array}$ & $\begin{array}{c}\text { Frontal- } \\
\text { länge } 8,5 \\
\text { Augen- } \\
\text { zwischenr. 6,5 }\end{array}$ & $\begin{array}{l}\text { lang } 2,7 \\
\text { breit } 1,7\end{array}$ & $\begin{array}{l}\text { Schnauze mässig } \\
\text { umgeschlagen, } \\
\text { Zähne deutlich, } \\
\text { aber klein, } \\
\text { kleine Grube } \\
\text { dazwischen }\end{array}$ & $\begin{array}{c}\text { wurmförmige } \\
\text { Flecke }\end{array}$ \\
\hline $\begin{array}{l}\text { nigricans; } \\
\text { Karagwe; } \\
\text { Jung., } \\
\text { Uebergang } \\
\text { zu sinuatus }\end{array}$ & I 2,7 & $\begin{array}{l}\text { lang } 2,1 \\
\text { breit } 2,3\end{array}$ & $\begin{array}{l}\text { lang } 2,0 \\
\text { breit } 2,3\end{array}$ & $\begin{array}{c}\text { Frontal- } \\
\text { länge 7,0 } \\
\text { Augen- } \\
\text { zwischenr. 7,0 }\end{array}$ & $\begin{array}{l}\text { lang } 2,6 \\
\text { breit } 1,7\end{array}$ & $\begin{array}{l}\text { ohne Höcker, } \\
\text { jedoch vorn eine } \\
\text { gerade } \\
\text { Schnauzenplatte, } \\
\text { durch schwache } \\
\text { seitliche } \\
\text { Einkerbungen } \\
\text { stark vortretend }\end{array}$ & $\begin{array}{c}\text { wurmförmige } \\
\text { Flecke }\end{array}$ \\
\hline $\begin{array}{l}\text { nigricans } \\
\text { (der Schale } \\
\text { nach); } \\
\text { Wawamba }\end{array}$ & 14,7 & $\begin{array}{l}\operatorname{lang} 2,2 \\
\text { breit } 2,8\end{array}$ & $\begin{array}{l}\text { lang } 2,3 \\
\text { breit } 2,9\end{array}$ & & $\begin{array}{l}\operatorname{lang} 2,4 \\
\text { breit } \mathbf{I}, 5\end{array}$ & nur Sch & haale \\
\hline $\begin{array}{l}\text { nigricans; } \\
\text { Dar-es-Sa- } \\
\text { laam }\end{array}$ & I 8,1 & $\begin{array}{l}\text { lang } 2,9 \\
\text { breit } 3,45\end{array}$ & $\begin{array}{l}\text { lang } 3,4 \\
\text { breit } 3,4\end{array}$ & $\begin{array}{c}\text { Frontal- } \\
\text { länge I,og } \\
\text { Augen- } \\
\text { 2wischenr.0,85 }\end{array}$ & $\begin{array}{ll}\text { lang } & 3,4 \\
\text { breit } 1,85\end{array}$ & $\begin{array}{c}\text { die Zähne minimal } \\
\text { vortretend, ganz } \\
\text { schwache Grube } \\
\text { dazwischen }\end{array}$ & $\begin{array}{c}\text { wurmförmige } \\
\text { Flecke }\end{array}$ \\
\hline $\begin{array}{l}\text { nigricans; } \\
\text { Sesse, } \\
\text { Uganda }\end{array}$ & 4,8 & $\begin{array}{l}\text { lang } 0,5 \\
\text { breit } I, 63\end{array}$ & $\begin{array}{l}\text { lang } 0,55 \\
\text { breit } I, 63\end{array}$ & $\begin{array}{c}\text { Frontal- } \\
\text { länge } 0,39 \\
\text { Augen- } \\
\text { zwischenr. } 0,32\end{array}$ & $\begin{array}{l}\text { lang } 0,75 \\
\text { breit } 0,39\end{array}$ & $\begin{array}{l}\text { schwach an- } \\
\text { gedeutete Grube, } \\
\text { ohne Ausbildung }\end{array}$ & $\begin{array}{c}\text { wurmförmige } \\
\text { Flecke }\end{array}$ \\
\hline
\end{tabular}




\begin{tabular}{|c|c|c|c|c|c|c|c|}
\hline $\begin{array}{l}\text { Art (nach der } \\
\text { Schnauze) }\end{array}$ & \begin{tabular}{|c|} 
Länge \\
$\mathrm{cm}$
\end{tabular} & $\begin{array}{c}\begin{array}{c}\text { Zweite } \\
\text { Vertebral- } \\
\text { platte } \\
\mathrm{cm}\end{array} \\
\end{array}$ & $\begin{array}{c}\text { Dritte } \\
\text { Vertebral- } \\
\text { platte } \\
\mathrm{cm} \\
\end{array}$ & $\begin{array}{c}\begin{array}{c}\text { Augen- } \\
\text { zwischenraum } \\
\mathrm{cm}\end{array} \\
\end{array}$ & $\begin{array}{c}\begin{array}{c}\text { Intergular- } \\
\text { platte } \\
\mathrm{cm}\end{array} \\
\end{array}$ & Schnauze & Kopffärbung \\
\hline $\begin{array}{l}\text { nigricans } \\
\text { (nur der } \\
\text { Schnauze } \\
\text { nach); } \\
\text { Pangani }\end{array}$ & 3,45 & $\begin{array}{l}\text { lang } 0,6 \\
\text { breit } I, 0\end{array}$ & $\begin{array}{l}\text { lang } 0,59 \\
\text { breit } 0,98\end{array}$ & $\begin{array}{c}\text { Frontal- } \\
\text { länge } 0,4 \\
\text { Augen- } \\
\text { zwischenr.0,25 }\end{array}$ & $\begin{array}{l}\text { lang } 0,6 \\
\text { breit } 0,35\end{array}$ & keine Wülste & $\begin{array}{l}\text { hellgelb } \\
\text { mit schwarzen } \\
\text { Punkten }\end{array}$ \\
\hline $\begin{array}{l}\text { uigricans } \\
\text { (nur der } \\
\text { Schnauze } \\
\text { nach) }\end{array}$ & 3,3 & $\begin{array}{l}\text { lang } 0,5 \\
\text { breit } I, 08\end{array}$ & $\begin{array}{l}\text { lang } 0,55 \\
\text { breit } 0,99\end{array}$ & $\begin{array}{c}\text { Frontal- } \\
\text { länge } 0,39 \\
\text { Augen- } \\
\text { zwischenr. 0,29 }\end{array}$ & $\begin{array}{l}\text { lang } 0,55 \\
\text { breit } 0,3\end{array}$ & nigricans typisch & $\begin{array}{l}\text { hellgelb } \\
\text { mit dunklen } \\
\text { Flecken }\end{array}$ \\
\hline $\begin{array}{l}\text { nigricans; } \\
\text { Pangani, } \\
\text { Neumann }\end{array}$ & II, 7 & $\begin{array}{ll}\text { lang } 1,9 \\
\text { breit } 2,55\end{array}$ & $\begin{array}{l}\text { lang } 1,95 \\
\text { breit } 2,4\end{array}$ & $\begin{array}{c}\text { Frontal- } \\
\text { länge } 0,85 \\
\text { Augen- } \\
\text { zwischenr. } 0,6\end{array}$ & $\begin{array}{l}\text { lang } 2,35 \\
\text { breit } I, 25\end{array}$ & typisch nigricans & $\begin{array}{l}\text { wurmförmige } \\
\text { Zeichnung }\end{array}$ \\
\hline $\begin{array}{l}\text { sinuatus } \\
\text { nach Botzl. }\end{array}$ & & $\begin{array}{c}\text { so lang } \\
\text { wie breit } \\
\text { bei Er- } \\
\text { wachsenen }\end{array}$ & $\begin{array}{l}\text { so lang } \\
\text { wie breit } \\
\text { bei Er- } \\
\text { wachsenen }\end{array}$ & $\begin{array}{c}\text { Frontale } \\
\text { länger als } \\
\text { Augen- } \\
\text { zwischenraum }\end{array}$ & $\begin{array}{l}\text { mehr als } \\
\text { zweimal } \\
\text { so lang } \\
\text { wie breit }\end{array}$ & $\begin{array}{c}\text { Zähne, } \\
\text { Grube dazwischen }\end{array}$ & $\begin{array}{l}\text { wurmförmige } \\
\text { Zeichnung }\end{array}$ \\
\hline $\begin{array}{l}\text { sinuatus; } \\
\text { Pangani }\end{array}$ & $5, \mathrm{I}$ & $\begin{array}{l}\text { lang } 0,9 \\
\text { breit } 1,6\end{array}$ & $\begin{array}{l}\text { lang } 0,8 \\
\text { breit } 1,55\end{array}$ & $\begin{array}{c}\text { Frontal- } \\
\text { länge } 0,45 \\
\text { Augen- } \\
\text { durchm. 0,35 }\end{array}$ & $\begin{array}{l}\text { lang } \mathbf{I}, 0 \\
\text { breit } 0,49\end{array}$ & Zähne und Grube & $\begin{array}{l}\text { mit dunkler } \\
\text { Zeichnung }\end{array}$ \\
\hline $\begin{array}{l}\text { sinuatus; } \\
\quad \text { Pangani }\end{array}$ & $34, \mathrm{I}$ & $\begin{array}{l}\text { lang } 6,5 \\
\text { breit } 5, \mathbf{I}\end{array}$ & $\begin{array}{l}\text { lang } 6,9 \\
\text { breit } 4,7\end{array}$ & $\begin{array}{c}\text { durch } \\
\text { Maceration } \\
\text { unkenntlich }\end{array}$ & $\begin{array}{l}\text { lang } 5, I \\
\text { breit } 2,3\end{array}$ & $\begin{array}{l}\text { grosse Zähne } \\
\text { und Grube da- } \\
\text { zwischen }\end{array}$ & $\begin{array}{l}\text { wurmförmige } \\
\text { Zeichnung }\end{array}$ \\
\hline $\begin{array}{l}\text { sinuatus; } \\
\text { Insel Ussi }\end{array}$ & 21,6 & $\begin{array}{l}\text { lang } 3,7 \\
\text { breit } 3,7\end{array}$ & $\begin{array}{l}\text { lang } 3,8 \\
\text { breit } 4,0\end{array}$ & $\begin{array}{l}\text { Frontal- } \\
\text { länge I,5 } \\
\text { Augen- } \\
\text { zwischenr. I,5 }\end{array}$ & $\begin{array}{l}\text { lang } 3, I \\
\text { breit I, } 8\end{array}$ & $\begin{array}{l}\text { grosse Zähne, } \\
\text { deutliche Grube }\end{array}$ & $\begin{array}{l}\text { wurmförmige } \\
\text { Zeichnung }\end{array}$ \\
\hline $\begin{array}{l}\text { sinuatus; } \\
\quad \text { Insel Ussi }\end{array}$ & 22,5 & $\begin{array}{l}\text { lang } 3,8 \\
\text { breit } 4,65\end{array}$ & $\begin{array}{l}\text { lang } 4,05 \\
\text { breit } 4,65\end{array}$ & $\begin{array}{c}\text { Frontal- } \\
\text { länge I, I5 } \\
\text { Augen- } \\
\text { zwischenr. 1,0 }\end{array}$ & $\begin{array}{l}\text { lang } 3, I \\
\text { breit } I, 8\end{array}$ & typisch & $\begin{array}{l}\text { wurnafürmige } \\
\text { Flecke }\end{array}$ \\
\hline $\begin{array}{l}\text { Uebergangs- } \\
\text { form; } \\
\text { Insel Ussi }\end{array}$ & 23,5 & $\begin{array}{l}\text { lang } 4, \mathrm{I} \\
\text { breit } 3,9\end{array}$ & $\begin{array}{l}\text { lang } 4,2 \\
\text { breit } 3,9\end{array}$ & $\begin{array}{c}\text { Frontal- } \\
\text { länge 1,3 } \\
\text { Augen- } \\
\text { zwischenr. I,2 }\end{array}$ & $\begin{array}{l}\text { lang } 3,7 \\
\text { breit } 3,3\end{array}$ & $\begin{array}{c}\text { keine Zähne, } \\
\text { keine Grube, } \\
\text { nur eine Platte } \\
\text { vorn }\end{array}$ & $\begin{array}{l}\text { wurmförmige } \\
\text { Flecke }\end{array}$ \\
\hline $\begin{array}{l}\text { sinuatus; } \\
\text { Bukoba, mit } \\
\text { Uebergangs- } \\
\text { charakter }\end{array}$ & 20,4 & $\begin{array}{l}\text { lang } 3 ; 7 \\
\text { breit } 4,0\end{array}$ & $\begin{array}{l}\text { lang } 3,9 \\
\text { breit } 4, I\end{array}$ & $\begin{array}{c}\text { Frontal- } \\
\text { länge I,2 } \\
\text { Augen- } \\
\text { zwischenr. 0,9 }\end{array}$ & $\begin{array}{l}\text { lang } 3,0 \\
\text { breit } 1,5\end{array}$ & $\begin{array}{l}\text { Zähne kaum } \\
\text { markirt, } \\
\text { Grube garnicht }\end{array}$ & $\begin{array}{l}\text { wurmförmige } \\
\text { Flecke }\end{array}$ \\
\hline $\begin{array}{l}\text { sinuatus; } \\
\text { Djipe-See, } \\
\text { Peters, } \\
\text { Decken }\end{array}$ & 37,2 & $\begin{array}{l}\text { lang } 6,75 \\
\text { breit } 4,65\end{array}$ & $\begin{array}{l}\text { lang } 7,5 \\
\text { breit } 4,8\end{array}$ & $\begin{array}{c}\text { Frontal- } \\
\text { länge 2,3 } \\
\text { Augen- } \\
\text { zwischenr. I,65 }\end{array}$ & $\begin{array}{l}\text { lang } 5,0 \\
\text { breit } 2,4\end{array}$ & typisch & undeutlich \\
\hline $\begin{array}{l}\text { sinuatus; } \\
\text { Djipe-See, } \\
\text { nur Schale }\end{array}$ & 36,6 & $\begin{array}{l}\text { lang } 6,45 \\
\text { breit } 5,2\end{array}$ & $\left\{\begin{array}{l}\text { lang } 6,9 \\
\text { breit 5,2 }\end{array}\right.$ & fehlt & fehlt & fehlt & fehlt \\
\hline
\end{tabular}


In neuerer Zeit (Annali del. Museo Civico di Genova, Sér. 2 da. Vol. XV [ I 895], S. I, Taf. I u: II) hat Boulenger eine neue Sternothaerus-Art (Sternothaerus bottegi) aus dem Somaliland beschrieben. Dieses Thier bestätigt insofern meine Angaben, als es in Betreff verschiedener Charaktere eine Mittelform zwischen S. sinuatus und nigricans ist. In Rücksicht auf diese Art möchte ich nebenbei noch auf die schon citirte Peters'sche Bemerkung hinweisen, dass bei grossen Sternothaerus sinuatus die zweite und dritte Vertebralplatte viel länger sind als bei jungen Thieren (die beiden letzten Thiere in oben stehender Tafel geben die Maasse). Diese Thatsache wird auch durch das in der Tafel erwähnte Riesenthier von Pangani bestätigt.

Die mir vorliegenden Sternoth. sinuatus ergeben übrigens in Betreff jener Schalenplatten Folgendes: Die zweite und dritte Vertebralplatte sind bei jungen Thieren viel breiter als lang, sie gehen dann beim Wachsen der Thiere mehr in die Länge als in die Breite und zum Schluss sind sie viel länger als breit. Ferner zeigen die Thiere noch folgende Altersverschiedenheiten: In der Jugend stehen ihre Dornfortsätze stark aus der Schale heraus, die Schale fällt flach (dreieckig im Querschnitt) nach beiden Seiten hin ab; mit zunehmendem Alter der Thiere füllen sich die Gruben zwischen den Dornfortsätzen allmählich aus und dadurch entsteht nach und nach eine nur wenig bucklige oder fast ganz gerade Rückenlinie. Gleichzeitig buchtet sich die Schale in der Gegend der Rippenmittelpunkte nach oben hin aus. Indem diese beiden Entwicklungsprozesse nebeneinander fortschreiten, bewirken sie, dass bei fast erwachsenen und erwachsenen Thieren die Schale eine völlige Umbildung zeigt: sie fällt nicht mehr, wie bei den Jungen, flach dachförmig (im Querschnitt dreieckig) nach beiden Seiten hin ab, sondern sie ist in der Gegend ihrer Rippenmittelpunkte so stark nach oben gewölbt, dass sie im Ganzen oval gewölbt erscheint, besitzt dann aber ausserdem an jeder Seite ihrer Dornfortsatzreihe, parallel derselben laufend, eine tiefe Längsrinne, welche vom Kopf bis zum Schwanzende der Schale zieht. Die Ausbuchtung der Rippen kann dann bei einigen Thieren eine so starke werden, dass die ganze Rückenmittellinie im Grunde einer Art Schalenlängsgrube verschwindet.

Erwachsene Individuen von Sternothaerus nigricans habe ich noch nicht gesehen, ebensowenig eine erwachsene Zwischenform (Sternothaerus bottegi?).

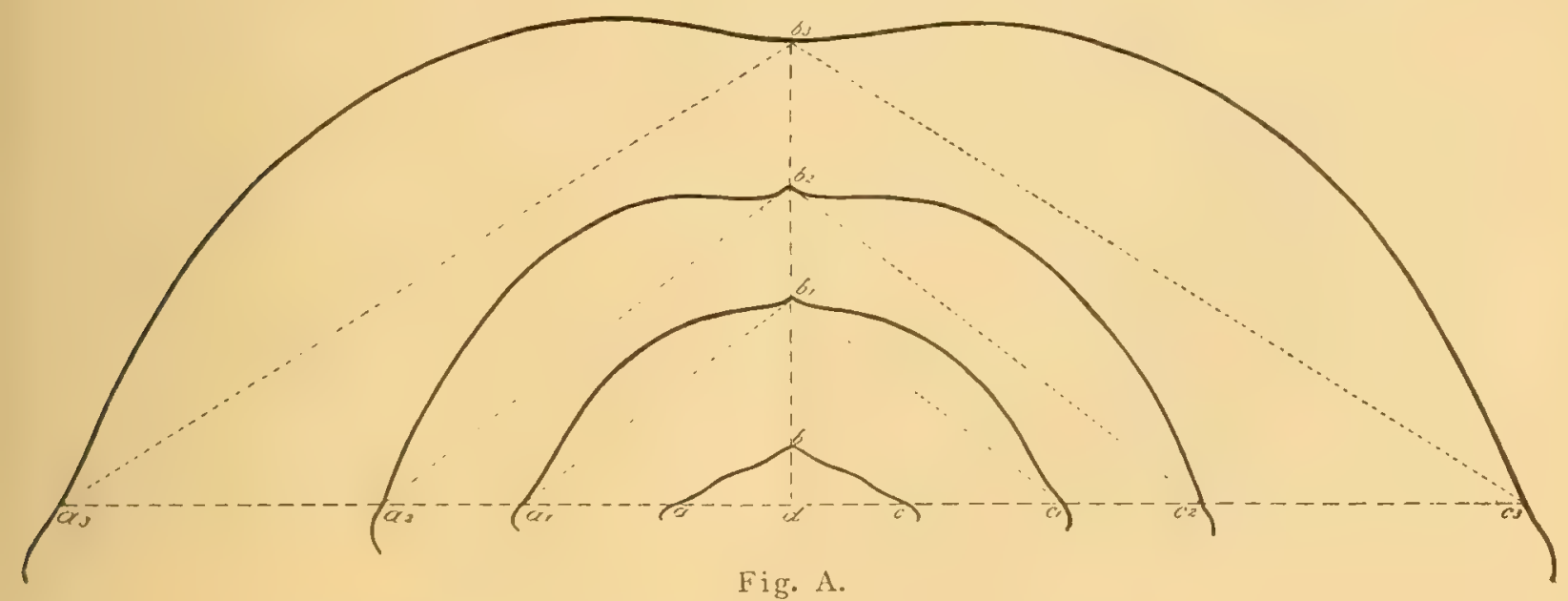

Die beifolgende Textfigur beweist das oben Gesagte, sie stellt genaue Querschnitte durch vier, im Alter verschiedene Sternothaerus-sinuatus-Schalen halb-verkleinert dar. Die Querschnitte sind aus Gipsabgüssen der Schalen gewonnen, die genau in der Naht zwischen der dritten und vierten Vertebralplatte 
durchsägt worden sind. Durch a $c, a_{1} c_{1}$ u. s. w. ist der Durchmesser je einer Schale bezeichnet, mit $d b_{1} d_{b_{1}} u_{\text {. }}$ s. w. ihre Höhe von der Scheitellinie bis zur Mitte der Schalen-Basis. Die Dreiecke $a b c, a^{1} b^{1} c^{1}$ u. s. w. zeigen sehr gut die mit dem Alter der Thiere zunehmende colossale Erhebung ihrer Rippenmittelpunkte und der Schalenseiten; sie lehren ausserdem, dass bei dieser Art die Schale anfangs in die Höhe und Breite, dann nur in die Breite wächst.

\section{Ordnung: Eidechsen, Lacertilia.}

\section{Subordnung: Lacertilia vera.}

\section{Familie: Geckonidae.}

\section{Gonatodes africanus (Werner)}

Usambara; I ठ , I $Q$; Linnaea Berlin S.; Werner, Verh. K. K. zool. -bot. Gesell. Wien, I895. Separat. S. I und Boulenger, Ann. Mag. nat. hist. I895 S. 173 (als Gonatodes africanus bestimmt).

Darema in Usambara; 1 ठ , 2 ; ; Conradt S.; 1892.

Tanga in Usambara; 2 \%; Reimer. S.; 1894.

Deutsch-Ost-Afrika, ohne näheren Fundort; I $q$; Stuhlmann S.

Schliesst sich, wie ich in Bestätigung der Angabe Boulenger's bemerken möchte, den indischen Arten und zwar G. ornatus dadurch an, dass Männchen und Weibchen gleiche Färbung haben, und sich nur dadurch unterscheiden, dass das Männchen Praeanalporen hat, das Weibchen nicht. Die Finger sind nicht aufgetrieben, die Flanken ohne dornartig hervorragende Tuberkeln. Das mir vorliegende Männchen hat zwölf Praeanalporen und keine Femoralporen. Das Männchen, welches Werner untersuchte, hat 8 - 9 Praeanalporen.

Rücken mit kleinen glatten Körnchen, unregelmässig untermischt mit grossen glatten Tuberkeln. Ventralschuppen glatt. Der Kopf ist bei meinen Thieren lang gestreckt, oval. Die Schnauze ist verlängert zugespitzt, länger als die Differenz zwischen Auge und Ohröffnung, 2 mal die Länge der Augenöffnung oder etwas darüber. Vorderkopf oben schwach eingedrückt, Ohröffnung aufrecht oval, nicht gross.

Unterscheidet sich von Boulenger's Beschreibung des Gonatodes ornatus nur in Folgendem: Schnauze übertrifft etwas die doppelte Länge des Augendurchmessers und ist so lang, wie der Raum zwischen Auge und Ohröffnung. Schnauze bedeckt mit Körnchen, von denen nur einige wenige schwache Kiele haben. Vier Nasalia. Auf der Schwanzunterseite die Schuppen der Mittellinie deutlich vergrössert.

\section{Hemidactylus squamulatus n. sp.}

Landschaft Ugundu (wahrscheinlich Kakoma); I ơ ; Böhm S.; 1882.

Diese Form ist sehr nahe verwandt Hemidactylus tropidolepis Mocq. und wird wahrscheinlich später damit vereinigt werden können. 
Das mir vorlicgende Männchen unterscheidet sich von dem Männchen, das Mocquard in den Mém. soc. philom. de Paris I 888, S. I I 3 beschrieben hat, durch die Zahl der Praeanalporen und durch die Rückenbeschuppung; in allen anderen Characteren stimmt es mit ihm genau überein. Mocquard's Exemplar besitzt 7 Praeanalporen, das vorliegende hat I6. Da bei Männchen von Lygodactylus picturatus die Zahl der Praeanalporen von 6 - - I variirt, würde dieser Character keinen Grund bieten zur Trennung der Individuen in Arten, denn es läge die Möglichkeit vor, dass die individuelle Kluft zwischen beiden Thieren nur deshalb so gross sei, weil sie bisher die beiden einzigen Vertreter der von ihnen repräsentirten Art wären.

Mehr weichen die Thiere in der Beschuppung von einander $a b$. Sie ist nach Mocquard's Beschreibung bei Hemidactylus tropidolepis folgende: "Le dessus de la tête est couvert de granulations, grandes, aplaties et carénées sur le museau, parsemées de petits tubercules sur la region céphalique posterieur et le cou. Elles disparaissent dans le tronc et sont remplacées sur la face dorsale par des écailles plus ou moins fortement carénées; légèrement imbriquées et de dimensions tres inégales. Celles de ces écailles qui correspondent à la ligne médio-dorsale sont beaucoup plus petites que les autres." (Mém. soc. philom. de Paris, 1888, S. I 14).

Das mir vorliegende Exemplar zeigt am Rücken eine Beschuppung, die entschieden einfacher und regelmässiger ist als die von Mocquard beschriebene: Die Schuppen der Mittellinie des Rückens sind auch bei meinem Exemplar kleiner als die übrigen Ruickenschuppen und liegen ausserdem auf einer deutlich hervorragenden Hautfalte. Die übrigen Rückenschuppen bilden dann aber nach Form und Gestalt nur zwei Gruppen, die Vertreter jeder Gruppe sind untereinander völlig gleich. Zwischen grossen gekielten Schuppen liegen nämlich wesentlich kleinere kiellose Schuppen, die einander dachziegelartig decken, und so angeordnet sind, dass ein Kreis von ihnen jede einzelne Kielschuppe einschliesst. Die Kielschuppen in der Nähe der Rückenlinie bilden ausserdem deutliche Längsreihen, die weiter von der Mittellinie entfernten mehr verwischte Längsreihen, was in Folgendem seinen Grund hat: Die Schuppen der einzelnen Längsreihen liegen nicht nebeneinander, bilden also nicht gleichzeitig Querreihen, sondern alterniren in Querrichtung mit einander, rücken nun die Längsreihen enger aneinander, so schieben sich die einzelnen Schuppenreihen fast ineinander, dadurch verwischen sich die Längsreihen und die Anordnung der Schuppen erscheint unregelmässiger als sie in Wirklichkeit ist.

Auch diese Unterschiede in der Beschuppung der beiden Formen dürften auf die Dauer kaum genügen, um die Individuen artlich zu trennen; bei vielen Arten, welche mit grösseren und kleineren Rückenschuppen versehen sind, stehen individuell die grösseren Schuppen oder Tuberkeln bald mehr, bald weniger in Längsreihen und was den Unterschied in den kleinen Rückenschuppen anbetrifft, so ist zu bemerken, dass die bei Hemidactylus brooki auf dem Rücken, zwischen den grossen gekielten Schuppen stehenden kleinen Schuppen individuell in der Art variiren, dass man deutlich merkt, es könnten unter Umständen aus diesen Zwischenschuppen solche entstehen, wie sie bei Hemidactylus tropidolepis und squamulatus gefunden werden. Weitere Forschung wird also wahrscheinlich ergeben, dass Hemidactylus tropidolepis und squamulatus in dieser Weise entstandene Varietäten ein und derselben Art sind.

\section{IIemidactylus mabouia (Mor. de Jon.)}

Sansibar; I Individ.; Stuhlmann S.; 2 Mai I 888 (Pfeffer, Stuhlmann X, S. 4). Sansibar; I Individ.; Stuhlmann S.; 7 Mai 1888 (Pfeffer, Stuhlmann X, S.4). Sansibar; Embryonen; Stuhlmann S.; 7 Mai I 888 (Pfeffer, Stuhlmann X, S. 4). 
Sansibar; Boulenger, Cat of Lizards Bd. I. S. I 25.

Sansibarküste; 4 Individ.; Hildebrandt S.; (Peters, Decken Bd. III Abtheil. I., S. I3).

Tanga (Usambara); 6 Individ.; Oscar Neumann S.; I890.

Usambara; I Individ.; Linnaea Berlin S.; F. Werner, Verhandl. K. K. zool. - bot. Gesell. I 895. Separat. S. 2.

Usaramo; 4 Individ.; Stuhlmann S.; I889.

Pongue (Useguha); 6 Individ.; Stuhlmann S.; 2. Aug. I888. (Pfeffer, Stuhlmann X., S. 4).

Dar es Salaam; I Individ.; Stuhlmann S.; I 895.

Kakoma (Ugundu); 4 Individ.; Stuhlmann S.; 24. Aug. I 888.

Kakoma (Ugundu); 4 Individ،; Böhm S.; I882.

\section{Hemidactylus brooki Gray}

Sansibar; 2 ठ ; Oscar Neumann S.; Mus.-Nro. I I $64-65$.

Massai-Nyika; I ?; Oscar Neumann S.; I888; Mus.-Nro. I 672.

Umbugwe; 1 \% ; Oscar Neumann S.; Nov. I 893.

Ndalalani (am Natron-See); Oscar Neumann S.; I6. Dec. I 893.

Taita (Engl. Ostafrika); I \&; Hildebrandt S.; Mus.-Nro. 9296.

Das eine Exemplar wurde von Oscar Neumann an einem Baum gefangen, das andere in einem verlassenen Termitenbau.

Erst im vorigen Jahr hat Günther (Proceed. Zool. Soc. I 894, S. 86) das Vorkommen dieser Art an Afrika's Ostküste definitiv festgestellt, obgleich ein Exemplar dieser Art ebenfalls von der Ostkuiste Afrika's viel früher Peters vorgelegen hat, der es als Hemidactylus verriculatus Cuv. (in Decken's Reisen Bd. III, S. 4) beschrieb. Hemidactylus verriculatus Cuv. ist aber nach Boulenger (Cat. I, p. I 26) synonym Hemidactylus turcicus (L.). Dass ein so gewiegter Herpetolog, wie Peters es war, Autorennamen verwechselt habe und Hemidactylus verriculatus Gray meinte, als er Hem. verr. Cuv. schrieb, darf nicht angenommen werden, noch weniger eine falsche Bestimmung; Peters konnte einfach aus Mangel an Material die Art nicht sicher feststellen, da das Individuum, welches ihm vorlag, ein $q$ war, und die Weibchen von $H$. turcicus $u$. brooki kaum artliche Differenzen zeigen. Das mir vorliegende $\delta$ hat eine ununterbrochene Reihe von Anal- und Präanalporen (in Summa 40) und erweist sich schon dadurch absolut sicher als Hemid. brooki Gray.

Die mir vorliegenden Vertreter dieser Art unterscheiden sich individuell, wie schon früher erwähnt wurde, durch die Form der Zwischenschuppen des Ruickens. Bei vier von diesen Individuen sind die Zwischenschuppen, welche unmittelbar dem Rücken angehören, sehr ungleich, die grösseren von ihnen zeigen ausserdem sehr entschieden die Neigung, sich über die anderen hinüberzulegen und einige von ihnen sind gekielt. An den Körperseiten der Thiere dagegen sind die Zwischenschuppen von annähernd gleicher Grösse und glatt, sie berühren einander entweder direkt oder schieben sich bereits übereinander. Die Rücken dieser Individuen zeigen also die Neigung, eine Beschuppung auszubilden, wie sie Hemidactylus tropidolepis auf dem ganzen Rücken besitzt; die Seiten aber haben Zwischenschuppen, die mit denen des H. squamulatus ibereinstimmen oder ihnen sehr nahe kommen.

\section{Hemidactylus bocagei n. sp.}

Dalalani; I Individ.; Oscar Neumann S.; I6. Dec. I895. An einem Baum.

Steht selbstständig zwischen Hemidactylus turcicus und brooki aus folgenden Gründen: Die freien Distalenden der Finger und Zehen sind lang. Am Rücken 
sind grosse gekielte Schuppen in I6 Längsreihen. Es sind so wenig Lamellen an Zehen und Fingern wie bei $H$. brooki, aber nur Praeanalporen wie bei H. turcicus. Die Beschuppung des Rückens weicht gleichmässig von der beider Thiere $a b$, sie stimmt genau mit der von Hemidactylus squamulatus überein. Zwischen den grossen gekielten Schuppen liegen wesentlich kleinere kiellose Schuppen, die einander dachziegelartig decken und so angeordnet sind, dass ein Kreis von ihnen jede einzelne Kielschuppe einschliesst.

Kopf zugespitzt eiförmig, Schnauze abgerundet, ein wenig länger als der Zwischenraum zwischen Auge und Ohröffnung, I ${ }^{3} / 4$ der Länge der Augenöffnung. Der Nasenrücken etwas eingedrückt. Ohröffnung nach unten zugespitzt oval, nicht ganz die Hälfte des Augendurchmessers. Der innere Finger gut entwickelt mit scharfer Kralle. 4 grosse Lamellen unter dem ersten Finger, 5 unter dem zweiten, 6 unter dem dritten, $6-7$ unter dem vierten. Vier Lamellen unter dem dritten, fünf unter dem mittleren Zeh. Nasenrücken bedeckt mit Pflasterschuppen, die in scharfen Winkeln aneinanderstossen, von ihnen die auf dem Canthus rostralis stehenden grösser und schwach gekielt. Hinterkopf mit convexen grossen Tuberkeln, zwischen ihnen kleinere, ebenfalls convexe Papillen, von welchen einige Andeutungen von Kielen zeigen. Rostrale 6-seitig, oben mit einem tiefen Spalt, nicht zweimal so breit wie hoch. Gleichsam seine Fortsetzung nach hinten bildend, stossen zwei grössere Supranasalia mit ihm zusammen und aneinander. Nasenöffnung vor der Rostral-Labial-Sutur, anstossend direkt an das Rostrale und umgeben von drei Nasalen, es berührt nicht das erste Labiale. Sieben obere, sechs untere Lippenschilder. Mentale gross, viereckig; wenigstens zweimal so breit als das benachbarte Labiale. Es liegt zwischen zwei grossen Kinnschildern, die in der Mittellinie eine grosse Sutur miteinander bilden. I -2 grosse Kinnschilder dahinter. Rücken bedeckt mit I 6 Reihen grosser flacher Schuppen, die einen Medialkiel tragen. Zwischen den grossen gekielten Schuppen liegen wesentlich kleinere, glatte, kiellose Schuppen, die einander dachziegelartig decken und so angeordnet sind, dass ein Kreis von ihnen jede einzelne Kielschuppe einschliesst. Die I6 Längsreihen kleiner Schuppen sind ausserdem in zwei Gruppen zu je 8 Längsreihen angeordnet; jede Gruppe gehört einer Körperhälfte an, getrennt sind sie beide in der Mittellinie des Körpers durch einen Längsstreifen nur kleiner Schuppen von ziemlicher Breite. Die Rückenbeschuppung dieses Thieres ist mithin dieselbe wie die des Hemidactylus squamulatus. Die Bauchschuppen des Thieres sind glatt, sechs-eckig mit etwas abgerundeten Ecken an der Hinterseite, einander deckend. Abdominalschuppen ebenso geformt und gelagert; der Afterrand selbst ist mit winzigen Schüppchen bedeckt. Männchen mit I I Präanalporen in einem gegen den After geöffneten Winkel. Schwanz cylindrisch, oben mit abgerundeten, sich deckenden kiellosen Schuppen; unten mit einer Mittelreihe in die Quere verbreiterter Schuppen.

Licht-braun mit schwarzen Punkten und Strichen, von der Nasenspitze durch das Auge jederseits ein schwarzer Strich; beide Striche umfassen den Hinterkopf und verwachsen in der Mittellinie des Körpers mit einander.

\section{Lygodactylus capensis Smith}

Kakoma;. 2 б'; Böhm S.; I 882.

Die Lygodactylus - Arten zerfallen unter Berücksichtigung der neueren Litteratur in drei Gruppen, solche mit vielen kleinen Schuppen unter dem Schwanz, solche mit einer Doppelreihe von Schildern unter dem Schwanz und solche mit einer einfachen Reihe sehr grosser Schilder unter dem Schwanz. Von allen drei Gruppen sind Vertreter in Ostafrika; zu der ersten Gruppe gehört Lygodact. capensis. 
Die 2 mir vorliegenden Männchen besitzen die typische Färbung und die typischen 5 Präanalporen. Die Färbung ist oliv-braun an den Seiten und grüngrau auf dem Rücken. Ein tiefschwarzer Strich geht durch das Auge, er löst sich hinter der Schulter in einige tiefschwarze Flecken auf.

$\mathrm{Zu}$ derselben Gruppe gehört:

\section{Lygodactylus thomensis (Ptrs.)}

Usambara; I Individ.; Linnaea Berlin S.; Werner, Verhandl. d. K. K. zool.-bot. Gesellsch. Wien, 1895. Separat., S. 2.

Es ist sehr zu berücksichtigen, dass zwei so nahe verwandte Formen wie L. thomensis und capensis in ein und demselben Gebiet gefunden worden sind. Dass die von mir oben erwähnten Lygodactylus capensis nicht etwa L. thomensis sind, konnte ich leicht konstatiren, da das Berliner Museum die Typen von Lygodactylus thomensis besitzt.

\section{Lygodactylus conradti Mtsch.}

Derema in Usambara; I 9 ; Conradt S.; I 892; Matschie, Gesell. nat. Freunde. Berlin I 892 , S. IO4.

Tanga in Usambara; I ठౌ; Reimer S.; I 894.

Buloa bei Tanga in Usambara; I $\delta$; G. Eismann S.; 1895.

Ist nach Matschie sehr ähnlich dem L. fischeri Blgr. (Proc. Zool. Soc. I890, p. 80) von Sierra Leone, aber unterschieden durch die Zahl der Lippenschilder ( 8 obere und 7 untere), den Mangel des schwarzen Achselfleckes und der Seitenflecken am Körper. Lygodactylus fischeri hat 9 obere und 6 untere Lippenschilder.

$\mathrm{Ob}$ sich die Art auf die Dauer aufrecht halten lässt, bezweifle ich. Die Zahl der Lippenschilder variirt bereits bei den mir vorliegenden zwei Individuen. Schon bei dem Individuum, das Herrn Matschie vorgelegen hat, kann man im Zweifel sein, ob man 7 obere und 7 untere, oder wie der Autor will, 8 obere und 7 untere, oder gar 8 obere und 8 untere Lippenschilder zählen soll. Das hängt wesentlich davon $\mathrm{ab}$, ob man den wirklich grossen oberen und unteren Lippenschildern noch einige mittelgrosse Schilder hinzurechnet, die ihnen folgen und auch dem Lippenrande angehören. Das eine der mir vorliegenden Männchen hat 7 obere und 7 untere grosse Lippenschilder, wozu dann noch 2 kleinere hinzugerechnet werden können. Das andere Männchen hat rechts $7-8$, links 8-9 Oberlippenschilder und 7-7 Unterlippenschilder. Beide Männchen haben 7 Praeanalporen.

Das Kinnschild ist gross und deutlich aus drei Schildern verwachsen. Es wird von 3 Gularschildern umgrenzt, welche ihrerseits umgrenzt werden von 5 Gularschildern, die einen flachen Bogen bilden.

Was nun die Färbung der Individuen betrifft, so ist sie ausserordentlich ähnlich derjenigen stark abgeblasster Lygodactylus-capensis-Individuen. Es sind nämlich beim Weibchen auf dem Rücken 4 schwarze Längsstreifen in schwarzen Punkten und Flecken angedeutet; von ihnen ist der durch das Auge gehende am besten erhalten und tritt zuerst als ein wirklicher Strich durch das Auge (als Post- und Praeocular-Streifen Werners) auf, dann löst er sich an den Seiten des Thieres in eine Längsreihe dunkelbrauner Querflecke auf, die dicht an einander liegen, vielzackige Ränder aufweisen und an vielen Stellen noch durch dunkle Querbrücken mit einander zusammenhängen, einer von ihnen dürfte wohl auch dem schwarzen Achselfleck des Lygodactylus fischeri Boul. homolog sein. 
Bei beiden Männchen sind die schwarzen Rückenstreifen stärker verblasst als bei Weibchen, das gilt auch von den Streifen, die durch die Augen ziehen, doch ist deren Prae- und Postocular-Partie so wie beim Weibchen erhalten.

\section{Lygodactylus picturatus Ptrs.}

$=$ Lygodactylus angularis Günth.;

$=$ Lygodactylus gutturalis Boc.; Bocage in Jorn. Sc. Lisboa IV, I873, S. 2 I I und Boulenger, Cat. of. Lizards Bd. I., S. I6I. Das Berliner Museum besitzt ein vom Autor übersandtes Exemplar der letztgenannten Art.

Sansibar; I Individ, ; v. d. Decken S.; Peters (Type des Lyg. picturatus) in Monatsber. Berl. Acad. I868, S. 449, und in Decken's Reise III, S. I 3 und Monatsber. Berl. Acad. I 870 , S. I 5. S. I I I.

Sansibar; 9 Individ.; M. G. Révoil S.; Mocquard., Mem. soc. philom. 1888,

Sansibarküste; I Individ.; Hildebrandt S.; Peters, Monatsber. Acad. Berlin I 868, S. 449. Mus.-N. 5570.

Sansibarkuiste; 8 Individ.; Hildebrandt S.; Monatsber. Acad. Berlin I 870 , S. II 5 ; M.-N. 8004.

Tanga (Usambara); I Individ.; Reimer S.; I894.

Magila (Pangani); J. Kirk S.; Boul., Cat. of. Lizards B. I., S. I6I.

Korogwe am Rufo; I Individ.; Stuhlmann S. I Pfeffer, Stuhlmann. X, Lewa (Usambara); I Individ.; Stuhlmann S. J S. 4.

Dar-es-Salaam; 3 Individ.; Stuhlmann S.; 1894 und 1895.

Mrogoro; I $\$$ 》 Stuhlmann S.; VI. I 894 mit legereifen Eiern.

Kakoma; 9 » Böhm S.; I882.

I junges Thier; Böhm S.; I882.

2 (ठำ

4 (ठ઼ u. ㅇ) 》»

Pinin (am Natron-See); I Individ.; Neumann S.; I893, 20. November.

Kagehi a. Victoria-Nyansa; I. Individ.; Fischer S.; Mus.-No. 3 I 32.

Radem in Kavirondo (Engl. Ostafrika); I Individ.; Oscar Neumann S.; Februar 1894.

Radana in Kavirondo (Engl. Ostafrika); 4 q; Oscar Neumann S.; Mitte Februar I 894 .

Lygodactylus picturatus Ptrs. zeigt als Art eine grosse individuelle Variabilität, was bei den von mir untersuchten 72 Vertretern dieser Art klar zum Ausdruck kommt, aber trotz der Variabilität der Art als solcher findet man unter ihren Vertretern keine Individuen, die in einer grösseren Anzahl anatomischer Charaktere nach derselben Richtung hin variiren, und deshalb als Subspecies oder gar Arten zu betrachten wären; im Gegentheil zeigen die Individuen bei ihrer Variation, eine willkürliche Mischung der individuell variirten, anatomischen Artcharaktere. Anders ist es mit der Färbung der untersuchten Individuen; nach der Art ihrer Zeichnung gehören sie nur einer von 3 Gruppen an, deren mehr oder weniger extrem entwickelte Glieder sie bilden.

Die Entwicklung der Gruppen aus gemeinsamer Urform ist dabei so divergent, dass beim ersten Anblick des Gesammtmaterials dem Beschauer die Meinung kommt, es enthalte das Material wenigstens drei distincte Lygodactylus-Arten, bis eingehendes Studium lehrt, dass es Farbenvarietäten einer Art sind.

Diese Farbenvarietäten nenne ich, ihren Hauptcharakteren nach:

Lygodactylus picturatus var. griseus, var. septemlineatus,

var. quinquelineatus. 
Uebergänge sind besonders zwischen griseus und septemlineatus sehr häufig.

Die Farbkleid-Entwicklung des Lygodactylus picturatus in den drei charakteristischen Richtungen ist folgende:

Alle Lygodactylus picturatus dürften bei der Geburt auf dem Rücken einfarbig und zwar gleichmässig dunkel, fast schwarz gefärbt sein, denn die jüngsten mir vorliegenden Individuen aller drei Farbengruppen zeigen ein auffälig dunkles Gesammtkolorid, in welchem die Zeichnung entweder garnicht zu erkennen ist, oder mühsam aus Bruchstücken rekonstruirt werden muss; jedenfalls stammen sämmtliche Lygodactylus picturatus phylogenetisch von solchen einfarbig dunkel gefärbten Individuen ab. Die Umbildung derartig gleichmässig gezeichneter Individuen zur 7- und 5-streifigen Varietät beginnt nach gleichem Prinzip: Es entstehen bei einzelnen Individuen in der gleichmässig dunklen Rückenzeichnung hellfarbige Flecken, zuerst nur angedeutet durch Uebergang der schwärzlichen Grundfarbe in grau (wie Taf. I, Fig. I, schematisirt zeigt); bei weiterem Abblassen der Grundfarbe treten sie jedoch stärker hervor (Taf. I, Fig. 2 schematisirt). Die Ursache der Fleckenbildung liegt im Schwinden des Pigments in den von den Flecken bezeichneten Rückenpartien. ( $\mathrm{Zu}$ vergleichen ist hiermit der die Färbung der Rappien behandelnde Text).

Die zuerst auftretenden Hellflecken sind scheinbar regellos über den Rücken des Thieres verstreut (Taf. I, Fig. I); wenn die bereits vorhandenen Flecken aber auf Kosten der stehengebliebenen Pigmentpartien umfangreicher geworden sind, und ausserdem neue Flecken hinzugebildet werden (Taf. I, Fig. 2, 3), zeigt sich die Linienbildung noch deutlicher, und zum Schluss verwachsen die Flecken auf Kosten der stehen gebliebenen Pigmentpartien zu wirklich hellen Längsstreifen (Taf. I, Fig. 5 und andere).

Bei der siebenstreifigen picturatus-Varietät legen sich auf diese Weise auf dem Rücken des Individuums in der Höhe der Vordergliedmaassen erst fünf (Fig. 3), dann sieben helle Längsstreifen an (Fig. 4), die auch über den Kopf hinwegziehen; doch kommen von ihnen nur vier zu voller Ausbildung, denn die drei mittleren zeigen auf dem Kopf des Individuums ein Verharren im Fleckenstadium, das zur Ausbildung einer sehr charakteristischen Kopfzeichnung führt.

Die vier hellen Vollstreifen sind folgende (Taf. I, Fig. 4 u. 5). An jeder Körperseite liegt ein Streifen (a und g), welcher zwischen Auge und Mundspalte an der Oberlippe entlang zieht (Oberlippenstreif), den Mundwinkel berührt und scheinbar am Schultergelenk endet, doch zieht er in Wirklichkeit in halber Ausbildung über das Gelenk hinweg bis zu den Hintergliedmaassen hin. Die beiden, einander entsprechenden Streifen der Körperseiten stossen unter den Nasenlöchern an der Schnauzenspitze zusammen.

Der zweite Streifen an beiden Körperhälften (b und f), der volle Ausbildung zeigt, zieht nach zwei Richtungen hin über den Vorderrand des oberen Augenlides hinweg (vorderer Augenlidstreifen) und geht einmal parallel dem Canthus rostralis zur Nasenspitze hin, wo er mit dem Gegenstreifen der anderen Körperseite verwachsen kann, andererseits läuft er bis zur Körpermitte und setzt sich dann angedeutet bis zur Schwanzwurzel fort.

Der erste Längsstreifen der Varietät, der nicht voll ausgebildet wird (d), läuft genau auf den Dornfortsätzen des Thieres entlang und zieht von der Mitte des Rückens bis zum Nacken hin (Medianstreifen).

Die von den sieben Längsstreifen der Varietät bisher noch nicht besprochenen 2 Längsstreifen (c unde) liegen, als Gegenstuicke für einander, zwischen dem Medianstreifen (d) und je einem Oberlidstreifen (b oder f). Sie kommen bei keinem Thier in voller Ausbildung vor, sondern zeigen bei jedem, besonders in den Nackenpartien, mehrere Unterbrechungen durch Pigmentbalken (bei $\mathrm{h}$ und i, $k$ und 1 ), also noch Halbfleckenbildung. Auf dem Kopf des Thieres laufen sie 
in zwei sehr breite Endzipfel aus (Fig. 5, m, n), welche mit einem, auch zu diesem Liniensystem gehörigen, aber selbstständig gebliebenen Stirnflecken und dem Medianstreifen (d) einen Rest der Primärfarbe einschliessen, der $\mathbf{T}$-förmig ist.

Sind bei einem Thier die sieben hellen Längsstreifen bis zu dieser Form ausgebildet, so kann bei ihm die Entwicklung der Hellzeichnung noch weiter fortschreiten, indem nunmehr in den dunklen Reststreifen der Primärfarbe des Thieres grössere Partien abblassen, und zwar geschieht das nach zweifacher Art: Erstens so (Fig. 8 u. 9,) dass die Reststreifen von den Abblassstellen der Quere nach unregelmässig durchbrochen werden, weshalb sie anfänglich noch aus dunklen und halbhellen Partien bestehen (Fig. 8). Sind die Abblassstellen endlich gänzlich verblasst (Fig. 9,) dann zerfallen die Reststreifen der Grundfarbe in selbstständig gewordene Pigmentflecken von sehr unregelmässiger Gestalt, die jedoch auf dem nunmehr vorwiegend hellgefärbten Ruicken des Thieres noch mehr oder weniger in Längslinien angeordnet sind. Weiter geht bei den mir vorliegenden Individuen die Entwicklung nach dieser Richtung hin nicht. - Der andere Zweig der siebenstreifigen Farbenvarietät (Fig. 6 u. 7) entwickelt sich, indem die Reststreifen der Grundfarbe mehr gleichmässig verblassen und zwar durch Fleckenbildung und Aufhellung entlang ihrer Mittellinien, sodass im Beginn der Entwicklung die Streifenränder unversehrt bleiben (Fig. 6). Die erhalten gebliebenen Pigmentflecken zeigen so das Bestreben auf ihre Kosten noch weitere Hellstreifen auf dem Rücken des Thieres auszubilden; doch kommt es dazu nicht, da die in der Streifenmitte entstandenen Flecke und Linien sehr bald auch die Streifenränder zerfressen und nie voll verblassen. Diese Entwicklung macht bei den mir vorliegenden Individuen auf einer Stufe halt (Fig. 7), 'auf welcher die sämmtlichen Streifen stark abgeblasst sind, doch erreicht bei keinem Thier dieses secundäre Verblassen der Grundfarbe die Intensität ihres primären Verblassens, d. h. die Reststreifen der Grundfarbe verschwinden bei den mir vorliegenden Individuen nie vollständig, sondern bleiben als hellgraue Linien bestehen, deren Ränder entweder streckenwcise dunkel geblieben sind, oder aus vielen feinen schwarzen Pünktchen von der urspriinglichen Intensität der Rückenfärbung bestehen.

Die Lygodactylus-picturatus-Zeichnung nach der fünfstreifigen Varietät beginnt ihre Entwicklung gemeinsam mit der siebenstreifigen Varietät, d. h. mit dem Entstehen von Hellflecken in der gleichmässig dunkeln Rückenzeichnung der Stammform (Fig. I, 2, 3). Erst später, wenn die zahlreich vorhandenen Hellflecken die Tendenz zeigen in fünf Längsstreifen zu verwachsen (Fig. 3), zweigt sich die eine Varietät von der anderen ab. Die alsdann bei der fünfstreifigen Varietät in Punkten angelegten fünf Längsstreifen sind: die beiden Oberlippenstreifen (Fig. IOa, g), die beiden vorderen Augenlidstreifen (b, f) und der Medianstreifen (d). Schon auf diesem frühen Entwicklungsstadium theilt sich die Varietät wiederum in zwei Entwicklungsrichtungen (Fig. IOa, u. Fig. I I-I 4); bei der einen Richtung (Fig. IOa), welche mir bisher nur in cinem Individuum rorliegt, kommen diese funf Streifen zu reiner Ausbildung, mit cler Zugabe, dass auf dem Kopf des Individuums auch noch die Kopfenden der beiden Rückenstreifen $(m-n)$ der Siebenstreifen-Varietät herausgebildet werden, und mit dem Medianstreifen (d) verwachsen, wodurch auch bei dieser Varietät zwischen den Augen der restirende Pigmentfleck in T-form auftritt, der bei der SiebenstreifenVarietät eine Rolle spielt.

Bei den anderen, von mir untersuchten Vertretern der Fünfstreifen-Varietät (Fig. I I-I4), die den Hauptzweig der Varietät und unter sich eine volle Entwicklungsreihe bilden, entstehen am frühsten und vollständigsten die beiden Oberlippenstreifen $(\mathrm{a}, \mathrm{g})$; sie ziehen, wie bei der Siebenstreifenvarietät, von der Schulter beginnend, uber das Trommelfell unter dem Auge hin bis zur Schnauzen- 
spitze, wo sie verwachsen. - Nicht ganz so frühzeitig gelangen bei dieser Varietätenreihe die vorderen Augenlidstreifen (b u.f) zu voller Ausbildung, denn die Mitte der beiden Streifen zeigt bis zu den extremsten Vertretern der Reihe Unterbrechung durch eine Pigmentleiste (p), welche als Urfarbenrest die benachbarten Reststreifen verbindet, und erst am Ende der Reihe ganz verschwindet. Der bei diesem Varietätenzweig ebenfalls in Hellflecken (Fig. IO, q, r, s, t) angelegte Medianstreif (d), kommt nie zu voller Ausbildung, sondern bleibt dauernd im Fleckenstadium. Bei den mehr extremen Vertretern dieses Entwicklungszweiges vergrössern sich diese Medianflecken (q, r, s, t) in Querrichtung durch Erwerbung fliigelartiger Fortsätze, deren Entstehungsursache im Verblassen benachbarter Reststreifen-Partieen liegt. Auf diese Weise wachsen die Flügel der Medianflecken solange fort, bis sie zum Schluss die benachbarten Reststreifen quer durchbrechen und dadurch mit den Oberlidstreifen (b u. c) verschmelzen. Es bleiben demnach beim Schluss dieser Entwicklung auf dem hellgewordenen Rücken des Thieres eine Anzahl Pigmentflecken zurück, die entweder garnicht mehr oder nur durch schmale Pigmentbrücken sehr lose zusammenhängen. Von den, bei der Siebenstreifen-Varietät vorhandenen, beiden Rückenstreifen ( $c$ u. d) entstehen auch bei diesem Varietätenzweig, wie bei dem Zweig Ioa nur die beiden äussersten Kopfenden ( $m$ und $n$ ) als selbstständige, später zu den Augenlidstreifen durchbrechende Flecken, was sich darin zeigt, dass auch bei den nicht zu extremon Vertretern dieses Entwicklungszweiges die bisher stets gefundene Kopf-Restzeichnung in Form eines $\mathrm{T}$ in bester Ausbildung angetroffen wird. Die so gewonnene Hauptzeichnung der Fünf-Streifen-Varietät (Fig. I2) entwickelt sich nun, selbst bei den extremsten Vertretern der Varietät, nur wenig fort: Die restirenden Pigmentflecken runden sich durch Verblassen ihrer Ränder $a b$, wodurch auch die noch zwischen ihnen vorhandenen Pigmentbrücken verschwinden. So verliert z. B. das, auf dem Kopf vorhandene T seinen Stiel und zerfällt in einen unteren und obereren Fleck (Fig. I3).

Die gra ue Lygodactylus-picturatus-Varietät in ihren Modifikationen (Taf. I, Fig. I 5- I8) entsteht dadurch, dass die gleichmässig dunkle, fast schwarze Totalzeichnung der Stammeltern aller Picturatus-Varietäten bei einigen Nachkommen fast auf dem ganzen Rücken zu verblassen beginnt. Dadurch wird die dunkle Grundfärbung der Stammeltern zu einer helleren, d. h. grauen bei den Nachkommen. Würde das Verblassen der Urzeichnung auf dem ganzen Rücken der Nachkommen ganz gleichmässig stattfinden, dann würden aus den gleichmässig dunkel gefärbten Stammeltern gleichmässig grau gefärbte Nachkommen entstehn; aber das Verblassen der Urzeichnung erfolgt auch bei dieser Entwicklung nicht gleichmässig, sondern stets so, dass gewisse Körperpartien entweder stärker verblassen als andere, oder sogar die Intensität der Urfärbung beibehalten. Daraus folgt dann, dass die grauen Nachkommen der dunklen Urform in der grauen Grundfarbe des Rückens eine undeutlich verschwommene Pigment-Restzeichnung aufweisen. Die Restzeichnung hat das Charakteristische, dass sie viele Charaktere jener Pigmentation ganz oder in Andeutungen wiederholt, welche bei einer Sieben- oder Fünfstreifenform in reinerer Ausbildung gefunden werden; so findet man auch bei fast allen grauen Individuen (Fig. I5, I7, I8) auf dem Kopf die charakteristische Pigmentpartie in Form eines T; oft ist sie allerdings nur leicht angedeutet in der sehr dunklen Grundfarbe des Individuums. Auf diese Weise entstehen aber auch Zweigformen der grauen Varietät, welche im Rohen alle charakteristischen Merkmale der Zeichnung gewisser sieben- oder fünfstreifiger Varietäten aufweisen, $d$. h. zu diesen Formen Convergenzformen bilden (Fig. I6 u. I7); wie ja auch die Sieben-Streifen-Varietät einen Entwicklungszweig (Fig. 6 u. 7) aufweist, der sich zur grauen. Varictät hin entwickelt, indem er durch ein mehr gleichmässiges Verblassen der Reststreifen auf dem Körper des Thieres ein Verschwimmen der Zeichnung bewirkt. 
Viele Vertreter der grauen Varietät (Fig. I8, z. B.) zeigen uibrigens in ihrer Rückenzeichnung ein Auftreten von Hellflecken (Augenflecken) in mehr oder weniger guter Ausbildung. Die Augenflecke, die hier vorliegen, entstehen aus einer hellen Pupille, umgeben von einem dunklen Ringe, der in vielen Fällen vollständig geschlossen, in anderen theilweise durchbrochen ist, und, soweit er intact bleibt, die Intensität der Urfärbung zeigt. So liegen die Ringe eingebettet in der nur wenig abgeblassten, d. h. grauen Grundfarbe des Thieres. Sie sind bei vielen Thieren in Längsreihen angeordnet und entsprechen dann entweder Hellflecken, welche die fünf oder sieben hellen Längsstreifen der anderen Varietäten zu erzeugen streben, oder sie repräsentiren auch Hellflecken die an den Stellen der Pigmentstreifen der anderen Varietäten entstanden sind. - Uebrigens zeigen auch einige Vertreter der Fünfstreifenvarietät im hinteren Rückenabschnitt sehr schwach angedeutete Augenflecke. Sehr schön ausgebildet finde ich sie ferner bei einer Siebenstreifenform auf dem Hinterkörper, als sehr helle Flecken mit tief dunklem, völlig geschlossenem Ring in der hellen Grundfarbe, und auf dem Vorderkörper ebenfalls mit sehr heller Pupille und tief dunklem, aber meist durchbrochenem Ring in der viel weniger verblassten Grundtärbung (Fig. 4b).

Die Augenflecke entstehen demnach wie andere Hellflecken und zeichnen sich eben nur dadurch vor diesen aus, dass zufälligerweise gerade um sie herum grössere Reste der Urfärbung erhalten bleiben. Uebrigens erwähne ich hier nebenbei, dass, wie schon dieses Beispiel ergiebt, gewisse Arten der thierischen Zeichnung zur Entstehung von Augenflecken prädisponirt sind, unter ihnen besonders schwarze netzförmige Zeichnungen mit erst halbausgebildeten Hellflecken, von denen dann nur einige noch heller werden.

Wie die Stammform aller Lygodactylus-picturatus-Varietäten. auf dem ganzen Rücken einfarbig dunkel-schwarz gefärbt war, so besass sie auch einen Unterkiefer mit tiefschwarzer Totalzeichnung; ja unter den Vertretern ihrer fünfund siebenstreifigen Nachkommen findet man zahlreiche Individuen, welche in der Unterkieferzeichnung noch jetzt dieser Stammform sehr nahe stehen. Bei einem Männchen der Siebenstreifenvarietät z. B. (Taf. I, Fig. 20) erscheint die Totalfärbung des Unterkiefers erst auf wenigen Unterlippenschildern etwas verblasst. Das Verblassen der Unterkieferzeichnung schreitet dann bei anderen Individuen, wie jenes der Ruickenzeichnung fort, indem neue Hellflecken auı Kosten der Totalfärbung entstehen (Taf. I, Fig. 2 I - 23). Diese entwickeln sich zum Theil inmitten der Totalzeichnung, häufiger allerdings in den Rändern derselben, besonders an der Kehle und dringen von dort aus in die Totalzeichnung ein. Durch Verwachsen der Binnenflecken und starkes Längenwachsthum der Randflecken entstehen spater Hellstreifen, die parallel den Rändern der dreieckigen Mundspalte verlaufen; und weil sie symmetrisch zur Längsachse des Körpers angelegt werden, verwachsen je zwei von ihnen unter dem Kinn zu einer winkelförmigen Figur $(\Lambda)$, deren Oeffnung gegen den After schaut. Bei den meisten Individuen fand ich am Unterkiefer 3 derartige Winkelfiguren ausgebildet. Zum Schluss können dann die, zwischen den hellen Winkelfiguren liegen gebliebenen Reststreifen soweit verblassen, dass sie nur noch in matt angedeuteten Flecken und Linien oder garnicht mehr zu erkennen sind. Ein derartig starkes Verblassen der Totalzeichnung der Kehle findet man nur bei fast allen Weibchen der beiden Varietäten, nicht bei den mir vorliegenden Männchen.

An die Siebenstreifenformen mit winkelförmiger Hellzeichnung schliessen sich die mir vorliegenden Formen der grauen Varietät unmittelbar an. Ich finde bei dieser Varietät im Maximum 4 Winkel ausgebildet, die bei den primitiveren Vertretern der Varietät eigentlich erst in Verblassstellen angedeutet sind; dann verschwinden bei anderen Individuen die Pigmentstreifen, die sie durchbrechen und die vier Winkel treten rein hervor; zum Schluss ver- 
blassen auch hier die Reststreifen der Unterkieferzeichnung mehr oder weniger und können zum Schluss völlig verschwinden. Die letzten Stadien dieser Entwicklung findet man auch hier vorwiegend bei den Weibchen, aber auch bei den Männchen. Schon Boulenger erwähnt Ann. Mus. Civ. stor. nat. Genova ein zweifellos der grauen Varietät angehöriges Männchen ohne jede Unterkieferzeichnung.

Die Fünfstreifenvarietät zeichnet sich von den beiden anderen Varietäten durch eine wesentlich plumpere Umbildung der Unterkieferzeichnung aus (Taf. I, Fig. 26-30). Auch von dieser Varietät liegen mir Männchen vor, bei welchen die Kehle fast schwarz ist; nur ein Hellstreifen auf den Sublabial-Schildern ist bei ihnen einigermaassen entwickelt und einige Hellflecken liegen bei ihnen bereits am Kinn und am unteren Rande der Unterkieferzeichnung. Bei anderen Thieren wachsen diese Randflecken durch Verblassen benachbarter Pigmentpartien in die Totalzeichnung streifenartig hinein, verwachsen zum Schluss mit dem Kinnfleck, der ebenfalls grösser geworden ist, und bilden so neben dem Sublabial-Winkelstreifen den zweiten, hellen Winkelstreifen am Unterkiefer des Thieres (Fig. 28). Hiermit ist die Entwicklung der Unterkieferzeichnung der Fünfstreifen-Varietät bereits abgeschlossen, höchstens entstehen noch in dem, an der Kehle stehen gebliebenen grossen Pigmentflecken einige sekundäre Hellflecken, meistens aber verblassen bereits Vorstufen dieser extremsten Kinnfärbuing bis zum Verschwinden (Taf. I, Fig. 29, 30). Auch bei dieser Varietät zeigen durchweg die Weibchen die extremeren Formen der Unterkieferzeichnung.

Ich untersuchte 22 Exemplare der grauen Varietät, 22 der fünfstreifigen und 28 der siebenstreifigen und möchte dazu noch bemerken: die drei Farbenvarietäten dieser Art sind nicht etwa Lokalformen, sondern kommen an weit getrennten Orten und oft daselbst nebeneinander vor. So besitze ich alle drei Varietäten von Mombas, zwei Varietäten (die graue und siebenstreifige) von Kakoma; die relativ seltenere fünfstreifige Varietät liegt mir bereits von zwei getrennten Fundorten vor, aus Mombas und Sansibar. Kommen sie in ein und demselben Orte vor, so scheinen sie nicht einmal getrennte Aufenthaltsorte zu bevorzugen, denn nach Böhm kommt eine Varietät (es ist nicht zu bestimmen, welche) sehr häufig an Zäunen und Baumstämmen vor; die andere Varietät war häufig »auf Bananen", also auch auf Bäumen. Oscar Neumann erwähnt von einem griseus, er sei gefangen »an einem Baum", und vier andere sammelte er an Kandelaber-Euphorbien.

Die Thiere sind nach Böhm »am Tage munter«; am I7. April fand er Weibchen mit legereifen Eiern; Oscar Neumann solche bereits im Februar.

In Betreff der drei Lygodactylus-picturatus-Varietäten wäre noch Folgendes zu erwähnen: Die grauen Individuen haben über den ganzen Rücken von der Schwanzspitze an bis zur Schnauze eine nach demselben Prinzip ausgeführte Zeichnung, d. h. schwarze Flecken auf dunklem Grund. Ganz anderes Verhalten zeigen dagegen die fünf- und sieben-streifige Varietät. Bei ihnen liegen nur auf Kopf und Nacken bis zur Schulterhöhe wirklich helle (in Natur gelbe) Streifen auf schwarzem Grund, von dort an hat ihr Körper eine graue Grundfarbe, in welcher stark verblasste schwarze Flecke liegen (Taf. I, Fig. I9). Hierdurch stimmen beide Varietäten mit anderen Eidechsen überein, deren Kopf ebenfalls heller als der Körper gefärbt ist und von denen wir wissen, dass sie, mit halbem Körper aus Baumlöchern heraushängend, auf Beute lauern. Auf Grund dieser Farbkleid-Analogien möchte ich die Vermuthung aussprechen, dass die erwähnten Lygodactylus-Varietäten ähnlich wie jene Eidechsen leben (also in Baumlöchern auf Beute lauern), während die graue Lygodactylus-Varietät ein herumstreifendes Thier sein dürfte, das vielleicht an mehr glatten Gegenständen lebt. Ein Beobachter in Afrika mag, wenn er dies liest, nachsehen, ob meine Vermuthung Berechtigung hat. 
In Rücksicht auf die, bisher im Text citirten Figuren der Tafel I wäre zu erwähnen: Sie sind peinlich genau nach der Natur, zum Theil nach Photographien, ausgeführte Abbildungen mit Ausnahme der Fig. I-3; diese sind schematisirt. Ich musste sie schematisiren, weil mir keine sehr jungen Vertreter der Art, sondern nur halb erwachsene zur Verfügung standen und diese nicht genau den Anforderungen entsprachen, welche man an die Anfangsglieder der Reihen stellen muss, und weil ich hier schon an einem Beispiel durchfuhren wollte, wie nach meinen Ansichten, den Resultaten sehr ausgedehnter Untersuchungen, Farbenvarietäten entstehen. Dass die schematisirten Figuren keine Phantasiegebilde sind, wird sofort klar, wenn man sie mit Fig. I6 - I 8 vergleicht, es ergiebt sich dann, dass diese $\nsim$ Abbildungen nach der Natur « genau dieselben Flecken in halber oder ganzer Ausbildung aufweisen, wie die schematisirten Figuren. - -

Ueber die anatomischen Charaktere des Lygodactylus picturatus ist Folgendes erwähnenswerth:

Bei allen Vertretern der Art trägt die Schwanzunterseite nur eine Reihe verhältnissmässig sehr grosser, in die Quere verbreiterter Schilder; es ist das ein durchaus konstanter Artcharakter.

Nicht so konstant ist die Lage des Nasloches. Boulenger's Angabe, dass das Nasloch hinter der Rostral-Labial-Sutur gelegen sei, stimmt für die meisten Individuen, daneben aber giebt es eine ganze Anzahl solcher Individuen, bei welchen das Nasloch unmittelbar über der Sutur liegt; ja, es giebt Individuen, bei welchen es an der einen Seite über der Sutur liegt, an der anderen Seite hinter derselben. Eine ähnliche Variabilität in der Lage des Naslochs zeigt nach Boulenger auch Lygodactylus capensis.

Auch die Zahl der Schilder, welche das Nasloch umgiebt, ist nicht absolut konstant: ausser dem Rostrale und Labiale nehmen an seiner Begrenzung Theil 2 oder 3 Nasalschilder. In Wirklichkeit aber muss man sagen, das Rostrale nimmt nicht an der Begrenzung des Nasloches Theil, denn das Nasale, welches an's Rostrale grenzt, erscheint bei allen Thieren als ein wirkliches Praenasale; es deckt nämlich das Nasloch nicht nur von oben, sondern reicht auch mit einem grossen Vorsprung an der Vorderseite desselben so tief hinab, dass es mit diesem Fortsatz in einer schrägen Naht das Labiale berührt, wodurch natürlicherweise das Rostrale an der Berührung des Nasloches verhindert wird. Bei manchen Individuen aber ist dieser, zum Labiale ziehende Fortsatz des Praenasale sehr verschmälert und es erfordert dann einige Anstrengung, ihn überhaupt zu erkennen.

Dass bald 2, bald 3 Nasalia das Nasloch von oben und hinten begrenzen, kommt bei Vertretern aller drei Farbenvarietäten vor, die physiologische Ursache dieser Varietätenbildung kann ich indess nicht finden.

Oberlippenschilder zähle ich 6-9, Unterlippenschilder 6-8. Ich finde, dass sogar bei ein und demselben Individuum an der rechten und linken Kopfseite die Zahl der Lippenschilder verschieden sein kann. Dies hat zum Theil in bekannten Ursachen seinen Grund. Ein, an einer Kopfseite normal gebildetes Labiale kann an der anderen Kopfseite durch eine Naht in zwei Lippenschilder zerfallen sein (da bei den Reptilien die grossen Kopfschilder dadurch entstehen, dass mehrere kleinere Schilder zu einem grossen verwachsen, so ist dies entweder eine Hemmungs- oder Missbildung) oder es können zwei normale Lippenschilder der einen Kopfseite an der anderen Kopfseite zu einem verschmelzen (fortschreitende Entwicklung); indess der Hauptgrund für dieses Variiren der Art ist: eine Anzahl kleiner Schüppchen, welche hinter den grossen Labialschildern liegen und dem Mund noch angehören, können bei einzelnen Individuen mit einander zu einigen grösseren Lippenschildern verwachsen und 
muissen dann in der Zahl »der Lippenschilder "mitgezählt werden; geschieht die Verwachsung nur an einer Kopfseite, dann ist die Zahl der Lippenschilder beider Kopfseiten auch verschieden. Die "Lippenschilder" nehmen übrigens, vom Rostrale und Mentale beginnend, gradatim an Höhe und Breite ab; die letzten sind also unter allen Umständen die kleinsten.

Ueber das Mentale und die benachbarten Gularschilder ist Folgendes zu bemerken: Bei den meisten Individuen ist das Mentale (Taf. I, Fig. 3 I-33, me) an seiner Hinterseite in der Mitte in einen zapfenartigen Vorsprung ausgezogen, welcher zwischen die Gularschilder hinabreicht. Er endet gegenuiber der Mitte der ersten Sublabialen. Der zapfenartige Vorsprung ist ausserdem gewöhnlich an der Spitze abgestumpft. Bei einem der von mir untersuchten Weibchen und mehreren Männchen schneiden in dieses nach hinten verlängerte Mentale, von den Mental-Sublabial-Furchen beginnend, zwei Furchen sehr tief ein; sie beweisen als Hemmungsbildungen, dass das Mentale des Lygodactylus picturatus aus wenigstens drei Unterkieferschildern zusammengewachsen ist. Bei anderen Thieren aber ist der hintere zapfenartige Vorsprung wesentlich kleiner und kann so stark reducirt werden, dass das Mentale mit seinem Hinterrand kaum über die Mental-Labial-Furchen hinausragt. Mir liegen alle Zwischenglieder dieser Varietätenreihe vor. (Siehe Taf. I, Fig. 32 u. 33, me).

Ich habe die Beobachtung gemacht, dass bei den Individuen mit lang herablaufendem Mentale die Schnauze etwas spitzer ist, als bei den Thieren mit weniger herabreichendem Mentale.

Bei Lygodactylus picturatus stossen an das Mentale (me) die Sublabialen (subl) und gewöhnlich drei Gularschilder (Taf. I, Fig. 32, I, $2+3$ und 4) an, aber nicht immer ist dies der Fall. Mir liegt ein Individuum (Taf. I, Fig. 3I) vor, bei welchem vier Gularschilder $(\mathrm{I}, 2,3,4)$ an das Mentale (me) stossen und 2 Individuen (Taf. I, Fig. 33), bei welchen nur zwei Gularschilder $(1+2,3+4)$ mit ihm in Berührung sind. Taf. I, Fig. 3 I-33 zeigen die Kehlpartien der betreffenden Individuen, gezeichnet nach photographischen Vergrösserungen. Aus diesen Figuren ergiebt sich zugleich, dass die Kehlen mit nur drei und zwei Gularschildern am Mentale aus jener entstanden sind, welche vier Schilder in dieser Lage hat. Im ersten Fall der Umbildung (Fig. 32) verschmelzen die beiden mittleren ( 2 u. 3) der vier Gularen $z u$. einem einzigen Schild, im anderen Fall je eins von ihnen mit dem benachbarten seitlichen.

Alle drei Individuen, deren Kinnpartien hier abgebildet sind, gehören der grauen L. picturatus-Varietät an. Man sieht an den Figuren ausserdem, dass der, gegen die Kehle hinabziehende Zapfen des Mentale bei Vertretern derselben Varietät an Grösse sehr verschieden sein kann, doch hängt seine Entwickelung nicht von dem Verhalten der unter ihm liegenden Gularschilder ab, was aus den Figuren fälschlich geschlossen werden kann, sondern, wie schon erwähnt, von der jeweiligen Form der Schnauze.

Praeanalporen besitzt Lygodactylus picturatus 6-II. Alle Zwischenformen sind bereits gefunden.

Mir liegen vor: I Individuum mit I I Praeanalporen;

3 Individuen mit IO;

I6 Individuen mit 9; 7 mit 8; 4 mit 7 Praeanalporen und Boulenger beschreibt (Annali del. Mus. Civ. Stor. nat. Genova (2) XII I 892 p. 6) ein Individuum mit 6 Praeanalporen.

Gehört Lygodactylus gutturalis Boc. zu Lygodactylus picturatus? Es lag mir zur Nachuntersuchung ein $q$ vor, welches von Prof. Bocage, dem Autor der Art, dem Berliner Museum übersandt worden ist. Dieses 
Individuum erweist sich als typischer Vertreter der granen Lygodactylus picturatus -Varietät.

Lygodactylus gutturalis hat nach Bocage und Boulenger (Cat. of Lizards, B. I) folgende Artcharaktere: "Das Thier besitzt eine Reihe quer verbreiterter Schuppen unter dem Schwanze - stimmt darin mit L. picturatus überein und steht ihm bereits deshalb sehr nahe -, sein Nasloch liegt hinter der MentalLabial-Sutur und ist von dem Rostrale durch das Supranasale getrennt. « Eine solche Lage des Nasloches haben auch alle Lygodactylus picturatus, nur dass bei einigen der Praenasalfortsatz des Nasale stark reduzirt ist. - Der Kopf des Lygodact. gutturalis ist breiter als der des Lygodactylus capensis" mag sein, weil das Thier überhaupt grösser ist, als die grössten mir vorliegenden Lygodactylus capensis, sein Kopf ist aber nicht breiter als der der grauen L. picturatus-Formen. - »Sein Mentale ist kurz, dessen hintere Ränder bilden einen sehr offenen Winkel « - ich habe gezeigt, dass diese Form des Mentale auch bei grauen picturatus-Formen gefunden wird und daselbst mit anderen extremen Formen des Mentale durch Zwischenformen verbunden ist. - „Das Männchen der Art besitzt zwei grosse concentrische, sparrenartige, schwarze Zeichnungen an der Kehle — die Kehlzeichnung des mir vorliegenden Exemplars ist abgebildet in Taf. I, Figur 25 und gehört, wie man sieht, in den Variationskreis der L. picturatus-Kehlzeichnung. - " Das Thier misst von der Schnauze zum Bauch $38 \mathrm{~mm}$; Schwanz (reproducirt) $28 \mathrm{~mm}$ «. - Unser Exemplar hat genau die Grösse der grösseren Picturatus griseus. „Gefunden: Westafrika, Bissao. — Da andere Unterschiede nicht angegeben sind, gehört Lygodactylus angularis Boc. zu Lyg. picturatus Peters.

Gehört Lygodactylus angularis Gthr. zu Lygodactylus picturatus Ptrs. var. griseus?

Die Charaktere des Lygodactylus angularis G. sind nach der Originalbeschreibung und Abbildung folgende: „Thier stark zusammengedrückt «。 Das sind die alten Thiere aller drei Varietäten, mit Ausnahme der trächtigen Weibchen; auch junge und halberwachsene Thiere sind, anscheinend immer, mehr walzenförmig.

„Schnauze stumpf, vorn verschmälert, ungefähr 2 mal so lang wie das Auge und länger als der Weg vom Auge zur kleinen Ohröffnung «. - Genau dieselbe Schnauzenform mit denselben Maassen haben sowohl die alten Vertreter der Fünf-Streifen-Varietät wie die der grauen.

»Rostrale breit; das Nasenloch über der Rostral-labial-Sutur«. - Kommt bei allen drei Varietäten vor.

„Oberlippenschilder 7 oder 8; Unterlippenschilder 6, andere Seite 7 Die Zahl der Oberlippenschilder variirt bei allen drei L. picturatus-Varietäten von 6-9, die der Unterlippenschilder von 6-8.

»Mentale breit, aber rückwärts nicht ausgedehnt bis zu den Hinterrändern der ersten Sublabialen, welche von einander durch zwei Gularschilder getrennt sind «. - Zwei Gularschilder fand ich auch bei Vertretern der grauen L. picturatusVarietät. Der Zapfen des Mentale variirt bei allen Varietäten sehr beträchtlich und in paralleler Weise.

»Finger und Zehen sehr ungleich und frei; der erste Finger und Zeh sehr kurz, aber versehen mit einer Kralle«. - So sind die Finger und Zehen bei allen Varietäten, und alle von mir daraufhin untersuchten Individuen besassen am ersten Finger und Zeh eine Kralle.

\7 Praeanalporen in einer $\Lambda$-förmig gestalteten Linie«. - Die Zahl der Praeanalporen schwankt bei Lygodactylus picturatus von 6-II. 
»Schwanz mit einer Medianreihe von vergrösserten Schuppen an der Unterseite«. - Ebenso bei Lygodactylus picturatus.

„Färbung braun, oben untermischt mit Dunkel, Seiten des Thorax mit alternirenden gelben und schwarzen Flecken, weiss unten. Kehle mit drei oder vier concentrischen, $V$-förmig gestalteten braunen Linien, die Winkel sind rückwärts gerichtet«. - Die Rückenfärbung entspricht jener der Uebergangsformen zwischen der grauen und der Sieben-Streifen-Varietät des L.ygodactylus picturatus. Die Kehlefärbung ist dem Individuum spezifisch; ich habe sie bei keinem der mir vorliegenden Individuen gefunden. Sie dürfte aber wohl nur eine besondere Modification des Verblassens einer ursprünglich dunklen Kehle darstellen.

Andere Charaktere nicht angegeben; Lygodactylus angularis gehört demnach zu Lyg. picturatus var. griseus.

Ich füge nun noch der Artbeschreibung eine Zahlentabelle an, welche einmal erkennen lässt, wie sehr variabel die Individuen der Art sind, und welche zweitens zeigt, dass bei allen drei Farbenvarietäten dieselbe individuelle Variabilität herrscht.

Lygodactylus picturatus var. griseus.

\begin{tabular}{|c|c|c|c|c|}
\hline Präßnalporen & $\begin{array}{l}\text { Mentale und Gularschilder } \\
\text { in Reihe } I \text { und } 2\left(G_{1} \text { und } G_{2}\right)\end{array}$ & $\begin{array}{l}\text { Oberlippen- } \\
\text { schilder }\end{array}$ & $\begin{array}{l}\text { Unterlippen- } \\
\text { schilder }\end{array}$ & Nasalia \\
\hline 9 & $\begin{array}{l}\text { M. wenig verlängert; } G_{1}=3 ; \\
\qquad G_{2}=5\end{array}$ & $7+7$ & $7+7$ & $2+2$ \\
\hline 9 & $\begin{array}{l}\text { Deutlich von den Seiten eingekerbt; } \\
\qquad \mathrm{G}_{1}=3 ; \mathrm{G}_{2}=7\end{array}$ & $8+7$ & $7+6$ & $2+3$ \\
\hline IO & $\begin{array}{l}\text { M. ein wenig abgestumpft; } G_{1}=3 \\
\qquad G_{2}=6\end{array}$ & $9+9$ & $7+7$ & $2+3$ \\
\hline 8 & $\begin{array}{l}\text { M. tief herabreichend: } G_{1}=3 ; \\
\qquad G_{2}=5\end{array}$ & $8+8$ & $8+5$ & $3+3$ \\
\hline 8 & M. gewöhnlich; $G_{1}=3 ; G_{2}=6$ & $7+7$ & $6+7$ & $2+2$ \\
\hline ro & $\begin{array}{l}\text { M. tief herabreichend, mit scharfen } \\
\text { Ecken; } \mathrm{G}_{1}=3 ; \mathrm{G}_{2}=7\end{array}$ & $8+7$ & $6+7$ & $2+2$ \\
\hline ㅇ (ohne) & $\begin{array}{l}\text { M. mit zwei Einschnitten; } G_{1}=3 ; \\
\qquad G_{2}=5\end{array}$ & $6+6$ & $7+7$ & $3+3$ \\
\hline 오 (ohne) & $\begin{array}{l}\text { M. mit scharfen Ecken hervor- } \\
\text { ragend; } G_{1}=3 ; G_{2}=5\end{array}$ & $7+8$ & $7+7$ & $2+2$ \\
\hline ㅇ Kadem. & M. tief herab; $\mathrm{G}_{1}=3 ; \mathrm{G}_{2}=6$ & $7+8$ & $7+6$ & $2+2$ \\
\hline ㅇ Kadem & M. sehr tief herab; $G_{1}=4 ; G_{2}=8$ & $7+7$ & $6+6$ & $2(3)+3$ \\
\hline 으 Kadem & M. normal; $\mathrm{G}_{1}=3 ; \mathrm{G}_{2}=7$ & $8+7$ & $6+7$ & $3+3$ \\
\hline 우 Kadem & M. normal; $\mathrm{G}_{1}=4 ; \mathrm{G}_{2}=7$ & $7+6$ & $5+6$ & $3+3$ \\
\hline 9 Kakoma & M. normal; $\mathrm{G}_{1}=3 ; \mathrm{G}_{2}=7$ & $7+6$ & $6+6$ & $2+2$ \\
\hline 8 Kakoma & M. tief herab, $G_{1}=3 ; G_{2}=5$ & $7+7$ & $7+7$ & $2+2$ \\
\hline
\end{tabular}


Lygodactylus picturatus var. quinquestriata.

\begin{tabular}{|c|c|c|c|c|}
\hline Präanalporen & $\begin{array}{l}\text { Mentale und Gularschilder } \\
\text { in Reihe } I \text { und } 2\left(G_{1} \text { und } G_{2}\right)\end{array}$ & $\begin{array}{l}\text { Oberlippen- } \\
\text { schilder }\end{array}$ & $\begin{array}{l}\text { Unterlippen- } \\
\text { schilder }\end{array}$ & Nasalia \\
\hline S & M. normal; $G_{1}=3 ; G_{2}=5$ & $6+6$ & $7+7$ & N. hinter Sutur \\
\hline 9 & M. normal; $G_{1}=3 ; G_{2}=5$ & $6+8$ & $7+8$ & N. genau über \\
\hline 8 & M. gewöhnlich; $G_{1}=3 ; G_{2}=5$ & $7+7$ & $7+7$ & $\begin{array}{c}3+3 \\
\text { N. genau iuber } \\
\text { Sutur }\end{array}$ \\
\hline 우 & wie vorher & $(6+1)+7$ & $(6+2)+6$ & $\begin{array}{l}2+2 \\
\text { N. hinter Sutur }\end{array}$ \\
\hline 우 & wie vorher & $(6+1)+7$ & $(6+1)+7$ & $\begin{array}{l}3+3 \\
\text { N. hinter Sutur }\end{array}$ \\
\hline 우 & wie vorher & $6+7$ & $(7+2)+(7+1)$ & $\begin{array}{c}3+3 \\
\text { N. genau uuber } \\
\text { Sutur }\end{array}$ \\
\hline of & wie vorher & $7+7$ & $8+7$ & N. hinter Sutur \\
\hline II & wie vorher & $8+9$ & $7+8$ & $\stackrel{3}{3}$ N. hinter Sutur \\
\hline 9 & M. stark winklig; $\mathrm{G}_{1}=3 ; \mathrm{G}_{2}=5$ & $8+8$ & $7+7$ & $3+3$ \\
\hline 9 & $\begin{array}{l}\text { M. mehr abgerundet; } \mathrm{G}_{1}=3 \\
\qquad \mathrm{G}_{2}=5\end{array}$ & $8+(8-9)$ & $7+7$ & N. hinter Sutur \\
\hline 9 & M. mehr abgerundet & $(8-9)+8$ & $7+7$ & N. hinter Sutur \\
\hline 9 & $\begin{array}{l}\text { M. wie gewöhnlich; } \mathrm{G}_{1}=3 ; \\
\qquad \mathrm{G}_{2}=6\end{array}$ & $8+8$ & $6+7$ & N. hinter Sutur \\
\hline 9 & $\begin{array}{l}\text { M. ziemlich stumpf; } G_{1}=3 \\
\qquad G_{2}=5\end{array}$ & $9+9$ & $7+7$ & $3+3$ \\
\hline 9 & normal & $7+7$ & $6+6$ & $2+2$ \\
\hline 9 & normal & $8+7$ & $7+6$ & $2+2$ \\
\hline 9 & normal & $8+(8-9)$ & $7+(6-7)$ & $\begin{array}{l}2+2 \\
\text { N. hinter Sutur }\end{array}$ \\
\hline 9 & normal & $9+8$ & $9+7$ & $\stackrel{3}{3}$ N. hinter Sutur \\
\hline 9 & $\begin{array}{l}\text { M. tief herab, mit zwei Kerben; } \\
\qquad G_{1}=3 ; G_{2}=5\end{array}$ & $(9-10)+9$ & $7+7$ & $3+3$ \\
\hline 우 & M. sehr tief & $(8-9)+(8-9)$ & $7+7$ & $3+3$ \\
\hline 우 & normal & $(8-9)+9$ & $(6-7)+6$ & $3+3$ \\
\hline q & normal & $8+(8-9)$ & $6+6$ & $3+3$ \\
\hline q & normal & $(8-9)+8$ & $5+(6-7)$ & $3+3$ \\
\hline
\end{tabular}


Lygodactylus picturatus var. septemstriatus.

\begin{tabular}{|c|c|c|c|c|}
\hline Präanalporen & $\begin{array}{l}\text { Mentale und Gularschilder } \\
\text { in Reihe I und } 2\left(G_{1} \text { und } G_{2}\right)\end{array}$ & $\begin{array}{l}\text { Oberlippen- } \\
\text { schilder }\end{array}$ & $\begin{array}{l}\text { Unterlippen- } \\
\text { schilder }\end{array}$ & Nasalia \\
\hline $\begin{array}{l}\text { No. } 8004 \mathrm{~g} \\
\text { IO }\end{array}$ & $\begin{array}{l}\text { M. reicht tief herab, ist aber nicht } \\
\text { winklig; } G_{1}=3 ; G_{2}=6\end{array}$ & $7+7$ & $7+7$ & $3+3$ \\
\hline $\begin{array}{l}\text { No. } 8004 \\
\text { Pr. } 9\end{array}$ & M. stumpf; $G_{1}=3 ; G_{2}=5$ & $8+(7-1)$ & $7+7$ & $3+3$ \\
\hline $\begin{array}{l}\text { No. } 8004 \text { e } \\
\text { Pr. } 10\end{array}$ & M. stumpf; $\mathrm{G}_{1}=3 ; \mathrm{G}_{2}=5$ & $7+8$ & $7+7$ & $3+3$ \\
\hline $\begin{array}{l}\text { No. } 8004 b \\
\text { Pr. } 10\end{array}$ & $\begin{array}{l}\text { M. ziemlich stumpf; } G_{1}=3 \text {; } \\
\qquad G_{2}=5\end{array}$ & $(8-1)+7$ & $8+8$ & $3+3$ \\
\hline $\begin{array}{l}\text { No. } 8004 \mathrm{a} \\
\text { 우 }\end{array}$ & $\begin{array}{l}\text { M. ziemlich stumpf; G. }=3 \text {; } \\
\qquad \mathrm{M}_{2}=5\end{array}$ & $7+6$ & $7+6$ & $3+2$ \\
\hline $\begin{array}{l}\text { No. } 8004 \mathrm{~d} \\
\text { Pr. } 7\end{array}$ & $\mathrm{G}_{1}=3 ; \mathrm{G}_{2}-7$ & $7+7$ & $6+7$ & $3+3$ \\
\hline
\end{tabular}

Lygodactylus gutturalis Boc.

\begin{tabular}{|c|c|c|c|c|}
\hline Präanalporen & Mentale und Gularschilder & $\begin{array}{l}\text { Oberlippen- } \\
\text { schilder }\end{array}$ & $\begin{array}{l}\text { Unterlippen- } \\
\text { schilder }\end{array}$ & Nasalia \\
\hline $\begin{array}{l}\text { No. } 7771 \\
\text { Pr. } 7\end{array}$ & $\begin{array}{l}\text { M. recht stumpf; } G_{1}=2 ; \\
G_{2}=5\end{array}$ & $6+6$ & $6+(6-I)$ & $3+3$ \\
\hline
\end{tabular}

\section{Pachydactylus boulengeri n. spec. (Tafel II, Fig. I.)}

Tabora; 2 Individ.; Stuhlmann S.; 23. März I890.

Kakoma; 5 Individ.; Böhm S.; r 882-I883.

Steht zwischen Pach. bibroni und capensis. Auf dem Rücken kleine Höckerchen mit grösseren Tuberkeln untermischt. Die Tuberkeln kegelförmig, schwach gekielt, relativ klein; zwischen diesen Tuberkeln relativ grosse, kegelförmige Höckerchen; die Rückenbeschilderung also wie capensis. Finger mit 8-IO Querlamellen, also entsprechend denen des Pachyd. bibroni (Taf. II, Fig. 2). Unter dem Schwanz eine Mittelreihe quer verbreiterter Schilder.

Gestalt wie Pachyd. bibroni und tarentola-artig. Schnauze abgestumpft dreieckig, doppelt so lang als der Durchmesser der Orbita. Wangen geschwollen. Ohröffnung seitlich zusammengedrückt, schräg nach vorn und unten laufend. Körper zusammengedrückt. Gliedmassen kräftig, kurz; Finger kurz, in der ganzen Länge verbreitert, bei älteren Thieren an der Spitze etwas breiter. Unter den Fingern 8-IO gefranzte Lamellen. Schwanz zusammengedrïckt, kegelförmig, in der Form etwas ähnlich einem regenerirten Schwanz.**)

* Es liegt der Verdacht vor, dass bei allen von mir untersuchten Individuen der Schwanz regenerirt worden ist. Dagegen spricht andererseits, dass fast alle Thiere von einem Sammler stammen, der wusste, dass gerade bei dieser Art der Schwanz sehr brüchig ist und der sowohl aus diesem Grunde als auch deshalb sicherlich unverletzte Stücke gesammelt hat, weil nach ihm die Art an ihren Standorten gemein ist.

Den Verdacht, dass bei allen diesen Individuen der Schwanz regenerirt sei, flösst die rübenförmige Gestalt der an der Wurzel stark verdickten Schwänze ein; so sieht ja gewöhnlich der 
Kopf bedeckt mit vielen, nur wenig grossen, kegelförmigen Höckerschuppen, grosse Tuberkeln gleich denen des Rückens findet man nicht auf dem Kopf, im Gregensatz zu Pach. bibroni, wo die Schnauze oben mit breiten Pflasterschuppen, und der ganze Hinterkopf gleich dem Rücken mit grossen gekielten Schuppen bedeckt ist. Bei Pachyd. bibroni um die Ohröfnung herum grosse gekielte Schuppen, besonders viele derselben hinter dem Ohr; bei dieser Art vor dem Ohr einige wenig grosse, hinter dem Ohr gar keine Tuberkeln. Bei älteren Thieren die Tuberkeln dicht, über den ganzen Rücken verstreut, nicht in Längslinien; bei einem der jüngeren Thiere, bei welchem die Schuppen viel stärker gekielt sind, als bei den älteren Thieren (individuelle Variation) Andeutung von Längslinien.

Am Schwanzrücken und an den Schwanzseiten die kleineren Schuppen dreieckig, dachziegelartig einander deckend, durch viele Kiele rauh; dazwischen grössere Schuppen, ebenfalls dreieckig, nach hinten gerichtet, in Wirteln stehend und mit einem starken Kiel in der Mitte. Hauptschuppen der Schwanzunterseite glatt, eine Mittelreihe bildend, welche an der Schwanzspitze die ganze Schwanzunterseite deckt.

Ueber die Lebensweise dieser Art schreibt ihr Entdecker, Dr. Böhm:

ఎDiese Art bewohnt häufig die Hütten und Tembe der WaniamewesiOrtschaften und kommt erst in der Dunkelheit aus ihren Schlupfwinkeln heraus, sich durch ein ganz eigenthümliches, gedehntes, mit einem hellen Laute endendes Knurren bemerkbar machend, von dem man oft lange nicht weiss, woher es kommt. Dem Lichte gehen diese Geckonen gerne nach und erscheinen regelmässig abends an ihren gewohnten Plätzen. So beobachtete ich in Kakoma lange 2 Exemplare, ein grosses $\sigma^{*}$ und ein kleines $q$, die ihr Versteck unter den Dachsparren unserer Veranda hatten. Das $q$ war sehr viel beweglicher und lebendiger als das $\sigma^{7}$ und fing mit erstaunlicher Gewandtheit und Schnelligkeit alle in seine Nähe kommenden Insekten, wobei es mit dem Schwanze wedelte und eine Art Zirpen ausstiess. Das $\sigma^{7}$ begleitete es bedächtiger überall hin, sein sonderbares Knurren ausstossend. Am 4. Juli erfolgte die Begattung. Das $\delta$ hockte dabei auf dem $q$, dasselbe fest umfangen haltend. Die Schwänze beider sind so gedreht, dass sich die Kloaken berühren. In dieser Stellung laufen sie auch mit einander herum. Das ठ liess vor der Begattung seine knurrende Stimme erschallen, während des Aktes zirpten beide und nach Beendigung zeigte besonders das $q$ durch Schwanzschlängeln u. sow. seine Erregung. Der Schwanz bricht, wie bei allen Geckonen, sehr leicht ab und verlieren die Thiere mit $\mathrm{ihm}$ sofort ihre ganze Gewandtheit und Schnelligkeit, sodass sie sich kaum fortzuhelfen vermögen.

\section{Platypholis fasciata Blgr.}

Kakoma; I б; Böhm S.; r882.

Diese bisher nur im Typ-Exemplar aus Mombas bekannte Art ist somit auch für das Nachbargebiet nachgewiesen und zeigt dabei das von mir untersuchte Individuum nur eine geringfügige Abweichung von derOriginalbeschreibung. Es hat nur vier halbmondförmige braune Flecke auf dem Rücken, Boulenger's Exemplar hatte deren fünf. In allen anderen Charakteren stimmen beide In-

Eidechsenschwanz in der Regeneration aus, andererseits finde ich bei meinen Thieren nicht die Spur der charakteristischen Anwachsstelle des regenerirenden Schwanzes.

Da Eidechsenschwänze, obgleich sie während der Regeneration, wie Boulenger nachgewiesen hat, einen Theil ihrer Phylogenese wiederholen, zum Schluss wohl die Form der unverletzten Schwänze einnehmen, so haben sicher die Schwänze unverletater Individuen dieser Art an ihrer Unterseite die erwähnte quer verbreiterte mediane Schuppenreihe; denn, wie gesagt, die Schwänze der mir vorliegenden Individuen sind wahrscheinlich garnicht oder schon vollständig regenerirt. 
dividuen genau ïberein, und benutze ich deshalb die Gelegenheit, die Originalbeschreibung etwas $\mathrm{zu}$ vervollständigen:

Das Nasloch liegt hinter der Rostral-Labial.Sutur in unmittelbarer Berührung mit der Mitte des Labialeı; es ist eingehüllt durch das Labiale und drej Nasalschilder, von denen das vordere, das Praenasalschild, in einer grossen Sutur das Labiale1, berührt. Die Sutur mündet ausserdem in die Mitte der Unterseite des Naslochs ein. Das Rostrale ist $\mathrm{I}^{1} / 2$ mal so breit wie hoch. Die Pupille ist vertikal. Am ersten Finger sind drei symetrische Haftlappen, am zweiten 4, am dritten 6, am äusseren 4. Am ersten Zeh deren 5, am zweiten 6, am dritten 7 , am vierten 7 , ebenso am fünften. Oberlippenschilder 10 , Unterlippenschilder an einer Kopfseite 9, an der anderen IO. Die beiden Praeanalporen durch ein grösseres Schild von einander getrennt. Die Färbung beider Thiere ist im Prinzip genau übereinstimmend. Grundfarbe auf dem Rücken grau-oliv, bei meinem Thier darin ausserdem vier halbmondförmige braune Querbänder mit dunkelbraunem Saum und gegen den Kopf geöffnet; sie sind schmäler als der Zwischenraum zwischen ihnen und durch geschlängte braune Linien verbunden. Der erste, auf dem Nacken liegende Halbmondffeck zieht mit seinen Spitzen bis zum Auge und eine bräunliche Linie bildet deren Fortsetzung auf dem Canthus rostralis.

Ferner bemerke ich noch: Herr Boulenger hat in seiner Originalbeschreibung angegeben, es besitze das von ihm untersuchte Individuum am Daumen und am grossen Zeh keine Krallen. Auch bei meinem Exemplar hat der Daumen keine Kralle, wohl aber der grosse Zeh. Da nun aber diese Kralle völlig von den Deckschuppen des letzten Gliedes überdeckt wird und nur durch mühsame Praeparation zu finden ist, nahm ich an, dass sie von Herrn Boulenger übersehen worden sei. Eine Anfrage wurde freundlichst dahin beantwortet, dass meine Vermuthung eine richtige war.

\section{Familie: Agamidae.}

\section{Agama hispida L.}

Deutsch-Ost-Afrika; näherer Fundort nicht bekannt; 3 Individ.; Stuhlmann S.

\section{Agama armata Ptrs.}

Usandani; I Individ.; Oscar Neumann S.; I7. Juli I893.

Ugogo; I Individ.; Oscar Neumann S.; 23. August I893.

Kakoma; 2 Individ.; Böhm S.; I6. October 1882.

\section{Agama mossambica Ptrs.}

Nahe dem Pangani-Fluss unweit der Küste; G. A. Fischer S.; Fischer: Afrikanische Reptilien, Hamb. Mus.; I 884. S. 2 I.

Mbusini (Usegua); I Individ.; Stuhlmann S.; 28. August 1888; Pfeffer, Stuhlmann VI, S. 5 und X (I 892) S. 4.

Dar es Salaam; I Individ.; Stuhlmann S.; November I894.

Mrogoro; auf dem Wege nach Mpapwa.; I Individ.; Stuhlmann S.; November 1894 . 


\section{Agama colonorum Ptrs.}

Sansibar-Küste; I Stuick; Hildebrandt S. Von Peters, Mon. Berl. Acad. I874 S. I 59 als Agam. cariniventris beschrieben.

Irangi; I Individ.; Neumann S.; Juli I 893.

Kakoma; 7 Individ.; Böhm S.; IO. Januar 1882.

Ohne näheren Fundort; I Individ.; Stuhlmann S.; I890.

\section{Agama doriae Blgr.}

Mpapwa; I Individ.; Oscar Neumann S.; Juli I893.

Nguruman; I Individ., jung; Oscar Neumann S.; 22. December 1893. Boulenger bestimmt.

\section{Agama planiceps Ptrs.}

Mhonda in Unguu; I Individ.; Stuhlmann S.; 6. September I888; Pfeffer, Stuhlmann X S. 4.

Irangi; I Individ.; Oscar Neumann S.; Juli 1893.

Bagamoyo; 2 Individ.; G. A. Fischer S.

Kakoma; I Individ.; Böhm S.; I882.

Kagehi am Victoria Nyansa; G. A. Fischer S; Mus.-Nro. 3I30.

Böhm schreibt über diese Art: „Mit ziegelrothem Kopf. Nur auf Felsen, bei Sonda, Tabora, in Ugalla und am Tanganikaufer gesehen. Richtet sich sehr hoch auf und nickt dabei mit dem Kopfe.

"Die grotesk geformten Granitfelsen bei Seke in Ugogo waren von Scharen dieser Agamen bevölkert. Dieselben pflegten, sich sonnend, auf der Oberfläche der Felsen zu sitzen, sodass die Köpfe in sonderbarer Weise reihenweise über den scharf abgebrochenen Rand derselben herabsahen.

\section{Agama atricollis A. Sm.}

Tanga; 4 Individ., I jung; Oscar Neumann S.

Bagamoyo; 2 Individ., I jung; G. A. Fischer S.

Massai-Land; I Individ.; Oscar Neumann S.; (Gefärbt wie junge Thiere)

Kakoma; I3 Individ.; Böhm S.; I882/83.

Vitschumbi; I Individ.; Stuhlmann S.; IO. Mai I89I.

Kingawanga; 2 Individ.; Stuhlmann S.; 4. Januar 1892.

Uganda (Englisch Ostafrika); 3 Individ.; Oscar Neumann S.

Mumiga in Uganda; I Junges; Oscar Neumann S.; I. Mai I894.

Durch zwei Charaktere soll sich Agama gregori von Agama atricollis unterscheiden: Rücken mit zahlreichen grösseren Schuppen verstreut zwischen den kleinen, die grössten bilden eine leidlich regelmässige Reihe an jeder Körperseite nahe der Mediane. Die Ventralschuppen sind gekielt. Die Kehlschuppen enden in einer Spitze. - Unter den mir vorliegenden zahlreichen Individuen, welche ich zu Agama atricollis rechne, sind solche, bei welchen keine der Kehl- und Bauchschuppen gekielt ist; bei diesen Thieren enden die betreffenden Schuppen mit abgerundetem Hinterrande; dann finde ich eine Anzahl von Thieren, bei welchen sämmtliche Kehl- und Bauchschuppen gekielt und nach hinten dreieckig zugespitzt sind; darunter drei Individuen, welche von Boulenger als A. gregori bestimmt worden sind. Ich habe aber, besonders unter den Thieren, die Böhm aus Kakoma mitgebracht hat, alle Uebergänge zwischen diesen beiden extremen Formen. Jene Uebergangsformen, welche den glatt- 
schuppigen Individuen am nächsten stehen, haben nur an der Kehle zugespitzte und gekielte Schuppen; ihre Brust- und Bauchschilder sind dagegen glatt und hinten abgerundet. Bei anderen Individuen nehmen ausser den Kehlschuppen auch noch Brustschilderreihen an der Kielbildung theil, und zwar sind es zuerst nur diejenigen Schuppenreihen, welche an den Brustseiten hart am Schultergelenk hinziehen. Bei einer dritten Uebergangsform bilden sämmtliche Schuppenreihen, die über die Brust hinziehen, Kiele aus, bei diesen Individuen sind also nur noch die Bauchschilder glatt und hinten abgerundet. Zum Schluss erlangen auch diese noch Kiele von allerdings stets nur geringer Ausbildung.

In Rücksicht auf die Rückenbeschuppung zeigen nur zwei unter den drei Individuen, welche von Boulenger als Agama gregori bestimmt worden sind, auf dem Rücken parallel zur Körpermediane die beiden Längsreihen grösserer hervorragender Schuppen, zwischen welchen etwas weniger grosse und hohe Schuppen eingelagert sind, das dritte dieser Individuen zeigt auf seinem Rücken die Beschuppung, welche bei Agama atricollis gewöhnlich (bei glatten und Uebergangsformen) gefunden wird; eine Medianlinie jener grossen und stark hervorragenden Schuppen und parallel zu ihr je eine weitere solcher Schuppenreihen. Zwischen den drei liegen dann die etwas kleineren und nicht so stark hervorragenden Schuppen. In beiden Charakteren schliesst sich also Agama gregori unmittelbar an Agama atricollis an, eine wirkliche Art Agama gregori kann ich deshalb nicht anerkennen und dies um so weniger, weil auch bei Agama colonorum die Kehl-, Brust- und Bauchschuppen bald glatt, bald schwach gekielt sind (Boulenger, Kat. of. Lizards, B I, S, 356). Noch mehr ist dies aber bei Zonurus tropidosternum, bei Zonurus cordylus und bei Gerrhosaurus nigrolineatus der Fall, aber auch hier verbinden Uebergangsformen, genau analog denen der Agama atricollis, die extremsten Individuen der Art untrennbar miteinander. Was nun der einen Art recht ist, ist der anderen billig; reisst man die Individuen einer dieser Arten wegen der Divergenz ihrer Bauchbeschilderung ohne Rücksicht auf die Zwischenformen auseinander, dann muss man in gleicher Weise auch die analogen Arten zerspalten, dazu kann ich mich aber aus Rücksicht auf die Zwischenformen nicht entschliessen. -

»Die Färbung dieser Agame, schreibt Böhm, welche nach Eintritt der Masika - etwa Ende November - zum Vorschein kommt, ist besonders bei alten Stücken prachtvoll. Kehle und Brust ist von leuchtendem Kobaltblau bedeckt. Sonst variirt die Färbung im dunkeloliven-, spann-, blau- und röthlichgrün. Einzelne Schuppenreihen sind orange-purpurroth. Die Thiere klettern an Bäumen und Pfählen umher und nicken nach Art ihrer Gattungsverwandten lebhaft mit dem Kopfe, besonders wenn sie etwas verdächtiges bemerken.

»Am 2. Januar fand ich $q$ mit fast legereifen Eiern.

Stuhlmann beschreibt das von ihm in Kingawanga gefangene Thier folgendermassen: Unten schwarz, fast orange, Rückenmitte und Seiten blau, an den Seiten einige Schuppen gelb gesprenkelt. Kehle und Brust lasurblau, Bauch hellgrau, Kopf blau gefeldert, Schwanz fast grau-braun. Felsiger Hügel: $950 \mathrm{~m}$ iiber dem Meer.

\section{Aporoscelis princeps (O'Shaughn).}

Sansibar-Insel; I Individ.; J. Kirk S.; Boul., Cat. of Liz. B. II., S. 4 II. und Proceed. Zool. Soc. I880, S. 43. 


\section{Familie: Zonuridae.}

\section{Zonurus tropidosternum Cope}

Zonurus frenatus Pfeffer. Pfeffer in Stuhlmann X (1892), S. 5, Taf. 1, Fig. I u. 2.

Usaramo; I Individ.; Stuhlmann S.; I 893.

Dar es Salaam; I Individ.; Stuhlmann S.; Nov. I894.

Mhonda in Unguu; I Individ.; Stuhlmann S.; 6. Sept. I 888.

Kakoma; I Individ.; Böhm S.; I882.

Lebt nach Stuhlmann auf sandigem Boden, klettert zuweilen an Baumstämmen in die Höhe.

Da Pfeffer aus Mhonda in Unguu eine neue ost-afrikanische Zonurus-Art: Zonurus frenatus Pfeffer beschrieben hat, während Boulenger im Zoological Record I889 (Reptilia u. Amphibia S. 9) die Vermuthung ausspricht, es gehöre das so beschriebene Individuum zu Zonurus tropidosternum, was Pfeffer in seiner Stuhlmann-Arbeit von 1892 S. 6 bestreitet, habe ich mich eingehend mit beiden Arten beschäftigt.

Nachdem ich mich überzeugt hatte, dass alle drei mir vorliegenden Individuen genau uibereinstimmen mit der in Boulengers Cat. of Lizards B. II, S. 254 enthaltenen Beschreibung von Zonurus tropidosternum Cope, wodurch zugleich festgestellt war, dass sie zu dieser Art gehören, verglich ich eingehend die Textbeschreibung des Zonurus tropidosternum mit der des Trop. frenatus und ausserdem meine Species mit Pfeffer's sehr guter Abbildung von Zonurus frenatus.

Die Litteraturvergleichung ergab, dass beide Arten in folgenden zwei Charakteren von einander abweichen sollen: Nach Pfeffer's Beschreibung hat sein Zonurus frenatus 7 Labialia superiora, das letzte ist ganz klein, das fünfte ist viel höher als die vorangehenden und ausserdem sind nach Pfeffer bei Zonurus frenatus die Rückenschilder in 26 Querreihen angeordnet. Nach Boulenger's Beschreíbung hat Zonurus tropidosternum dagegen nur 6 Supralabialia, das füfte nicht mehr erhoben als die übrigen und ausserdem sind nach ihm bei dieser Art die Rückenschilder in nur 24 Querreihen angeordnet.

Die Nachuntersuchung der mir vorliegenden Species von Zonurus tropidosternum ergab, dass die Litteraturangaben, welche die beiden Arten trennen sollen, sich gegenseitig nicht ausschliessen, und deshalb auch keine Unterschiede der Individuen anzeigen. Ich selbst hatte an meinem Exemplar zuerst nur 6 Oberlippenschilder gezähit, weil ich nur, dem allgemeinen Gebrauch folgend, die wirklich grossen Oberlippenschilder berücksichtigte. Erst Pfeffer's Beschreibung machte mich auf das winzig kleine Schildchen hinter dem sechsten Oberlippenschild aufmerksam, das man, damit stimme ich mit Pfeffer überein, zu den Oberlippenschildern rechnen kann. Dieses Schildchen ist, wie Anfangs von mir, auch in Boulenger's Beschreibung nicht berücksichtigt worden. (Ausserdem fand ich noch bei einem der von mir untersuchten Individuen an der einen Kopfseite mit Berücksichtigung dieses kleinen Oberlippenschildes deren acht statt sieben. Ein winziges überzähliges Schildchen ist hier zwischen das vierte und fünfte eingeschoben und liegt unmittelbar unter dem Subocularschild. An der anderen Kopfseite des Individuums - sowie bei den anderen Individuen an beiden Kopfseiten - ist es mit einem der benachbarten Oberlippenschilder verwachsen.

Was nun die Höhe des fünften Supralabialen betrifft, so ist dieses auch bei den mir vorliegenden Individuen nicht höher als in Pfeffer's Abbildung des Zonurus frenatus. In beiden Fällen aber ist es "nicht stark erhoben." In der 
Abbildung z. B. ist es nur etwas höher als das vierte Labiale, dagegen nicht höher als das erste, zweite, dritte und sechste, es liegt nur höher am Gaumen und erscheint deshalb höher als es in Wirklichkeit ist. Viel höher, doppelt so hoch wie das vierte Labiale ist es dagegen bei Zonurus cordylus, dort stösst es unmittelbar an das unterste Postoculare, während es bei Zonurus tropidosternum und auch in Pfeffer's Abbildung durch ein Temporale von ihm getrennt ist. Bei Zonurus cordylus reicht es so hoch hinauf, weil das erwähnte Temporale mit ihm untrennbar verwachsen ist.

In Rücksicht auf die Labialen stimmt also Zonurus tropidosternum mit Zonurus frenatus genau überein.

Was nun die Zahl der Rückenschilder-Querreihen anbetrifft, so giebt Boulenger an, es seien 20 Querreihen vorhanden, »from nape to opposite femur", während Pfeffer nur ganz allgemein von »Rückenschildern in 26 Querreihen « berichtet. Bei meinen Individuen kann man ohne Zwang 24 oder, unter Bezugnahme auf das Femur, 26 Rückenschilder-Querreihen zählen, wenn man entweder die Reihen bis zum Femur zähit, oder noch diejenigen hinzurechnet, welche der Femurbreite entsprechen; bis zum Femur sind es 24, der Femurbreite entsprechen zwei Reihen, mit den vorhergehenden sind es also 26 Reihen. Daraus folgt: Auch diese Angaben konstatiren keinen Unterschied zwischen Zonurus tropidosternum und frenatus.

Pfeffer berücksichtigt in seiner eingehenden Beschreibung des Zonurus frenatus ausser den besprochenen Charakteren noch eine Reihe von anderen, welche in der Beschreibung von Zonurus tropidosternum nicht erwähnt werden und so variabel sind, dass sie zur Unterscheidung von Arten kaum Verwendung finden dürften. Ich gehe auch darauf etwas näher ein:

Nach Pfeffer ist bei Zonurus frenatus das Frontonasale viel länger als breit. Meine Exemplare zeigen darin grosse Variabilität: Das erste hat es so lang wie breit, das zweite viel länger wie breit, das dritte etwas länger wie breit.

Bei Zonurus frenatus sind die vorderen seitlichen Ränder des Frontonasale bedeutend länger als die hinteren. Bei meinen Exemplaren zeigt das erste die betreffenden Ränder gleich lang, das zweite die vorderen Ränder etwas länger, das dritte die vorderen Ränder wesentlich länger.

Bei Zonurus frenatus stösst das Frontonasale mit einer Spitze an das Rostrale, die Nasalia trennend; bei meinen Exemplaren stösst es unter Abstumpfung an das Rostrale, die Nasalia trennend.

Bei Zonurus frenatus sind die Nasalia nicht aufgetrieben; bei zwei von meinen Exemplaren ebenfalls nicht, beim dritten ein wenig.

Bei Zonurus frenatus liegen die Naslöcher in der hinteren Ecke des Nasale; ebenso bei meinen drei Exemplaren.

Bei Zonurus frenatus ist die mittlere Naht der Praefrontalia von mehr als halber Länge der Nasalia; bei meinen drei Exemplaren ebenso.

Bei Zonurus frenatus ist das Frontale sechseckig, nach vorn verbreitert; bei meinem ersten Exemplar ebenso; beim zweiten ist es auch sechseckig, aber plumper, fast kubisch, an den Längsseiten nicht eingedrückt; beim dritten Exemplar ist es sanduhrartig.

Bei Zonurus frenatus sind die Frontoparietalia breiter wie lang; bei meinen Exemplaren ebenso.

Bei Zonurus frenatus sechs Temporalschilder; bei meinem ersten und zweiten Exemplar desgleichen, das dritte hat dagegen 7 Temporalschilder.

Bei Zonurus frenatus sind drei Supraciliarschilder; bei meinen Exemplaren ebenso.

Bei Zonurus frenatus ist das Zügelschild klein, an das Nasloch stossend. Meine Exemplare variiren sehr stark im Verhalten des Zügelschildes und seiner Nachbaren in folgender Weise: 
Ich gehe von dem Individuum aus, welches bisher als das dritte bezeichnet wurde (Textfig. B, I); dasselbe hat an der linken Kopfseite ausser dem Praeoculare (po) zwei Frenalia, ein oberes (3) und ein unteres $(I+2)$, die so gelagert sind, dass das oberste zum Theil auf dem unteren Frenale, zum Theil auf dem Praeoculare liegt. Das obere Frenale berihrt dabei folgende Schilder, vorn das Nasale (n), unten das Praeoculare und das untere Frenale, hinten stösst es an das Suboculare 1 (so) und Supraciliare, $(\mathrm{sc}$ ), oben an das Praefontale (pf). Das zugehörige untere Frenale berührt das Nasale an seiner Hinterseite, unten berührt es das Labiale 1 und $2\left(l_{1}\right.$ und $\left.I_{2}\right)$, hinten das Praeoculare (die Naht, welche beide Schilder trennt, endet am hinteren Drittel des Labiales), oben berührt es das obere Frenale.
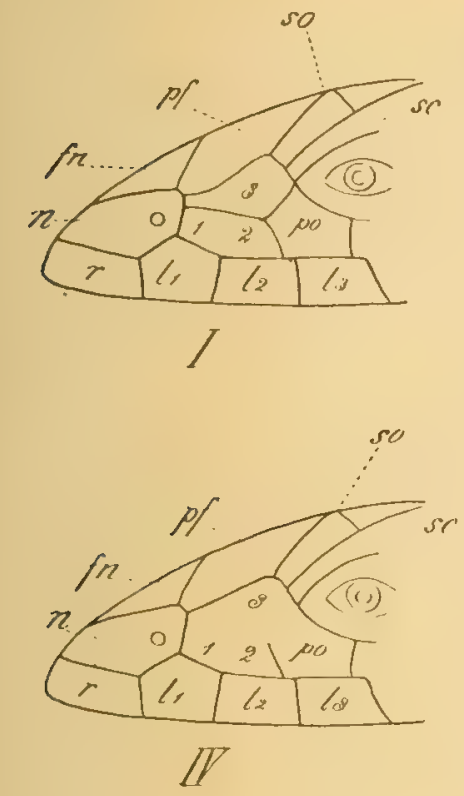
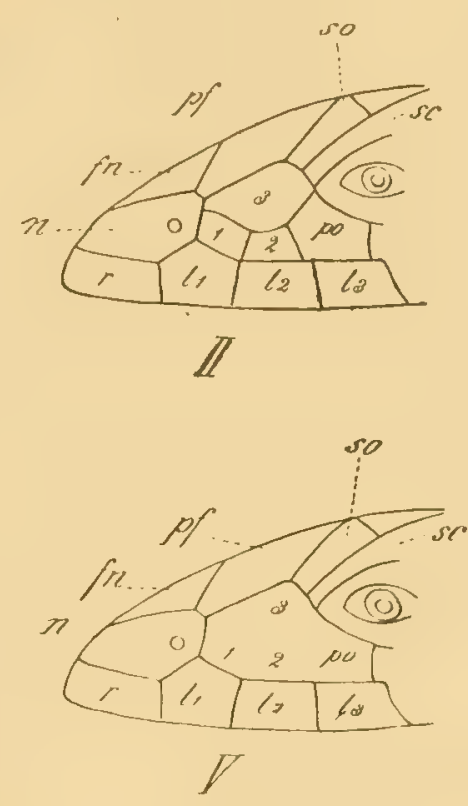

Fig. B.
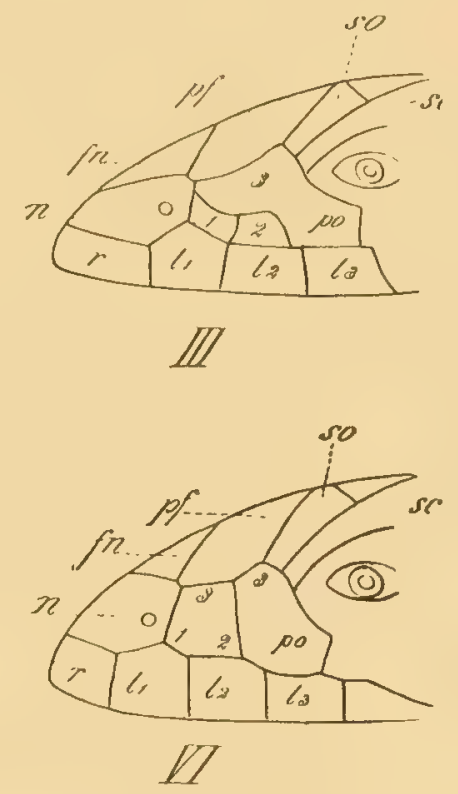

An der rechten Kopfseite des Thieres ist dieses obere Frenale mit dem Praeoculare untrennbar verwachsen (Fig. B, III, po +3 ). Das so vergrösserte "Praeoculare (richtiger: Praeoculare + oberem Frenale) stösst deshalb an all' die Kopfschilder, welche bisher mit beiden Schildern in Berührung waren, also ausser an das Labiale 2 und 3 und an das untere Frenale ( $\mathrm{I}$ u. 2), auch an das Nasale (hinten-oben), an das Praefontale, Suboculare 1 und Supraciliare.

An der rechten Kopfseite des Thieres ist aber ausserdem noch das untere Frenale der anderen Kopfseite durch zwei Frenalia ersetzt (Fig. B, III I u. 2); beide zusammen haben genau die Grösse und Lage des einen der anderen Kopfseite. Durch den Besitz dieser zwei unteren Frenalia steht diese Kopfseite des Thieres auf einer tieferen Stufe der Phylogenese als die andere, während sie durch die Verschmelzung des Praeoculare mit dem oberen Frenale phylogenetisch weiter fortgeschritten ist.

Bei dem Individuum, welches bisher als das zweite bezeichnet wurde, zeigen beide Kopfseiten in Rücksicht auf die Frenalgegend ein gleiches Verhalten; an beiden ist das ursprünglich selbstständige obere Frenale mit dem ursprüinglichen I'raenculare verwachsen. Das so entstandene Frenal-PraeocularSchild hat genau die Form und Lage des beim vorigen Individuum vorhandenen, entsprechenden Schildes. Ausserdem finde ich an beiden Kopfseiten 
dieses Individuums nur ein unteres, besonders grosses Frenale, nämlich das aus den ursprünglichen zwei kleineren zusammengewachsene.

Es sei schon hier bemerkt: Weiter noch als bei den eben besprochenen Individuen geht bei Zonurus vittifer Rchw. das Verwachsen der Frenalschilder mit dem Praeocularschild, denn bei dieser Art nimmt an der Verwachsung auch noch das grosse untere Frenale theil. Die Verwachsung desselben mit dem Praeoculare und oberen Frenale kann dabei eine völlige sein, sodass ein sehr grosses Schild die ganze Zügelgegend deckt (Fig. B, V), oder es erhält sich in dem Schild (Fig. B, IV) ein Rest jener Furche, welche urspriunglich das untere Frenale vom selbstständigen Praeoculare trennt. Ist der Rest dieser Furche vorhanden, so schneidet er als tiefe Rinne vom Hinterrand des Labiale 2 ( $1_{2}$ ) in das Schild ein. Das ist zum Beispiel am Typ-Exemplar der Art der Fall, obgleich es vom Autor der Art nicht erwähnt wird.

Der mir vorliegende Zonurus tropidosternum (Fig. B, I), welcher bisher als erstes Exemplar bezeichnet wurde, zeigt an seiner linken Kopfseite ein oberes Frenale (3), ein unteres Doppelfrenale $(I+2)$ und ein selbstständiges Praeoculare (po), stimmt darin also genau mit der linken Kopfseite des dritten Individuums überein; um so mehr weicht die rechte Kopfseite dieses Thieres von allen bisher beschriebenen ab (Fig. B, VI): Sie besitzt nur ein Frenale $(3+\mathrm{I}+2)$ und das Praeoculare $($ po +3$)$, beide aber in folgender Lage und Anordnung: Dieses Frenale nimmt mit seinem unteren Theil die Lage ein, welche das Doppelfrenale der bisher beschriebenen Arten hat, d. h. es berührt das Nasale hinten und unten, ferner das Labiale I und 2 und das Praeoculare, ausserdem aber reicht es viel höher hinauf, berührt das Nasale an der Hinterseite ${ }^{-}$auch oben, berïhrt ferner das Fronto-nasale und das Praefrontale. Ebenso sonderbar verhält sich das zugehörige Praeoculare; dasselbe hat unten genau die Lage des selbstständigen Praeoculare der anderen Thiere, reicht aber auch seinerseits viel höher hinauf als sie, denn es gelenkt mit dem Supraciliare I, mit dem Suboculare I, mit dem Praefrontale und vorn nur mit dem Frenale, durch das es vollständig von der Berührung mit dem Nasale ausgeschlossen wird. (Ganz genau so verhält sich das Frenale und Praeoculare bei allen, mir vorliegenden Zonurus cordylus.) Aus alle dem folgt, man kann entweder annehmen: das an der anderen Kopfseite des Thieres vorhandene, obere, selbstständige Frenale sei an dieser Kopfseite in zwei Theile gespalten und sei dann zur Hälfte mit dem unteren Doppelfrenale, zur anderen Hälfte mit dem ursprünglichen Praeoculare verwachsen und habe so zum Höhenwachsthum der beiden Schilder beigetragen, oder aber man muss annehmen, was viel wahrscheinlicher ist, es sei das selbstständige Praeoculare der bisher beschriebenen Individuen keine ursprüngliche Bildung, sondern es sei entstanden durch Verwachsung zweier ursprünglich selbstständiger Kopfschilder, aus einem oberen (kleineren) Frenale und einem oberen selbstständigen Praeoculare. Da bei anderen Eidechsen diese Schilder thatsächlich selbstständig gefunden werden, so ist anzunehmen, dass auch noch Zonurus tropidosternum-Individuen werden gefunden werden, welche eine derartige Beschilderung der Zügelgegend aufzuweisen haben. Wie dem auch sei, soviel steht fest, die mir vorliegenden, wenigen Zonurus tropidosternum zeigen eine geradezu abnorme Variabilität in der Beschilderung der Zügelgegend und einige von ihnen stimmen in dieser Beziehung genau mit Zonurus frenatus Pfeff. überein, bei welchem ein unteres Doppelfrenale und ein mit dem Praeoculare verwachsenes oberes Frenale vorhanden sind.

Endlich stimmen die mir vorliegenden Zonurus tropidosternum auch noch in der Zahl der Femoralporen mit Zonurus frenatus überein; das eine Individuum hat $6+6$, das andere $6+7$, das dritte $7+8$ Femoralporen, Zonurus frenatus hat nach Pfeffer deren $7+7$. (Die Zeichnung zeigt aber nur sechs.) 
$\mathrm{Da}$ andere Unterschiede zwischen Zonurus frenatus und tropidosternum nicht angegeben sind, die Angaben aber keinen wirklichen Unterschied zwischen beiden Arten erkennen lassen, gehört $Z$. frenatus $\mathrm{zu} \mathrm{Z}$. tropidosternum.

Am Schluss dieser Abhandlung ist noch Folgendes erwähnenswerth: Die mir vorliegenden Zonurus tropidosternum variiren noch untereinander in Rücksicht auf die Bauchschuppen. Bei dem ersten Exemplar sind die Kehl- und Bauchschuppen ganz glatt, beim zweiten Exemplar sind alle Kehlschuppen und die Bauchschuppenreihen, welche am Bauchrande stehen, schwach gekielt, beim dritten Individuum sind all' die Bauchschuppenreihen, welche zwischen den Oberarmen verlaufen, gekielt, nur einige Reihen von Bauchschuppen um die Nabelgegend herum bleiben dann noch ungekielt. Es zeigen also die Zonurustropidosternum-Individuen in Rücksicht auf die Bauchschuppen-Bekielung ein Verhalten gegeneinander, wie es von mir in genau derselben Weise bei den Individuen von Agama atricollis nachgewiesen worden ist.

\section{Zonurus spec? (cordylus oder vittifer oder?)}

Usambara (Potuë); I Individ.; Oscar Neumann S.; I893.

Dieses Individuum ist sehr interessant, weil es gewisse Charaktere zweier angeblicher Zonurus-Arten in sich vereinigt, gleichzeitig aber auch noch beiden gegenüber eine gewisse Selbstständigkeit bewahrt; zu einer neuen Art möchte ich es aber trotzdem nicht erheben. Es steht am nächsten Zonurus cordylus und vittifer. Wie bei diesen beiden Arten stossen bei ihm die Nasalia hinter dem Rostrale aneinander, doch ist bei ihm die Berührung der beiden Schilder eine so geringe, dass sie nur durch Lupenvergrösserung erkannt werden kann. Das Individuum steht deshalb in diesem Charakter dem Zonurus cordylus näher als vittifer und es nähert sich in diesem Charakter sogar, wenn auch nur wenig, Zonurus tropidosternum, bei welchem die Nasalia garnicht aneinanderstossen, weil sein Fronto-nasale das Rostrale berührt. Dabei steht es natürlicherweise jenem Zonurus tropidosternum am nächsten, welchen Pfeffer als Zonurus frenatus beschrieben hat, weil bei diesem Individuum das Fronto-nasale durch die Berührung mit dem Rostrale nicht abgestumpft ist, sondern in eine feine Spitze ausläuft; eine ähnliche Spitze besitzt auch das mir vorliegende Individuum, die aber nicht mehr das Rostrale erreicht; so ist in der Schnauzenbildung zwischen beiden Arten kaum ein Schritt Differenz. Auch sonst steht dieses Individuum Zonurus tropidosternum so nahe, dass man es unweigerlich dazu stellen müsste, wenn eben nicht die Nasalia hinter dem Rostrale zusammenstossen würden; ein Beweis zugleich wie nah $Z$. cordylus und tropidosternum verwandt sind.

Andererseits weicht dieser Zonurus aber auch von den bisher bekannten Zonurus cordylus in manchen Stücken ab. Er hat kein sechs-eckiges Frontonasale sondern ein vier-eckiges; ferner ist seine Zügelgegend von nur einem Schild bedeckt, von einem grossen Schild, zu welchem das Praeoculare, obere Frenale und untere Doppelfrenale so völlig verwachsen sind, dass nicht einmal ein Rest der Furche vorhanden ist, welche das ursprüngliche Praeoculare vom unteren Doppelfrenale trennt. Auch hat dieses Individuum auf dem Ruicken zwei Querschilderreihen mehr als Zonurus cordylus und es sind bei ihm sämmtliche Kehl- und Bauchschilder mit relativ starken Längskielen versehen, die z. Theil sogar fortlaufende Kiellinien bilden. In allen anderen Charakteren stimmt das Individuum mit Zonurus cordylus überein.

Wie verhält es sich nun zu Zonurus vittifer?

Ich benutze zunächst die Gelegenheit hier einige Angaben über Zonurus vittifer einzuschieben:

Das Typ-Exemplar dieser Art, das im Berliner Museum ist, unterscheidet sich nach des Autors Beschreibung von dem nahe verwandten Zonurus cordylus in Folgendem: 
Sein Kopf ist stark von oben nach unten zusammengedrückt. Die sehr geringe Grösse seines Fronto-nasale unterscheidet es von allen vor ihm beschriebenen Arten. Das Schild ist viereckig und durch die Nasalia vom Rostrale getrennt. Die Nasalia sind breit und stossen ziemlich in ihrer ganzen Breite aneinander, da das Fronto-nasale sich nur wenig zwischen sie drängt. Das Interparietale ist funfseitig und stösst mit seinem vorderen Theil an die Frontoparietalia. Die Art hat kein Zügelschild, hat 20-22 Schuppenreihen auf dem Rücken, Zonurus cordylus hat I6- I8, hat am Bauch an den breitesten Stellen I6 Längsreihen von Schuppen (Zonurus cordylus nur IO-I4) und hat 3 grosse Praeanalporen (Z. cordylus nur 2); Fundort: Transvaal.

Nach dem Typ-Exemplar sind Io Individuen, welche vor einigen Jahren dem Berliner Museum aus Transvaal übersandt worden sind, von Herrn Matschie als Zonurus vittifer bestimmt worden, mit vollem Recht, da unter ihnen 4 Individuen sind, welche genau mit dem Typ-Exemplar übereinstimmen, während ihm die anderen sehr nahe stehen. Gerade diese letzteren aber zeigen, dass eine Anzahl der, beim Typ-Exemplar vorhandenen anatomischen Charaktere, welche Reichenow deshalb für typische Charaktere des Zonurus vittifer hielt, bei anderen Individuen, die auch zu dieser Art gerechnet werden müssen, nicht gefunden werden, dass sie also individuelle Bildungen sind.

All' diese Exemplare besitzen das verhältnissmässig kleine Fronto-nasale und die vor demselben in grosser Ausdehnung aneinanderstossenden Nasalia; bei keinem dieser Individuen ist ein selbstständiges Zügelschild vorhanden. Doch theilen sich schon in Rücksicht auf diesen Charakter, wie bereits erwähnt, die Individuen in zwei Gruppen, bei vier von ihnen ist das ursprüngliche Praeoculare mit dem oberen Frenale und den beiden unteren vollständig verwachsen, bei der Mehrheit der Individuen aber, so auch bei dem Typ-Exemplar, obgleich es der Autor der Art nicht erwähnt hat, ist ein Rest der Naht vorhanden, welche ursprünglich das Praeoculare von unterem Doppelfrenale trennt. Sie ist die Furche, welche vom Labiale 2 in verschiedener Ausdehnung in das grosse "Praeoculare" des Thieres einschneidet. Nur bei drei Individuen stösst ferner, wie beim Typ-Exemplar, das Interparietale an die Fronto-parietalia, bei einem anderen Individuum reicht es mit einer scharfen Spitze fast an dieselben, bei allen anderen liegt es, wie bei Zonurus cordylus, eingeschlossen zwischen die vier Occipitalschilder und ist annähernd so breit wie lang.

4 Exemplare haben 24 Rückenschilder-Längsreihen, 2 26. Bauchschilderlängsreihen sind bei vier Exemplaren 16 vorhanden, bei einem 18. An den übrigen Exemplaren habe ich die Schilder nicht gezählt, weil die Individuen entweder zu klein waren, oder keinen guten Erhaltungszustand aufwiesen. Ich zähle ferner bei den Männchen $7+7,8+8 ; 7+8$ Femoralporen, also so viel wie bei Zonurus cordylus. Endlich wäre noch zu erwähnen, dass alle Io der neu hinzugekommenen Individuen nicht 3 Praeanalschilder, sondern nur zwei besitzen, darin also ebenfalls mitZonurus cordylus übereinstimmen; und endlich finde ich, dass bei drei unter zehn Individuen die Kehl- und Bauchschuppen zwar schwach aber deutlich gekielt sind.

Demnach würde sich die Art nur durch Folgendes von Zonurus cordylus unterscheiden: Ihr Fronto-nasale ist auffällig klein, viereckig, nicht wie bei Zonurus cordylus gross und sechseckig, vor $\mathrm{ihm}$ stossen die Nasalia in grosser Ausdehnung aneinander. Alle Schilder der Zügelgegend sind bei dieser Art miteinander verwachsen. An jeder Ruickenseite hat die Art I-3 Schuppenlängsreihen mehr als Zonurus cordylus, schliesst sich andererseits darin aber Zonurus cordylus unmittelbar an. An jeder Bauchseite hat die Art eine höchstens zwei Schuppenlängsreihen mehr als Zon. cordylus, schliesst sich ihm aber auch hierin unmittelbar an. Nicht die Art als solche, sondern nur einige Vertreter derselben weichen von Zon. cordylus ausserdem noch dadurch $a b$, dass sie schwach gekielte Bauchschuppen haben. 
Der mir vorliegende Zonurus verbindet nun Zonurus cordylus und vittifer in folgender Weise: er hat ein viereckiges Fronto-nasale wie vittifer, das aber lang gestreckt ist, und deshalb die Nasalia an inniger Berïhrung hindert, wie bei cordylus. Die Schilder seiner Zügelgegend sind vollständig verwachsen, wie bei vittifer, nicht einmal der Rest der Furche ist vorhanden, welcher vom Labiale 2 bei einigen $Z$. vittifer in das grosse »Praeocular-Schild « einschneidet. Das Individuum hat 20 Rückenschuppenquerreihen wie vittifer, aber nur I4 Bauchschuppenlängsreihen, wie cordylus. Die Temporalia sind bei ihm ohne Stacheln und nur schwach gekielt, und nur zwei Praeanalporen sind bei ihm vorhanden, wie bei beiden Arten. Es hat sämmtliche Kehl- und Bauchschuppen gekielt und zwar stärker gekielt als eins der drei mir vorliegenden Zonurus vittifer, deren Bauchschuppen ebenfalls gekielt sind und die ihm deshalb nahe stehen.

Das Individuum steht, wie man sieht, Zonurus vittifer viel näher als cordylus, es weicht nur durch grössere Länge des Fronto-nasale und durch die um zwei geringere Zahl der Bauchschuppenlängsreihen von ihm ab, und stimmt darin mit Zonurus cordylus überein. Es könnte daher ohne Bedenken zu Zonurus cordylus gerechnet werden, dann aber wird die Annäherung von Zonurus vittifer an cordylus so eng, dass für vittifer als specifische Charaktere nur folgende übrig bleiben: Das Fronto-nasale ist viereckig, sämmtliche Schilder der Zuigelgegend sind verwachsen; auf dem Rücken hat die Art 2-6 Schuppenreihen mehr als Zonurus cordylus. Ich denke, dass es nicht möglich ist, mit Hilfe dieser drei Charaktere Zonurus vittifer als Art aufrecht zu erhalten und man wird mir um so leichter zustimmen, wenn man beruicksichtigt, wie sehr variabel bei Zonurus tropidosternum die Beschilderung der Zügelgegend ist, und wenn man bedenkt, wie leicht sich bei einem Zonurus die Zahl der Rückenschuppen durch stärkere Ausbildung der in den Seitenfalten liegenden kleinen Schuppen vermehren kann.

\section{Chamaesaura tenuior Gthr.}

Kossowo und Kwa-Raschuongo in Kavirondo an der Ugowe-Bai (Englisch-Ostafrika); ठ u. む; Oscar Neumann S.; 6. März I894.

Das Weibchen mit grossen Embryonen im Uterus, woraus folgt, dass die Art lebendig gebährend ist.

Während beim $\sigma^{\circ}$ die Supranasalia hinter dem Rostrale aneinanderstossen, wie beim Typ, ist dies beim $q$ nicht der Fall, sondern hier stösst das Fronto-nasale an das Rostrale. Die Untersuchung der Embryonen ergab nun das sehr interessante Resultat, dass bei zwei Embryonen wie bei der Mutter das Rostrale und Fronto-nasale aneinanderstossen, bei den übrigen dagegen sind die Supranasalia mit einander in Berührung; die letzterwähnten Embryonen zeigen also die Charaktere des männlichen Thieres, womit aber nicht gesagt sein soll, dass nur sie Männchen, und die anders gebildeten $q$ sind.

\section{Familie: Varanidae.}

Varanus albigularis Daud.

Sansibar; 2 Individ.; M. G. Révoil S.; Mocquard, Mém. soc. philom. I888, S. III.

Rubu?; I Individ.; Oscar Neumann S. 


\section{Varanus occellatus Rüpp.}

Tanga in Usambara; I Individ.; Oscar Neumann S.

Von mir bestimmt als "Varanus albigularis mit den meisten Charakteren des occellatus «, von Boulenger als ocellatus Rüpp; dem besseren Reptilienkenner zu Ehren wird es hier als occellatus beschrieben.

Die Nichtübereinstimmung unseres Urtheils erklärt sich aus Folgendem: Die beiden Arten unterscheiden sich nach den bisherigen Litteraturangaben nur durch drei Charaktere: Bei Varanus ocellatus sollen die Rücken- und besonders die Nackenschilder grösser sein als bei V. albigularis, deshalb sollen sie die zugehörigen Hinterhauptsschilder an Grösse bedeutend übertreffen, während das bei Varanus albigularis nicht der Fall sein soll. Ferner besitzt Varanus occipitalis mehr Bauchschilder-Transversalreihen als Varanus albigularis und drittens hat er eine andere Körperzeichnung: er ist gelbbraun, mit mehr oder weniger distinkten, gelblichen, braun-eckigen, runden Flecken, und an den Halsseiten findet man bei ihm keinen schwarzen Strich.

Das mir vorliegende Thier mag in den beiden ersten Charakteren mit V. occipitalis übereinstimmen, sicher hat es weniger Bauchschilderquerreihen als $\mathrm{V}$. albigularis Daud., es hat aber zweifellos die Färbung des V. albigularis. Es ist hellgrau und gelbgrau gemischt, hat auf dem Rücken grosse, runde, gelbe, schwarz-eckige Flecken in Querreihen, und ein schwarzer Postocularstreif zieht bei ihnen vom Auge aus über den ganzen oberen Rand des Nackens hin.' Also unterscheidet sich dieses Individuum im günstigsten Fall nur durch zwei Charaktere von Varanus albigularis.

In Betreff der Nackenschilder der beiden Arten und in Rücksicht auf deren Verhalten zu den zugehörigen Occipitalschildern möchte ich aber noch Folgendes bemerken: Das Berliner Museum besitzt zwei Varanus occipitalis, von Peters bestimmt, bei welchen die Nackenschilder in der That durchschnittlich grösser sind als die zugehörigen Occipitalschilder, das ist aber auch bei Varanus albigularis der Fall, z. B. auch bei dem Thier aus Rubu, welches Oscar Neumann gesammelt hat und das von Boulenger in Uebereinstimmung mit mir für Varanus albigularis bestimmt worden ist. Dass bei diesem Individuum die Nackenschilder im Verhältniss zu den Occipitalschildern kleiner sind als bei dem hier als Varanus occellatus beschriebenen Thier, glaube ich; es kann aber auch anders sein, da bei Beurtheilung dieser Verhältnisse keine genaue Maassmethode, sondern Abschätzung durch das Auge entscheidet und diese höchst trügerisch ist.

Nach dem mir vorliegenden Material will es mir scheinen, als wären beide Arten nur verschieden-alterige Individuen ein und derselben Art, bei welcher die Nackenschilder der Artvertreter bis ins hohe Alter an Grösse zunehmen und so bedeutende Ausdehnung erfahren können, während ihre Hinterkopfschilder nicht in gleichem Maasse wachsen. Ist dies der Fall, dann liefern die Jungen dieser Art bis zu einem bestimmten Alter die Species Varanus albigularis; halberwachsene und erwachsene Individuen der Art wären dann die Species Varanus occellatus.

\section{Varanus niloticus $\mathbf{L}$.}

Sansibar; I Individ.; von d. Decken S.; Peters, Decken, S. I5.

Sansibar; I Individ.; M. G. Révoil S.; Mocq., Mém. soc. philom. I 888 , p. I I I.

Sansibarküste; mehrere Exemplare; v. d. Decken S.; Peters in Decken, B. III, S. 15; einige davon als Var. saurus beschrieben im Sitzb. Acad. Berl. I 886 , p. 888.

Sansibarküste; mehrere Exemplare; Hildebrandt S.; Peters, Monatsber. Acad. I870, S. I08-I09, und Mossamb. III, S. 23, Taf. IV. 
Tanga (Usambara); I Individ.; Reimer S.; 1895.

Tanga (Usambara); I Individ.; Oscar Neumann S.

Dar es Salaam; I Individ.; Stuhlmann S.; I 5. März I 894.

Ugalla-Fluss; mehrere Häute; Böhm S.; I1. Juni I88I.

Böhm schildert das Leben dieser Art folgendermaassen: "Kommt in grossen, mehr als meterlangen Exemplaren vor. Entfernt sich gewöhnlich nicht weit vom Wasser und ist deshalb besonders häufig an Flüssen zu finden. Indess trifft man ihn zur Regenzeit auch an ganz kleinen Teichen und sumpfigen Wiesen. Von hier aus geht er dann selbst in benachbarte, völlig kahle Felder. Erschreckt flüchtet er keineswegs immer ins Wasser, wenn dieses auch in nächster Nähe ist. Die Flucht geht sehr schnell, wenn auch scheinbar unbeholfen vor sich. Die Extremitäten werden nämlich sehr gespreizt gehalten und unter Schlangenbewegungen des Körpers und Schwanzes kräftig von oben aufgesetzt, wodurch ein lautes, stampfendes Geräusch entsteht. Auf schräg stehende Bäume klettert die Art öfters.

»Die kleineren, zierlicher und reicher gezeichneten Individuen, die Böhm fälschlich für eine besondere Art ansieht, d. h. die jüngeren Thiere, werden nur unmittelbar an Flüssen und fast immer auf überhängenden Wurzeln und Bäumen bis zu bedeutender Höhe angetroffen. Sie flüchten bei Beunruhigung sofort ins Wasser und lassen sich dabei von den Aesten, selbst aus grosser Höhe, einfach herabfallen, so dass sie oft mit dem Bauch nach oben ins Wasser platschen. Gewisse Aussteige werden immer wieder benutzt und gleichen im Kleinen denen der Krokodile. Im März fanden wir im Wala-Flusse zahlreiche Exemplare auf Baumstämmen, unter ihnen z. Th. noch nicht fingerlange Junge sitzend, welche letztere sich in Astlöcher zuriickzuziehen pflegten.

»Nach einer Sage der Wasuaheli führt das Krokodil die aus seinen Eiern ausgekrochenen Jungen ans Wasser. Diejenigen, welche davonschwimmen, erkennt es als seine eigenen an, die, welche am Land bleiben, verjagt es, und aus diesen werden die »Kenge .

\section{Familie: Lacertidae.}

\section{Nucras tessellata Smith}

Südküste des Victoria Nyansa; Emin Pascha S.; Boulenger, Ann. Mag. nat. hist. 1890, S. 93 .

\section{Latastia longicaudata Reuss}

Kakoma; 3 Individ., darunter ein junges; Böhm S.; I88I.

Nguruman; 4 Individ.; Oscar Neumann S.; Dez. 1893.

Deutsch-Ostafrika, aber ohne nähere Fundortangabe; 2 Individ.; Stuhlmann S.; 9. Jan. I89I.

\section{Ichnotropis squamulosa Ptrs.}

Kakoma; 9 Individ.; Böhm S.; I 882/83.

Nach Böhm: „Habitus und Benehmen sehr an Lacerta agilis erinnernd.

„Am 6. Mai $q$ mit grossen Eiern am Ovar«.

\section{Eremias specki Gthr.}

Tanga in Usambara; 3 Individ.; Neumann S.

Tanga in Usambara; 4 Exemplare; Oscar Neumann S.; 2. Sendung. 
Usambara; I Individ.; Linnaea Berlin S.; Werner, Verh. k. k. zool.-bot. Gesellsch. Wien, I895. Separat, S. 2.

Mbusini; I Individ.; Stuhlmann S.; 29. Aug. I888; Pfeffer X [1 892] S. 5.

Kakoma; 9 Exemplare; Böhm S.; IO. Dec. 82.

Südküste des Victoria Nyansa-Sees; Emin Pascha S.; Boulenger, Ann. Mag. I 890, S. 93.

\section{Eremias lugubris Smith}

Sansibarküste; I Individ.; v. d. Decken S.; Peters, Decken III, S. I 5.

Ein Exemplar mit der Fundortsangabe »Sansibarküste " fehlt in der Sammlung, dagegen ist eins vorhanden mit der Bezeichnung »Mombas, Sammler v. d. Decken « und dürfte dieses von Peters gemeint sein.

\section{Holaspis guentheri Gray}

Derema in Usambara; 2 Individ.; Conradt S.; Matschie, Gesell. nat. Freunde, Berlin I 892 , S. I Io.

Usambara; I Individ.; Linnaea Berlin S.; Werner, Verh. d. K. K. zool. - bot. Gesell. zu Wien I895. Separat'S. 2 als subspecies laevis beschrieben.

Bukoba am Victoria-Nyansa; I Individ; Stuhlmann S.

Franz Werner hat die Holaspis guentheri Gray, welche er aus Usambara erhielt, unter dem Namen subspec. laevis für eine "ostafrikanische Lokalform « erklärt und will sie der typischen Hollaspis guentheri als der »westafrikanischen Form " gegenüberstellen. Ich bemerke hierzu: das Berliner Museum besitzt neben den zwei ostafrikanischen Individuen, welche nach Werner mit seiner "Lokalform " übereinstimmen sollen, und in der That übereinstimmen, noch weitere 7 Individuen gleicher Art aus Westafrika. Es stammen davon 2 vom Kongo, gesammelt von Strahl, 2 vom Gabun, gesammelt von Büttner, eins aus "Westafrika«, gesammelt von Fischer, eins aus Kribi in Süd-Kamerun, gesammelt von Morgen.

Wie verhalten sich nun die westafrikanischen Individuen zu den ostafrikanischen?

Die Subspecies hat nach Werner 3 specifische Charaktere: ein Halsband mit I 5 sehr kleinen Schüppchen, Dorso-lateral-Schuppen glatt, Praeanalporen $22-23$ und eine sehr charakteristische Zeichnung.

Sechs unserer westafrikanischen Individuen stimmen nun in der Zahl der Praeanalporen genau mit denen aus Ostafrika überein, haben nämlich 21 bis 23 Praeanalporen; nur eins unserer westafrikanischen Individuen, das aus Kribi, hat I5 Praeanalporen und nähert sich dadurch dem Typ-Exemplar, welches nur I3 hat. 2 I -23 Praeanalporen findet man also jedenfalls nicht nur bei ostafrikanischen Individuen.

All' unsere westafrikanischen Individuen stimmen ferner in Zeichnung und Färbung ganz genau mit dem Typ-Exemplar und ebenso mit den Ostafrikanern überein. Die Färbung ist indess bei all' unseren Individuen scheinbar eine andere: Die Stellen nämlich, die an Werners Exemplar gelb oder meergrün, an Günther's Exemplar braun gefärbt sind und in der Zeichnung weiss erscheinen, haben bei unseren Individuen prachtvoll hellblaue Färbung; unsere erwachsenen Thiere haben deshalb am Rücken auf tiefschwarzem Grund himmelblaue Streifen und Flecken und einen rein himmelblauen Bauch. Die nur scheinbare Farbendifferenz erklärt sich aus Folgendem: Unsere Individuen haben fast am ganzen Körper die Epidermis verloren; diese Epidermis ist braun oder braunröthlich und glänzend. Wo sie in Fetzen dem Körper aufliegt, erscheint er durch die Mischung der Epidermis- und Cutisfärbung schmutzigschwarz, meergrü oder 
bräunlich, wo die Epidermis fehit, tritt die Cutisfärbung rein hervor, sie ist tiefschwarz und hellblau.

Interessant ist, dass bei allen jungen Thieren der Bauch tiefschwarz gefärbt ist und nur einige wenige himmelblaue Flecke aufweist, während er bei allen erwachsenen Thieren in seiner ganzen Ausdehnung prachtvoll himmelblau erscheint, d. h. in ganzer Ausdehnung Pigmentverlust aufweist.

Durch die Zahl der Halsbandschuppen weichen unsere westafrikanischen Individuen von den Ostafrikanern ein wenig ab, sie haben 9 bis i I derselben, die Ostafrikaner, wie Werner's Exemplar, dagegen I5. Das sind aber doch nur 2 an jeder Körperseite mehr; und ein fundamentaler Unterschied dürfte darin wohl kaum gefunden werden.

Mehr divergent erscheint dagegen die Beschuppung der Körperseiten bei unseren Individuen. Fur das westafrikanische Typ-Exemplar giebt Günther an: die Schuppen der Körperseiten sind gewölbt und gekielt, während Werner dieselben bei seinem Ostafrikaner glatt und kiellos fand. Auch unsere Ostafrikaner haben an den Körperseiten glatte Schuppen. Haben aber unsere westafrikanischen Individuen im Gegensatz dazu gekielte Schuppen? Die Frage war sehr schwer zu lösen; nach eingehendstem Studium mit stärkeren Ocularen fand ich Folgendes: Auch ihre Seitenschuppen sind nicht gekielt, sondern nur enorm stark bucklig gewölbt und viel länger als breit. Wenn nun zwischen diesen Schuppen beim Untersuchen etwas Spiritus haften bleibt, so machen sie selbst bei mässig stärkerer Vergrösserung den Eindruck, als wären sie wirklich gekielt. Abtrocknen der Stellen lehrt aber, dass es nicht der Fall ist. Wahrscheinlich sind auch am Typ-Exemplar diese Schuppen nur übermässig gewölbt und von den Seiten ein wenig zusammengedrückt, jedoch nicht wirklich gekielt. Die Epidermisreste der Schuppen unserer Individuen zeigen ausserdem nicht die Spur einer Kielung.

Bilden nun wirklich die wenigen bisher bekannten ostafrikanischen Individuen, weil sie von den bisher bekannten westafrikanischen Individuen in der Zahl der Halsbandschuppen und in der Form der Seitenschuppen ein wenig abweichen, eine besondere »Lokalform《?

Ich kann diese Frage nicht entscheiden, einmal aus Mangel an Material, und dann weil für mich noch die Möglichkeit vorliegt, dass die Unterschiede nur Altersdivergenzen sind:

Unsere ostafrikanischen Individuen sind junge Thiere, unsere Westafrikaner dagegen sind erwachsen. Es ist nicht unmöglich, dass bei den alten Individuen der Art die Schuppen der Körperseiten stärker gewölbt sind, als bei jungen, und dass man bei letzteren, wegen der geringen Grössendifferenz zwischen den mittleren (eigentlichen) und den Randschuppen des Halsbande's, einige von letzteren zu den eigentlichen Halsbandschuppen hinzurechnet. Jedenfalls ist der Unterschied zwischen den beiden Halsbändern nur ganz gering.

\section{Familie: Gerrhosauridae.}

\section{Gerrhosaurus maior A. Dum.}

Sansibar (Kibueni); 2 Stiick; Stuhlmann S.; Pfeffer (X I892), S. 6. $\left.\begin{array}{l}\text { Sansibar; I Individ.; v. d. Decken S. } \\ \text { Sansibar; I Individ.; Peters S. }\end{array}\right\}$ Peters in Decken III, S. I 5. Sansibar; 2 Individ.; Hildebrandt S.

Sansibar; 3 Individ.; G. M. Révoil S.; Mocquard, Mém. soc. philom. I 888 , p. III. 
Tanga in Usambara; I Individ., jung; Oscar Neumann S.

Auch Böhm erwähnt Gerrhosaurus maior von Sansibar mit der Bemerkung: "Kriecht ziemlich träge im Schatten von dichtem Gebüsch und Mangobäumen umher."

\section{Gerrhosaurus nigrolineatus Hallow.}

Ponguë (Useguha); I Individ.; Stuhlmann S.; Pfeffer VI (I888) S. 8; und X (I 892), S. 6.

Bukoba; I Stück; Stuhlmann S.; 23. März I 892.

Kakoma; 3 Individ.; Böhm S. I88I--82.

Böhm schreibt: »Die Art ist nicht häufig, nur zur Regenzeit im Peri zu finden und schwer zu erlangen, da sie sich nicht weit von ihren Erdlöchern entfernt, in welche sie bei Beunruhigung sofort flichtet."

Sansibarküste; 2 Individ.; Hildebrandt S.; Mus.-Nro. 79I4.

Tanga in Usambara; I Individ.; Oscar Neumann S.

Dar es Salaam; I Individ.; Krüger S.

\section{Gerrhosaurus flavigularis Gray}

Sansibarküste; 2 Individ.; Hildebrandt S.; Mus.-Nro. 79I4.

Tanga in Usambara; I Individ.; Oscar Neumann S.

Dar es Salaam; I Individ.; Krüger S.

\section{Familie: Scincidae.}

\section{Mabuia comorensis (Ptrs.)}

Tanga in Usambara; 2 Individ.; Reimer S.

Tanga in Usambara; 3 Individ.; Oscar Neumann S.

Usambara; I Individ.; Linnaea Berlin S.; Werner, Verh., K. K. zool.bot. Gesell. Wien 1895, Separat S. 3.

Ostafrika, ohne näheren Fundort, wahrscheinlich Sesse (Uganda); I Individ.; Stuhlmann S.

\section{Mabuia maculilabris Gray}

Uganda (Kwa Mtessa?); I Individ.; Oscar Neumann S.

\section{Mabuia brevicollis (Wiegm.)}

Kakoma; 2 Individ.; Böhm S.

\section{Mabuia quinquetaeniata (Licht.)}

Uganda (Englisch-Ostafrika); I Individ.; Stuhlmann S.; Aug.-Okt. I 894.

\section{Mabuia isseli (Ptrs.)}

Kakoma; I Individ.; Böhm S.

Das Nasale genau über der Rostral-Labial-Sutur. Bei diesem Exemplar Fronto-nasale und Frontale in ausgedehnter Berührung.

\section{Mabuia bayoni (Boc.)}

Sero; I Individ.; Oscar Neumann S.; 8. Jan. I 893. 


\section{Mabuia megalura Ptrs.}

Kakoma; I Individ.; Böhm S.; I88I; Peters, Mon. Berl. Acad. I878, S. 204, Taf. II, Fig. 4 und Boul., Cat. of Liz. B. III, S. I95.

Kakoma; I Individ.; Böhm S.; I882.

Kinjanganja (Turu) $4^{0} 50^{\prime}$ s. B.; I Individ.; Neumann S.; I 5 . Juni I 892. Kossowa (Englisch-Ostafrika); 2 Individ.; Oscar Neumann S.; 5. März I 894 .

Kwa Buschmanjo in Kavirondo an der Ugowe-Bay (Englisch); 2 Individ.; Oscar Neumann S.; 6. März I 894.

Kissuma in Kavirondo (Englisch); 2 Individ.; Oscar Neumann S.; April I 894. I894.

Kwa Mumya in Kavirondo; 2 Individ.; Oscar Neumann S.; 29. April

Mtale in Chagwe (englisch); I $9 ;$ Oscar Neumann S.; 21. Mai I 894.

Kwa Mtessa in Nord-Uganda; I Individ.; Oscar Neumann S.; Sept. I 894 .

Das am 2I. Mai gefangene Weibchen hatte grosse Eier am Ovar; das im September gefangene hatte Eier mit sehr entwickelten Embryonen im Uterus: Beweis, dass die Art lebendig gebährend ist.

Anatomisch unterscheiden sich die zahlreichen Individuen nicht. Auch die Färbung der Thiere ist ziemlich konstant. Bei den meisten von ihnen ist die Grundfarbe des Rückens und Schwanzes ein schönes Kastanienbraun, darin geht ein intensiv weiss gefärbter Streifen an der Oberlippe entlang über das Ohr und die Achsel hinweg bis zum Hüftgelenk, von dort verläuft er weiter als beständig dunkler werdender Streif an der Schwanzseite; dazu kommen zwei intensiv schwarze, parallele Rückenstreifen, die am Schwanz zu einem Medianstreifen zusammenfliessen.

Bei zwei Individuen ist die Rückenfarbe viel dunkler, d. h. schwarzbraun, und es sind 4 schwarze Parallelstreifen darin, von denen nur die mittleren denen der zuerst beschriebenen Individuen entsprechen und deshalb auf dem Schwanz zum Medianstreifen verwachsen.

Bei einem der von mir untersuchten Thiere fehlen auf dem Rücken in der stark aufgehellten, d. h. gelbbraun gewordenen Grundfarbe die schwarzen Längsstreifen ganz. Auch ist hier der weisse Seitenstreif nur angedeutet; das ganze Individuum demnach fast einfarbig (Exemplar von Taita).

\section{Mabuia varia (Ptrs.)}

S. 263 .

Afrika südlich vom Aequator. Boulenger, Cat. of Lizards., B. III.

Dar es Salaam; 2 Individ.; Stuhlmann S.

Marangu (Kilima Ndjaro); 5 Individ.; Volkens S.

Kifinika im Kilima-Njaro $1950 \mathrm{~m}$ hoch; Oscar Neumann S.; Jan. 1895 .

Loita; 2 Individ.; Oscar Neumann S.; 3. Jan. I895.

Kakoma; I Individ.; Böhm S.

Vitschumbi am Albert Nyansa (englisch); I Individ.; Stuhlmann S.

Die von Neumann im Januar gesammelten Weibchen trugen so entwickelte Embryonen, dass die Art als lebendig gebährend sich erweist.

Das Exemplar aus Kakoma hat 3 Fronto-parietalia, unterscheidet sich aber in keinem anderen Charakter von den übrigen.

Diese Art ist nach Volkens "die Eidechse der oberen Bergwiesen " und wurde von ihm in Höhen von 2000 bis über $4000 \mathrm{~m}$ beobachtet. 


\section{Mabuia chimbana Blgr.}

Marangu im Kilima-Njaro; I Individ,; Volkens S.

Kakoma; I Individ.; Böhm S.

Bemerkungen über diese Art unter Mabuia striata.

\section{Mabuia striata (Ptrs.)}

Afrika südlich vom Aequator. Boulenger, Cat. of Lizards III., S. 205. Sansibar; I Individ.; Kirk S.; Boul. Cat. III, S. 205.

Sansibar; I Individ.; Stuhlmann S.; Pfeffer VIII (I 888 ) S. 8 und X Sansibar; 4 Individ.;

Sansibar; 2 Individ.; Oscar Neumann S. Typ.)

Sansibarküste; I Individ.; Hildebrandt S. (Euprepes striatus Ptrs.

Sansibarküste; I Individ.; v. d. Decken S.; Von Peters als Euprepes punctatissimus beschrieben).

Usambara; I Individ.; Linnaea Berlin S.; Werner, Verh. K. K. zool.bot. Gesell. Wien I895, S. 3.

Tanga in Usambara; I Individ. mit Embryonen; Oscar Neumann S.

Lewa in Usambara; I Individ.; Stuhlmann S.; Pfeffer X (1892) S. 7.

Kilima-Njaro bei Marangu; 2 Individ.; Volkens S.

Mhonda in Usaramo; I Individ.; Stuhlmann S.; P'feffer X (1892) S.7.

Dar es Salaam; I Individ.; Stuhlmann S.

Bukoba; 8 Individ.; Stuhlmann S.

Kakoma; 20 Individ.; Böhm S.

Kakoma; 5 Individ.; Böhm S.

Die Art ist, wie trächtige Weibchen ergeben, lebendig gebährend.

Die Individuen aus Sansibar fing Stuhlmann auf dem Dach eines Hauses und in faulendem Palmenholz.

Volkens nennt die von ihm am Kilima-Njaro gesammelten Stücke, »die Eidechse des Kulturlandes zwischen I 200 bis $I 900 \mathrm{~m}$; dort sehr gemein, besonders in den Strohdächern der Huitten«. Aehnlich schreibt Böhm: „In Uniamwesi, wie auf der ganzen Route von der Küste aus, ist diese Art in den Ortschaften gemein, wo sie sich auf den Boma (Pfahlzäunen) und den spitzen Strohdächern der Hütten umhertreibt. Ebenso begegnet man ihr aber auch an Waldrändern und in der Halbboya, wie zwischen dem Gestein der Berge. Sehr genehm sind ihr die glatten Stämme der Borassuspalme. Ihre Bewegungen sind durchaus eidechsenartig. Wie bei diesen findet man zahlreiche Exemplare, die durch Zufall oder bei einer Balgerei den Schwanz verloren haben und anfangs, wenn das nachwachsende Stück noch klein ist, sich nur verhältnissmässig schlecht fortzubewegen vermögen. Vielen Vögeln und Schlangen dienen sie als Nahrung."

Unter den von Böhm gesammelten Individuen waren 20, bei welchen das Suboculare die Lippe erreicht, während bei 5 dies nicht der Fall ist, damit dies auch bei den letzteren geschehe, muss das bei ihnen unter dem Suboculare liegende, echte siebente Labiale mit dem Suboculare verwachsen; bei den Mabuien, bei welchen das Suboculare »kaum verschmälert" die Mundspalte berührt, ist nicht nur das siebente, sondern auch das sechste Labiale mit dem ursprünglichen Suboculare verwachsen.

Die Varietätsgrenzen der Mabuia striata sind, wie schon Pfeffer schreibt, noch nicht festgestellt. Vertreten Boulenger und Pfeffer die Ansicht, dass die Art Mabuia wahlbergi Ptrs., welche 40 Schuppen rund um den Körper und nur dreikielige Schuppen besitzt, zu Mabuia striata gehört, so ist es nach meiner Ansicht ebenso 
wahrscheinlich, ja nach den eigentlichen Thatsachen eigentlich schon sicher, dass auch Mabuia chimbana als Varietät zu striata gehören dürfte: Mabuia striata hat nach Boulenger 32-36 Schuppen rund um den Körper, ihre meisten Dorsalschuppen sind dreikielig; das Suboculare ist, wenn es die Mundspalte erreicht, stark nach unten verschmälert. Mabuia chimbana hat 36-38 Schuppen rund um den Körper, die Dorsalschuppen sind fünfkielig, die Ohrlappen kurz. Mir liegen nun erstens typische striata und chimbana vor. Bei beiden Arten sind die Ohrläppchen und das Suboculare gleich. In der Beschuppung schliesst sich ferner chimbana mit $36-38$ Schuppen unmittelbar an striata mit $32-36$ Schuppen an. Dann liegt mir aber aus Kakoma eine striata mit 34 Schuppen rund um den Körper vor, deren sämmtliche Rückenschuppen fünf vollentwickelte Kiele tragen, während mir andererseits aus Dar es Salaam ein Individuum vorliegt, welches 38 Schuppenreihen rund um den Körper hat, dessen meiste Schuppen indes nur drei vollentwickelte Kiele besitzen. Dieses Individuum wurde von Dr. Pfeffer (offenbar wegen seiner Schuppenzahl) als Mabuia chimbana bestimmt, doch ist seine Beschuppung der Structur nach nur die einer striata. Bei Mabuia striata zeigen nämlich, darin stimmen meine Erfahrungen mit denen Boulenger's überein, viele oder die meisten Rückenschuppen nur drei voll ausgebildete Kiele, die übrigen aber sind fünfkielig; von den dreikieligen zeigen ausserdem, je nach dem Individuum, die meisten oder alle den vierten und fünften fehlenden Kiel auf einem seiner verschiedenen Entwicklungsstadien. Die beiden Kiele beginnen ihre Ausbildung als zwei buckelförmige Erhebungen in der Nähe der Schuppenbasis zu den Seiten der bereits vorhandenen Kiele; dann treten zu diesen Buckeln zwei neue, näher dem Schuppenrand hinzu; zum Schluss verschmelzen die beiden Erhebungen jeder Schuppenseite zu einem kurzen Kiel, die Schuppe wird dadurch vier- und fünfkielig. Alle Uebergänge von der drei- zur fünfkieligen Rückenschuppe findet man bei jeder von mir untersuchten Mabuia striata. (Also auch hierin Uebergang von striata zu chimbana.) - Die Färbung ist bei beiden Arten dieselbe, ausserdem kommen beide Arten auf denselben Standorten in inniger Gemeinschaft miteinander vor, denn sowohl Volkens wie Böhm sandten sie »als Individuen einer Art zusammenverpackt dem Berliner Museum ein. Das ist wichtig, da beide Forscher die Arten $z \mathrm{u}$ sondern suchten und den Funden Notizen beilegten.

\section{Lygosoma modestum (Gthr.)}

Ugogo; I Individ.; E. J. Baxter S.; Günther, Ann. Mag. I895, S. 526 als Sepacontias modestus, Gthr.

Wpapwa; I Individ.; J. W. Bates S.; Boulenger, Cat. of Lizards,

B. III, S. 306.

Kahé auf dem Kilima Ndjaro; 2 Individ.; Oscar Neumann S.; Febr. 1895 .

Nguruman; I Individ.; Oscar Neumann S.; 25. Dec. 1893.

Usandani; 4 Individ.; Oscar Neumann S.; Boulenger bestimmt. bestimmt.

Ngaruka im Massailande; I Individ,; Oscar Neumann S.; Boulenger

Südküste des Victoria Nyansa-Sees; I Individ.; Emin Pascha S.; Boulenger, Ann. Mag. I $\$ 90$, S. 93; mit 24 Schuppen rund um den Körper und das Nasale völlig in zwei getrennt.

\section{Lygosoma sundevalli (A. Sm.)}

Sansibar, Insel Baui; I Individ.; Stuhlman S. ( Pfeffer, Stuhlm. VIII (I 888),

Sansibar; I Individ.; Stuhlmann S. J S. 8 u. X (I892), S. 7 . 
Sansibar; I Individ.; Kirk S.; Boul., Cat. of Liz. III, S. 308.

Sansibar; I Individ.; Hildebrandt S.; Peters als perdicolor beschrieben.

Sansibarküste; I Individ.; v. d. Decken S.; Peters in Decken III, S. I 5 , als Eumeces afer beschrieben.

Sansibarküste; I Individ.; Hildebrandt S.; Peters als reticulatus beschrieben.

Sansibarküste; I Individ.; Kirk S.; Boul., Cat. of Liz., B. III, S. 308.

Tanga in Usambara; I Individ.; Oscar Neumann S.

Pangani; I Individ.; Stuhlmann; Pfeffer, X. [I892], S. 7.

Pangani; I Individ.; Fischer S.; Mus.-No. I07I7.

Usandani; I Individ.; Oscar Neumann S.

Bagamoyo; I Individ.; Stuhlmann S.; Pfeffer, X [1892], S. 7.

Dar es Salaam; I Individ.; Krüger S.

Dar es Salaam; 2 Individ.; Schmidt S.

Kakoma in Marungu; 2 Individ.; Böhm S.

Nkobi in Uganda (Englisch); I Individ.; Oscar Neumann S.; 30. Mai I 894.

\section{[Lygosoma guineensis (Ptrs.)}

Von Peters aus Ostafrika beschrieben, wahrscheinlich Englisch-Ostafrika.]

\section{Lygosoma kilimensis Stejneger.}

Buloa bei Tanga in Usambara; I Individ.; Eismann S.; I895.

Marangu auf dem Kilima-Njaro; I Individ.; Volkens S.

Bemerkung dazu: "Am Fuss einer Banane bei $1400 \mathrm{~m}$ gefangen. Bewegungen sehr langsam. Nur dies eine Exemplar gesehen«.

Beide Exemplare stimmen genau mit der Originalbeschreibung überein.

\section{Ablepharus boutoni (Desj.)}

Sansibar, Insel Changu; I Individ.; Stuhlmann S.; Pfeffer, VIII [I888]. S. 8 und $X[1892]$, S. 7 .

Sansibar auf der Todteninsel; I Individ.; Neumann S.; Dez. I 892.

Bagamoyo; I Individ.; Fischer S. lebend «.

Neumann fand es »an den Korallenriffen in Gemeinschaft mit Krabben

\section{Ablepharus wahlbergi (A. Sm.)}

Auf den Korallenfelsen der kleinen Insel French Island bei Sansibar; I Individ.; Böhm S.

Zwischen der Küste und Unyamwesi, $5^{0} 7^{\circ}$ lat. S.; Capt. Speke S.; Boul., Cat. of Liz. B. III, S. 35 I.

Mhonda; 4 Individ.; Stuhlmann S.; Pfeffer, X [1892], S. 7.

Dar es Salaam; 3 Individ.; Stuhlmann S.

Mrogoro auf dem Wege nach Mpapwa; I Individ.; Elpons S.

Nahe dem Tanganyika-See; Kirk S.; Boul., Cat. of Liz. B. III, S. 35I.

\section{Sepsina (Rhinoscincus) tetradactyla Ptrs.}

Sansibarküste; I Stück; Hildebrandt S.; Peters, Monatsber. Acad. Berlin, I 874 , S. 374 .

\section{Melanoseps ater (Gthr.)}

Karagwe am Pangani; I Individ.; Oscar Neumann S.; I 5. Mai I 893. 


\section{Familie: Anelytropidae.}

\section{Feylinia currori Gray}

Bukoba, W.-Niansa; I Individ.; Stuhlmann S.; I9. Okt. I890.

Wahrscheinlich Bukoba; I Individ.; Stuhlmann S.

Das eine Individuum ist tiefschwarz, das andere hellgrau.

\section{Subordnung: Rhiptoglossa.}

\section{Familie: Chamaeleontidae.}

\section{Chamaeleon roperi Blgr.}

Kakoma; 2 Individ.; Böhm S.

Mombas (Englisch); I Individ.; G. A. Fischer S.

Nakuro; I Individ.; Oscar Neumann S.; Nov. I894.

Ohne näheren Fundort; I Individ.; Oscar Neumann S.

Anmerkung: Peters erwähnt 6 Chamaeleon senegalensis Cuv. var. gracilis Hall. von Taita und Ukamba, durch J. M. Hildebrandt gesammelt. Die im Berliner Museum befindlichen Originalexemplare für diese Angabe gehören indess zu der später aufgestellten Art: Chamaeleon roperi, welche von Kilifi, Englisch-Ostafrika stammt. Chamaeleon gracilis ist demnach in Ostafrika nur in einem Exemplar constatirt (Böttger I $q$ von dem Somaliland; Zool. Anzeiger I 893 , S. I 16).

\section{Chamaeleon parvilobus Blgr.}

Magila; I Individ.; Oscar Neumann S.

Kakoma; 3 Individ.; Böhm S.

Ohne näheren Fundort; 3 Individ.; Stuhlmann S.

\section{Chamaeleon dilepis Leach}

Sansibar; mehrere Individ.; Boul., Cat. of Lizards, B. III, S. 45 I.

Sansibar; 10 Individ.; M. G. Révoil S.; Mocquard, Mém. soc. philom. I 888 , S. I I I.

Sansibar; I6 Stück; Stuhlmann S.; Pfeffer X [1892], S. 7.

Sansibar; I Stück; Stuhlmann S.; Berl. Mus. No. I Ioo6.

Sansibarküste; 16 Individ.; Fischer S.; Peters, Mon. Ac. Berlin 1878 , S. 203

Ostafrika; mehrere Individ.; Kirk S.; Boul., Cat. of Lizards, III, S. 45I.

Tanga in Usambara; I Individ.; Reimer S.

Tanga in Usambara; I Individ.; Oscar Neumann S.

Magila; I Individ.; Oscar Neumann S.

Pangani; I Individ.; Fischer S.; Berliner Mus. No. I0665.

Bagamoyo; I Individ.; Stuhlmann S.; Pfeffer X [1892], S. 7.

Useguha; I Individ.; Oscar Neumann S.; Berliner Mus. No. I166I.

Dar es Salaam; 7 Individ.; Stuhlmann S.

Irangi; I Individ.; Neumann S. 
Rubu Mbahi; I Individ.; Stuhlmann u. Emin S.

Margusia in der Sud-Massai-Steppe; I Individ.; Stuhlmann S.

Kakoma; 4 Individ.; Böhm S.

Morogoro auf dem Wege nach Mpapwa; I Individ.; Stuhlmann S., I 894.

Ngorome oder Kavirondo (Englisch); I Individ.; Oscar Neumann S.; Febr. I 894 .

"Von Sansibar bis Unyamwesi an den verschiedensten Orten, indess nirgends häufig. " Böhm.

Sehr eingehend schildert Böhm den Farbwechsel und die Färbung der Thiere: „Der Farbwechsel der Individuen geht bei Erregung oft sehr schnell vor sich und durchläuft das Colorit von einem hellen Orangegelb alle Stadien von Grin - einfarbig oder mit schwarzer Fleckenzeichnung - bis zum Tiefschwärzlichen. So notirte ich mir z. B.: Tabora, Hauptfarbe ein schönes Steingrau mit dunkelchokoladebraunen Fleckenstreifen. An den Bauchseiten und hinter den Kopflappen weiss, dazwischen lichtgelb. Durch Ausdehnung dieses Gelb über den ganzen Körper, namentlich auf den beschatteten Stellen, geht die Grundfarbe in ein lichtes, die der Flecken in gesättigtes Gelbgrün über. Unterseite weissgrau bis weiss. Bei Aufregung werden die Flecken ganz schwarz und auf der geblähten Kehle treten gelbe Längsstreifen hervor. Iris lebhaft rothgelb. Individuen aus der Mgunda Mkali waren ganz röthlich gelb und veränderten diese Färbung in Rosenroth «.

Stuhlmann berichtet ebenfalls von verschieden gefärbten Individuen und ist sogar geneigt, auf Grund seiner Studien auf drei Farbenvarietäten des Chamaeleon dilepis zu schliessen, von denen er, soweit seine Untersuchungen reichen, annimmt, dass sie auch standörtlich getrennt sind:

»I. Form (Küstenform nach Stuhlmann): »In der Ruhe hellgrün, Seitenstreif und Flecken darüber gelb, ebenso Bauchstreif und Fusssohlen. In der Erregung: Mit schwarzen Punkten und Flecken bis ganz braunschwarz. Aufspreizung des Hinterhauptlappens und Kehlsacks; Gegenstemmen der Zunge von Innen, wodurch die orangefarbenen Längsfalten der Kehle herauskommen; faucht. Im Dunkeln und bei völliger Ruhe: Gelbgrau-erdfahl mit heller Seitenlinie und Flecken."

»2. Form (Steppenform): Grösse und Gewohnheiten ganz wie die vorige Form. In der Ruhe: hellaschgrau, etwas gelb-bräunlich, fein rostbraun gesprenkelt. Zehenenden ebenfalls rostbraun; ein breiter weisser Seitenstreif und darüber I bis 3 weisse Punkte; in Mitten der Körperseiten und an den Schwanzseiten leichte Andeutung dunkler Querbinden. Erregung: Die Querbinden treten stärker auf, das Graugelb verdunkelt sich etwas; der Kehlsack wird aufgebläht, wobei die gelben Falten sichtbar werden. «

»In den Wüstensteppen von Ugogo nicht selten, niemals dort grüne Formen wie in Unjoro und Uniamwesi."

»3. Form: Ohne weisse Seitenbinde oder Flecken, gelb vorherrschend. In Erregung: Dunkelschwarzgrun und grosse, intensiv gelbe Flecken; an der Kehle grülich mit einigen weissen Punkten. In der Ruhe: Schwarze Querbinden mit grünen Zwischenräumen, viele gelbe kleine Flecke; Kamm schwärzlich; Kehlsack gelb gestreift. Zehen nicht rostbraun gefärbt. Auf den Seitenbindenpartien fehlt das dunkle Pigment, doch sind keine weissen Binden vorhanden. Schwanz grüngelb mit schwarzen Binden. Licht- und Schattenseite stets bedeutend verschieden gefärbt. Faucht sehr stark. Unterschied von den beiden vorigen: Mangel der weissen Binde und Vorherrschen der gelben Sprenkelung. Mangel der braunen Zehen. Grösseres Thier wie die übrigen. Fundort: Mkonse in Uniamwesi. -

„Die Waniamwesi«, schreibt Böhm, »fürchten lächerlicher Weise diese Thiere als giftig". 
Bei den mir vorliegenden zahlreichen Individuen dieser Art fällt besonders auf: die auf den Occipitallappen zu findende grosse Verschiedenheit der Schuppen und Schuppenanordnung. Es giebt unter diesen Individuen so extreme Formen, dass ich keinen Augenblick anstehen würde, sie zu besonderen Arten zu erheben, wenn sie nicht durch Uebergänge mit den anderen Individuen der Art untrennbar verbunden wären. So bilden die variirten Vertreter der Art die Glieder einer Entwicklungsreihe, an welcher man das Fortwachsen grosser Tafelschuppen auf Kosten benachbarter kleiner Schuppen sehr schön verfolgen kann.

Das Individuum, welches in der Kopflappenbildung als der Ausgangspunkt aller anderen Individualformen zu betrachten ist, ist ein grosses Männchen aus Irangi (Taf. III, Fig. I). Die grossen Kopflappen dieses Individuums tragen an ihrer Oberfläche eine grössere Anzahl rundlicher Tafelschuppen, die nicht aneinanderstossen, sondern durch eine grosse Anzahl kleiner Schuppen getrennt sind. Diese kleinen Schuppen liegen in sehr seichten Furchen, welche die einzelnen Tafelschuppen voneinander trennen, und bilden eine oder zwei, selbst vier Längsreihen. Liegen sie in drei und vier Längsreihen nebeneinander, dann sind die Schuppen der Mittelreihe gewöhnlich die grösseren; ausserdem treten die Hauptreihen der kleinen Schuppen zu einem vieleckigen Netzwerk zusammen, zwischen dessen Maschen die Tafelschilder eingebettet sind. Man findet so vier- bis siebeneckige Maschen, deren Ecken nicht selten durch etwas vergrösserte Schuppen ausgezeichnet sind. Würden nun die kleinen Schuppen, welche ein Vieleck bilden, mit einem der umschlossenen Tafelschilder verwachsen, und würden dann gleichfalls die restirenden zweiten und dritten Reihen der kleinen Schuppen mit den uibriggebliebenen Tafelschuppen verwachsen, dann würden die ursprünglich runden Tafelschuppen, als vieleckige Tafelschuppen aneinanderstossen. Diese, hier hypothetisch mögliche Entwicklung der Tafelschuppen findet bei anderen Individuen thatsächlich statt und ist bei ihnen durch alle Entwicklungsstadien zu verfolgen.

Einen Schritt vorwärts in dieser Entwicklung zeigt der Kopflappen eines grossen Männchen aus Rubu Mbahi (Taf. III, Fig. 2). Er gehört seiner Beschuppung nach zu den weniger extrem geformten, denn in seiner Mitte sind die Tafelschuppen noch rundlich und durch eine, zwei, selbst drei Reihen kleiner Schuppen voneinander getrennt, doch haben diese Reihen kleiner Schuppen nicht mehr die regelmässige Anordnung des primitiveren Kopflappens und ferner zeigen auf dem fortgeschritteneren Kopflappen eine Anzahl Tafelschuppen auf den ersten Blick, dass sie auf Kosten benachbarter kleiner Schuppen vergrössert sind, dies gilt besonders von den in Fig. 2 mit a, b, c, d bezeichneten: Die Ränder dieser Tafelschuppen besitzen nämlich eine regelmässige Einkerbung und die Schuppenabschnitte zwischen den Kerben erheben sich buckelartig, wie der wellenförmige Rand einer Halskrause. Die erwähnten Tafelschuppen zeigen den gekerbten, welligen Rand, weil zahlreiche, ihnen ursprünglich benachbarte kleine Schuppen, nunmehr mit ihnen verwachsen sind, aber nur mit ihnen, während sie gegeneinander noch ihre urspriingliche Selbstständigkeit beibehalten haben; auch haben sie sich noch so wenig der Gesammtschuppe eingefügt, dass sie über deren Niveau als Buckel und Leisten herausragen; ihre Verschmelzung mit den Tafelschuppen ist also erst eine beginnende.

Der vorliegende Kopflappen zeigt ferner Randschilder, die als vollausgeprägte Polygone unmittelbar aneinanderstossen und besitzt drittens eine sehr charakteristische Hemmungsbildung (Taf. III, Fig. 2, e, und f), die dem Lappen der anderen Kopfseite völlig fehlt, und deren Entstehen Folgendes war: Wie deutlich zu erkennen ist, verhinderte (im Embryonal-Stadium des Individuums) an einer Stelle des Kopflappens eine äussere Ursache das Entstehen mehrerer Tafelschuppen. Da diese Tafelschuppen entstehen, indem viele embryonale Cutispupillen zu einer Einheit verschmelzen, so wurden die embryonalen Cutispupillen 
gezwungen sich mehr oder weniger selbstständig anzulegen. Die Tafelschuppen zeigen also mit anderen Worten einen Rückschlag in frïhere phylogenetische Entwicklungsstadien. - Ein Zerfall grösserer Körperschuppen in kleinere kommt ja, wie bekannt, bei den sehr variablen Schuppen der Reptilien nicht selten vor und auch für manche dieser Variationen lässt sich nachweisen, dass sie Rückschläge darstellen.

Einen sehr grossen Schritt vorwärts in der Entstehung der polygonalen Kopflappenschilder macht ein Thier aus Mombas, das in Taf. III, Fig. 3 abgebildet ist. Die Tafelschuppen dieses Individuums zeigen durchweg starke Neigung zum Vieleckig-werden. Mit ihren eigenthümlich krausen, abgerundeten Rändern berühren sie sich bereits in grosser Ausdehnung aber mit wenig Intensität; und nur noch an den Stellen, wo mehrere von ihnen zusammenstossen, sind sie durch kleine Schuppen von einander getrennt. Eine oder zwei Reihen dieser kleinen Schuppen finden sich allerdings auch noch auf den Lappen, doch sind gerade in diesen Reihen die kleinen Schuppen stark degenerirt und zum Theil sogar miteinander verwachsen. Dafür zeigen aber gerade auf diesem Kopflappen die Tafelschuppen an ihren Rändern in sehr schöner Ausbildung die bereits früher beschriebenen Charaktere ihres Fortwachsens auf Kosten benachbarter kleiner Schuppen, d. h. Kerben, wellenförmige Erhebungen und Vertiefungen, Buckel und Verbindungsbrücken mit benachbarten, noch selbstständigen kleinen Schuppen.

Die auf diesem Kopflappen zwischen mehrere Tafelschuppen eingeklemmten, kleinen Schuppen entsprechen meistens, wie man durch Vergleichung leicht erkennt, den Schuppen, welche auf primitiveren Kopflappen die Ecken der kleinschuppigen Vielecke darstellen und gewöhnlich durch eine gewisse Grösse in die Augen fallen.

Es giebt endlich Chamaeleon-dilepis-Individuen, auf deren Kopflappen die Tafelschuppen vollständig polygonal geworden sind, und mit geradlinigen, scharf umrissenen, fest ausgeprägten Rändern gleichsam aneinander verkeilt sind. Einen derartigen Lappen zeigt Taf. III, Fig. 4; doch ist selbst auf ihm die Entwicklung nicht ganz abgeschlossen, da auch noch auf ihm an vereinzelten Stellen, in den Zwischenräumen zwischen mehreren Schildern, kleine Schuppen zu beobachten sind. Kopflappen, auf welchen die Ausbildung der Tafelschuppen bis zum Maximum gesteigert ist, $d$. $h$. wo zwischen den polygonalen Lappenschildern gar keine kleinen Schuppen zu finden sind, dürften zu den grössten Ausnahmen gehören.

\section{Chamaeleon bitaeniatus Fisch.}

Marangu auf dem Kilima-Ndjaro; 3 Individ.; Volkens S.; Bemerkung dazu: Die beiden Erwachsenen im Gürtelwalde zwischen $2000-2500 \mathrm{~m}$, daselbst nicht selten. Das Kleine als einziges Individ. in einer Schlucht bei $2700 \mathrm{~m}$.

Kilima-Ndjaro, 3000-5000 Fuss (englisch); 2 Individ.; H. H. Johnston S.; Boul., Cat. of Liz. III, S. 452.

Kifinika auf dem Kilima-Ndjaro in $190 \mathrm{~m}$ Höhe; 3 Individ.; Oscar Neumann S.; Jan. I895.

Leikipia, westlich vom Kenia, auf einem Hochland von 6000 Fuss Höhe (Englisch); I Individ.; Ritter von Höhnel S.; von Steindachner als Chamaeleon leikipiensis beschrieben. Sitzungsber. Kais. Akad. der Wiss. Wien. Math.-Nat. Kl. I89I. S. 3 I I.

Mau-Gebirge; 4 Individ.; Oscar Neumann S.; Nov. I894.

Nakuro; 2 Individ.; Oscar Neumann S.; Nov. I 894.

Gurui: Ueber dem Urwald in ca. 3000-3200 m Höhe gesammelt; 2 Junge; Oscar Neumann S.; Anfang Oct. I 894. 
Kagehi, Südwestufer des Victoria Nyansa; 2 Individ.; Fischer S. (Eins davon in Berlin No. IO743).

Sesse in Uganda (Englisch); I Individ.; Stuhlmann S.

Chagwe in Uganda; 4 Individ.; Oscar Neumann S.; Aug. 94 u. Oct. 1894. Karagwe in I 500 m Höhe (Englisch); 2 Individ.; Stuhlmann S.; 23.Jan. I 89I. Kafuro in Karagwe; 2 Individ.; Stuhlmann S.; IO. März I89I.

Banjoroberg in Karagwe; I Individ.; Stuhlmann S.; 30. Oct. I890.

Vitschumbi (südwestlich vom Albert Eduard See), Englisch; 2 Individ.; Stuhlmann S.

Lendu-Plateau (Englisch); 2 Individ.; Stuhlmann S.; I4-I600o m; I7. Sept. I89I.

Näherer Fundort unbekannt; 2 Individ.; Stuhlmann S.

Näherer Fundort unbekannt; I Individ.; Oscar Neumann S.

Chamaeleon bitaeniatus Fisch. hat folgende Varietäten in völlig geschlossener aufsteigender Entwicklungsreihe:

Chamaeleon bitaen. var. ellioti, Gthr. (Ann. Mag. nat. hist. I895, S. 524 mit Taf. XXI, Fig. A).

Chamaeleon bitaen. var. bitaeniatus, Fisch. (Jahrb. Hamb. Wiss. Anst. I 884, S. 23 mit Taf. II, Fig. 7).

Chamaeleon bitaen. var. leikipiensis, Steind. (Sitz.-Bericht Acad. Wien I89I, S. 3I I mit Taf. BI, Fig. 2).

Chamaeleon bitaen. var. höhneli, Steind. (Sitz.-Bericht. Acad. Wien I89I, S. 3 I I mit Taf. II, Fig. I).

Die durchweg ausgezeichneten, soeben citirten Abbildungen genügen als Unterlage für meine nachfolgenden Auseinandersetzungen. Besonders mache ich darauf aufmerksam, dass Steindachner's Abbildungen die extremsten Formen der Varietätenreihe in natürlicher Grösse und in natürlichen Verhältnissen peinlich genau darstellen. Die Zeichnungen sind in jeder Beziehung unïbertrefflich.

Die zu Chamaeleon bitaeniatus gehörenden Individuen, die von mir untersucht worden sind, bilden eine geschlossene Entwicklungsreihe, deren Anfang und Ende so weit voneinander abweichen, dass man es wohl begreifen kann, dass Steindachner aus Mangel an genügendem Untersuchungsmaterial oder als Vertreter eines eigenen Artbegriffs neben dem vor ihm beschriebenen Mittelglied der Reihe (Chamaeleon bitaeniatus Fisch.) ein weiteres Glied und das Endglied derselben unter den Namen Chamaeleon leikipiensis und höhneli als distinkte Arten beschrieben hat. Dazu hat dann noch Günther in neuester Zeit eines der Anfangsglieder der Reihe als besondere Art hinzu beschrieben. Im Gegensatz dazu aber kann ich nur Boulenger's Angabe bestätigen, dass die Thiere durch Uebergangsformen so eng miteinander verbunden sind, dass sie zu einer Art gerechnet werden müssen, wenn man als Morphologe mit Boulenger und Pfeffer den Artbegriff definirt als eine Gesammtheit von Thieren, die einen geschlossenen Entwicklungskreis bilden, d. h. durch Uebergangsformen untrennbar verbunden sind, mag in diesem Formkreis die Zahl der Glieder d. h. die Zahl der Varietäten so gross sein, wie sie will. Der physiologischchemische Artbegriff, dass alle Individuen zu einer Art gehören, die sich durch mehrere Generationen fruchtbar begatten, ist für Morphologen nicht brauchbar. Wie weit er sich mit dem angegebenen morphologischen Artbegriff deckt, ist hier nicht näher zu untersuchen. Es sei nưr erwähnt, dass er annähernd dasselbe besagt.

In folgenden Charakteren zeigt Chamaeleon bitaeniatus individuelle Variation: Im Verhalten seiner Rücken- und Kinnschuppenreihe, in der Beschuppung der Körperseiten, in der Form der Helmcrista und des Nasenfortsatzes.

Die aufsteigende Entwicklung der Rückenschuppen ist folgende: Die Anfangsglieder der Individuenreihe tragen auf ihrem Rücken einen Schuppen- 
kamm, dessen Elemente sehr klein, lanzettförmig, seitlich zusammengedrückt, nach hinten gerichtet, gleich weit von einander entfernt sind und gleiche Höhe und Ausbildung zeigen. Bei etwas weiter fortgebildeten Individuen zeigen die Rückenschuppen noch dieselbe Form, Höhe und Ausbildung, sind aber zu Gruppen von 2, 3 bis 4 angeordnet; jede Gruppe ist von der anderen durch einen etwas erweiterten Zwischenraum getrennt. Bei noch stärker vorgeschrittenen Individuen beginnt in jeder Gruppe die hinterste Schuppe zu wachsen, während die vor ihr liegenden Schuppen entsprechend an Grösse verlieren, die vordersten ausserdem mehr als die mittleren; dadurch wird der ursprünglich gleichzinkige Kamm $\mathrm{zu}$ einem solchen mit welligem Rand. Dieses divergente Wachsthum der Schuppen setzt sich so lange fort, bis die vorderen Schuppen zu je einer Deckschuppe für die Basis der enorm vergrösserten hinteren Schuppe geworden sind, und da nun auch seitlich an die hintere Schuppe einige dort liegende Schuppen als Deckschuppen hinzutreten, erscheint bei den extremsten Individuen die Rückencrista aufgelöst in eine Reihe vereinzelter Dornen, die an der Basis durch mehrere secundäre Schuppen gestutzt werden.

Uebrigens zeigen die Dornschuppen bei ihrem Längenwachsthum zugleich ein gewisses Breitenwachsthum. Für dasselbe wurde Raum geschafft, indem die vor den wachsenden Dornen liegenden Deckschuppen nicht nur an Höhe, sondern auch an Breite entsprechend verloren. An den mir vorliegenden Individuen kann man bis ins Detail alle Zwischenformen dieser Kammentwicklung studiren.

Einfacher aber nach demselben Princip verläuft die Entwicklung der Kinncrista. Wie man bei Durchmusterung der Individuen sicht, bleiben von den ursprünglich gleichartigen Schuppen der Kinncrista abwechselnd eine zurück, während die benachbarte um so stärker wächst; zum Schluss verschwinden die zurickbleibenden ganz, während die bevorzugten - bei vorwiegendem Wachsthum in die Länge und geringer Breitenzunahme - nach extremer Ausbildung etwa 4 mal so lang und nicht ganz doppelt so breit sind als im Beginn der Entwicklung.

Die Schuppen der Körperseiten sind bei allen, von mir untersuchten Individuen ungleich, $\mathrm{d}$. h. es liegen bei allen Individuen an den Körperseiten zahlreiche grössere Schuppen zerstreut zwischen einer weit grösseren Anzahl kleiner Schuppen. Bei den niedrigst stehenden Individuen sind die Grössenverhältnisse beider Schuppenarten nur gering, die grösseren liegen ausserdem regellos zwischen den kleineren. Bei den Mittelgliedern der Individuen-Reihe verändert sich die Beschuppung der Körperseiten in der Weise, dass eine Anzahl ihrer mittelgrossen Schuppen ein sehr beträchtliches Flächenwachsthum beginnen und dadurch mehr und mehr zu platten, kreisrunden Tafelschildern umgewandelt werden. Die auf diese Weise immer stärker hervortretenden Schuppen zeigen ferner die Eigenschaft, dass sie an jeder Körperseite zwei Längsreihen bilden und zwar eine obere Rückenlinie, welche als Fortsetzung der Wangengräte hinter dem Auge beginnend, im oberen Drittel des Rumpfes bis zu den Seiten des Schwanzes hinzieht, während die untere Seitenlinie das Bestreben zeigt, das Schultergelenk mit dem Hüftgelenk zu verbinden. Von ihnen wird zuerst die obere Reihe angelegt, dann erst die untere. Bei den Endgliedern der Individuenreihe sind diese Tafelschuppen sehr gross und fallen, wie die von ihnen gebildeten Linien, ungemein auf.

Helmcrista: Bei den am tiefsten stehenden Individuen ragt der Hinterkopf nur wenig empor, denn die Parietalcrista steigt hier als fast gerade Linie in einer nur schwach geneigten Ebene nach hinten auf. Auch ist bei diesem Kopf der Zwischenraum zwischen Mundwinkel und Nasenspitze etwas länger als der Zwischenraum zwischen Mundwinkel und Helmspitze. Je extremer die Thicre werden, desto mehr ändert sich dieses Verhältniss zu Gunsten der Helmspitze, bald ist deren Entfernung vom Mundwinkel gleich der Länge der Mundspalte, 
zum Schluss ibertrifft sie sogar die Länge derselben ein wenig. Die extrem entwickelten Individuen haben ausserdem eine Parietalcrista, die bereits zwischen den Augen in einem hohen Bogen aufsteigt, daraus folgt: Bei dieser Entwicklung wächst der Hinterkopf nur wenig in die Höhe, sehr dagegen vorn über, weil seine Parietalcrista sich mehr und mehr vertical stellt.

Der Nasenaufsatz. Bei den tiefststehenden Individuen giebt es gar keinen Nasenaufsatz. Bei ihnen stossen nur die scharfen Ränder der beiden Canthus rostrales hart über dem Schnauzenrand in einem spitzen Winkel aneinander. Bei einer Anzahl von Thieren beginnt nun diese Verwachsstelle der beiden Canthus rostrales in Verbindung mit benachbarten Schuppen der Schnauze buckelartig emporzustreben und zwar dadurch, dass die der Verwachssteile angehörigen Cutispartien an Masse zunehmen, dadurch entsteht-zuerst ein mehr oder weniger abgerundeter Nasenhöcker, bei einigen Thieren kaum angedeutet, bei anderen deutlich knopfförmig; zum Schluss wird daraus ein beschupptes Nasenhorn, das stark seitlich zusammengedrückt ist. -

Färbung: Am genauesten hat Volkens die Färbung der von ihm gesammelten Individuen beschrieben. „Die Farbe der Erwachsenen ist, nach ihm, in der Ruhe wie die der Spiritusexemplare« (Grundfarbe grau - weiss mit vielen braunen Flecken, besonders am Rücken und mit einer gelben oberen Seitenlinie, die über die daselbst befindlichen Tafelschuppen hinwegläuft - die Schuppenlinie und Farbenlinie decken sich hier also). „Beim gereizten Thier schlägt die Farbe in ein helleres Grasgrün um." - Aehnliche Angaben iiber die Färbung der von ihm gesammelten Individuen hat Stuhlmann geliefert: „Die Thiere aus Kafuro waren graubraun und grauweiss. « Die Thiere aus Charagwe beschreibt er als »grau-braun-grünlich, Kehlfalten orange«; die vom Lendu-Plateau waren: „Grün bis graubraun mit gelbbrauner Seitenlinie, Kehlfalten blau und blaugrün." Bei dem Individuum aus Sesse bemerkt er: „Die braunen Körperpartien verschwinden nie, weder in der Ruhe noch im Zorn; diese Farbe wird nur etwas heller oder dunkler, Kehlfalten hellblau.«

Ein junges Thier, von Volkens gesammelt, weicht nicht unwesentlich von den obigen Farbenangaben ab, es ist vorn durchweg tief schwarzbraun gefärbt, nur seine Lippenränder sind $z u$ hellerem Braun abgeblasst und sein Körper von der Mitte bis zur Schwanzwurzel ist hellgrau mit braunen Flecken. Eine ganze Anzahl der mir vorliegenden erwachsenen Thiere hat diese dunkle Färbung des jungen Thieres auf dem ganzen Körper beibehalten, sie dürfen in der Färbung als die tiefststehenden Individuen angesehen werden.

In Betreff des anatomischen Gesammtvariirens der einzelnen Individuen ist Folgendes hervorzuheben:

Sehr wichtig ist es, dass sowohl Männchen als Weibchen die Entwicklungsstadien der Art bis zum Endpunkt durchlaufen können; es folgt daraus, dass bei dieser Art kein Dimorphismus der Geschlechter herrscht, wie Boulenger und Günther annehmen. Ja, unter den mir vorliegenden Individuen bieten gerade Weibchen die extremsten Artcharaktere am reinsten dar; das gilt auch vom Nasenaufsatz, was um so bemerkenswerther ist, weil bei anderen ChamaeleonArten die Nasenaufsätze als »secundäre Geschlechtscharaktere nur bei Männchen gefunden werden. Ebenso wichtig ist, dass bei relativ jungen Embryonen, welche ich einem dieser extrem entwickelten Weibchen entnehmen könnte, bcreits alle Charaktere der extremen Form, mit Ausnahme des Rückenschuppenkammes, wohl ausgebildet sind, darunter auch der stark knopfartig hervorragende Nasenaufsatz. Das fällt besonders auf, weil bei anderen Chamaeleon-Arten die viel grösseren Nasenaufsätze bei der Geburt als nur schwache, beschuppte Buckel zu erkennen sind, sich also erst postembryonal entwickeln. Alles dies lässt den Schluss zu, dass diese Embryonen gleich von vorn herein als extreme Formen angelegt werden, und wenn sich dies an ganz jungen Embryonen bestätigen 
lässt, dann zeigen hier anatomische Charaktere einer Art, wie Theodor Eimer bereits an der Zeichnung der Arten nachgewiesen hat, dass unter Umständen die extrem geformten Individuen eines geschlossenen Formkreises ontogenetisch ihre Entwicklung, entgegen jeder Vermuthung, nicht mit der Ausbildung der Durchschnitts- oder Anfangscharaktere der Art beginnen, sondern gleich mit den extremen Charakteren, d. h. die Ontogenese folgt hier so schnell der Phylogenese, dass sie wenig oder nichts über den Verlauf derselben lehrt. Als Gesammtergebniss dieses letzten Abschnitts folgt aber zum Schluss, dass der Forscher, der ein Glied dieses Thierkreises als 》Art anerkannt sehen will, alle Hauptglieder der Individuenreihe ebenfalls als "Arten " anerkennen muss, d. h. er muss unter diesen Umständen die geschlossene Formenreihe Chamaeleon bitaeniatus Fisch. in wenigstens 4 Arten zerspalten, ihm liegt dann aber auch die Schwierigkeit ob, die restirenden Uebergangsglieder der Reihe unter diese Arten zu vertheilen.

Es fragt sich nun noch: Kommen die verschiedenen Entwicklungsstadien der Art an denselben Standorten vor oder sind sie Lokalformen? Wie Herr Oscar Neumann angiebt, sind die extremsten Formen von ihm nur in einem Gebiet, und zwar im Mau-Gebirge in sehr beträchtlicher Höhe gefunden worden, dort waren sie allein herrschend und kamen andere Formen neben ihnen nicht vor; dagegen giebt Steindachner an, dass er sowohl die extreme wie mittlere Form, die er als distinkte Arten beschreibt, von Leikipia, also aus demselben Fundort und aus gleicher geographischer Höhe erhalten habe. Es stehen sich hier die Angaben also direkt gegenüber, doch dürfte es, nach dem bisher über die Verbreitung der Art bekannt gewordenen, nicht unwahrscheinlich sein, dass die Individuen um so extremer sind, je höher im Gebirge sie auftreten und dass die extremsten Formen nur in den höchsten Gebirgsregionen auftreten. Dies ist um so wahrscheinlicher, weil auch die einander ungemein nahe verwandten Chamaeleon fischeri und tavetensis vicariirende Formen des Berglandes und Hochgebirges sind.

Die Individuen nach ihrer Stellung in der Entwicklungsreihe geordnet, ergeben folgende Fundorte:

Sesse in Uganda und Kagehi am Victoria-Nyansa: Anfangsglieder der Reihe.

Chagwe in Uganda und Nakuro: etwas fortgeschrittene Individuen. Zwischenraum zwischen Mundwinkel und Helmspitze gleich der Mundspalte. Rückenschuppen in Gruppen getheilt, auch findet man an den Körperseiten die Andeutung der oberen Schuppenlinie, indem viele etwas vergrösserte Schuppen nebeneinander liegen.

$\mathrm{Zu}$ dieser Gruppe gehören auch die Individuen von Chamaeleon ellioti Günth. aus Kavirondo (Höhe 3900-4000 Fuss englisch) und vom Fuss des Ruwenzori (5000-600o Fuss englisch).

Karagwe: Helm etwas höher wie die Mundspalte lang, Rückenschuppen noch annähernd gleich, Kehlschuppen etwas vergrössert, obere Seitenreihe in vergrösserten Schuppen deutlicher, aber die vergrösserten Schuppen noch verhältnissmässig klein.

Lendu-Plateau. Helmhöhe und Mundspalte gleich; der Parietalkamm etwas stärker erhoben. Obere Rückenschuppen mit deutlicher Tendenz zum Ueberwiegen der hintersten; die erste stark verkleinert, die zweite noch in ursprünglicher Grösse, die dritte vergrössert; und wenn nur zwei Schuppen eine Gruppe bilden, die erste stark verkleinert, die zweite vergrössert. Obere Seitenlinie sehr deutlich, vergrösserte Schuppen derselben mittelgross.

Diese Individuen entsprechen der Form Chamaeleon bitaen. var. bitaeniatus Fisch.

Banjoro-Berg: Annähernd dem vorigen Thier entsprechend. 
Gurui: Junge Thiere, Helmlänge und Mundspalte gleich, Parietalcrista noch schräg liegend, wenig gekrümmt, am Rücken die Schuppen sehr ungleich, Kehle mit abwechselnd grossen und kleinen Schuppen, an den Körperseiten zwei Reihen von Plattenschuppen. Erwachsen dürften die Individuen auf der Stufe der Folgenden stehen.

Kifinika: Helmlänge und Mundspalte gleich; Rückenkammschuppen in Gruppen, sehr ungleich; Kinnschuppen abwechselnd grösser und kleiner. Das am tiefsten stehende Individuum hat am Körper nur die obere Plattenreihe, zweites 2, daneben viele halbvergrösserte Schuppen. Das grösste und stärkste Thier hat die Form des letzten, aber Helmhöhe übertrifft um ein winziges die Mundspalte, und die Verwachsstelle seiner Canthus rostrales hat deutliche aber nur schwach bucklige Erhebung: also Beginn der Hornbildung. Dieses Individuum bildet den direkten Uebergang zu den Folgenden.

Marangu und Leikipia: Helmlänge und Mundspalte gleich, Crista nur mässig gewölbt. Rückenkamm schrotsägeförmig, Kinnkamm mit abwechselnd kleinen und grossen Schuppen. Obere und bei einem Exemplar auch untere Plattenreihe; Platten noch mässig entwickelt. Deutliches knopfförmiges Horn, bei einem Individuum stärker als beim andern. Junges ohne Andeutung eines Hornes.

Hierzu gehört das Chamaeleon bitaen. var. leikipiensis Steind.

Mau und Leikipia. 2 dieser Individuen extrem in allen Charakteren; ebenso deren Junge; 2 andere Individuen ebenso extrem mit der Ausnahme, dass bei ihnen die an den Körperseiten liegenden Tafelschuppen zwar in zwei Reihen angeordnet sind, aber in der Ausbildung nicht wesentlich von denen der voran gehenden Thiere abweichen, d. h. sie sind von verhältnissmässig geringer Entwicklung. Die beiden Individuen bilden also den Uebergang von der vorigen Form zu der extremsten.

Hierzu gehört das Chamaeleon bitaen. var. höhneli Steind.

\section{Chamaeleon senegalensis var. laevigatus Gray}

Kadem in Kavirondo; I Individ.; Oscar Neumann S.

Isirnumo in Kavirondo; I Junges; Oscar Neumann S.; 6. Mai I894.

Raischuongo in Kavirondo an der Ogowe-Bay; 2 Individ.; Oscar Neumann S.; 7. Mai I 894 .

Kafuro in Karagwe in Höhe über I $500 \mathrm{~m} ; 2$ Individ.; Stuhlmann S.

Die Neumann'schen Exemplare hat Boulenger bestimmt.

Kommt nach Stuhlmann auf niederen Kräutern und Büschen vor.

Die Kafuro-Exemplare haben »keine Längsstreifen, Kehlfalten blau, Körperfarbe grau-braun, etwas oliv, besonders Bauch und Augen. E Ebenso gefärbt ist das von Stuhlmann ohne Angabe eines Fundorts eingesandte Junge. Die anderen Individuen haben zwei voll entwickelte, bräunliche Längsstreifen; ausserdem fand ich ein Individuum, bei welchem der obere Streifen an beiden Körperhälften durch langgezogene Flecken ersetzt wird, während bei einem anderen Individuum an der einen Körperseite ein vollentwickelter oberer Längsstreif, an der anderen statt seiner eine Fleckenreihe vorhanden ist. Das Junge aus Kavirondo zeigt an beiden Körperhälften eine obere Seitenlinie in Flecken angelegt uizd einen vollentwickelten unteren Längsstreifen.

\section{Chamaeleon sphaeropholis Rchw. (Taf. II, Fig. 3.)}

Victoria-Nyansa; I Individ.; G. A. Fischer S.; Mus.-No. Io 745.

Das Typ-Exemplar ist in Besitz des Berliner Museums. Dieses Thier unterscheidet sich nur in einem Punkt von den erwachsenen Individuen der vorigen 
Art. Bei erwachsenen Vertretern der vorigen Art läuft aủf dem Hinterkopf eine Parietalcrista entlang, die in guter Ausbildung bis zum Rand des Hinterkopfes reicht, desgleichen findet man bei ihnen an jeder Kopfseite eine Occipitalcrista, die annähernd parallel der Parietalcrista; aber tiefer liegend als sie, bei einem Thier bis zum Hinterkopfrande zieht, beim andern schon vor ihm endet. Am Kopfrande sind die, bei allen ostafrikanischen Vertretern der Species überhaupt nur mässig ausgebildeten Cristen nicht durch Quercristen verbunden, sie enden blind. Bei nicht ausgewachsenen Individuen der Art dagegen zeigt der Hinterkopf, wie bei anderen Chamaeleon-Arten so lange sie jung sind, keine der Cristen, sondern ist abgerundet, fast halbkugelig. Das Chamaeleon sphaeropholis Rchw: entspricht nun genau einem erwachsenen Chamaeleon senegalensis var. laevigatus mit dem Kopf eines jungen Thieres, d. h. man kann sagen, sein Hinterkopf erscheint wie ein auf dem Jugendstadium stehen gebliebener Kopf jener Varietät: er ist plump, abgerundet und besitzt keine nennenswerth ausgebildete Parietal- oder Occipitalcrista, doch sind sie leise angedeutet.

Die Färbung des Thieres ist dieselbe wie die bei Chamaeleon senegalensis vorgefundene: In der Grundfarbe des Leibes liegen zwej braune Seitenlinien, die untere ist vollständig entwickelt, die obere in Punkten angelegt.

$\mathrm{Ob}$ das von Reichenow als Chamaeleon spaeropholis beschriebene Thier den Typus einer wirklichen Art darstellt, oder ob es nur ein, in der Kopfentwicklung auf dem Jugendstadium zurückgebliebenes Chamaeleon senegalensis var. laevigatus ist, wie Boulenger und ich vermuthen, muss die Zukunft lehren.

Chamaeleon deremensis Mtsch. (Taf. II, Fig. 8.)

Buloa bei Tanga in Usambara; I 9 ; Eismann S.; 1895.

Tanga in Usambara; I \&; Reimer S.; I894.

Derema in Usambara; $3 \delta^{\pi}, I$ I , I Junges; Conradt S.

Usaramo; I Individ.; Stuhlmann S.

Diagnose: Weisse Linie vom Kinn bis zum After; weisse Höcker vom Kinn bis zum After; Flośsenkamm am Rücken. Keine Occipitalcrista, Helm hinten zugespitzt dreieckig, kleine Occipitallappen, Männchen mit drei Hörnern auf der Schnauze, Weibchen ohne dieselben.

Ich folge nunmehr Matschie's ausführlicher Beschreibung (Gesell. nat. Freunde Berlin, I9. Juli I 892 S. I05):

Diese prächtige Art hat auf Kehle und Bauch eine ununterbrochene Reihe weisser conischer Schuppen. Drei blassgelbe, mit paralleler Ringelung versehene runde Hörner, welche direkt nach vorn gerichtet sind, auf dem Vordertheile der Schnauze. Von ihnen je eins auf der Vorderecke des Augenrandes, das dritte liegt an der Schnauzenspitze und ist von den Lippenschildern durch zwei Schuppenreihen getrennt; die Orbitalhörner sind länger als das Rostralhorn; alle drei Hörner liegen einander parallel. Ruicken ohne Sägerand auf der Wirbellinie. mit einem I $2 \mathrm{~mm}$ hohen Hautkamm, welcher mit pflasterartigen Schuppen bedeckt ist. Hinterhaupt und Helm dem von cristatus überaus ähnlich, aber hinten mit zwei Hautlappen, welche, grösser als diejenigen von oweni, aber kleiner als diejenigen von brevicornis mit ihren oberen kurzen Rändern aneinanderstossen. Von den Orbitalhörnern gehen am Rande des Helms stark gesägte Superciliarleisten nach hinten, welche an der hinteren Ecke des Helms unter abgerundet spitzem Winkel zusammenstossen. Occipitalcrista fehlt, Stirngegend ziemlich eben, Occipitalgegend in der Mitte ausgehöhlt, während die Superciliarkanten in ziemlich gerader Linie verlaufen. Schilder des Oberkopfes platt polygonal; Körperbedeckung aus runden, ungleich grossen Körnerschuppen bestehend; Schwanz kürzer als der Kopf + Körper. Dem Weibchen fehlen die drei Hörner, sonst wie das Männchen. 
Ganze Länge . . . . . . . . . . $282 \quad 250 \quad 180$

Schnauzenspitze bis After ......... 150 I $26 \quad 95$

Schwanz . . . . . . . . . . . 132 I 2495

Maulspalte bis zum letzten Lippenschilde . . . $\begin{array}{llll}27 & 24 & \text { I9 }\end{array}$

Oberschenkel . . . . . . . . . . $30 \quad 2730$

Unterschenkel . . . . . . . . . . . 292630

Rostralhorn . . . . . . . . . . . . $-176,2$

Praeorbitalhorn . . . . . . . . - 197,7

Schnauzenspitze bis zum Helmende . . . . . $48 \quad 48 \quad 34$

Grösste Helmbreite . . . . . . . . I7 17 I3

Abstand des Rostralhorns von den Orbitalhörnern — $\begin{array}{lll}\text { I } & 9\end{array}$

Abstand der Orbitalhörner unter sich . . . - $\quad$ I 59

\section{Chamaeleon tigris Kuhl}

S. 461 .

Sansibar; 5 Alte mit Jungen; J. E. Parish S.; Boul., Cat. of Liz. B. III,

Chamaeleon taitensis Steind. (Taf. II, Fig. 9.)

Kiboscho im Kilima-Ndjaro; $9 \sigma^{7}, 3$ \%; Oscar Neumann S.; Januar I 895.

Modji im Kilima-Ndjaro; I $\sigma^{7}$; Oscar Neumann S.; Januar I 895.

Marangu im Kilima-Ndjaro; 4 Individ., darunter 2 Junge; Volkens S. mit folgender Bemerkung:

»In Hecken und auf Bäumen im Culturlande bei I 300 bis I $500 \mathrm{~m}$. Das kleinste Exemplar auf dem Rücken des grössten beobachtet."

Das Nähere über diese Art und ihre Unterschiede von Chamaeleon fischeri Rchw. findet man in der unmittelbar folgenden Beschreibung der letztgenannten Art.

Chamaeleon fischeri Rchw. (Taf. II, Fig. 4.)

Buloa bei Tanga in Usambara; $13 \sigma^{\top}, 4 \%, 3$ Junge; Gustav Eismann S.; 1895.

Usambara, (wahrscheinlich Tanga); $6 \sigma^{\pi}, 4$ \%; Reimer S.; I 894.

Derema in Usambara; $2 \sigma^{\circ}$, I 0 , I Junges; Conradt S.; Matschie, Gesell. naturf. Freunde, Berlin I892, S. I06; (eins dieser Individuen soll nach Werner eine neue Art sein.) Werner, Verhand. Kais.-K. zool.-bot.-Gesell. I895. S. 4.

Usambara; $2 \sigma^{\circ}, 2$, I Junges; Linnaea Berlin S.; Werner, Verhand. K. K. bot.-zool.-Gesell. Wien 1895. S. 4.

Nguru-Berge; I Individ.; G. A. Fischer S.; Reichenow, Zool. Anzeiger 1877, S. 371, Typ der Art.

Usaramo; I Individ.; Stuhlmann S.

Die von Herrn Matschie aus Derema erwähnten Individuen sind nicht, wie Herr Matschie schreibt, 2 Männchen und I Junges, sondern I $\sigma^{\top}$, ein $q$ und ein Junges. So wie dieses Männchen hoch interessant ist durch den stark entwickelten »Flossenkamm" des Rückens, welcher Franz Werner veranlasst hat, dieses Individuum von Chamaeleon fischeri abzutrennen, dem dieser Flossenkamm fehlen soll, und es zu einer neuen Art, Chamaeleon matschiei, zu erheben, so interessant ist auch das Weibchen, weil es Hörner besitzt, die denen gleich kommen, welche bei mittel grossen Männchen der Art gefunden werden.

Unter den anderen, hierher gehörigen Individuen finde ich drei Männchen mit einem ähnlich entwickelten Flossenkamm neben vielen anderen, deren 
Flossenkamm nur gering entwickelt ist. Alle anderen, mir vorliegenden Weibchen (vier aus Buloa bei Tanga, vier wahrscheinlich von Tanga) haben dagegen keine voll entwickelten Hörner, wohl aber wulstige Hervorragungen der Canthus rostrales, welche in Form und Ausbildung genau den Hörnern ganz junger Männchen entsprechen.

Diese Thatsachen deuten auf folgende vier Möglichkeiten: Entweder haben wir bei Chamaeleon fischeri Dimorphismus bei Männchen und Weibchen, oder das mir vorliegende Weibchen ist ein Zwitter, oder es ist eine Varietät, bei welcher die bei allen weiblichen Chamaeleon fischeri in der Anlage vorhandenen Hörner voll ausgebildet sind, oder es sind bisher wirklich zwei Chamaeleon-Arten für eine beschrieben worden, wie das Werner annimmt.

Wenn die letzterwähnte Annahme berechtigt wäre, würde die neue Art natürlicherweise mit dem Namen zu belegen sein, welchen Herr Werner vorgeschlagen hat.

Ich habe schon vor dem Erscheinen der Werner'schen Arbeit alle diese Fragen in Erwägung gezogen. Ich überzeugte mich sofort, dass das gehörnte Weibchen ein normales Thier, also kein Zwitter, war. An Dimorphismus bei beiden Geschlechtern einer Chamaeleon-Art mochte ich nicht glauben. Da mir aber kurz zuvor durch eigene Untersuchung bekannt geworden war, dass es Chamaeleon-Formen giebt, bei welchen beide Geschlechter gleich entwickelte Hörner haben, Arten also, bei denen kein Dimorphismus der Geschlechter vorhanden ist, war auch ich zuerst geneigt, wie Werner anzunehmen, dass in den Derema-Thieren eine ähnliche Art gefunden sei, die von Chamaeleon fischeri zu trennen sei, wo dann die Geschlechter dimorph wären. Vergleicht man aber eingehend die für Chamaeleon matschiei in Frage kommenden Männchen und Weibchen mit denen, welche für die echten Chamaeleon fischeri in Frage kommen - und von beiden angeblichen Arten liegen mir viele Exemplare darunter die "Typen" vor -, so ergiebt sich sehr bald, dass sie sich in facto nur in einem Charakter von einander unterscheiden: Die Chamaeleon matschiei sind von geradezu riesigem Wuchs. Diesem Riesenwuchs verdanken einmal beide Geschlechter ihren Flossenkamm, und ihm verdankt wahrscheinlich auch das Weibchen die sehr stark entwickelten Hörner.

Der Kamm dieser Riesenthiere wird, wie Herr Matschie richtig angegeben hat, durch die Dornfortsätze der Wirbel »gestützt " und dem Kamm sitzen dann ausserdem in der Nackengegend eine Anzahl von Hautstacheln auf. Genau denselben Rückenkamm mit Stachelreihe, nur nicht in so gewaltiger Ausdehnung, besitzen nun aber auch alle kleinen Thiere von sonst gleicher Form, die nach Werner die echten Chamaeleon fischeri sein sollen. Dieser "Rückenkamm " wird einfach dadurch erzeugt, dass zwischen den Muskelpartien, welche die Dornfortsätze umgeben, und denjenigen, welche den Rippen aufliegen, eine muskellose Zone, d. h. eine Grube liegt; in diese Grube drängt sich die Haut mit einer Falte ein. Diese Grube findet man am Rücken aller Chamaeleonen. Wachsen nun bei einigen Individuen die Dornfortsätze hoch empor, dann entsteht der hier vorliegende, durch die Dornfortsätze gestützte Rückenkamm. Es ist ein Gebilde am meisten analog der Nackenbildung des Gorilla und verschiedener Wiederkäuer, dagegen nicht analog der Fettflosse der Delphine und nicht analog den reinen Hautdublicaturen, wie sie durch die Kopflappen der Chamaeleonen repräsentirt werden. In der ersten Anlage besitzen, wie gesagt, alle Chamaeleonen diesen Rückenkamm, bei kleinen Individuen von Chamaeleon fischeri ist er mässig hoch; dass er bei Riesenexemplaren dieser Art befremdlich gross erscheint, frappirt wohl nur bei oberflächlicher Besichtigung.

Wie schon erwähnt, sind bei allen hier zu vergleichenden Weibchen Schnauzenhörner in Andeutung vorhanden; genauere Untersuchung zeigt, dass sie genau so gebaut sind wie die der Männchen, und nur weniger hervor- 
ragen; bei einigen mir vorliegenden Weibchen erheben sie sich indess unmittelbar über den Naslöchern zu spitzen Höckerchen von mehreren Millimetern. Würde eins von diesen verhältnissmässig kleinen Weibchen die Körperdimensionen erreichen, welche das mir vorliegende Riesenweibchen aufzuweisen hat, dann, zweifle ich durchaus nicht, würde es in der Hornbildung diesem wenigstens sehr nahe kommen. Das ist natülicherweise nur eine Vermuthung, denn es ist auch möglich, dass gerade dieses gehörnte Weibchen in der Hornbildung zu einem gewissen Extrem gelangt ist. Jedenfalls aber ergiebt die Ueberlegung das sichere Resultat, dass der verhältnissmässig grosse Rückenkamm der Riesenthiere und die bei dem grossen Weibchen vorkommenden, voll entwickelten Schnauzenhörner nur Extreme von Charakteren darstellen, welche bei den angeblich echten Chamaeleon fischeri ebenso angelegt sind; Dimorphismus in beiden Geschlechtern dürfen wir also nicht annehmen, wenn wir alle diese Thiere in einer Art zusammenfassen.

In allen anderen Charakteren, selbst in sekundären, weichen die Chamaeleon matschiei durchaus nicht von den sogenannten echten Chamaeleon fischeri ab, selbst die Beschuppung des Rückenkammes ist bei beiden Formen dieselbe, nur sind bei der einen Gruppe die in gleicher Zahl vorhandenen Schuppen natülicherweise kleiner als bei der andern. - Aus alledem folgt: Ich kann ein Chamaeleon matschiei nicht anerkennen.

In Rücksicht auf die individuelle Variabilität der Species Chamaeleon fischeri ist nun noch Folgendes zu bemerken: Variabel sind die Individuen der Art in der Form der Beschuppung des Schwanzes. Werner giebt von seinen Exemplaren an, und zwar als Art-Merkmal: "Schwanzfirste in regelmässigen Abständen mit kleinen konischen Tuberkeln besetzt. « Das ist auch bei den meisten der mir vorliegenden Männchen der Fall, aber nicht bei allen, z. B. nicht bei dem Typ-Exemplar, nach welchem Reichenow die Art beschrieben hat, ferner nicht bei den Riesenmännchen der Art, ausserdem nicht bei sämmtlichen Weibchen.

Werner's Angabe ist aber ausserdem etwas ungenau. Bei allen Individuen, die hierbei in Betracht kommen, folgen auf der Schwanzfirste nicht einfache Hautstacheln in Abständen aufeinander, sondern Gruppen von je 3 solcher Hautstacheln, von denen der mittlere der weitaus grössere ist, während die beiden anderen, vor und hinter ihm liegend, seine Stütze bilden. Es sind also am Schwanz einiger Chamaeleon fischeri Verhältnisse vorhanden, wie sie bei den extremeren Formen des Chamaeleon bitaeniatus in ganz ähnlicher Weise auf der ganzen Rückenfirste gefunden werden.

Chamaeleon fischeri variirt ferner individuell in der Zahl jener Hautstacheln, welche auf seinem Rückenkamm in der Nackengegend sitzen. Von diesen Stacheln bemerkt Werner mit Recht: »Kein gezähnelter Ruickenkamm, sondern nur ungefähr fünf weit von einander entfernte, weiche, kleine Dornen auf der vorderen Hälfte der Rückenfirste. Es sind aber durchaus nicht immer nur 5 Dornen vorhanden, denn ich fand bei den verschiedenen, von mir untersuchten Männchen alle Zahlen von 5 bis 15 , allerdings nur unter Berücksichtigung auch der, aus der Rückenfirste kaum noch hervorragenden Dornen. Bei den Weibchen sind diese Ruckendornen entweder schwach und kaum wahrnehmbar oder gar nicht ausgebildet und an Zahl stets sehr gering, es sind höchstens drei bis vier vorhanden. Bei dem Weibchen mit wohlentwickelten Hörnern dagegen treten auch die Rückendornen weit stärker hervor, also zeigt das Thier auch hierin fast männliche Charaktere.

Chamaeleon fischeri zeigt ferner eine gewisse individuelle Variabilität im Bau seiner Schnauzenhörner. Um die Wichtigkeit dieses Variirens zu konstatiren, muss ich zuerst kurz auf die entsprechenden Charaktere des Chamaeleon tavetensis hinweisen. 
Chamaeleon tavetensis und fischeri sind sehr nahe verwandte Arten, aber trotzdem scharf getrennt, ich wenigstens fand bisher keine Uebergangsformen zwischen beiden; sie dürften vielmehr einer dritten gemeinsamen Stammform entsprossen sein.

Von beiden Arten liegen mir voll entwickelte Individuen vor, denn ich fand bei Weibchen beider Arten im Uterus legereife, hartschalige Eier, woraus zugleich hervorgeht, dass beide Arten nicht lebendig gebährend sind.

Nach den Angaben von Steindachner und Stejneger weicht Chamaeleon tavetensis durch den Mangel eines Rückenkammes und ferner dadurch von Chamaeleon fischeri ab, dass bei ihm die Augenbraubogen direkt in die laterale Gräte der Hörner übergehen.

Der Ruickenkamm fehlt den meisten, aber nicht allen von mir untersuchten Männchen von Chamaeleon tavetensis, denn ich fand drei unter ihnen, welche auf ihrem Ruicken einige recht gut entwickelte Dornen tragen, die so gross sind, dass der Rückenkamm der betreffenden Männchen nicht kleiner ist, als der der Weibchen des Chamaeleon fischeri. Von diesen Männchen, welche aus Kiboscha von Oscar Neumann heimgebracht worden sind, hat das erste 2, das
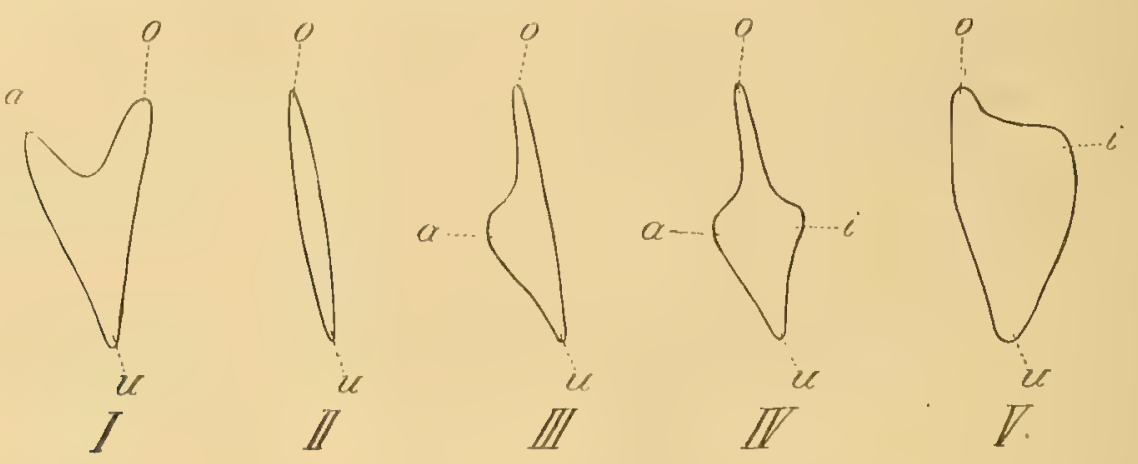

Fig. C.

zweite 3, das dritte sogar 8 solcher Stacheln. Auch die Weibchen dieser Art haben stets einige, wenn auch schwach ausgebildete Stacheln am Ruicken in der Nackenregion. Demnach unterscheiden sich Chamaeleon fischeri und tavetensis nur durch einen Charakter voneinander: Durch die Form der Hörner.

Die Angabe der Autoren, dass bei Chamaeleon tavetensis die Augenbraugräten direkt in die lateralen Horngräten übergehen, bezeichnet nicht das, für diese Chamaeleon-Art Charakteristische der Hornbildung. Mir liegen zahlreiche Individuen von Chamaeleon fischeri vor, bei welchen ebenfalls die Augenbraugräten unmittelbar in die laterale Gräte der Hörner übergehen, ohne dass dadurch der Hörnercharakter des Chamaeleon fischeri verwischt wird (Tafel II, Fig. 9). Der wirkliche Unterschied ist: Bei Chamaeleon taitensis (Taf. II, Fig. 4) geht die Augenbraugräte nur in die laterale Horngräte über, weil die Rückengräte des Hornes blind endet, nachdem sie sich in einem geschweiften Bogen gegen die Stirn des Thieres gewendet hat; bei Chamaeleon fischeri dagegen geht die Augenbraugräte sowohl in die laterale wie dorsale Horngräte über; gerade das letztere ist das Charakteristische. Daher ist auch der Querschnitt beider Hörner ein durchaus verschiedener: Schneidet man sie beide in der Nähe der Basis ab, so ist der Querschnitt des Chamaeleon tavetensis-Hornes ungefähr herzförmig (Fig. C. I), seine beiden oberen Flügel sind annähernd gleich und weichen schräg auseinander; bei Chamaeleon fischeri (Fig. C. II-IV) ist der Hornquerschnitt nicht herzförmig, er ist lang gestreckt von oben nach unten und hat gewöhnlich an der Aussenseite eine kleine Ausbuchtung (a), welche zeigt, dass hier am Horn eine geringe laterale Firste vorhanden ist. 
Bei einigen Individuen findet man ausserdem noch an der Innenseite des Hornes eine Ausbuchtung (i), da hier das Horn eine vierte, innere Firste auszubilden beginnt. In jedem Fall aber bleibt typisch für das Chamaeleon fischeriHorn, dass sein Vertikaldurchmesser den Transversaldurchmesser an Länge bedeutend übertrifft. - Bei Chamaeleon bifidus, das, wie bekannt, den beiden besprochenen Arten sehr nahe steht, ist der Horn-Querschnitt dreieckig, da bei dieser Art drei Hornkanten (die obere, innere und untere) annähernd gleiche Ausbildung haben (Fig. C. V).

Will man bis ins Detail feststellen, welche Unterschiede die Hörner des Chamaeleon fischeri von denen des Chamaeleon taitensis trennen, dann muss man die Hornformen in's Auge fassen, welche bei den Weibchen und Jungen der beiden Arten vorhanden sind. Die Weibchen beider Arten haben zwar, bis auf das eine abweichende, keine voll ausgebildeten Schnauzenhörner, aber an deren Stelle buckelartige Erhebungen, die von darauf liegenden Schuppen bedeckt sind. Genau dieselbe Ausbildung zeigen die Schnauzenhörner neugeborener Männchen und daraus folgt: Die Weibchen bleiben in der Hornbildung auf einer Stufe stehen, die von den Männchen in der Jugend eingenommen wird. Nun ergiebt die Untersuchung ferner das sehr wichtige Resultat, dass bereits dieses erste Entwicklungsstadium der Hörner die charakteristischen Artcharaktere, d. h. die typischen Firsten aufweist; man kann deshalb die Weibchen der beiden Arten an ihren Hörnern sehr gut von einander unterscheiden. Die Hörner der jungen Männchen und die der Weibchen eignen sich aber ausserdem noch dadurch besser zur Vergleichung mit denen der andern Art, weil bei ihnen die Cutispapillen, welche zur Hornbildung Veranlassung geben, noch wenig aus der Schnauze hervorragen, so dass man an ihnen viel besser iibersehen kann, wie viel und welche Cutispapillen bei jeder Art an der Hornbildung theilnehmen. Ihre Untersuchung ergiebt dann, dass bei beiden Arten derselbe Schnauzenbezirk die Hornbildung veranlasst hat, dass bei beiden Arten die Hornspitzen durch ho mologe Cutispapillen gebildet werden, dass dagegen die Basen beider Hörnerformen nicht homolog, sondern analog sind, weil bei jeder Art besondere Papillen der Schnauze an der Ausbildung der Hörnerbasen betheiligt sind. An den Hornwülsten der Weibchen sieht man z. B. sofort, dass am Chamaeleon-fischeri-Horn die Schuppen der Canthusrostralis-Firste von den Augenbrauschuppen aus die obere Hornkante bilden, während sie bei Chamaeleon tavetensis durch einwärts vom Canthus rostralis liegende Schuppen gebildet wird; und es ergiebt sich ferner, dass auch die lateralen Hornkanten der beiden Hörner nicht streng homolog sind, weil bei Chamaeleon tavetensis höher liegende Schuppen die Wurzel dieser Kanten bilden als bei Chamaeleon fischeri, was bei erwachsenen Individuen von Chamaeleon fischeri dadurch zum Ausdruck kommt, dass die Augenbrauschuppen in einem Winkel mit der eigentlichen lateralen Hornkante zusammenstossen, während sie bei Chamaeleon tavetensis in einem sehr flachen, abgerundeten Bogen in einander übergehen.

In Rücksicht auf die Variabilität der Hörner der beiden Arten ist Folgendes zu bemerken:

Während bei Chamaeleon tavetensis die Hörner stets genau denselben anatomischen Bau aufweisen und nur dadurch variiren, dass sie bald einander parallel gestellt sind, bald, und zwar meistens, in spitzem Winkel auseinanderweichen, sind die Hörner der männlichen Chamaeleon fischeri, wie das mir vorliegende Material ergiebt, nicht nur in der Stellung zueinander, sondern selbst im anatomischen Bau variabel.

Was ibre Stellung zueinander anbetrifft, so können sie einander parallel stehen, können aber auch mit ihren Spitzen gegeneinander convergiren, ebenso oft weichen sie indess auch in einem spitzen Winkel auseinander. Dann findet 
man gerade bei dieser Art sehr viel pathologische Hornbildungen, welche beweisen, wie energisch die Hörner von den Thieren gebraucht werden; mir liegen z. B. Individuen vor, deren beide Hörner gleichartig nach links oder rechts verbogen sind; bei einem Individuum sind sie nicht symmetrisch zueinander gestellt, sondern die Spitze des einen liegt viel tiefer als die Spitze des anderen; bei einem Thier zeigen beide Hornspitzen bogenförmig nach unten, bei einem anderen sind sie umgekehrt nach oben gerichtet und machen den Eindruck, als wären sie von der Spitze aus zusammengedriickt. Ueberhaupt sieht man all diesen pathologisch verbogenen Hörnern sofort an, dass ein uibernormaler Druck (beim Wühlen?) ihre Deformation erzeugt hat.

Im anatomischen Bau der Hörner von Chamaeleon fischeri unterscheide ich folgende Formen:

Einfachste Form: Das Horn ist messerartig scharf, von den Seiten zusammengedrückt, steht wagerecht, die obere Augenbraucrista setzt sich ohne Unterbrechung in die obere Hornkante fort; eine laterale Hornkante fehlt; sämmtliche Schuppen des Hornes sind flach, nicht gekielt (Reichenow's TypExemplar).

Zweite Form: Der Bau des Hornes ist derselbe wie beim vorigen Individ.; aber seine sämmtlichen Schuppen sind schwach gekielt.

Dritte, häufigste Form: Alle Schuppen des Hornes sind gekielt, weitaus am schärfsten aber die, welche der Aussenseite des Hornes in der Mitte aufliegen. Infolge ihrer starken Kielung treten sie aus der Aussenseite des Hornes als laterale Hornkante hervor und sind ferner durch eine Anzahl stark gekielter Schuppen, welche am vorderen Augenrande terrassenartig übereinander liegen, mit dem oberen Augenrand direkt verbunden. Diese Hornkante nur ist analog gebildet der gleichnamigen des Chamaeleon tavetensis, dessen Hornschuppen ubrigens viel stärker gekielt sind, als die irgend eines Chamaeleon fischeri.

\section{Chamaeleon temporalis Mtsch. (Taf. II, Fig. 5.)}

Derema in Usambara; I Individ.; Conradt S.; Matschie in Sitzungsber. Ges. nat. Freunde Berlin I892, S. Io8 als Chamaeleon (Brookesia) temporalis beschrieben.

$\mathrm{Da}$ das Individuum, entgegen den Angaben des Artautors, glatte (nicht »stachlige «) Sohlenschilder hat, ist es ein echtes Chamaeleon.

Ausgezeichnet durch die stark zugespitzte Schnauze, welche in einen kurzen, nur schwer wahrnehmbaren Nasenfortsatz ausmündet, der die Oberlippe ein wenig überragt; besitzt einen schmalen Flossensaum auf dem Rücken und der vorderen Schwanzhälfte und hat stark hervortretende Helmkanten. Schwanz kürzer als der Körper. Klauen einfach, ohne Nebenklauen; Sohlenschilder nicht stachlig. Schnauze vorn verlängert, wie bei Brokesia nasus, und in einen runden Tuberkel auslaufend, so dass die Oberlippe über die Unterlippe hervorragt. Von den Superciliarkanten ziehen die Seitenkanten des Helms zu dem hinteren Ende desselben, wo sie sich spitzwinklig treffen. Temporalgegend mit Pflasterschuppen bedeckt, in welche wenige starke Körnerschuppen eingelagert und so angeordnet sind, dass sie eine beginnende Temporalcrista bilden. Das Thier hat demnach wohl ausgebildete Parietalcristen, die hinten zusammenstossen, in der Bildung begriffene Temporalcristen, dagegen keine Occipitalcrista. Der Oberkopf ist bis zu den Augen mit Körnerschuppen, zwischen den Augen mit Pflasterschuppen besetzt, unter welche einzelne stark hervortretende Körnerschuppen eingestreut sind; auf dem Hinterhaupte finden sich grosse Pflasterschuppen. Körperbeschilderung besteht aus kleinen, ungleich grossen, wenig konischen Schuppen, unter welche grössere, stärker konische 
eingestreut sind. Von diesen treten je zwei am Unterarm besonders stark hervor. Die Temporalgegend ist unten von 3 bis 5 stark konischen Schildern begrenzt. Ein schmaler Flossensaum zieht über den Rücken bis zum Schwanz, ähnlich wie bei $\mathrm{Ch}$. fischeri, deremensis, cristatus und montium.

Hervorzuheben wäre vielleicht noch, dass die Gegend vor den Augen stark konkav erscheint, während sie bei Cham. brevicaudatus eben ist.

\section{Maasse:}

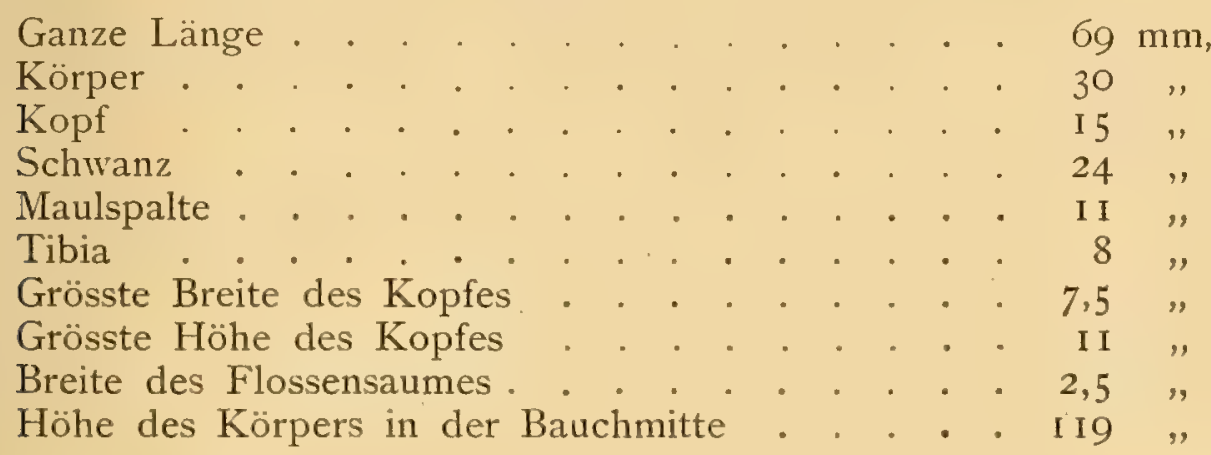

\section{Chamaeleon melleri (Gray)}

Magila in Usambara; I Individ.; Oscar Neumann S.

Usaramo; I Individ.; G. A. Fischer S.; Mus.-Nro. 10405.

Usaramo; I Individ.; Stuhlmann S.

Dar es Salaam; I Individ.; Stuhlmann S. I895.

Berge im Inneren von Ostafrika, Dr. Meller S.; Gray, Proceed. zool. Soc. I 864 S. 478 , beschrieben als Ensirostris melleri. am Bach.

Oscar Neumann fand das von ihm eingesandte Exemplar auf Orangen

\section{Chamaeleon tenuis Mtsch.}

Derema in Usambara; 4 Individ.; Conradt S.; Matschie, Gesell. nat. Freunde, Berlin, 19. Juli I892, S. 106.

Es folgt die Originalbeschreibung:

Chamaeleon tenuis Mtsch. spec. nov. unterscheidet sich von Ch. nasutus durch deutliche Helmkanten und Parietalcrista, spitz gezähnelten Rostralfortsatz, längeren Schwanz und längere Beine und durch die grössere Anzahl von Schilderreihen zwischen den Superciliarleisten.

Brust- und Bauchcrista fehlen. Schnauze in einen häutigen, mit breiten, glatten Schildern bekleideten, am Rande gezähnelten Lappen auslaufend. Occipitallappen fehlen. Helm hinten wenig vom Körper abgesetzt und stark gewölbt, stumpfwinklig endigend; Parietalcrista sehr deutlich; Seitenkanten des Helms mit einer Reihe stark konischer Schuppen bedeckt. Superciliarkanten deutlich. Kopfschilder flach, zwischen den Superciliarkanten in 6, nicht in 4 Reihen wie bei nasutus.

\section{Maasse :}

Ganze Länge .

$120 \mathrm{~mm}$,

Körper . . . . . . . . . 37 »

Kopf . . . . . . . . . . . . . I7 》

Schwanz. . . . . . . . . 66 »

Kopfhöhe . . . . . . . . . . . II 》

Kopfbreite . . . . . . . . . . 7.5 "

Rostralanhang, Länge . . . . . . 3,5 "

Tibia . . . . . . . . . . 9 » 
Chamaeleon spinosus Mtsch. (Taf. II, Fig. 6.)

Derema in Usambara; I Individ.; Con radt S.; October I891; Matschie, Gesellsch. nat. Freunde Berlin 1892, S. I05.

Usambara; I Individ.; Linnaea Berlin S.; Franz Werner, Verh. K. K. zool.-bot. Gesell. Wien I 895 , S. 4.

Einzureihen in Boulenger's Katalog als Nro. 43a. Weder Gular- noch Ventralcrista. Nase endet in einen einzigen Anhang; er ist seitlich zusammengedrückt, nach vorn verbreitert, am senkrecht stehenden Vorderrand abgerundet. Keine Occipitallappen.

Folgt die Originalbeschreibung:

Ausgezeichnet durch die niedrige Form des Schädels und das Vorhandensein von 2 Reihen weicher Hautstacheln zu beiden Seiten der Wirbelsäule auf dem Rücken und Schwanz und vorn und hinten an den Gliedmaassen.

Brust- und Bauchcrista fehlt. Schnauze endigend in einen einzelnen zusammengedruickten Fortsatz, welcher abgerundet eiförmige Gestalt hat und beweglich ist. Derselbe ist mit konischen Schildern bekleidet. Occipitallappen fehlen. Helm hinten fast rechtwinklig abgerundet, etwas abgesetzt wie bei Ch. nasutus; Occipitalcrista nicht vorhanden. Auf den Helmkanten keine fortlaufende Sägezähnelung, sondern nur einzeln hervorstehende grosse Tuberkeln. Interocular- und Parietalschilder flach, alle übrigen, besonders in der Occipitalgegend und an der Schnauzenspitze stark konisch. Kopf sehr schmal und lang; Körperbeschilderung aus länglichen Gruppen von pflasterförmigen, platten Schildern, welche untermengt sind mit grossen, stark konischen Schuppen und durch netzartige, mit ganz kleinen konischen Schildchen gefüllte Kanäle (Hautfalten Ref.) getrennt werden. Am Bauch finden sich schwach konische Körnerschuppen von gleicher Grösse. Neben der Rückenlinie, auf der Schwanzoberseite, an der vorderen Hälfte der Seiten der Schwanzunterseite, an den Seiten des Oberarmes und Oberschenkels vorn und hinten, sowie längs der Unterkieferäste am Kinn findet sich je eine Reihe von stachelförmigen, weichen Hautpapillen, welche spitz endigen.

\section{Maasse:}

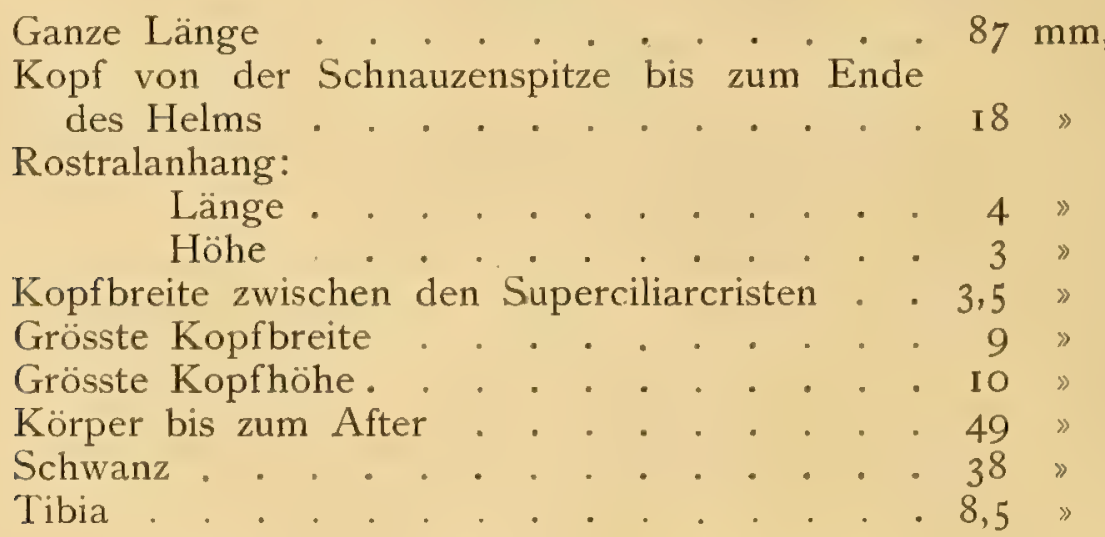

Rhampholeon brevicaudatus (Mtsch.) (Taf. II, Fig. 7).

Chamaeleon (Brockesia) brevicaudatus; Matschie; Gesell. nat. Freunde Berlin 19. Juli 1892 , S. 105.

Rhampholeon brachyurus; Günther, Proceed. zool. Soc. London, I. November I 892.

Derema in Usambara; I 9 ; Conradt S.; Matschie 1. cit.

Dunda am Kingani; I Individ.; Stuhlmann S.; 28. Januar 1894. 
Für den Artnamen hat Matschie die Priorität. Das Thier ist irrthümlich von ihm für ein Chamaeleon gehalten worden.

Ausgezeichnet durch sehr kurzen, nicht $1 / 5$ der Körperlänge einnehmenden Schwanz, Mangel einer Crista am Bauch oder Riicken und das Vorhandensein von zwei spitzkonischen Dornschuppen an der Vorderseite des Unterarms. Bei einem zweiten Exemplar finde ich gleiche Dornen in ähnlicher Anordnung am Unterschenkel, einzelne derselben ausserdem zerstreut am Ober- und Unterschenkel, sowie an den Körperseiten des Thieres.

Schwanz sehr kurz, nicht $1 / 5$ der ganzen Körperlänge einnehmend. Krallen mit sehr schwachen, aber wohl ausgebildeten Nebenkrallen, das Thier bildet dadurch eine Art Uebergangsform zwischen Chamaeleon und Rhampholeon. Sohlenschilder stachlig, Superciliar-Fortsätze und Canthus rostralis stark entwickelt und deutlich gesägt, keine Parietal- und Occipitalcristen, Helm wenig vom Rücken abgesetzt, die Helmkanten nur sehr schwach angedeutet, am meisten noch eine Temporalcrista entwickelt, die von der Mitte des hinteren Augenrandes gerade nach hinten geht. Rücken- und Bauchcrista fehlen. Rücken bei einem Thier flossenartig mit deutlich welligem Rand, beim anderen Thier ohne solche Bildung und ohne Wellen-Rand.

Bei dieser Art erhält der seitlich zusammengedrückte Körper durch die »als Hauptblattader « stark hervortretende obere Seitenlinie und durch die graugelbe Grundfarbe ein blattartiges Aussehen.

Maasse des grossen Thieres nach Matschie:

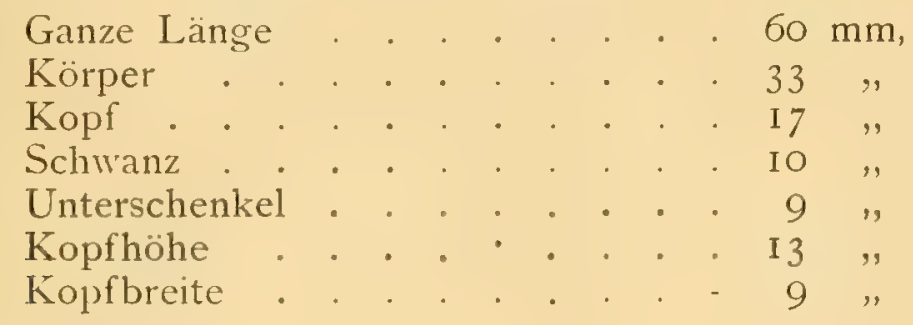

\section{Rhampholeon Kersteni (Ptrs.)}

Tanga in Usambara; 2 Individ.; Oscar Neumann S.

Busini; I Individ.; Stuhlmann S.

Wpwapwa; I Individ.; Bates S.; Boul., Cat. of. Liz. B. III, S. 476.

Ravinjiro im Massai Gebiet; I Individ.; Oscar Neumann S.; 2. Dezember 1893 .

Peri Nfiomi in Umbugwe; I Individ.; Oscar Neunann S.; 2. Nov. I 893.

\section{Rhampholeon spectrum Bchh.}

Mbusini; I Individ.; Stuhlmann S.;

Wald bei Kibissibili; I Individ.; Stuhlmann S.; Pfeffer, Stuhlmann $\mathrm{X},(\mathrm{I} 892), \mathrm{S} .7$.

Färbung nach Stuhlmann: Grïn und schwar\% gefleckt mit drei rostbraunen schrägen Längslinien.

\section{Rhampholeon Boettgeri Pfeffer}

Bagamoyo; I Individ.; Stuhlmann S.; Pfeffer in Stuhlmann X (I892), S. 8.: Beschreibung und Figur. 


\section{Ordnung: Schlangen, Ophidia.}

\section{Familie: Typhlopidae.}

\section{Typhlops punctatus (Leach)}

Usambara (wahrscheinlich Tanga); I Individ.; Reimer S.; I894.

Usambara (Buloa bei Tanga); I Individ.; G. Eismann S.; I 895.

Usambara (am Pangani); I Individ.; Conradt S.; Matschie in Gesell. nat. Freunde Berlin, I892, S. I Io.

Marangu im Kilima-Ndjaro; I Individ.; Volkens S.

Victoria Nyansa (Kagehi); 2 Individ,; G. A. Fischer S.; Mus.-No. 3133.

Kavirondo in Uganda; I Individ.; Neumann S.; März I 894.

Chagwe in Uganda; 2 Individ.; Neumann S.; 20. Mai I894.

Volkens begleitet seine Sendung mit folgender Bemerkung: 》Vitschwa wibili: die Zweiköpfige der Nasuaheli. Am Kilima-Ndjaro in der Kulturregion häufig." Ebenso schreibt Böhm: "Die Eingeborenen sehen die Typhlopiden als Schlangen mit zwei Köpfen an.«

\section{Typhlops humbo, Boc.}

Inneres von Ost-Afrika (Mpapwa); 2 Individ.; Boul., Cat. of Snakes, Bd. I, S. 46.

\section{Typhlops nucroso (Ptrs.)}

Sansibar; 3 Individ.; Sir. J. Kirk S.; Boul., Cat. of Snakes, Bd. I, S. 47. Marungu (wahrscheinlich Kakoma); I Individ.; Böhm S.

[East-Afrika; I Individ.; Capt Speke S.; Boul., Cat. of Snakes, Bd. I, S.47.]

\section{Typhlops pallidus (Cope)}

Sansibar; I Individ.; Sir. J. Kirk S.; Boul., Cat of Snakes, Bd. I, S. 57.

Sansibar; I Individ.; Sir Lambert Playfair S.; Boul., Cat. of Snakes, Bd. I, S. 54 .

\section{Typhlops lumbriciformis (Ptrs.)}

Sansibar; I Individ.; G. A. Fischer S.; Mus.-No. IO I87.

Sansibar; 2 Individ.; G. A. Fischer S.; Mus.-No. 8045.

Sansibar; I Individ.; Sir. J. Kirk S.; Boul., Cat. of Snakes, Bd. I, S. 55.

Sansibarküste; 2 Individ.; J. M. Hildebrandt S.; Peters, Sitz. Akad. Berlin, I874, S. 377 als Onychocephalus (Letheobia) lumbriciformis beschrieben. Tanga; 3 Individ.; O. Neumann S.

\section{Typhlops caecus, A. D.}

[Deutsch?-Ost-Afrika, ohne nähere Fundortsangabe; 2 Individ.; Stuhlmann S.; Pfeffer in Stuhlmann. X., S. 9.]

\section{Typhlops unitaeniatus, Ptrs.}

Buhuri in Usambara; I Individ.; Neumann S.; 27. April I893.

"Schwarz mit citrongelbem Rückenstreif." O. Neumann. - Von dieser Art sind bisher, so viel ich weiss, erst drei Exemplare gesammelt worden: das 
Originalexemplar aus Taita in Englisch-Ost-Afrika; das zweite aus Mombasa in Englisch-Ost-Afrika, erwähnt von Boulenger im Cat. of Snakes, Bd. I, S: 56, gesammelt von M. Last, und das hier erwähnte. Boulenger's Katalog-Angabe, dass das Thier auch in Sansibar gefunden worden sei, beruht wohl auf einem Irrthum.

\section{Familie: Stenostomidae.}

\section{Stenostoma emini Blgr.}

Karagwe a. Victoria Nyansa; 2 Individ.; Dr. Emin. S.; Boul., Cat. of Snakes, Bd. I, S. 64 .

Niomkolo am Tanganyika; I Individ.; A. Parson S.; Boul., Cat. of Snakes, Bd. I, S. 64.

Basaiba am Duki; I Individ.; Stuhlmann S.; 6. Okt. I89I

Urwald N. W. Runssóroro; I Individ.; Stuhlmann S.; 6. Sept. I89I.

\section{Stenostoma conjuncta, Jan.}

Kilima-Ndjaro; 2 Individ., erwachs. u. jung; F. J. Jackson S.; Boul., Cat. of Snakes, Bd. I, S. 68.

Korogwe; I Individ.; Stuhlmann S.; Pfeffer in Stuhlmann X., S. 9.

Ohne näheren Fundort; I Individ.; Stuhlmann S.; IS92.

\section{Familie: Boidae.}

\section{Python sebae frmel.}

Dar es Salaam; I Individ.; Stuhlmann S.

Morogoro; I riesiger Kopf; Elpons S.; I894.

"Python sebae, schreibt Böhm, sah ich nur einmal und zwar ein $3^{1 / 2} \mathrm{~m}$ langes Exemplar an einer feuchten Stelle einer boga in Kawende. Ich wolltc das unbeweglich am Pfade liegende Thier erschiessen, wurde aber durch die angstvollen Bitten unserer Leute davon abgehalten, welche mich. beschworen, die Schlange nicht zu verletzen, da diese ein mcimu (Zauber-Geist) sei. Sie opferten darauf kleine Grasbüschel, welche sie auf die Schlange warfen, bis diese sich entfernte.

\section{Familie: Colobridae.}

\section{Series A. Aglypha. \\ Tropidonotus olivaceus (Ptrs.)}

Sansibarküste; 2 Individ.; J. M. Hildebrandt S.; Mus.- No. 8594. Erwähnt in Peters, Mossambique S. I I4.

Sansibarküste; 2 Individ.; ohne Sammler; Boul., Cat. of Snakes, Bd. I, S. 228.

Dar es Salaam; I Individ.; Stuhlmann S.; 1894.

Aruscha am Kilimandjaro; I Individ.; G. A. Fischer S.; J. G. Fischer, Afrikanische Rept. Hamb. I884, S. 6.

Vitschumbi am Sü. Albert-Eduards-See; I Individ.; Stuhlmann S.; 25. Okt. I 892. 


\section{Boodon lineatus D. e. B.}

Sansibar; 3 Individ.; Sir J. Kirk S.; 29 Schuppenreihen; Boul., Cat. of Sinalies. Bd. I, S. 333 .

Sansibar; I Individ.; Sir J. Kirk S.; 27 Reihen; Boul., Cat. of Snakes, Bd. I, S. 333 .

Sansibar; I Individ.; Geschenk des Hamburg. Mus.; Mus.-No. 5934 (als Boodon niger Fisch. mit 25 Schuppenreihen in der Sammlung).

Sansibarkiiste; 6 Individ,; J. M. Hildebrandt S.; Schuppen 25 oder 27 Querreihen; Mus.-No. 8584.

Sansibarküste; I Individ.; J. M. Hildebrandt S.; Erwähnt von Peters In Decken's Reisen S. I6.

Tanga in Usambara; I Individ.; O. Neumann S.; 27 Schuppen quer.

Derema in Usambara; I Individ.; Conradt S.; Matschie, Gesell. nat. Freunde Berlin, IS92, S. I IO.

Kotonito in Usambara; I Individ.; O. Neumann S.; Dez. 1893.

Lewa in Usambara; I Individ.; Stuhlmann S.; 26. Sept. 1888 ; Pfeffer in Stuhlmann I892, S. I9.

Usambara, wahrscheinlich Tanga; I Individ.; Reimer S.; 27 Schuppen quer. Massai oder Kavirondo; 2 Individ.; Neumann S.

Kihengo in Unguru; I Individ.; Stuhlmann S.; I2. Sept. I888; Pfeffer in Stuhlmann I892, S. I9.

Dar es Salaam; I Individ.; Stuhlmann S.; I 894.

Kingani am Dunda; 3 Individ.; Stuhlmann S.; 27 Schuppen quer.

Aruscha am Kilima-Ndjaro; 3 Junge; G. A. Fischer S.; J. G. Fischer, Hamburg. I 884, S. I0.

Marangu im Kilima-Ndjaro; I Individ.; Volkens S.

Kilima-Ndjaro; I Individ.; F. J. Jackson S.; Boul., Cat. of Sn., Bd. I, S. 333 .

Kokotoni; I Individ.; Stuhlmann S.; IO. Sept. I 889; Pfeffer in Stuhlmann IS92, S. 19.

Mpapwa; I Individ.; Stuhlmann S.; Febr. I894.

Mpapwa; 2 Individ.; kein Sammler genannt; Boul., Cat. of Snakes, 13d. I, S. 333 .

Bukoba; I Individ.; Stuhlmann S.; 10. Sept. I889; 2 Anteocularia.

Tanganyika; 2 Individ.; J. Kirk S.; mit 25 u. 27 Schuppen quer.

Kafuro in Karagwe; I Individ.; Stuhlmann S.; 6. März I89I. (Kopf).

Uganda in 3900-4500 Fuss; I Individ.; G. F. Scott Elliot S.; Günther, Ann Mag. I 895 , S. 525, als Boodon praeocularis.

Beim dritten Exemplar aus Sansibar und bei dem Individuum aus Dar es Salaam sind eine Anzahl der paarigen Schwanzschilder (bei I das 3.-IO. Paar, bei II das 3.- 13. Paar) miteinander zu vergrösserten unpaarigen Schwanzschildern verwachsen.

\section{Lycophidium acutirostre, Gthr.}

Sansibar; 6 Individ.; J. Kirk S.; Boul., Cat. of Snakes. 13d. I, S. 338.

\section{Lycophidium capense (A. Sm.)}

Sansibar; I Individ.; Sir J. Kirk S.; Boul., Cat. of Snakes, Bd. I, S. 339. Sansibarkiiste; 4 Individ.; Hildebrandt S.; Mus.-No. 8583 .

Sansibarkuiste; 2 Individ.; Hildebrandt S.; Mus.-No. 1795.

Usambara, wahrscheinlich Tanga; I Individ.; Reimer S.; r893.

Usambara (Buloa bei Tanga); 6 Individ.; Eismann S. 
Usambara; I Individ.; Stuh 1 mann $\mathrm{S}$. (wahrscheinlich aus der H. Meyer'schen Expedition); Pfeffer in Stuhlmann I892, S. I9.

Mhondo in Unguru; I Individ.; Stuhlmann S.; 6. Sept. I 888; Pfeffer in Stuhlmann 1892, S. I9.

Kingani am Dunda; I Individ.; Stuh1mann S.; 1894.

Dar es Salaam; I Individ.; Krüger S.; I894.

Bagamoyo; 3 Individ.; Stuhlmann S.; Febr. 1890; Pfeffer in Stuhlmann I 892, S. 19.

Ugogo; I Individ.; E. J. Baxter S.; Günth., Ann Mag. I895. S. 527. (var. Jacksoni).

Aruscha im Kilima-Ndjaro; I Junges; G. A. Fischer S.; J. G. Fischer, Hamburg. Mittheil. I 884 , S. 10.

Undussuma; I Kopf; Stuhlmann S.; 29. März I89I. gefunden

Das letztgenannte Exemplar wurde nach Stuhlmann in Grasbüschen

\section{Lycophidium jacksoni Blgr.}

Kilima - Ndjaro; 2 Individ.; F. J. Jackson S.; Boul., Cat. of Snakes, Bd. I, S. 340 .

\section{Simocephalus poensis (A. Sm.)}

Lewa in Usambara; I Individ.; Stuhlmann S.; Pfeffer in Stuhlmann I 892, S. I 8, als Heterolepis bicarinatus.

Kokotoni; I Individ.; Stuhlmann S.; 21. Aug. I889; Pfeffer in Stuhlmann I 892, S. I8.

Ferner zwei Stücke ohne näheren Fundort; Stuhlmann S.; Pfeffer in Stuhlmann I892, S. I 8 .

\section{Chlorophis hoplogaster (Gthr.)}

Pinnin?; I Individ.; Neumann S.; Dez. I 893.

Ventralia I 70, Subcandalia 95.

Von Boulenger's Beschreibung nur in Folgendem abweichend: An der einen Seite zwei Postocularia, an der anderen das obere verwachsen mit dem Supraoculare, so dass dieses an der Hinterseite des Auges tief herabreicht. Die Praeocularia stossen an beiden Kopfseiten nur sehr wenig, d. h. mit einer feinen Spitze, an das Frontale.

\section{Chlorophis neglectus (Ptrs.)}

Sansibarküste; I Individ.; ohne Sammler; Boul., Cat. of Snakes, Bd. II, S. 94.

Usambara; 5 Individ.; Stuhlmann S. (Wahrscheinlich aus Dr. H. Meyer's Expedition stammend); Pfeffer, Stuhlmann I892, S. I7. Mit Beschreibung.

Derema in Usambara; 3 Individ.; Conradt S.; Matschie, Gesell. nat. Freunde Berlin, I892, S. IIO.

\section{Chlorophis heterolepidotus (Gthr.)}

Sansibarküste; I Individ.; ohne Sammler; Boul., Cat. of Snakes, Bd. II, S. 96. 


\section{Chlorophis irregularis (Leach)}

Ugogo in Ostafrika; I $\sigma^{\top}$; Capt. Speke S.; Boul., Cat. of Snakes, Bd. II, S. 97.

Kagera-Ufer bei Kanjonsa; I Individ.; Stuhlmann S.; »Am Papyrusrand «.

Beifolgende Textfiguren geben den
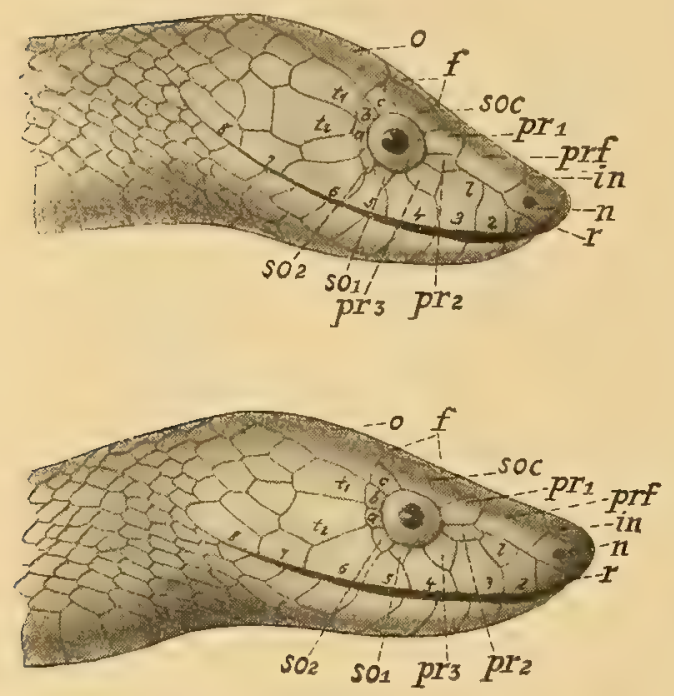

Fig. D. Kopf eines Individuums der Gattung Chlorophis wieder, das aus Ostafrika (Mtungun) stammt, aber nicht näher zu bestimmen war, weil der Kopf sehr unregelmässige Beschuppung hat und der Leib des Thieres nicht mitgeschickt wurde. Die Figuren sind nach Photographien gezeichnet und deshalb besonders wichtig, weil der Kopf dieses Thieres nach meiner Ueberzeugung eine auffällig phylogenetisch-primitive Beschuppung zeigt. An seiner Oberseite zeigt er nur das Charakteristische, dass an ihm das Frontale durch eine Quernaht in zwei Theile gespalten ist (Hemmungsbildung). An der rechten Kopfseite hatte das Thier ein Zügelschild (1) und einen fast geschlossenen Ring um das Auge, bestehend aus 3 Praeocularschildern ( $\mathrm{pr}_{2}$ bis $\mathrm{pr}_{3}$ ), 3 Postocular- $(\mathrm{a}-\mathrm{c})$ und aus 2 Subocular-

schildern ( $\mathrm{so}_{1}$ und $\mathrm{so}_{2}$ ). Nur das Labiale 4 stösst an das Auge, weil das [bei anderen Thieren - Textfigur E - zwischen ihm und dem Auge liegende] Praeoculare $_{4}\left(\mathrm{pr}_{4}\right)$ mit ihm verwachsen ist.

Die andere Kopfseite des Thieres weicht in folgenden Charakteren von der vorigen $\mathrm{ab}$. Bei ihr ist das Zügelschild (1) mit dem Labiale ${ }_{3}$ verwachsen und es liegt hier zwischen dem unteren Temporale der ersten Reihe $\left(t_{2}\right)$ und dem Labiale ${ }_{6}$ ein besonderes Schild (in der Figur ohne Bezeichnung). Dieses Schild ist, wie seine Lage ergiebt, ein drittes Temporale der ersten Reihe und an der erstbesprochenen Kopfseite mit dem Labiale ${ }_{6}$ verwachsen.

\section{Philothamnus semivariegatus (A. Sm.)}

Sansibar; 2 Individ.; v. d. Decken S.; Peters in Decken III, S. I6.

Sansibar; 3 Individ.; Mocq., soc. phil. I888, S. I I , als Leptophis punctatus erwähnt.

Sansibar; I Individ.; Salmin S.; Mus.-No. 5735.

Sansibar; I Individ.; Salmin S.; Mus.-No. 6035.

Offenbar Sansibar; 3 Individ.; Stuhlmann S.; Aug.-Nov. I888. Pfeffer in Stuhlmann X, I892, S. I 5. Genaue Beschreibung als Philothamnus punctatus var. sansibaricus Pfeffer.

Sansibar; 4 Individ.; Sir John Kirk S.; Boul., Cat. of Snakes, Bd. II, S. Ioo.

Sansibarküste; 3 Individ.; von d. Decken S.; Peters, Decken Bd. III, S. 16; Mus.-No. 8596.

Sansibarküste; 2 Stück; J. M. Hildebrandt S.; Mus.-No. I797.

Sansibarküste; I Stück; J. M. Hildebrandt S.; Mus.-No. I788.

Lewa in Usambara; I Individ.; Stuhlmann S.; 28. Sept. I889; Pfeffer in Stuhlmann I892, S. I 5 als Phylothamnus punctatus Ptrs.

Usambara, wahrscheinlich Tanga; I Individ.; Neumann S.; Mus.No. II 166 . 
Usambara, wahrscheinlich Tanga; I Individ.; Neumann S.; hat drei Postocularia und ist ohne Flecken auf dem Rücken.

Usambara, wahrscheinlich Tanga; I Kopf; Neumann S.; das vierte, fünfte und sechste Labiale stossen an's Auge; 2 Postocularia.

Aruscha am Kilima-Ndjaro; I Individ.; G. A. Fischer S.; J. G. Fischer, Hamburg. Mittheil. I884, S. II6 als Philoth. spec. affinis irregularis.

Kilima-Ndjaro; 2 Individ.; F. J. Jackson S.; Boul., Cat. of Snakes, Bd. II, S. IOO.

Dar es Salaam; 2 Individ.; Stuhlmann S.; 8. Nov. I894.

Dunda am Kingani; I Individ.; Stuhlmann S.; 1894.

Ostafrika; I q; J. Kirk S.; Boul., Cat. of Snakes, Bd. II, S. Ioo.

Ostafrika; I + ; Capt. Speke S.; Boul., Cat. of Snakes, Bd. II, S. Ioo.

Das Individuum aus Dunda am Kingani hat beiderseits nur das fünfte und sechste Labiale am Auge, würde also var. Kirki (Gthr.) sein.

\section{Philothamnus dorsalis (Boc.)}

Lubwa's Ussoga; I Individ, Neumann S.; Sept. I894.

Ventralia 182, Caudalia IO2. Das Praeoculare der einen Seite stösst an das Frontale, das der anderen nicht. Einfach olivenbraun, an den Seiten etwas mit grün. Bauchunterseite gelblich, Schwanz schwärzlich.

\section{Philothamnus thomensis (Boc.)}

Jambiani; I Individ.; Stuhlmann S.; Pfeffer-Stuhlmann I892, S. I6.

»Die lebhaft grünen Baumschlangen, schreibt Böhm, sind häufig auf Büschen und Bäumen dicht bei den Ortschaften und kommen oft in die Häuser. Eine hatte einen Hemidactylus im Magen.»

\section{Coronella semiornata (Ptrs.)}

Küste von Sansibar; 2 Individ.; J. Kirk S.; Boul., Cat. of Snakes, Bd. II, S. I 96.

Aruscha am Kilima-Ndjaro; I Individ.; G. A. Fischer S.; J. G. Fischer, Hamburg. Jahrbuch I 884 , S. 6.

Umbugwe; I Individ.; Neumann S.; I 893.

Nyassa-See; I Individ.; ohne Sammler; Boul., Cat. of Snakes, Bd. II, S. 359.

\section{Prosymna ambigua Boc.}

Sansibar; IO Individ.; J. Kirk S.; Boul., Cat. of Snakes, Bd. II, S. 248.

Usambara; 2 Individ.; Stuhlmann S.; I888; Pfeffer in Stuhlmann I892, S. I 6 , als Liganorostra Stuhlmanni Pf.

\section{Scaphiophis albopunctata (Ptrs.)}

Tabora; I Individ.; Dr. Böhm S.; Mus.-No. IO 377.

Ugogo; I Individ.; E. J. Baxter S.; Günther, Ann. Mag. I 895, S. 526.

Utundu S.-W. Nyansa; I Individ.; Stuhlmann S.

Das dritte Individuum hat drei Praefrontalia und vier Occipitalplatten, zwischen welchen ein Interoccipitalschild liegt, so dass der Hinterkopf dieser Schlange eine eidechsenartige Bildung zeigt. Die beiden anderen, mir vorliegenden Vertreter dieser Art zeigen ähnliche Beschilderung des Hinterkopfes, beweisen aber zugleich, dass die hinteren Occipitalplatten bei dieser Art erst 
durch Zusammenwachsen von kleinen Schuppen entstehen, der Prozess ist individuell bald mehr bald weniger weit vorgeschritten. (Siehe die Figur von Peters Monatsb. Acad. Berlin I870, S. 652.)

Das dritte Individuum hat ferner an der rechten Kopfseite 2 kleine übereinanderliegende Zügelschilder, an der linken Kopfseite des Thieres ist nur noch eins selbstständig, das andere mit dem Postnasale verwachsen, welches in Folge dessen an das obere Praeoculare stösst.

Das Individuum hat ferner rechts drei Postocularia, drei Subocularia und ein Praeoculare, links sind die beiden oberen Postocularia bis auf eine geringe Einkerbung am Auge miteinander verwachsen, in der Richtung der ursprünglichen Naht ist ausserdem noch das Schild mit einer Grube versehen, Zeichen, dass hier zwei Schilder miteinander verwachsen sind.

Bei diesem Individuum sind ferner die beiden Schuppen der zweiten, dritten und vierten Schwanzschuppenpaare miteinander verwachsen.

Die Färbung dieselbe, wie die der uibrigen Thiere.

V. $215 ;$ C. 75 .

Das Individuum aus Keta, nach welchem Peters die Art beschrieb, hat jederseits 2 Loreale, 2 Postoculare und 3 Subocularia.

Das Individuum aus Tabora hat rechts 4 Postocularia und 3 . Subocularia, von denen aber das erste in zwei iibereinanderliegende Schilder gespalten ist, links 3 Postocularia und 3 Subocularia, von denen das mittlere in zwei übereinanderliegende Schilder getrennt ist, und an beiden Kopfseiten zwei Zügelschilder.

Die Art ist also in der Kopfbeschilderung recht variabel.

\section{Homalosoma lutrix (L.)}

Marangu im Kilima-Ndjaro; 6 Individ.; Volkens S.

Marangu im Kilima-N djaro(Mambaberge I 500 m); 2 Individ.; Kretschmer S.; 8. Sept. I 894 .

Bukoba; I Individ.; Stuhlmann S.

Bukoba; I Individ.; Neumann S.; Juli I 894.

Volkens begleitet seine Sendung mit folgenden Worten: »Im Kulturlande, zwischen 1200 - I $700 \mathrm{~m}$ beobachtet; das schwarze Individuum, welches ich fing, richtete beim Ergreifen sämmtliche Schuppen empor, so dass es dadurch ein ganz borstiges Ansehen erhielt.

Zur Untersuchung und Vergleichung lagen mir von der Gattung Homalosoma vor: 5 Individuen (No. I-5 der später folgenden Individual-Beschreibung), welche von meinen Amtsvorgängern (Lichtenstein u. Peters) als Homalosoma lutrix bestimmt worden sind, sie stammen sämmtlich vom Kap; die oben erwähnten Io Individuen, darunter 6 aus Marangu von einem Sammler (Volkens) stammend, 2 aus Marangu von einem andern Sammler (Kretschmer), ferner 2 Individuen aus Bukoba, eins ist von Stuhlmann, das andere von Neumann dem Museum überwiesen.

Bei Berücksichtigung der Bestimmungstabelle der Homalosoma-Arten, welche Boulenger im Catalog of Snakes gegeben hat, könnte ich mit Leichtigkeit aus vorliegendem Vergleichsmaterial drei neue Homalosoma-Arten beschreiben mit folgenden Charakteren:

Ventralia II 5 -I I 4 .

A. Nasale nicht in Berührung mit Praenasale; 2 Postocularia, Frontale länger wie das Parietale.

Eine neue Art.

Diese Art nahe verwandt H. lutrix. Aus Kapland und Marangu; zusammen mit Homalosoma lutrix gefunden. 
B. Nasale nicht in Kontakt mit Praeoculare (bei einem Thier nur einseitig so); ein Postoculare; Frontale gleich dem Parietale.

Zwei neue Arten.

Bei der ersten die Sutur zwischen den Internasalien länger als die Praefrontal-Sutur: Thier aus Bukoba. Zweite Art: Die Internasal-Sutur kiirzer als die Praefrontal-Sutur: Thier aus Bukoba. - Wenn ich diese Arten nicht beschreibe, so geschieht es deshalb, weil das mir vorliegende Material zu dem Schluss berechtigt, dass es überhaupt nur eine einzige Homalosoma-Art mit I 15-I44 Bauchschildern geben dürfte und dass diese Art dann Homalosoma lutrix genannt werden muss. Die Grüinde dafür sind folgende:

Unter den Individuen, welche ich untersuchen konnte, entsprechen eine Anzahl genau jenen Anforderungen, welche Boulenger an die Art Homalosoma lutrix stellt, denn sie haben zwischen II 5-I44 Bauchschilder, ihr Nasale berüht nicht das Praenasale, sie haben zwei Postocularschilder und ein Frontale, welches so lang ist wie die Occipitalia. (I. Individuum vom Cap; I Individuum und zwar das grösste aus Marangu). Ich fand dann weiter Individuen, welche von den eben erwähnten, nur in einem Charakter abweichen, und zwar dadurch, dass bei ihnen die Parietalia ein wenig oder beträchtlich länger sind als das zugehörige Frontale, unter ihnen sind eine Anzahl jener Individuen, welche Peters und Lichtenstein als Homalosoma lutrix bestimmt haben. (Individuen vom Cap und 6 von Marangu.) Können wir wegen dieses Divergenzcharakters die betreffenden Individuen, die sich sonst durchaus nicht von den übrigen unterscheiden, zu einer neuen Art erheben? Ich glaube nicht.

Nur indirekt spricht gegen ihre artliche Verschiedenheit erstens das gemeinsame Vorkommen beider Formen. Nur indirekt spricht es dagegen, denn man kann mit Recht behaupten, es können zwei nahe verwandte Formen in demselben Gebiet vorkommen. - Wichtiger schon ist Folgendes: Auch bei jenen Individuen, bei welchen die Occipitalia länger sind als das Frontale, ist die Längendifferenz der beiden Schilder nicht immer gleich gross. Es giebt, wie die Tabelle weiter unten lehrt, Individuen, bei welchen die Schilder fast gleich lang sind und solche, bei welchen ihre Differenz zu Gunsten der Occipitalia eine beträchtliche ist. Mit anderen Worten, schon unter den wenigen mir vorliegenden Individuen, deren Occipitalschilder länger sind, als das zugehörige Frontale, giebt es Uebergänge zu Homalosoma lutrix. Man erkennt aber ausserdem bald, dass alle diejenigen Individuen, bei welchen die Parietalia viel länger sind als das zugehörige Frontale, körperlich weniger entwickelt, d. h. kürzer und viel dünner sind, als die Individuen, welche von mir als typische Vertreter der Homalosoma lutrix bezeichnet wurden; während die Individuen, welche in der Schilderdifferenz fast mit Homalosoma lutrix übereinstimmen auch in der Körpergrösse ihr nahe kommen: Hieraus schliesse ich bis auf weiteres, dass alle diese Individuen nicht artlich $\mathrm{zu}$ trennen sind, weil bei Jungen von Homalosoma lutrix das Frontale kürzer ist als bei Alten. Dies wird um so wahrscheinlicher, wenn man bedenkt, dass bei allen Wirbelthieren, so auch bei allen Reptilien, das Gehirn (und naturlicherweise deshalb auch seine Hülle) in der ontogenetischen Entwicklung den anderen Körpertheilen weit vorauseilt. Wer diese allbekannte Thatsache nicht glaubt, sehe sich die Tafeln in Rathke's Entwicklung der Natter an, oder messe Schnauze und Hinterkopflänge eines Krokodil- oder Eidechsenembryo und vergleiche die Maasse mit den entsprechenden erwachsener Thiere, immer wird er finden: Nach der Geburt eines Thieres wächst stets dessen Gesicht stärker wie dessen Hinterkopf und dadurch verschieben sich seine Kopfmaasse mehr und mehr zu Gunsten des Gesichts.

Die bisher noch nicht besprochenen, aus Bukoba uns gesandten Vertreter der vorliegenden Gattung sind deshalb sehr eigenartig, weil sie beide zu den 
B-Individuen des Catalog of Snakes gehören würden, wenn sie von dieser Gruppe nicht dadurch unterschieden wären, dass bei ihnen das Frontale gleich dem Parietale ist. Da aber ausserdem bei einem von diesen Individuen an einer Kopfseite das Nasale von dem Praeoculare durch ein Zügelschild getrennt ist, während an seiner anderen Kopfseite das Nasale direkt an das Pracoculare stösst, weil hier das Zügelschild mit dem Praenasale verwachsen ist, deshalb werden durch dieses Individuum die beiden Gruppen des Katalogs thatsächlich aufgehoben, denn ihre Unterschiede sind nur Folgende:

Bei der A-Gruppe (Homalosoma lutrix) ist das Nasale nicht in Kontakt mit dem Praeoculare; gewöhnlich sind zwei Postocularia vorhanden und das Frontale ist so lang wie das Parietale (Homalosoma lutrix). Die Charaktere der B-Gruppe sind: das Nasale ist hier in Kontakt mit dem Praeoculare; das Frontale ist kiirzer als die Parietalia, und nur ein Postoculare ist vorhanden.

Da nun bereits durch Boulenger nicht nur bei Individuen der B-Gruppe sondern auch der A-Gruppe ein Postoculare nachgewiesen ist und da nunmehr durch mich ein Individuum bekannt wird, welches in Rücksicht auf das Nasale mit einer Kopfseite zur A-Gruppe, mit der zweiten zur B-Gruppe gehört und weil drittens die Längendifferenz des Frontale zum Parietale in beiden Gruppen mit dem Alter der Thiere Veränderungen erleidet, so fallen beide Gruppen zusammen.

$\mathrm{Ob}$ sich trotzdem die beiden, der B-Gruppe des Katalogs untergeordneten Homalosoma-Arten (H. shiranum und abyssinicum), welche Boulenger nach Thieren beschrieben hat, die vorher von Günther und Blanford als Homalosoma lutrix bestimmt waren, werden aufrechthalten lassen, bezweifle ich. Die beiden Charaktere, welche die Arten trennen, besagen im Grunde nur, dass das eine Individuum einen etwas längeren und schmaleren Kopf als das andere besitzt, was auch aus Taf. XIII, Fig. I und 2 des Katalogs zu erkennen ist. Aehnliches Variiren der Kopfform finde ich aber auch bei solchen von mir untersuchten Individuen, die sonst durch nichts voneinander unterschieden sind. Ob diese Kopfformen aber aus individueller Variation der Individuen, oder aus ihrer Ontogenese oder aus artlicher Verschiedenheit zu erklären sind, wage ich aus Mangel an Material noch nicht zu entscheiden.

\section{Charaktere der einzelnen Individuen:}

No. I. Mus.-No. I 568, als Homalosoma lutrix vom Cap: Frontale $=$ Occipitale (4 mm); ein Zügelschild beiderseits; I Praeoculare, 2 Postocularia. V. I 36, C. 26. Das dritte und vierte Paar der Caudalschilder bilden durch Verwachsung zwei grosse Schwanzschilder. Frontale breit $2,5 \mathrm{~mm}$. Sutur zwischen den Internasalen kürzer wie die der Praefrontalen. Färbung gelber Bauchstreif; dunkelbraune, schwarzgesprenkelte Seitenstreifen; Rücken heller, in der Mittellinie weit auseinander stehende schwarze Punkte.

No. 2. Mus.-No. 1568. Cap. d. g. Hoffnung: Jünger als das vorige Thier. Die Parietalia viel länger wie das Frontale (P. $5 ; \mathrm{Fr} .3,9)$. Im Frontale vorn eine Naht. Dasselbe ist vorn breit $3 \mathrm{~mm}$ und verjünt sich nach hinten. Die Internasalsutur kleiner wie die Praefrontalsutur. Kopf des Thieres vorn abgerundet, aber die Schnauzenspitze breiter wie beim vorigen Thier. Beiderseits ein Loreale. V. 128, C. 39. Färbung ganz wie das vorige Individuum, aber gelbe Bauchlinie durch eine schwarze Punktlinie eingefasst, die Seitenbänder etwas mehr schwarz gesprenkelt wie beim vorigen Thier.

No. 3. Mus.-No. I 569: Frontale und Occipitale gleich $(4 \mathrm{~mm})$, Frontale breit 2,9, gleichmässig breit; Zügelschild jederseits. Die Internasalnaht kleiner wie die Praefrontalnaht; Kopf klein und schmal, etwas zugespitzt nach vorn. V. 128, C. 27; Färbung genau die der vorigen Thiere. Mittelgrosses Thier. 
No. 4. Mus.-No. I570; vom Cap.: Frontale kürzer als Parietale (Fr. 3,3; O. 3.9); Frontale vorn breit $2 \mathrm{~mm}$, gleich breit; Zügelschild jederseits. Kopf klein und schmal, nach vorn zugespitzt. V. I 33, C. 3I. Färbung wie vorige Form, nur Seitenstreifen mehr aufgehellt hell-graubraun, Rücken rein braun, auf der Rückenlinie schwarze Punktreihe. Thier erwachsen, aber von mässiger Dicke.

Nr. 5. Mus.-No. I 566: Occipitale etwas länger wie Frontale $(O, 4,2 \mathrm{~mm}$; Fr. 4.); Frontale vorn breit 2,5, nach hinten etwas verschmälert. Zügelschild jederseits; Internasalnaht gleich der Praefrontalnaht. Schnauze des Thieres wenig verschmälert. V. 134, C. 34. Weisse Bauchlinie; Rücken und Seiten des Thieres tief schwarzbraun, doch beginnt die Seite des Thieres sich aufzuhellen, indem auf den Schuppen zahlreiche, winzig kleine weiss-graue Punkte entstehen, die dann zusammenfliessen und amöbenartige Formen bilden. Die dunkle Rückenfärbung des Thieres entsteht wesentlich durch die dunkeln Epidermisschuppen, an Stellen, wo diese Schuppen fehlen, zeigt sich der Rücken des Thieres heller gefarbt wie die Seiten; das Thier stimmt also in der Cutisfärbung mit den anderen Thieren überein.

No. 6. Marangu: Aeltestes Thier, $37 \mathrm{~mm}$ lang. Frontale gleich dem Occipitale $(4,5 \mathrm{~mm})$, Frontale vorn breit $3 \mathrm{~mm}$, nach hinten etwas verschmälert. Ein Loreale jederseits. Jederseits ein selbstständiges Postnasale, das bei allen anderen Thieren mit dem Nasale verwachsen ist. Jederseits nur ein Postoculare. Die Sutur zwischen den Internasalen gleich der Praefrontalsutur, Schnauze wenig verschmälert. V. I 35, C. 25. Bauchschilder: Grundfarbe schwarz mit vielen weissen Spritzflecken, dieselben unter dem Kinn und nach hinten mehr und mehr zunehmend, so dicht stehend und miteinander verwachsen, dass hier das Weisse vorwiegt; ausserdem wird in der Mitte der Bauchschuppen durch derartige, theilweise verschmelzende Flecke eine deutliche Längslinie gebildet. Rücken und Seiten des Thieres kastanienbraun; Seiten mit mehr schwarz; auf dem Rücken eine schwarze Mittellinie, welche die Tendenz zeigt sich in Flecken aufzulösen.

No. 7. Junges Thier, $25,3 \mathrm{~mm}$ lang: Occipitale länger als Frontale (O. 4,2; Fr. 3,2); Frontale vorn breit 2,2 , nach hinten nicht verschmälert; Internasalnaht länger wie Praefrontalnaht. Loreale jederseits. 2 Postocularia. Schnauze kurz, nicht verschmälert, wenig abgerundet. V. 127, C. 35. Färbung ähnlich der vorigen, Bauch aber mit viel mehr weiss; Rückenseiten gegen den kastanienbraunen Rücken mehr abgesetzt, sie sind graubraun. In der Rückenmitte eine ununterbrochene schwarze Rückenlinie.

No. 8. Junges Thier; lang $25,2 \mathrm{~mm}$ : Occipitale länger wie das Frontale (P. 4,$2 ;$ Fr. 3); Frontale vorn breit $2 \mathrm{~mm}$, nach hinten nicht verschmälert. Naht zwischen den Internasalen so lang wie die zwischen den Praefrontalen. Beiderseits ein Zügelschild und nur ein Postoculare. V. I3I, C. 3I-32. Das Thier nähert sich in der Färbung den Thieren des Caplandes, hat hellbraunen Rücken mit schwarzem Mittelstreif, und mehr dunkle Seiten. Unter dem Bauch ist eine weisse Linie fast ganz ausgebildet, sie zeigt aber noch deutlich ihr Entstehen aus weissen Stippchen; die am Rande mit schwarzer Hauptfarbe versehenen Bauchschuppen zeigen darin sehr viel weisse Pünktchen, die zuweilen deutlich in Querreihen gestellt sind.

No. 9. Marangu: Junges Thier, Länge $175 \mathrm{~mm}$; Occipitale etwas länger wie Frontale $(\mathrm{O} .3,5 \mathrm{~mm}$; Fr. $3 \mathrm{~mm})$; Frontale vorn breit 2, I, nach hinten ziemlich stark verschmälert. Die Praefrontalsutur dürfte etwas länger sein wie die Praenasalsutur. Schnauze kurz, wenig verschmälert. Links ein Zügelschild und zwei l'ostocularia: rechts zwei ubereinander liegende Zügelschilder, das untere ist winzig klein, und durch seine Verkuirzung ist das Nasale in den Stand gesetzt, sich mit einem Fortsatze fast bis ans Praeoculare vorzuschieben. Diese Kopfseite hat nur ein Postoculare. Rücken und Seiten tief dunkelbraun, so dass die vollständig 
ausgebildete schwarze Rückenlinie nur wenig vortritt. Bauch in der Hauptfarbe blaugrau (also im ganzen verblasst); weisse Punktlinie in der Mitte; viel weisse Punkte, die oft in der Mittellinie der Schuppen querbindenartig zusammenfliessen, unter dem Kinn und an der Brust. V. 125, C. 36.

No. IO. Marangu. Junges Thier, Länge 2,83: Occipitale länger wie das Frontale $(\mathrm{O} .4,5$; Fr. 3,5). Occipitale der einen Seite um I $\mathrm{mm}$ kürzer als das der andern, weil sich von ihm ein Stückchen als selbstständige Schuppe losgelöst hat. Frontale breit 2,5, nach hinten ein wenig verschmälert. Internasalnaht gleich der Praefrontalnaht. Loreale beiderseits. Schnauze kurz, nicht verschmälert. Jederseits nur ein Postoculare. Das ganze Thier ist tiefschwarz, aber am Kinn und an der Brust desselben sind einige jener amöbenartigen weissen Flecke ausgebildet, welche bei anderen Thieren in viel grösserer Zahl vorhanden sind. Achnlich gestaltete, aber bräunliche Flecke zeigen sich auf dem Kopf des Thieres verstreut; in diesen bräunlichen Flecken haben wir den ersten Anfang der Rückenbraunfärbung zu erkennen. V. I2I; C. 35. Anale zweitheilig.

No. I I. Marangu. Fast erwachsenes Thier, lang $265 \mathrm{~mm}$ : Occipitale nicht länger als das Frontale $(4 \mathrm{~mm})$. Frontale vorn breit 2,9. Internasalnaht ein Minimum länger als die Praefrontalnaht. Beiderseits ein Zügelschild. Schnauze kurz, etwas zugespitzt. Links ein Postoculare, rechts zwei. Beiderseits 7 Labialia; an der linken Kopfseite stösst das dritte und vierte, wie bei allen anderen Thieren an das Auge, indem sich das dritte zwischen das vierte und das Praeoculare schiebt. An der rechten Kopfseite des Thieres ist das dritte Labiale so klein, und das vierte auf seine Kosten so vergrössert, dass hier nur das vierte Labiale das Auge berührt, während es gleichzeitig ans Praeoculare stösst. V. I28, C. 33 . Anale einfach. Rücken und Seiten des Thieres sind gleichmässig dunkelbraun gefärbt mit so tiefer Farbe, wie sonst nur die Rückenlinie der Thiere sie aufweist; sein Bauch ist einfarbig blaugrau und zwar sind die Bauchschilder in ihrer ganzen Ausdehnung so gefärbt, doch liegen an den Unterkieferrändern auch bei diesem Thier einige der charakteristischen verästelten weissen Flecke.

No. I2. Marangu. (Kretschmer, Sammler; stark eingetrocknetes Thier.) Länge $285 \mathrm{~mm}$ : Occipitale länger als Frontale (O. 5, Fr. 4); Breite des Frontale vorn 2,5, nach hinten kaum verschmälert. Internasalnaht gleich der Praefrontalnaht. Schnauze nicht zugespitzt. Jederseits ein Zügelschild. Links I, rechts 2 Postocularia. 6 Supralabialia. V. I 23, C. 38. Anale einfach. Färbung: brauner Rucken mit dunkler Mittellinie, Seiten dunkler; Bauch, Grundfarbe schwarz, darin viel weisse Flecke, die nicht zu einer Mittellinie zusammenzutreten streben, sondern in der Mittellinie der Schuppen Querreihen bilden oder zu Querlinien vereinigt sind.

No. I3. Marangu. (Kretschmer, Sammler; Kopf zerschlagen.) Länge 295 mm: Occipitale nur wenig länger als Frontale $(\mathrm{O} .4,5 ; \mathrm{Fr} .4)$. Frontale breit $3 \mathrm{~mm}$. Internasalnaht gleich der Praefrontalnaht oder ein Minimum grösser. Beiderseits ein Zügelschild. Beiderseits 2 Postocularia. 6 Supralabialia. V. I26, C. 33 (?). Anale einfach. Färbung wie die des vorangehenden Thieres.

No. I4. Bukoba. (Neumann, Sammler; erwachsenes Thier.) Lange 3,30: Parietale so lang wie Frontale $(\mathrm{P} .=\mathrm{Fr} .=4 \mathrm{~mm})$; Frontale vorn breit 2,8 , nach hinten ein wenig verschmälert. Die Internasalnaht viel länger wie die kaum noch vorhandene Praefrontalnaht. Schnauze ziemlich stark zugespitzt. Rechts ein Zuigelschild, links stösst das Nasale ans Praeoculare. 6 Labialia. Jederseits ein Postoculare. V. I4I, C. 26. Anale ganz. Graubraun: Rücken und Seiten; mit dunkler Rückenlinie, die an vielen Stellen von der Seite angefressen oder bereits durchbrochen ist. Auf den meisten Schuppen mehrere schwarze Punkte, besonders viel an den Seiten. Bauch: Grundfärbung schwarz mit zahllosen weissen Pünktchen, unter ihnen herrscht die Neigung zur Querreihenbildung, am Halse auch die Tendenz zur Ausbildung einer Mittellinie. 
No. I 5. Bukoba. (Stuhlmann, Sammler; erwachsenes Thier.) Länge $3,55 \mathrm{~mm}$ : Occipitale und Frontale gleich (beide $4 \mathrm{~mm}$ ), Frontalbreite vorn 2,6; Internasalnaht gleich der Praefrontalnaht. Beiderseits stösst das Nasale an das Praeoculare. Rechts drei Praeocularia, links eins. Schnauze etwas zugespitzt. Sechs Labialia beiderseits. V. I43; C. 3I. Anale einfach. Färbung wie das vorige Thier, nur Rücken wesentlich heller braun.

\section{Rückblick auf die Färbung der Individuen:}

Die vorliegenden Individuen scheinen nach der Beschreibung in der Färbung unendlich variabel und grundverschieden zu sein und doch ist es nicht der Fall. Die meisten von ihnen bilden nur Glieder dreier divergirender Individuenreihen, in welche - der Färbung nach - die Gattung Homalosoma zerfällt.

Alle drei Reihen beginnen, das ist zweifellos, von einem Punkt, d. h. mit Individuen, welche an Kopf und Bauch einfarbig und gleichmässig schwarz gefärbt sind (Taf. V).

Erste Reihe:

Die erste Individuenreihe entwickelt sich nun von hier aus in folgender Weise: Es treten bei den Anfangsgliedern der Reihe zuerst nur am Kopf und an der Brust zahlreiche amöbenartige verästelte Flecken auf. Die, am Kinn und Bauch der Thiere liegenden (Fig. 5) sind weiss gefärbt, die ihrer Oberkopfseite angehörigen braun bis bräunlich gelb (Fig. 10). (Die gelbliche Färbung der Oberkopflecke rührt iibrigens nur davon her, dass die Epidermisschuppen des Rückens der Thiere mehr geib gefärbt sind, als die ihres Bauches; Bauch und Rückenflecke sind deshalb auch in ihren Cutispartien gleichmässig weissgrau oder reinweiss.) Die Entwicklung der Individuenreihe schreitet dann in der Art fort, dass die regellose Fleckenbildung auf dem Rücken und Bauch des Thieres bis zur Schwanzspitze fortschreitet, wobei die bereits vorhandenen Flecke auf Kosten der in der Urfärbung bleibenden Körperpartien wachsen können, bis sie sekundär ineinander fliessen. Ist diese Entwicklung vollendet, so sind Thiere entstanden, wie sie das Typ-Exemplar der Peters'schen Homalosoma variegatum, der einzige Vertreter dieser Art in unserem Museum, bietet (Fig. 8 und I3). Hier liegen auf dem Riicken des Thieres die gelblichen Flecke so dicht aneinander, dass die schwarze Restfärbung des Thieres nur noch ein weitmaschiges Netzwerk bildet, in welchem, weil die Fleckenbildung regellos war, zahlreiche schwarze Flecke zerstreut sind

Am Bauch dieser Art ist die Fleckenbildung noch weiter fortgeschritten und eine so grosse gewesen, dass hier das, auf dem Rücken noch vorhandene Netzwerk der Primärfärbung so völlig zerrissen erscheint, dass von ihr nur noch zahlreiche, vielfach verästelte, schwarze Restflecke, Restpinktchen und -strichel auf hellgrauem Grund zu erblicken sind.

\section{Zweite Reihe:}

Bei der Umfärbung der Thiere nach dem zweiten Modus beginntdie Fleckenbildung wie in der ersten Individuenreihe (Fig. 5 und ro), dann aber werden von der Fleckenbildung sehr bald besondere Körperpartien besonders begiinstigt. Derartige Körperpartien sind die Bauchmittellinie und an beiden Rückenseiten des Thieres ein Streifen, der unmittelbar über dem Auge entspringt und von dort parallel der Körperlängsachse zur Schwanzwurzel zieht. Deshalb häufen sich bei diesen Thieren in der Bauchmittellinie die weissen Flecke bald derartig an, dass sie eine ununterbrochene Linie bilden (Fig. 6), später verschmelzen sie dann vollständig zu einem weissen Längsstreifen, der von der Schnauze des Thieres bis zu seiner Schwanzspitze zieht (Fig. 7). Dieser Streifen nimmt, wie selbstverständlich ist, die Mittellinie der Bauchschuppen ein, hat aber nicht ihre 
Breitenausdehnung, sondern lässt stets ihre Randzonen frei. Ebenso werden bei diesen Thieren die beiden, von der Fleckenbildung begünstigten Rückenstreifen durch die Fleckbildung bald so stark aufgehellt, dass sie zum Schluss einfarbig braun, ja, fuchsroth gefärbt sind. Der bei den Thieren zwischen beiden Rückenstreifen liegende Rückenkamm behält im Beginn der Individualentwicklung seine Primärfärbung bei, so dass die Thiere in diesem Entwicklungsstadium einen hellen Rücken mit ununterbrochener schwarzer Mittellinie aufweisen (Fig. I I), bald aber dringt die Aufhellung, von den beiden aufgehellten Rückenstreifen aus, in diese schwarze Linie ein, zerfrisst sie zu grösseren Strichen (Fig. I 2), die später in Punkte zerfallen und ganz verschwinden, dann ist der Rücken der Thiere einfarbig braun oder bräunlichroth. - Die Seiten der zu dieser Entwicklungsreihe gehörigen Individuen zeigen stets nur wenig Fleckenbildung, sie werden daher auch stets nur wenig aufgehellt und erscheinen im Maximum ihrer Fleckenausbildung fein grau-schwarz marmorirt.

\section{Dritte Reihe:}

Die Umfärbung der Individuen nach dem dritten Modus geschieht so, dass ihr Riicken und Bauch einfarbig bleiben, d. h. ohne direkte Fleckenbildung in ihrer ganzen Ausdehnung verblassen (Fig. 9 und 14). Während bei den, aus dieser Reihe mir vorliegenden Individuen der Rücken dabei nur wenig heller wird, verblasst der Bauch in seiner ganzen Ausdehnung zu hellem blau-grau. Höchst wichtig ist nun, dass eins dieser Thiere ausserdem noch am Kinn eine grössere Anzahl weisser amöbenartiger Flecke besitzt (Fig. 9), ein Beweis dafür, dass bei diesem Individuum die Entwicklung der Zeichnung als Fleckenbildung fortzugehen strebt.

\section{Grayia smythi (Leach)}

Uganda; I Individ.; G. F. Scott Elliot S.; Günth., Ann. Mag. I 895, S. 526.

\section{Oligolepis macrops, Blgr.}

Usambara; I Junges; Linnaea Berlin S.; Boulenger, Ann. Mag. nat. hist. I895, S. I7I, mit Artbeschreibung.

\section{Dasypeltis scabra $\mathbf{L}$.}

Sansibar; 3 Individ.; Sir. J. Kirk S.; Boul., Cat. of Snakes, Bd. II, S. 356.

Sansibar; I Individ.; S. E. Revoil S.; Mocquard Mem. archiv. philomat. I888, S. III.

Sansibarküste; I Individ.; Hildebrandt S.; Mus.-No. 8597.

Sansibarküste; I Individ.; Hildebrandt S.; Mus.-No. I790.

Sansibarküste; I Individ.; Salmin S.; Mus.-No. 5737; Peters in den Monatsber. Berlin. Acad. I868, S. $45 \mathrm{I}$, als fasciolatus beschrieben.

Usambara; I Individ.; Reimer S.

Usambara; I Junges; Linnaea Berlin S.; Verhandl. der K. K. zool.bot. Gesellsch. Wien, I895, S. 4; als var. B.

Massai od. Kavirondo; I Individ.; Neumann S.

Kilima-Ndjaro; 2 Individ.; F. J. Jackson S.; Boul., Cat. of Snakes, Bd. II, S. 356 .

Dar es Salaam; I Individ.; Stuhlmann S.

Kingani am Dunda; I Individ.; Stuhlmann S.; Jan. I894; var. B.

Mpapwa; I Individ.; Stuhlmann S.; mit schwarzen Flecken. 


\section{Subfamilie: Opisthoglypha.}

\section{Psammophylax notataenia (Gthr.)}

Synonymie: Bocage, Herpétologie d'Angola et du Congo. I895. S. Io9.

Aruscha am Kilima-Ndjaro; I Individ.; G. A. Fischer S.; J. G. Fischer in Jahrb. Hamb. wiss. Anst. 1884, S. 7; als Ablabes hildebrandti.

\section{Amblyodipsas unicolor (Rhdt.)}

Bagamoyo; I Individ.; Stuhlmann S.; Febr. I890; Pfeffer in Stuhlmann. X. (1890), S. 9 .

\section{Aparallactus jacksoni (Gthr.)}

Boul., Ann. Mag. I 896. S. I 70.

\section{Aparallactus werneri, Blgr.}

Usambara; 2 Individ.; Linnaea Berlin S.; Boul., Ann. Mag. I896, S. I72. Usambara; 2 Individ.; Conradt S.

Usambara; 6 Individ.; Reimer S.; I894.

Unter den mir vorliegenden 8 Individuen variirten 3 von der Originalbeschreibung, die übrigen 5 stimmen genau damit überein. Die eine Varietät hat an der linken Kopfseite ein durch eine Quernaht vollständig in zwei Schilder getrenntes Nasale, die andere Kopfseite hat ein einfaches Nasale. Beim zweiten Exemplar ist an der linken Kopfseite I Postnasale, links sind zwei. Beim dritten Exemplar haben beide Kopfseiten nur ein Postoculare.

\section{A parallactus concolor (Fisch.)}

Aruscha am Kilima-Ndjaro; G. A. Fischer S.; J. G'. Fischer, Afrik. Rept. Hamb. gelehrt. Anst. I884, S. 4; als Urieihis concolor n. sp.

\section{Aparallactus nigriceps (Ptrs.)}

Tanga in Usambara; I Individ.; Neumann S.; I892.

Marangu; I Individ,; Böhm S.; Mus.-No. I0735.

Während das Individuum aus Marangu mit dem von Peters aus Tette beschriebenen Originalexemplar in der Färbung genau übereinstimmt, ist das Individuum aus Usambara einfarbig schiefergrau sowohl am Kopf wie Bauch. Ventralia dieses Thieres I48, Caudalia 49.

\section{Aparallactus capensis, A. Sm.}

Tanga in Usambara; I Individ.; Oscar Neumann S.

Ventralia 155; Caudalia 26. Das Thier ist einfarbig schwarz auf dem Rücken; ebenfalls einfarbig, aber ein wenig heller am Bauch; die Zwischenräume zwischen den Schuppen sind weiss.

\section{Rhagerhis oxyrhynchus Rhdt.}

Sansibarküste; 2 Individ, von der Decken S.; Peters, Mossambique S. 126 als Rhamphiophis rostratus beschrieben. 
Tanga; I Individ.; Neumann S.

Massai-Nyika; I Individ.; Oscar Neumann S.; Juni I 893.

Massai-Nyika; I Individ,; Oscar Neumann S.; Juni 1893.

Kingani am Dunda; I Individ.; Stuhlmann S.

Dar es Salaam; 2 Individ.; Krüger S.

Irambe (südl. Wembere-Rand); I Kopf; Stuhlmann S.; 8. Juli I 892.

Die Individuen sind in der Beschuppung sehr variabel; ich beschreibe daher zuerst die Individuen und werde dann versuchen, ihre Stellung zu einander zu skizziren.

No. I. Massai-Nyika. Rechte Kopfseite: 3 Praeocularia; 2 Postocularia; ein Suboculare, welches dadurch, dass es ans zweite Praeoculare stösst, alle Labialia vom Auge trennt. Linke Kopfseite: 3 Praeocularia; I Suboculare, 2 Postocularia, das vierte Sublabiale stösst zwischen dem untersten Prae- und Suboculare an das Auge, hat also die Schilder auseinander geschoben, das fünfte Labiale ist auch an dieser Kopfseite vom Auge durch das Suboculare getrennt.

No. 2. Massai-Nyika. 3 Praeocularia, das unterste winzig klein, trennt aber auch hier das vierte Labiale vom Auge. Kein Suboculare zwischen dem fünften Labiale und dem Auge, sondern das fünfte Labiale stösst in derselben Ausdehnung an das Auge wie früher das Sublabiale; Beweis, dass hier das ursprünglich kleine Labiale mit dem ursprünglichen Suboculare verwachsen ist. Beiderseits zwei Postocularia.

No. 3. Tanga, Neumann. Rechts: 4 Praeocularia, trotzdem stösst das vierte Labiale an das Auge. Ebenso das fünfte in grosser Ausdehnung, wobei es das sechste durch einen schmalen Fortsatz vom Auge trennt. 2 Postocularia. Linke Kopfseite nur drei Praeocularia, die beiden mittleren der anderen Kopfseite sind miteinander verwachsen; das dritte Praeoculare der vorigen Thiere entspricht also dem vierten dieses Thieres. Auch hier stossen das vierte und füfte Labiale an das Auge und sind zwei Postocularia vorhanden. Anale doppelt.

No. 4. Tette, Peters, Originalexempl. des Rh. rostr.: Beiderseits 3 Praeocularia, das unterste stösst mit dem Labiale 5 zusammen und trennt das vierte Labiale vom Auge. Labiale 5 stösst ans Auge und trennt mit einem hinteren Flügel das Labiale 6 vom Auge. 2 Postocularia. An beiden Kopfseiten ist ein Postnasale vom Nasale abgetrennt und an der rechten Kopfseite ist das Labiale 6 durch eine vom Labiale 5 ausgehende Vertikalnaht in zwei Schilder zerfallen. Anale doppelt.

No. 5. Peters, Mombas. Rechts: 4 Praeocularia, das vierte stösst mit dem fünften Labiale zusammen und schliesst das vierte Labiale völlig vom Auge aus. Labiale 6 durch einen Fortsatz des Labiale 5 vom Auge getrennt. 2 Postocularschilder. Ein selbstständiges Postnasale. Links: drei Praeocularschilder (das vierte und dritte der vorigen Seite sind miteinander verschmolzen). Das Verhalten der Labialia, wie auf der vorigen Seite. 2 Postocularia. Das Postnasale nicht völlig vom Nasale abgetrennt. Anale doppelt.

No. 6. Dar es Salaam. Rechts: 3 Praeocularia, nur das Labiale 5 stösst ans Auge. Das dritte Praeoculare gleich dem dritten und vierten des vorigen Thieres. 2 Postocularia. Links: Praeocularia und Labialia wie rechts. 3 Postocularia (die beiden untersten an der rechten Kopfseite miteinander verwachsen). Selbstständiges Postnasale beiderseits. Anale doppelt.

No. 7. Dar es Salaam. Links: 3 Praeocularia; das vierte und füfte Labiale stossen an das Auge; 2 Postocularia. Rechts: 3 Praeocularia, trotzdem stossen das vierte und fünfte Labiale ans Auge und wie hier deutlich wird, hat das fünfte Labiale dabei so viel an Ausdehnung verloren, wie das vierte gewonnen hat; 2 Postocularia. Beiderseits: selbstständiges Postnasale. 
No. 8. Kingani am Dunda. Rechts: Drei Praeocularia; viertes Labiale kaum das Auge berührend; 3 Postocularia. Links: Drei Praeocularia; das vierte Labiale berührt stärker das Auge auf Kosten des funften Labiale; drei Postocularia sind noch zu erkennen, aber das unterste ist bereits völlig mit dem Labiale verwachsen; nur eine Grube, die quer über das vergrösserte Lippenschild läuft, zeigt die ursprüngliche Grenze seiner Ausdehnung an. In Folge dieser Verwachsung stösst das Labiale 5 an das untere Temporale an. Das dritte Postoculare kann also bald mit dem fünften Labiale, bald mit dem zweiten Postoculare verwachsen.

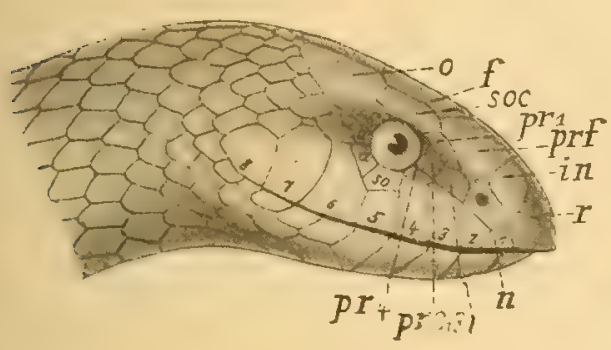

Fig. E.

Als Urform, von welcher alle diese Varietäten ausgegangen sind, oder wahrscheinlicherweise noch jetzt individuell oder ontogenetisch sich abzweigen, ist ein Individuum zu betrachten, welches das Maximum der nachgewiesenen Ocularschilder besitzt. Bei einem derartigen Individuum (Fig. E.) bilden dann, wie die Untersuchung lehrt, die Ocularschilder einen vollständig geschlossenen Schuppenring um das Auge und hindern dasselbe an jeder Berührung mit den Lippenschildern. Der Ring selbst besteht unter diesen Umständen aus einem Supraocularschild, aus 4 Praeocularschildern, aus einem Subocularschild und aus vier Postocularschildern in folgender Anordnung: Das vierte dieser Praeocularschilder $\left(\mathrm{pr}_{4}\right)$ liegt zwischen dem Auge und dem vierten Lippenschild (4), das Subocularschild (so) trennt das Labiale 5 (5) vom Auge, während das dritte Postoculare (a) das sechste Labiale (6) vom Auge trennt. Am häufigsten verschmilzt nun das Subocularschild mit dem Labiale 5, so dass nun scheinbar das Labiale 5 an das Auge stösst. Mit dem so vergrösserten Labiale 5 kann dann aber ausserdem noch das vierte Praeoculare verschmelzen, so dass dann das Labiale 5 das Labiale 4 vom Auge trennt. Verwächst dagegen das Praeoculare 4 mit dem benachbarten dritten, dann legt sich scheinbar das dritte Praeoculare vor das Labiale 4, und nur dann, wenn das Praeoculare 4 und das Labiale 4 miteinander verwachsen, vergrössert sich das letzere scheinbar bis zum Auge. Jedenfalls schiebt es sich nicht auf Kosten des Labiale 5 oder des Praeoculare 3 ans Auge, wie man fälschlich schliessen wird, wenn man die Verhältnisse nicht ganz übersieht.

Mit dem vergrösserten, ans Auge reichenden Labiale 5 kann aber andererseits auch das Postoculare 3 verwachsen, dann trennt das so vergrösserte Labiale 5 das Labiale 6 vom Auge, während bei der Verwachsung der beiden untersten Postocularschilder das nun der Zahl nach zweite an Stelle des Labiale 5 diese Aufgabe versieht. Möglich wäre auch eine Verwachsung des Praeoculare 3 mit dem Labiale 6, wonach dann das letztere das Auge berïhren würde, doch habe ich, wie die Individualbeschreibung ergiebt, eine derartige Verwachsung der Schilder nicht gefunden.

\section{Rhagerhis tritaeniata (Gthr.).}

Tanga in Usambara; I Individ.; O. Neumann S.; Boulenger bestimmt.

\section{Dipsina rubropunctata Fisch.}

Usambara (Tanga); I Individ.; Neumann S.; Boulenger bestimmt. Aruscha am Kilima-Ndjaro; I Individ.; G. A. Fischer S.; J. G. Fischer, Jahresb. Hambg. gelehrt. Anstalt. I884, S. 7, Typ. 


\section{Amphiophis angolensis, Boc.}

Synonymie: Bocage, Herpétologie d'Angola. I 895. S. I I 3.

Südufer des Victoria-Nyansa; Emin Pascha S.; Boulenger, Ann. Mag. I 890, S. 93, als Dromophis angolensis, Boc.

\section{Psammophis subtaeniatus, Ptrs.}

Usambara, wahrscheinlich Tanga; I Individ.; Neumann S.; Boulenger bestimmt.

Aruscha am Kilima-Ndjaro; I Individ.; G. A. Fischer S.; J. G. Fischer 1884 , S. I 2 .

\section{Psammophis punctulatus, D. e. B.}

Massai od. Gurui; I Individ.; Neumann S.

Aruscha am Kilima-Ndjaro; I Individ.; G. A. Fischer S.; J. G. Fischer, Hamburg. gelehrte Anstalten 1884, S. I2, var. C. 160 .

Victoria-Nyansa; I Individ.; C. A. Fischer S. ; Mus.-No. 3I28; V. I89,

\section{Psammophis sibilans, L.}

Sansibar; I Individ.; Révoil S.; Mocq., Mém. soc. phil. I88I, S. I I I.

Sansibar (Kumbuni); I Individ.; Stuhlmann S.; Pfeffer, Stuhlmann X, S. I 8.

Bagamoyo; I Individ.; Stuhlmann S.; Pfeffer, Stuhlmann X, S. r8, als var. intermedius Fisch.

Aruscha am Kilima-Ndjaro; 3 Individ.; G. A. Fischer S.; J. G. Fischer I 884, S. I4, var. intermedius. S. I 8 .

Msere in Usegua; I Individ.; Stuhlmann S.; Pfeffer in Stuhlmann X,

Tanga in Usambara; 3 Individ.; Neumann S.; Boulenger bestimmt.

Victoria-Nyansa (Kagehi); I Individ.; G. A. Fischer S.; Mus.-No. 3127.

\section{Psammophis biseriatus, Ptrs.}

Tanga in Usambara; I Individ.; Neumann S.; Boulenger bestimmt.

Aruscha am Kilima-Ndjaro; I Individ.; G. A. Fischer S.; J. G. Fischer, Jahresb. Hamburg. gelehrt. Anst. I 884, S. I3, mit Beschreibung.

Süd-Ufer des Victoria-Nyansa; Emin Pascha S.; Boulenger, Ann. Mag. I 890 , S. 93.

\section{Bucephalus capensis, A. Sm.}

Mauroi am Pangani; I Individ.; G. A. Fischer S.; J. G. Fischer, Hamburg. gelehrt. Anst. I 884, S. I I.

Mgera in Unguru; I Individ.; Stuhlmann S.; I. Juni I893.

Dar es Salaam; I Individ.; Stuhlmann S.; 8. Nov. I894; ganz grïn.

Kingani am Dunda; I Individ.; Stuhlmann S.; rein braun, an den Bauchseiten Schuppenzwischenräume und Schildränder grün.

Ugogo; I Individ.; E. J. Baxter S.; Günther, Ann. Mag. I895, S. 527.

Bukoba; I Individ.; Stuhlmann S.; mit vielen gelben Flecken.

Bukoba; I Individ.; Neumann S.; mit vielen gelben Flecken.

Das Stuhlmann'sche Individuum aus Bukoba hat an beiden Kopfseiten 2 Zügelschilder und 2 Praeocularia, die bei den anderen Individuen zu einem 
verwachsen sind. Alle anderen Individuen haben nur ein Zügelschild (das unterste der oben erwähnten zwei Zuigelschilder), weil bei ihnen das oberste mit dem Praefrontale verwachsen ist. Der Kopf dieses Thieres ist einfarbig. Die gelben Flecke sind annähernd in Querreihen über den Körper vertheilt.

Das Individuum aus Mgera (Unguru) hat an der linken Kopfseite zwei Zügelschilder übereinander; I Pracoculare; 3 Postocularia; das dritte und vierte Supralabiale stossen ans Auge; Temporale I und 2. An der rechten Kopfseite sind die beiden Zügelschilder miteinander verwachsen, nur eine an der hinteren Randmitte in dasselbe einschneidende Kerbe deutet ihre urspriingliche Grenzlinie noch an; sonst hier alles wie an der anderen Kopfseite. Färbung: reines Braun.

\section{Thelotornis Kirtlandi, Hall.}

Tanga in Usambara; 2 Individ.; Reimer S.; I 894.

Usambara (Derema); I Individ.; Conradt S.; Matschie, Gesell. nat. Freunde Berlin, I892. S. III.

Usambara (Derema); I Individ.; Conradt S.

Aruscha am Kilima-Ndjaro; I Individ.; G. A. Fischer S.; J. G. Fischer, Hamburg. gelehrt. Anst. I 884 , S. I I.

Marangu im Kilima-Ndjaro; I Individ,; Volkens S.; I 895. Bemerkung: Baum- und Erdschlange des Kulturlandes. Bei 1500 gefangen.

Kingani am Dunda; 3 Individ.; Stuhlmann S.; Jan. 1894.

Tumbanatju; Kopf; Oscar Neumann S.

Südufer des Victoria-Nyansa; Emin Pascha S.; Boulenger, Ann. Mag. I 890, S. 93.

\section{Crotaphopeltis rufescens (Gmel.)}

(Barboza du Bocage, Herpétologie d'Angola. S. I22.)

Sansibarküste; I Individ.; v. d. Decken S.; Peters, Decken, S. I7.

Sansibarküste; I Individ., jung; Hildebrandt S.; Mus.-No. I789.

Buloa bei Tanga; 2 Individ.; G. Eismann S.

Usambara bei Tanga; 4 Individ.; Reimer S.

Usambara; 5 Individ.; Stuhlmann S. (wahrscheinlich von Dr. H. Meyer's Expedition stammend). Pfeffer X (I888), S. I9.

Usambara; I Individ.; Linnaea, Berlin S.; Werner, Verhandl. K. K. zool.-bot. Gesellsch. Wien, I895. S. 4.

Matamonda in Unguu; I Individ.; Stuhlmann S.; 9. Aug. I 888; Pfeffer in Stuhlmann X, S. 19.

Massai oder Kavirondo; I Individ.; Neumann S.; 1894.

Dar es Salaam; 2 Individ.; Stuhlmann S.; 8. Nov. I 894.

Dar es Salaam; 4 Individ. (3 Junge, ein Altes); Krüger $\mathrm{S}$.

Kingani am Dunda; 2 Individ.; Stuhlmann S.

Peri Memgati in Ufiomi; I Individ.; Neumann S.; Oktober I893.

Fuss des Ruwensori, westlich am Zomba. Günth., Ann. Mag. I 895 , S. 525; Unregelmässiges Netzwerk schwarz, darin gelbe Punkte.

\section{Crotaphopeltis semiannulata (Gthr.)}

(Barboza du Bocage, Herpétologie d'Angola. S. I22.)

Ugogo; I Individ.; E. J. Baxter S.; Günth., Ann. Mag. I 895, S. 527, als Leptodira semiannulata.

Dar es Salaam; I Individ.; Schmidt S.; I 894. 


\section{Dipsas obtusa.}

Usambara; I Individ.; Linnaea S.; Verhandl. K. K. zool.-bot. Gesell. I 895 , S. 4 .

\section{Subfamilie: Proteroglypha.}

\section{Atractaspis irregularis, Rhdt.}

Sansibarküste; I Individ.; Hildebrandt S.; I895.

Sansibarküste; I Individ.; Salmin S.; Mus.-No. 5736.

Tanga; I Individ.; Reimer S.

Uganda; 2 Embryonen; Scott Elliot S.; Günth., Ann. Mag. I895, S. 527.

\section{Atractaspis fallax Ptrs.}

$=$ irregularis nach Pfeffer.

Drei Tagereisen von Kircamo; I Individ.; von d. Decken S.; Peters in Decken, S. I7.

\section{Elapsoidea güntheri, Boc.}

Tanga in Usambara; I Individ.; Reimer S.

Buloa in Usambara; I Individ.; G. Eismann S.

Berg bei Magila; I Individ.; Neumann S.; 3. Mai I 893.

Victoria-Nyansa (Kagehi); 2 Individ.; G. A. Fischer S.; Mus.-No. 3 I29.

Ruwensori; I Individ.; Scott Elliot S.; Günth., Ann. Mag. I895, S. 525.

Ussogo oder Uganda; I Individ; Neumann S.

\section{Elapsoidea nigra, Gthr.}

Usambara; junges Exemplar; Linnaea Berlin S.; Werner, Verh. K. K. zool.-bot. Gesellsch. Wien. I 895, S. 5.

\section{Naja nigricollis, Rhdt.}

Sansibar; I Individ.; Neumann S., Mus.-Nro. I I 157.

Aruscha am Kilima-Ndjaro; I Individ.; G. A. Fischer S.; J. G. Fischer, Hamb. gelehrt. Anst. 1884, S. I7. var. mossambica.

Dar es Salaam; I Individ.; Stuhlmann S.

Victoria-Nyansa bei Kagehi; I Individ.; G. A. Fischer S.; Mus. Nro. 3 I 26.

\section{Naja haje (L.)}

Uganda; I Individ.; E. J. Baxter S.; Günther, Ann. Mag. I895, S. 527; Schwarze Varietät.

Ostafrika, ohne näheren Fundort; I Kopf; Stuhlmann S.; Soweit zu sehen: Schwarze Varietät.

"Naja haje, schreibt Böhm, ist seltener, z. Th. in sehr grossen Exemplaren in Wald und Feld zu finden. Alle von mir gesehenen waren tiefschwarz mit z. Th. orangeröthlicher Unterseite. Ihr zu begegnen gilt als böses Omen. Die bereits von Anderen gemachte Beobachtung, dass die Brillenschlangen bei Be- 
unruhigung ihren ätzenden Speichel weit fortschleudern und dabei nach den Augen der Feinde zielen (cf. Reichenow, Archiv f. Naturg. 40. Jahrg., Bd. I, S. 293; Mohr, Victoriafälle des Sambesi S. 277), kann ich bestätigen. Gst. Cambier erzählte mir, dass eine in der belgischen Station Karema aufgestörte Brillenschlange nach ihm gespieen habe. Eine andere, welche auf einer Granitkuppe bei Gonda in die Wohnstätte meines Kollegen, Dr. Kaiser, eingedrungen war, spie zweimal nach den sie verfolgenden Jungen, wobei der eine in die Augen getroffen wurde und infolgedessen einen Tag lang an starken Schmerzen litt.

\section{Dendraspis intermedius Gthr.}

Dendraspis (Dinophis) intermedius, Günth. = polylepis Günth. nach Boc., Herpétologie d'Angola. S. I 40.

Tanga; I Individ.; Neumann S.; Boulenger als D. polylepis bestimmt.

Aruscha a. Kilima-Ndjaro; I Individ.; G. A. Fischer S.; J. G. Fischer, Hamburg I 884 , S. I7 als D. intermedius.

\section{Familie: Viperidae.}

\section{Atheris ceratophora, Werner}

Usambara; I Individ.; Linaea Berlin S.; Franz Werner, Verhandl. K. K. zool.-bot. Gesell., Wien I 895 S. 5.

Usambara; I Individ,; Reimer S.

Buloa bei Tanga in Usambara; 5 Individ.; G. Eismann S.

$\mathrm{Zu}$ Werner's eingehender Beschreibung habe ich nur wenig hinzuzufügen. Die von mir untersuchten Individuen haben über jedem Auge zwei Schuppen, die hornartig hoch aufragen. Vor und hinter ihnen stehen gewöhnlich noch eine bis zwei ähnlich geformte Schuppen. Aus der Thatsache, dass eine der vorausstehenden zuweilen etwas grösser ist als die übrigen, erklärt sich Werner's abweichende Angabe, dass drei hornartige Schüppchen bei den Thieren über dem Auge stehen.

Lippenschilder fand ich 2I-24; Schuppen am Rücken quer 27; V., wie angegeben, I 45; Anale I; C. 54.

Die Färbung der Art zeigt individuelle Verschiedenheiten. Die meisten Individuen sind so gefärbt, wie es Werner angiebt; ausserdem sah ich ein Thier, das fast gleichmässig gelbgrün war und ein gleichmässig braungelbes.

\section{Atheris squamiger, Hall.}

Isanso (Kisihamo); I Kopf mit Körperbeschreibung; Stuhlmann S.

Stuhlmann's Beschreibung: Lang $518 \mathrm{~mm}$; Schwanz $90 \mathrm{~mm}$. Alle Schuppen gekielt, oben olivgrün mit verwaschenen braunen Flecken, Seiten grü; unten mit einigen gelben Flecken in einer Reihe; Bauch blau-grün, Kehle fahl-gelb, 18-19 Schuppenreihen, I 53 V., 55 C. einreihig.

\section{Viperia nasicornis Merr.}

Lulu-Thal, Urwald Ulegga, West Ulegga; I Kopf; Stuhlmann S.; Juli I 89I.

Bundikowald ( $10^{\circ} \mathrm{I} 2^{\circ} \mathrm{N}$. Breite) ein Junges und ein Kopf; Emin-Pascha S.; 6. August I 89 I. 
Vipera arictans, Merr.

Sansibarküste; I Individ.; von d. Decken S.; Peters in Decken, S. 17.

Usambara; I Individ.; Stuhlmann S., wahrscheinlich von Dr. H. Meyers Expedition. Sept. I888.; Pfeffer in Stuhlmann X, S. 7.

Tanga in Usambara; I Individ.; Neumann S.; April 1893.

Massai-Nyika; 2 Individ.; Neumann S.; Juni I 893.

Dar es Salaam; I Individ.; Krüger S.; I894.

Dar es Salaam; I Individ.; Stuhlmann S.; I894.

Kingani am Dunda; 2 Individ.; Stuhlmann S.; Juni I894.

Mpwapwa; I Individ.; Böhmer S.; Jan. I 894.

Tabora; I Individ; Stuhlmann S.; 24. Aug. I890.

Wembere-Steppe; ein Kopf; Stuhlmann S.; 6.-7. Juni I 892.

Ostfrika, ohne näheren Fundort; 2 Individ.; Stuhlmann S.

Wahrscheinlich Bukoba; ein Kopf; Stuhlmann S.

»Vipera arietans, schreibt Böhm, findet man nicht selten in der Boga an alten Ameisenbauten und an Waldrändern und kommt dieselbe wie andere Schlangen zuweilen in die Häuser. Grosse Exemplare wurden so in einer Hütte unseres Lagers in Konko (Ugogo), mehrmals in Kakoma und im Stationsgehöft von Karema am Tanganyika erlegt."

\section{Causus rhombeatus (Lcht.)}

Bagamoyo; 5 Individ.; Graf Schweinitz S.; I3. Septbr. 1895.

Bukoba; I Individ.; Stuhlmann S.; 7. April I892.

Wahrscheinlich Bukoba; I Individ.; Stuhlmann S.

\section{Causus resimus (Ptrs.)}

(Bocage, Herpetol. d'Angola S. I46.)

Dar es Salaam; I Individ.; Stuhlmann S.

Kingani am Dunda; I Individ.; Stuhlmann S.

Marungu; I Individ.; Böhm S.; Mus.-Nro. Io 734 (3IO3).

Massai oder Kavirondo; I Individ.; Neumann S.

Alle Individuen, welche mir vorliegen, stimmen, abgesehen von der Färbung, mit dem Typ-Exemplar genau überein und ebenso mit der Beschreibung der Individuen, welche von Bocage als Causus resimus gedeutet worden sind. Bei allen Individuen, auch bei dem Peters'schen Typ-Exemplar stösst das Internasale neben dem Postnasale an das Zügelschild.

In der Färbung stimmen die beiden ersten der aufgezählten Individuen genau mit den Individuen überein, welche Bocage als Causus resimus var. angolensis beschrieben hat, von einer specifischen Farbenvarietät »angolensis " dürfte daher wohl nicht die Rede sein. Das Peters'sche Typ-Exemplar und das Individuum aus Massai oder Kavirondo weichen davon nur scheinbar sehr wesentlich ab. Das Individuum aus Massai oder Kavirondo ist das einfachst gefärbte, es ist auf dem Rücken blau-schwarz gefärbt, am Bauch weisslich gelb. Ihm schliesst sich in der Färbung das Peters'sche Originalexemplar unmittelbar an, es hat dieselbe Bauch- und Rückenfärbung, aber in der Rückenfärbung liegen zahlreiche weisse Strichelchen regellos verstreut.

Aus dieser Form hat sich die Var. angolensis dadurch entwickelt, dass bei ihr grössere Partien der einheitlichen, blau-schwarzen Rückenfärbung der Stammform zu einem lichten Gelb-grau verblasst sind. Die bei dieser extremen Farbenvarietät der Art vorhandenen blau-schwarzen Rückenflecken und die, in ihre Grundfärbung eingestreuten, zahlreichen, weissen Stricheichen sind demnach unveränderte Ueberbleibsel aus der Färbung der vorangehenden Varietät. 
Im Uebrigen möchte ich noch bemerken, dass Causus rhombeatus und resimus jedenfalls sehr nahe verwandte Arten sind, besonders dann, wenn man Causus nasalis Steinjr. zu der letztgenannten Art zieht. Sie unterscheiden sich, da Causus rhombeatus anscheinend dieselben Farbenvarietäten wie resimus bildet, im Grunde nur durch das mehr oder weniger starke Hervorragen des Schnauzenrandes über seine Umgebung. Der bei den extremsten Individuen von Causus resimus gleich einem Schweinerüssel aufgeworfene Schnauzenrand wird ausserdem noch durch den Frontaltheil des Rostrale, der wulstig verdickt ist, gegen Rückbiegung auf die Stirn fest versteift und die ganze Schnauze beweist, dass mit ihr versehene Individuen starke Schnauzenwühler sind. Ausser diesen extremen Thieren giebt es dann aber andere, das Peters'sche Originalexemplar von resimus z. B. und das Individuum aus Massai oder Kavirondo, bei welchen die Versteifung des ebenso stark wie bisher aufgeworfenen Rostralrandes völlig fehlt, Individuen, welche sich dadurch als weniger begabte Schnauzenwühler zu erkennen geben. Von diesen Individuen bis zu Causus rhombeatus dessen Schnauzenrand fast garnicht oder auch garnicht (?) hervorragt, ist dann nur noch ein Schritt. Sonst unterscheiden sich die Arten nach der Beschreibung nur noch dadurch, dass bei der einen die Zahl der Schwanzschilder da aufhört, wo sie bei der anderen Art anfängt.

Geringwerthige Variabilität der Individuen von Causus resimus liegt dann in Folgendem: Alle Individuen haben um das Auge einen geschlossenen Schuppenring, aber es wechselt bei ihnen die Zahl seiner Componenten. Während das Peters'sche Originalexemplar an der rechten Kopfseite zwei Praeocularia, ein langes, schmales Suboculare, und zwei Postocularschilder besitzt, hat es an der linken Seite zwei Praeocularia, ein sehr langes, schmales Suboculare und nur ein Postocularschild, denn hier ist das unterste Postoculare der anderen Seite mit dem Subocularschild untrennbar verwachsen. Das Individuum aus Massai oder Kavirondo hat zwei Praeocularia, ein Post- und ein riesiges Suboculare, welches aber noch von zwei Quergruben durchzogen wird, den letzten Resten ursprünglicher Nähte, welche drei Schilder von einander trennten. An der anderen Kopfseite hat das Individuum zwei Prae-, zwei Postocularia und ein Suboculare, welches wiederum durch eine Quergrube durchzogen wird, also durch Verwachsung von zwei Subocularschildern entstanden ist. Die anderen drei Individuen haben beiderseits zwei Praeocularia, 2 Subocularia - von denen das hintere als stark nach unten verlängertes Postoculare gelten könnte - und ein Postoculare.

\section{Schlussbemerkung.}

Ich habe in dieser Arbeit bei allen mir vorliegenden Reptilien genau die Variabilität der Kopfschilder untersucht und bei einer grossen Anzahl der Arten konstatiren können, dass einzelne dieser Schilder unter Umständen miteinander verschmelzen können. Diese Thatsache ist für den Reptiliensystematiker nicht neu. Sie wird in vielen systematischen Arbeiten als etwas fast selbstverständliches angeführt, ist aber trotzdem noch niemals in ihrer wirklichen Bedeutung voll gewürdigt worden, da sie in denselben Arbeiten an anderen Stellen ebenso geflissentlich nicht beachtet wird; ich will hier deshalb mit einigen Worten darauf etwas näher eingehen.

Die grossen tafelförmigen Kopfschuppen gewisser Reptilien sind das Schlussresultat der Vereinigung vieler kleiner Schuppen, welche bei anderen primitiveren Reptilien ihre Stelle einnehmen und von je einer Cutispapille gebildet werden. Bei den Eidechsen speciell verwachsen wohl zuerst an den Oberlippen die kleinen Schuppen zu grossen Lippenschildern. Auf diesem Standpunkt stehen gegenwärtig noch die Geckoniden. Dann legt sich bei vielen Eidechsen, die dieser Stufe angehören, um das Frontalauge herum ein grosses Interoccipitale an, so 
bei einer Reihe von Agamen. Bei Iguaniden (Anolis) bilden sich dann die oberen Kopfschilder bis zur Stirn hin aus, wo sie mit zwei Postfrontalschildern abschliessen. Bei den extremsten Iguaniden und besonders bei den Tejiden tritt die vordere Reihe der Occipitalschilder hinzu. Bei Cnemidophorus murinus sind es noch fünf an der Zahl, bei Tejus teju sind es nur noch drei, da je zwei äussere der vorgenannten Art hier miteinander verwachsen sind. Bei den Zonuriden schreitet diese Occipitalschilder-Entwicklung mit Ausbildung der hinteren noch weiter fort. Bei Pseudocordylus microlepidotus liegen die letzteren in Form von mässig grossen Schuppen noch in zwei Querreihen; bei der Gattung Zonurus sind nur noch zwei sehr grosse, hintere Occipitalschilder vorhanden, demnach hat diese Gattung entweder 5 oder 4 Occipitalschilder ausser dem Interoccipitalschild. Bei den Lacertiden sind dann die beiden Postfrontalschilder mit den, bei den Vorfahren dieser Familie vorhandenen 2 Praeoccipitalschildern zu je einem grossen Schild verwachsen, das vom Frontale bis zum Interoccipitale reicht. Bei Zonosaurus madagascariensis endlich, der dadurch von den Lacertiden abweicht, dass bei seinen Vorfahren ein selbstständiges Interoccipitale nicht ausgebildet wurde, verwächst sogar an jeder Kopfseite das Postfrontale mit dem vorderen und hinteren Occipitale, sodass der ganze Hinterkopf dieses Thieres nunmehr nur noch von zwei riesig grossen Schildern bedeckt wird.

Damit ist indess die Verwachsung der Kopfschilder bei anderen Arten noch keineswegs abgeschlossen. Bei den grabenden Eidechsen, besonders bei den extremsten unter ihnen - bei den Amphisbaeniden - treten geradezu abnorme Verwachsungen derselben ein, sodass zum Schluss - bei Monopeltis z. B. die ganze Kopfoberseite eigentlich nur noch von zwei oder gar nur von einem riesigen Schild iiberdeckt wird.

$\mathrm{Da}$, wie bekannt, in den Zellen der Epidermis die Hornbildung durch Reibung sehr vergrössert werden kann und wahrscheinlich von ihr überhaupt abhängt, da.Thiere, welche ihre Haut nicht der Reibung aussetzen, nur wenig oder garnicht verhornte Epidermiszellen - Hautschuppen und -Schüppchen aufweisen, so werden Untersuchungen über das Verhalten der Reptilienschilder von ganz besonderem Werth für die Descendenzlehre, weil man hier, wie bei den später zu besprechenden Farbkleid-Entwicklungen die Anpassungsprozesse des Organismus bis tief in den Organismus hinein verfolgen kann, weil man sowohl die physiologischen Prozesse kennt, auf welchen in letzter Instanz die beobachteten Variationen des Organismus und seiner Zellen aufgebaut sind, als auch die äusseren Ursachen, welche diese physiologischen Prozesse im Organismus auslösen. Wir sehen bei diesen beiden Anpassungsprozessen des Organismus - genau wie bei dem von mir nachgewiesenen Entstehen der Gelenkformen, dass die äusseren Ursachen direkt auf die Zellen einwirken, welche durch sie zur Umbildung gezwungen werden, und wir sehen ausserdem die Umbildung der von dem Reiz getroffenen Körperpartien proportional dem Reiz verlaufen, d. h. wir konstatiren, dass der betreffende Reiz nicht erst, wie das Weismann will, auf das Geschlechtsorgan einwirkt, dort "Determinanten « auslöst und erst durch diese Determinanten die von ihm getroffenen Körperpartien zur Umwandlung zwingt.

$\mathrm{Ob}$ solche Anpassungen vererbbar sind, wird sich leicht »auch experimentell « beweisen lassen, da sie in der Natur, was wohl Niemand leugnen wird, vererbbar sind.

Es freut mich, zum Schluss noch darauf hinweisen zu können, dass sich Herr H. Zacharias entschlossen hat, das Entstehen der Schlangenkopfschilder eingehend zu studiren. Diese wichtige und interessante Arbeit sei hiermit zur Lektüre dringend empfohlen. 
Amphibien. 



\section{Subordnung: Phaneroglossa.}

\section{Series: Firmisternia.}

\section{Familie: Ranidae.}

Rana occipitalis (Gthr.)

Kakoma; 26 б̆, 2 \%; Böhm S.; I882.

Kakoma; I6 Junge; Böhm S.; I882.

\section{Rana adspersa Bibr.}

Usambara; I Individ.; Oscar Neumann S.; Mus.-Nro. II I7T.

Usambara (Tanga); 2 Individ.; Oscar Neumann S.

\section{Rana angolensis Boc.}

Buloa bei Tanga; I4 Individ.; G. Eismann S.

Dar es Salaam; 2 ठ im Hochzeitskleid; Stuhlmann S.; Febr. I894.

Marangu im Kilima Ndjaro; 3 Junge; Volkens S.; „Gefangen im Himobach oberhalb des Waldes in $2700 \mathrm{~m}$ Höhe".

Kifinika im Kilima Ndjaro 1950 m hoch; 7 Individ.; Oscar Neumann S.; Febr. I 895 .

Bukoba; 2 Individ.; Stuhlmann S.; Januar 1891.

Bukoba; 4 Individ,; Stuhlmann S.; 20. Febr. 1892.

Die Thiere von Kifinika wurden zur Begattungszeit gefangen, darunter Männchen und Weibchen direkt in Copula. Die Thiere erscheinen auffälig dunkel gefärbt, fast schwarz; bei genauerem Hinsehen erblickt man jedoch in dem dunkeln Grund etwas hellere wurmförmige Zeichnung; am hellsten sind diese wurmförmigen Flecken an den Körperseiten. Das eine Thier ist jedoch ganz dunkelschwarz. Trommelfell bei allen braun. Die Haut rauh durch zahlreiche feine Stacheln, die aus ihr hervorragen; auch die von Stuhlmann gesammelten brünstigen Männchen zeigen sehr schön diesen Hautcharakter.

Auch unter den Thieren von Bulua sind die dunkel gefärbten mit allen Begattungscharakteren versehen, während die heller gefärbten solche Begattungscharaktere nicht aufweisen, es scheint daraus hervorzugehen, dass die Thiere sich während der Begattungszeit dunkler färben.

\section{Rana oxyrhyncha Sund.}

Sansibar; Mehrere Individ.; Peters, Mossambique Bd. III, S. I 48.

Kikoko in Usaramo; I Individ.; Stuhlmann S. I Pfeffer in Stuhlmann X, Korogwe am Rufu; 2 Individ; Stuhlmann S. $\quad$ S. 22. 
Kakoma; 7 Individ., junge, halb- und ganz erwachsene Thiere; Böhm S. Undussuma; 2 Individ.; Stuhlmann S.; I 5 . November I890 u. I89I.

\section{Rana mascareniensis D. e. B.}

Sansibar; I Individ., jung; J. Kirk S.; Boul., Cat. of Batr. S. 53.

Sansibar; I Altes und viele Junge; Stuhlmann S.; Pfeffer in Stuhlmann $\mathrm{X}$, S. 22.

Sansibar oder Mombas; I Individ.; von d. Decken S.; Peters in Decken S. I 76 als R. nilotica Seeken beschrieben.

Usambara; 4 Individ.; Oscar Neumann S.; Mus.-Nro. I II72-75.

Usambara (Tanga); 2 Individ.; Oscar Neumann S.

Dar es Saalam; I 2 Individ.; Stuhlmann S.; 1895.

Korogwe am Rufu; I Individ.; Stuhlmann S.; 22. September 1888.

Yaquiro in Ugogo; 2 Individ.; Stuhlmann S.; 9. Juli I 890.

Itole in West-Nianza; 2 Individ.; Stuhlmann S.; 2. November I89o. Am Victoria Nianza; I Individ.; Stuhlmann S.

Peri Nsiomi in Umbugwe; I Individ.; Oscar Neumann S.; Nov. I 893. Manjaro; 5 Individ,; Oscar Neumann S.; November 1893.

Kwa Mumija in Kavirondo; I Individ.; Oscar Neumann S.; I. Mai I 894. Bukoba; 6 Individ.; Stuhlmann S.; 2. März I892.

\section{Rana bravanus (Ptrs.)}

Limnodytes bravanus Ptrs., Gesell. nat. Freunde zu Berlin, I7 Jan. I882. S. 3. Barawa (Englisch-Ostafrika); 2 Individ.; Hildebrandt S.; Typ-Exemplare. Bagamoyo; 2 Individ.: G. A. Fischer S.

Kiboscha; 6 Individ.; Oscar Neumann S.; Januar I895.

Kakoma; 4 Individ., darunter 2 Junge; Böhm S.

Böhm fing sowohl die Jungen wie die Alten in Kakoma, die letzteren im Dorfteich und findet sie, mit Recht, einer grossen Rana temporaria ähnlich.

Um mehrere Bemerkungen daran zu knüpfen, lasse ich zuerst die Originalbeschreibung der Art wörtlich folgen.

"Limnodytes bravanus $\mathrm{n}$. sp. Vomerzähne zwischen dem vorderen Theile der Choanen, ebenso weit von einander wie von den Choanen entfernt, nach hinten etwas konvergirend. Choanen kleiner als die weiten Tubenöffnungen. Zunge hinten gabelförmig. Kopf merklich länger als breit, Nasenlöcher gross, hinter der abgestutzten Schnauze, welche ein wenig länger ist, als der Augendurchmesser. Trommelfell wenig kleiner als das Auge.

Körper oben glatt, am Bauche, wie die Unterseite der Oberschenkel granulirt, mit einer wohlentwickelten Postpectoralfalte. An jeder Seite des Rückens eine schmale Drüsenlinie. Vordere Extremität bis an das Ende des Körpers reichend; der erste Finger länger als der zweite, kaum kürzer als der vierte, hinter dem längsten dritten zurückstehend. Sämmtliche Finger frei und mit nur kleinen Haftscheiben versehen. Hintere Extremität ragt mit dem Hacken bis an die Zügelgegend. Die dritte Zehe überragt nur wenig die fünfte, während die vierte um zwei Fünftel länger als dieselbe ist. Nur halbe Schwimmhäute, welche an die Basis der zweiten Phalanx der vierten Zehe gehen. Haftscheiben an den Zehenspitzen sehr klein.

Oben olivengrün mit schwarzen Flecken, welche einen unregelmässigen Mittelstreifen bilden. Eine schwarze Binde unter dem Canthus rostralis, welche hinter dem Auge breit an den Oberschenkel geht und in der hinteren Hälfte hell gefleckt ist. Untere Körperseite, vordere und hintere Seite des Oberschenkels schwarz und gelb-weiss marmorirt. Aussenseite der Gliedmaassen schwarz gefleckt und gestreift. Unterseite schmutzig gelb. 
»Totallänge $7 \mathrm{~cm}$; Kopflänge $23 \mathrm{~mm}$; Kopfbreite $19 \mathrm{~mm}$; vordere Extremität $47 \mathrm{~mm}$; Hand mit drittem Finger $20 \mathrm{~mm}$; vordere Extremität I I $3 \mathrm{~mm}$; Fuss mit vierter Zehe $54 \mathrm{~mm}$.

»Zwei weibliche Exemplare aus Brava von J. M. Hildebrandt.

¿Es ist dieses die erste aus dieser Gattung bekannt gewordene Art von der Ost-Küste Afrikas. Sie hat einige Aehnlichkeit in der Vertheilung der Farben mit dem Lymnodytes malabaricus, welcher sich aber auch durch den viel breiteren Kopf und die einander mehr genäherten Vomerähne von ihr unterscheidet $\ll$.

Das mir vorliegende grössere Material (I4 Exemplare mehr) gestattet, die Peters'sche Beschreibung in manchen Punkten zu berichtigen und zu erweitern. Peters schreibt: Die Schnauze der Rana bravanus sei abgestutzt. Das ist ein Irrthum, hervorgerufen durch folgendes: Die bei lebenden Fröschen bekanntlich am Schädel und unter einander beweglichen Ober- und Zwischenkieferknochen
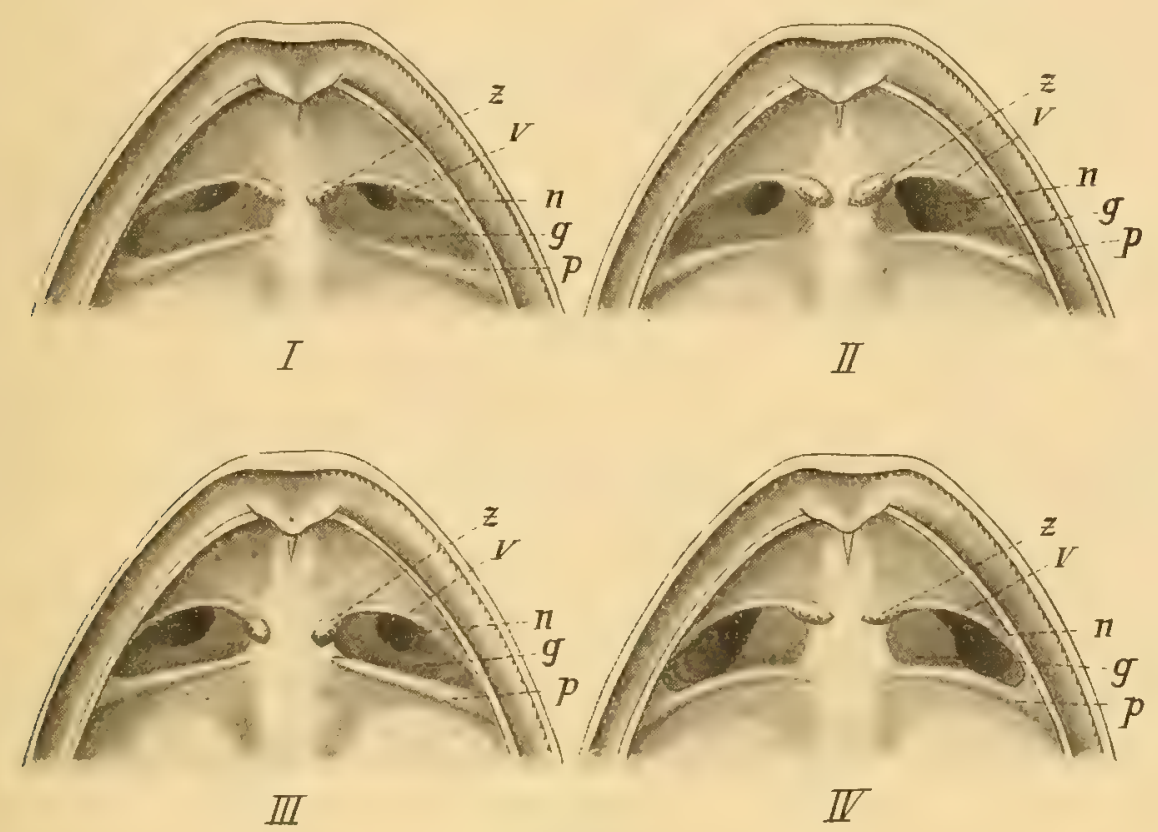

Fig. F.

sind bei den Typ-Exemplaren aus der "Ruhelage" so nach oben verschoben, dass sie mit den Frontonasal-Knochen in einer Ebene liegen und die Zwischenkiefer sich ausserdem in eine Vertikalebene eingestellt haben, daher das scheinbare Abgestutztsein der Schnauze. Diese Deformation des Kopfes der Thiere dürfte durch Druck auf denselben erzeugt sein, während er noch frisch war — durch zu enges Verpacken der Thiere nach dem Absterben - und Erstarrung derselben in dieser Stellung bei der Eiweissgerinnung. Bei den von mir untersuchten, garnicht gedrückten Exemplaren ist der Kopf nicht ganz so flach, wie bei den Typ-Individuen, die Schnauze verläuft ohne Ausbildung eines Canthus rostralis bogenförmig zum Mundrand, der wiederum einen horizontal liegenden Bogen bildet. Von einer abgestumpften Schnauze ist bei meinen Individuen nicht die Rede; doch kann ich auch bei ihnen durch Druck auf Kopf und Zwischenkiefer die Schnauzenform erzeugen, welche bei den Typ-Exemplaren fixirt ist.

Die mir vorliegenden Exemplare von Rana bravanus zeigen eine ungemein grosse Variabilität in der Stellung der Vomerzähne zu den Naslöchern. Ich sah einige Individuen (Fig. F, I), bei welchen die Vomerzähne (z) dicht an den Nas- 
löchern (n) und mit ihnen in einer Höhe liegen; dann fand ich ein Thier (Fig F II), bei welchem an einer Kopfseite das Nasloch ebenso liegt, das der anderen Kopfseite ist aber wesentlich grösser und die zugehörige Zahnreihe liegt hier in halber Höhe des Nasloches. Ich sah dann Individuen (Fig. F, III), bei welchen die Vomerzähne weit $a b$ von den Naslöchern und zwischen diesen liegen und andere Thiere (Fig. F, IV), bei welchen sie sehr weit ab von den Naslöchern, aber höher als diese liegen. Kaum zwei der mir vorliegenden Thiere stimmen in Rücksicht auf den eben erwähnten Charakter ganz genau mit einander überein.

Die einzelnen Individuen zeigen auch deutlich, woher das kommt: Bei allen Thieren durchbrechen die Naslöcher $(\mathrm{n})$ die Gaumenhaut in einer Grube (g), welche im Gaumendach über einem Loch ausgespannt ist, das vorn von einem seitlichen Vomerast (v), hinten vom Palatinum ( $p$ ) begrenzt wird. Jede derartige Gaumenhautgrube hat eine beträchtliche Grösse. Die Naslöcher der verschiedenen Individuen durchbrechen sie nun an sehr verschiedenen Stellen und in sehr verschiedener Ausdehnung und dadurch entsteht dann das scheinbar sehr starke Variiren der Vomerzahnstellung.

Genau dasselbe Variiren in der Bezahnung fand ich auch bei den vielen mir vorliegenden Individuen von Rana angolensis und daraus folgt, dass wahrscheinlich auch bei anderen Rana-Arten ein ähnliches Variiren zu finden sein wird und dass man nicht gleich zwei Rana-Arten aufzustellen braucht, wenn zwei Individuen gefunden werden, die sich nur allein oder vorwiegend durch Vomerzahnstellung unterscheiden.

Die bei dieser Art an Fingern und Zehen vorhandenen "Haftscheiben « sind auffällig klein und daher sehr leicht zu übersehen. Diese Finger- und Zehenspitzen machen beim ersten Anblick nur den Eindruck als wären sie stark abgestumpft.

In der Färbung bilden die mir vorliegenden Thiere zwei sehr ausgesprochene Varietäten, die durch Zwischenformen ineinander übergehen und die beide von Oscar Neumann in ein und demselben Teich gefunden worden sind.

Bei der einen Varietät zeigt der ganze Rücken auf gratl-gelbem, im Leben grünem Grund viele regellos verstreute schwarze Flecke von sehr verschiedener Grösse, alle mit starker Aufhellung von innen heraus. Die Grundfarbe bildet bei diesen Individuen nirgends helle Längslinien, sondern windet sich als krausmaschiges Netzwerk zwischen den schwarzen Flecken hindurch.

Die jungen Thiere der zweiten Farbenvarietät besitzen auf dem Rücken vier helle, weiss-gelbe Längsstreifen, die durch drei schwarze, sehr breite Reststreifen getrennt sind. Die vier Hellstreifen vertheilen sich in symmetrischer Anordnung auf die beiden Körperhälften, sodass jeder Körperhälfte zwei von ihnen zukommen: ein Oberkieferstreif, welcher zieht von der Schnauzenspitze, an der Mundspalte entlang, hart über das Schultergelenk hinweg, bis zum Hüftgelenk; und ein Rückenstreif, der ebenfalls an der Schnauzenspitze beginnt, über den Rand des oberen Augenlids hinwegzieht, und am Hüftgelenk endet. Diese oberen weissen Linien sind zugleich ausgesprochene Drüsenfalten.

Von den drei breiten schwarzen Reststreifen dieser Individuen nimmt der grösste fast den ganzen Rücken ein, die beiden anderen ziehen als Post- und Praeocularstreifen durch das Auge von der Schnauzenspitze bis zum After. Rein schwarz sind sie indess nicht mehr; fast schwarz ist der Rückenstreif, aber auch er zeigt bereits an vielen Stellen eine schwache Neigung zur Ausbildung verästelter Hellflecken; doch ist der Pigmentschwund an diesen Stellen noch so gering, dass die Stellen erst bei sehr eingehender Betrachtung des Thieres wahrnehmbar sind. Stärker noch ist das Verblassen in den dunkeln Seitenstreifen; hier sind bereits zahlreiche, stark verästelte wirkliche Hellflecken in die dunklen Streifen eingelagert, Hellflecke, die bei lebenden Thieren "goldgrün", bei Spiritusexemplaren sehr hellgrau gefärbt sind. 
Die erwachsenen Individuen der Farbenvarietät stimmen nun mit den jungen genau darin überein, dass auch sie die vier hellen Längsstreifen an der Körperoberfläche besitzen, weichen aber dadurch von den jungen $a b$, dass bei ihnen sowohl in den schwarzen Postocularstreifen wie im schwarzen Rückenstreifen die Hellflecken nicht nur an Zahl und Grösse selır zugenommen haben, sondern auch noch viel stärker aufgehellt sind. In Folge dessen sind bei den meisten erwachsenen Individuen alle drei Reststreifen in ein schwarzes Netzwerk reduzirt, dessen krause Maschen an vielen Stellen nur noch sehr lose zusammenhängen. Ausserdem ist noch zu berücksichtigen:

Bei allen erwachsenen Individuen von Rana bravanus zeigen nur die dunkeln Seitenstreifen annähernd denselben Grad der Verblassung, dagegen ist bei den verschiedenen Individuen der Rückenstreif verschieden stark und in verschiedener Weise verblasst. Es giebt Individuen, bei welchen er erst in das erwähnte feine schwarze Netzwerk verwandelt ist; ein Netzwerk, dessen auf den Dornfortsätzen liegende Maschen bei einigen Individuen von besonderer Dicke sind und dadurch den von Peters beschriebenen gewundenen schwarzen Medianstreifen bilden. Bei anderen Individuen aber ist der ganze Rückenstreif entweder bis auf einige Restflecken oder ganz abgeblasst, und hat die Färbung der neben ihm liegenden Hellstreifen, mit denen er so verwächst. Die Thiere haben dann im Leben einen einfarbig grün-braunen Rücken.

Wie die Peters'sche Artbeschreibung ergiebt, vergleicht der Verfasser garnicht Rana bravanus mit der ihr zweifellos sehr nahe stehenden Rana elegans, von der mir leider nur die Beschreibung und Abbildung in Boulenger's Batrachier-Katalog bekannt ist. Ich hole diese Vergleichung hier nach.

Die beiden Arten unterscheiden sich nach der Peters'schen Beschreibung, die schon das Maximum der Unterschiede angiebt, nur durch die Bezahnung und durch geringe Unterschiede in der Färbung; denn ein scheinbarer dritter Unterschied: Boulenger's Angabe, dass bei Rana elegans das Tibio-tarsal-Gelenk bis nahe zur Spitze der Schnauze reicht (nearly to the tip of the shnout), und die I'eters'sche Angabe, dass dasselbe Gelenk bei Rana bravanus bis zur Zügelgegend reicht, dürften in anderer Form dasselbe sagen, oder jedenfalls nur einen durchaus sekundären Unterschied anzeigen.

Andererseits finde ich, dass die erwachsenen Männchen von Rana bravanus darin sogar mit den Männchen von Rana elegans übereinstinımen, dass sie unter ihren Schallblasen an der Vorderseite des Oberarmes eine ovale Schwiele besitzen, was Peters nicht angegeben hat.

Was nun den Unterschied in der Bezahnung betrifft, so ist der zwischen den Typ-Exemplaren bestehende allerdings nicht unwesentlich; aber unter den mir vorliegenden Individuen von Rana bravanus sind solche, welche Rana elegans in der Bezahnung zum wenigsten sehr nahe stehen, ob sie darin vielleicht gar mit ihr vollig übereinstimmen, kann nur direkte Gegenüberstellung der betreffenden Objekte lehren.

Die meisten erwachsenen Rana bravanus stehen rücksichtlich der Färbung der Rana elegans sehr fern, um so mehr nähern sich Rana elegans aber die Jungen ihrer längsstreifigen Varietät und noch mehr die alten längsgestreiften Individuen, deren Rücken völlig aufgehellt ist. Sie unterscheiden sich eigentlich nur noch dadurch von Rana elegans, dass bei ihnen die äusseren Postocularstreifen von zahlreichen Verblassflecken durchsetzt sind, während diese Streifen bei Rana elegans noch einfarbigs schwarz sind. Einen fundamentalen Artunterschied wird darin Niemand sehen.

Weiteres Vergleichsmaterial und vor Allem eine direkte Vergleichung der beiden Buch-Arten werden lehren, ob sie wirkliche Natur-Arten sind. 


\section{Rana albolabris Hall.}

Dar es Salaam; I Individ.; Stuhlmann S.; 1895.

Dorf bei Kibissibili; I Individ.; Stuhlmann S.

Bukoba; I Individ.; Stuhlmann S.; I89I.

\section{Chiromantis rufescens Gthr.}

Lewa in Usambara; 2 Individ.; Stuhlmann S.; 26. Sept. I889; Pfeffer in Stuhlmann I892, S. 24.

\section{Chiromantis xerampelina Ptrs.}

Kakoma; 2 Individ.; Böhm S.; Mus.-Nro. 8246; Peters in Mossambique Bd. III, S. I 72 .

Usegua; I Individ,; Oscar Neumann S.

\section{Phrynobatrachus natalensis Sm.}

Festland von Sansibar; Mehrere Individ., Peters S.; Peters, Mossambique Bd. III, S. I 56 .

Sansibar; 4 Individ.; Oscar Neumann S.

Usambara; 20 Individ., junge, halberwachsene und erwachsene; Oscar Neumann S.

Sansibarküste; 2 Individ.; v. d. Decken S.; Peters in Decken S. I8.

Lorgu-Busch in Usagara; 8 Individ.; Stuhlmann S.; 27. Juni 90.

Kakoma; 64 Individ.; Böhm S.

Turu in Unyamwesi; 4 Individ.; Stuhlmann S.; 2I. Juli 90 (faul.).

Itole am Nyansa, S.W.-Ufer; 7 Individ.; Stuhlmann S.; 21. Nov. 90. Undussuma; 2 Individ.; Stuhlmann S.; I5. Nov. I89I.

Kinangiri. $4^{0} 27^{\prime}$ s. Br.; 8 Individ.; Stuhlmann S.; 12. Juni 1892.

Ohne näheren Fundort, aus Ostafrika; 2 Individ.; Stuhlmann S.; I 890.

\section{Phrynobatrachus acridoides (Cope)}

Sansibar; Typ; Cope, Journal Acad. Philad. I867 (VI) S. 198 und Boul., Cat. of Batr. sal., S. II 3.

Sansibar; 5 Individ.; Hildebrandt S.; Mus.-Nro. Ioogo.

Sansibar; I Individ.; Stuhlmann S.

Sansibar beim Clubhaus; I Individ.; Stuhlmann S., Pfeffer in Stuhlmann X, S. 24 .

\section{Gattung Rappia}

Als in Deutsch-Ostafrika und Sansibar gefundene Rappia-Arten finde ich in der Litteratur erwähnt:

Rappia flaviviridis Ptrs. = Rappia tettensis Ptrs. nach Pfeffer Stuhlmann $\mathrm{X}, \mathrm{S} .3 \mathrm{O}$, gefunden in Korogwe am Rufo.

Nro. 7818

Rappia argus Ptrs., Sansibarküste; 2 Individ.; Hildebrand S.; Mus.-

Rappia concolor Hall., Darema in Usambara; I Individ.; Conradt S.; Matschie, Gesell. nat. Freunde Berlin 19. Juli I892, S. IOI.

Rappia cinctiventris Cope, Sansibarküste; I Individ.; v. d. Decken S.; Peters in Decken S. I8. 
Darema in Usambara; I Individ.; Conradt S.; Matschie, Gesell. nat. Freunde Berlin r892, S. 99.

Rappia sansibarica Pfeffer; Sansibar; I Individ.; Stuhlmann S.; Pfeffer in Stuhlmann X, S. 30., Typ.

Rappia puncticulata Pfeffer; Sansibar, hinter dem deutschen Clubhause; Stuhlmann S.; 6. Aug. I888; Pfeffer in Stuhlmann X, S. 3 I.

Rappia vermiculata Pfeffer; Sansibar-Insel; 2 Individ.; Stuhlmann S.; 6. August I888; Pfeffer X in Stuhlmann X, S. 30.; Typ.

Die Systematik der Rappien liegt, wie bekannt, noch völlig im Argen. Seit Boulenger mit gewohntem Scharfblick das Fundament fur eine gediegene Vergleichung dieser Individuen schuf, und I'feffer auf die Wichtigkeit der IIautcharaktere hinwies, hat niemand auf diesem liundament weitergebaut; deshalb stehen wir auch heute noch vor einer ungeheuer grossen Anzahl beschriebener Rappien-»Arten " mit der Frage: sind alle diese beschriebenen Formen wirkliche Arten, d. h. sind sie nahe verwandte Thiere, unterschieden durch anatomische Charaktere, die nicht in einander übergehn, oder sind sie »Farbenvarietäten « nur einer oder weniger Arten? So lange diese Frage nicht erledigt ist, wird es natürlicherweise auch nicht möglich sein, die Rappienfauna eines begrenzten Gebietes richtig zu bestimmen; wie immer, wird dann auch hier die Frage entstehen: sind die verschiedenen Individuen Farbenvarietäten oder wirkliche Arten?

Die unverhältnissmässig grosse Anzahl der Rappien, die mir zu bestimmen oblag, das reiche Vergleichsmaterial unseres Museums, das aus zahlreichen » Typen " und solchen Exemplaren besteht, die als »Typen « zu gelten haben, weil sie direkt von den Art-Autoren an das Museum gesandt worden sind, ferner die Liebenswürdigkeit der Herren Professor Kräpelin und Dr. Pfeffer, die mir das gesammte Rappienmaterial des Hamburger Museums zum Studium überliessen, veranlassten mich zu einer eingehenden Untersuchung des auf diese Weise angesammelten Materials von circa 800 Individuen.

Um die Sache gründlich zu beginnen, sah ich zuerst von den bisherigen Artbeschreibungen $a b$ und suchte mich einfach darüber zu orientiren, in welchen anatomischen Charakteren die Individuen, welche ich untersuchen konnte, Divergenz zeigten. Um hierbei nichts $z u$ übersehen, studirte ich vorweg eingehend die Litteraturangaben über die einzelnen Arten und erhielt aus diesen Litteraturstudien das merkwürdige Resultat, dass bei den Rappien, wenn die Angaben der Autoren berechtigt waren, mit der scheinbar unbegrenzten Variabilität in der Färbung, eine unbegrenzte Variabilität in den anatomischen Charakteren vereinigt sei. Ich fand nämlich folgende Angaben betreffend die Unterschiede der Arten:

Tympanon: verborgen oder frei.

Finger: ohne Schwimmhaut, mit einer Viertel-, Knapp-Drittel-, und einer Drittel-Schwimmhaut, mit nahezu halber, mit halber und 's. Schwimmhaut.

Zehen: mit halber, nahezu ganzer oder ganzer Schwimmhaut; die Schwimmhaut erreicht alle Scheiben der Zehen mit Ausnahme der vierten.

Schnauze: merklich zugespitzt, annähernd zugespitzt, kurz zugespitzt, dreieckig, mehr lang, vorragend, kurz abgestutzt, quadratisch; Canthus rostralis deutlich abgerundet; die Frenalgegend ist schrage nach aussen geneigt.

Schnauzenlänge: gleich dem Augendurchmesser, um die Hälfte den Augendurchmesser übertreffend, etwas länger als der grösste Augendurchmesser. Nasloch: vom Augenvorderrand dreimal so weit entfernt als von der Schnauzenspitze.

Interoccipitalraum: ist mehr als doppelt so breit als ein oberes Augenlid. Kopfes。

Augenzwischenraum: $1 / 3$ der Länge des Kopfes, $1 / 2$ der Länge des 
Das Tibio-Tarsal-Gelenk: erreicht nicht das Auge, erreicht das Auge, geht bis zum Vorderrand des Auges, vor das Auge, fast bis zur Schnauze, bis zur Schnauzenspitze. Der Querknochen des unteren Tarsusgelenks reicht bis zur Schnauzenspitze.

Hautcharaktere: Rücken gewöhnlich glatt, bei einer Art mit einigen flachen Warzen. Kehle, Bauch und Oberschenkel-Unterseite bald glatt, bald körnig• oder grobkörnig, oder granulös oder tuberculär. Erwähnt werden auch: in der Mundgegend einige Warzen.

Hautanhänge: Distinkte Falte um das Abdomen; sie kann auch fehlen. Männchen mit Kehlsack, aber ohne anhängende Scheibe, oder mit anhängender Haftscheibe, die Haftscheibe kann die Brust decken und nierenförmig sein. An der Brust Querfalten oder keine; auch wird an ihr "eine doppelte Querrunzel « erwähnt. Ferner wird erwähnt eine Falte entlang der Wange und eine Haftscheibe am Bauch.
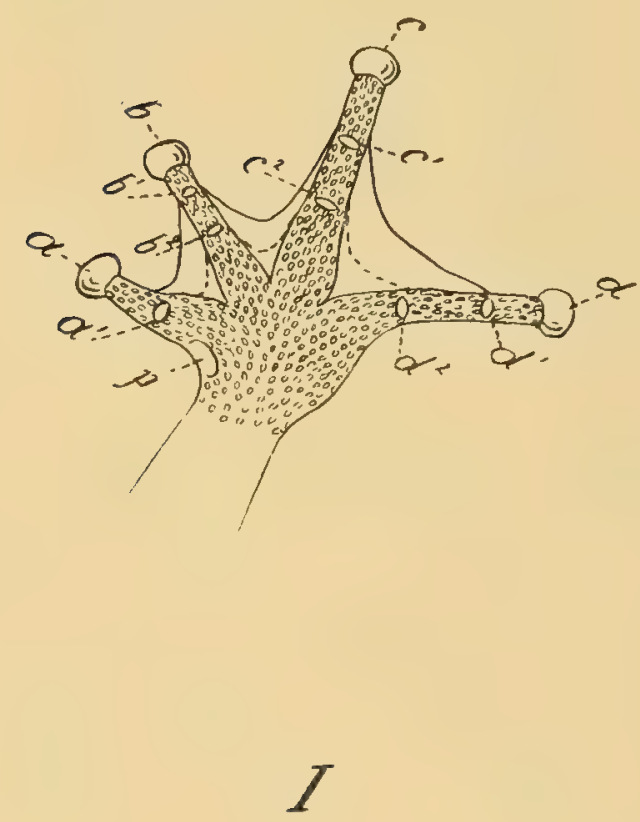

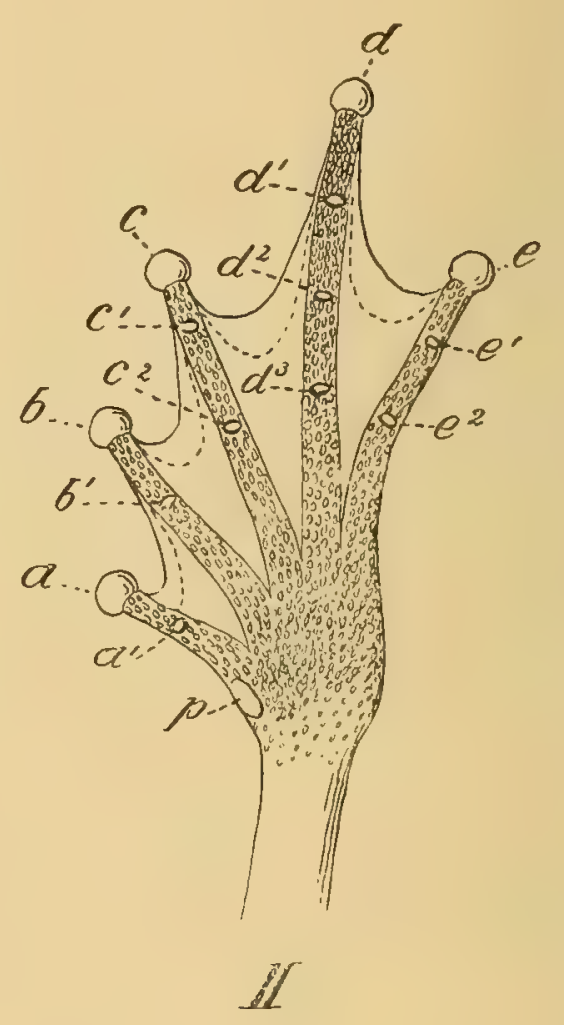

Fig. G.

Körperform: Körper dick, dicker als der Kopf, bei anderen schlank, dünner als der Kopf.

Für die meisten der aufgezählten Unterscheidungsmerkmale ergiebt die Nachprüfung, dass sie systematisch nicht verwerthbar sind, und von den meisten der citirten Angaben muss leider gesagt werden, dass sie trotz scheinbar grösster Genauigkeit durchaus nichtssagend sind. Von den Angaben, welche das Tympanum betreffen, gilt das nicht, um so mehr von denjenigen, welche darauf berechnet sind, von der Grösse der Hand- und Fussschwimmhäute eine Vorstellung zu erwecken. Beneidenswerth ist der Forscher, welchem es möglich ist, unter Lupenbenutzung an oft recht kleinen und mehr oder weniger vertrockneten Froschhänden eine Viertel-, eine Drittel-, eine nahezu halbe und eine halbe Schwimmhaut zu unterscheiden, da das aber leider nicht jeder kann, entschloss ich mich von der Schätzung der Schwimmhäute ganz abzısehen und habe mich einer 
Methode bedient, die auch der simpelste Forscher nachprifen kann. Ich zeichnete mit peinlichster Genauigkeit die Hände und Füsse der von mir zuerst untersuchten Rappia mit gespreizten Fingern und dadurch gespannten Schwimmhäuten und verglich mit diesen Zeichnungen alle anderen Rappienhände und -Füsse. Hierbei ergab sich, dass die mir vorliegenden Rappien der Grösse ihrer Schwimmhäute nach nur in zwei Gruppen gesondert werden können. Die beigegebene Textfigur $G$ zeigt diese beiden Typen vereinigt in je einer Zeichnung. Fig. G, I zeigt die Schwimmhäute an der Hand beider Formen, Fig. G, II die der Füsse. Die kleinen Schwimmhäute der einen Form sind punktirt, die grossen der anderen in Linien ausgefuhrt. Sie können so sehr gut miteinander verglichen werden.

Direkte Uebergänge zwischen diesen zwei Schwimmhautformen fand ich nicht. Das ist ganz naturlich: die Unterschiede sind im Grunde nur quantitativ und ausserdem sehr gering. Ein nur geringes Wachstum der kleineren Schwimmhautformen würde sofort das Entstehen der grossen veranlassen; und umgekehrt würden durch ein geringes Schrumpfen der grossen Schwimmhäute die kleinen entstehen, d. h. eine Form würde alsdann ohne Zwischenformen in dic andere übergehen.

Die Rappien, welche mir vorliegen, können in Rücksicht auf ihre Vorderkopfformen in drei Gruppen getheilt werden. Ich unterscheide nämlich erstens eine spitzschnauzige, kleinmäulige Form. Ihre Schnauzenspitze überragt knopfartig die Nasenlöcher; ihr Oberkiefer fällt nicht senkrecht, sondern schräg nach innen $a b$, sodass ihre Maulöffnung etwas klejner ist, als ihr Schnauzenrand, welcher von den beiden Canthus rostrales begrenzt wird. Als Typus kann gelten Rappia tettensis Ptrs.

Die zweite Form ist kurz- und stumpfschnäuzig - mopskopfartig - und hat ein massig grosses Maul. Ihre Schnauze ist so abgestumpft, dass ihr Vorderrand als gerade Linie die Naslöcher verbindet, ihre beiden Canthus rostales sind etwas nach innen eingebuchtet. Ihr Mund ist nur ganz wenig grösser als ihr Schnauzenrand, welcher von den beiden Canthus rostrales begrenzt wird. Ihr Oberkiefer steht deshalb nicht senkrecht, sondern ist etwas nach aussen gegen die Horizontalebene geneigt. Auch unsere Laubfrösche haben diese Schnauzenform; als Typus kann gelten Rappia marmorata.

Die dritte Vorderkopfform der Rappien ist grossmäulig, verflacht-schnauzig. Ihre Canthus rostrales treten nicht stark hervor, sondern verfliessen sanft in den Oberkieferbezirk. Ihre Ober- und Zwischenkiefer liegen schräg, fast horizontal, sodass ihre Aussenwand sehr schräg nach aussen gerichtet ist. Die Schnauze des Thieres macht gewöhnlich den Eindruck, als wäre sie über die Naslöcher hinaus verlängert; sie ist es aber nicht, der Anschein davon wird durch die Schrägstellung der Zwischenkiefer hervorgerufen.

Da sowohl bei den Rappien mit grossen, wie bei denen mit kleinen Schwimmhäuten diese drei Schnauzenformen vorkommen, so könnte man daran denken, die mir vorliegenden Rappien nach den Schwimmhäuten in zwei Gruppen, dann nach der Schnauzenform in je drei Arten zu sondern. Leider ist dies nicht möglich, denn, wie bekannt, sind bei den Fröschen sowohl Ober- wie Zwischenkiefer am Kopfskelett beweglich eingelenkt, und sie können deshalb auch stark gegen das Kopfskelett und gegen einander verschoben werden, was schon beim Athmen der Thiere und besonders dann, wenn sie Beute verschlingen, zu erkennen ist. Daher steht es bisher noch durchaus nicht fest, dass die beschriebenen Schnauzenformen der Rappien »fixirte "Bildungen sind, obgleich es wenigstens für die ersten beiden Formen wahrscheinlich ist. Wie sich aber die breitmaulige Kopfform der Rappien zu der mopskopfartigen Form derselben verhält, kann ich noch nicht sagen; es scheinen mir hier noch Uebergänge vorhanden zu sein.

Des Weiteren ist von allen Maassangaben, welche bei Fröschen den Augendurchmesser und die Schnauzenspitze zum Ausgangs- und Zielpunkt haben, zu 
bemerken, dass sie jeder Sicherheit entbehren. Das Auge der Frösche kann bekanntlich in die Augenhöhle hineingezogen werden und weit aus ihr hervortreten. Thiere, welche in Spiritus abgetödtet wurden, haben bald die eine bald die andere Augenstellung, und es erscheint das Auge deshalb bei ein und derselben Art bald auffallig klein, bald übertrieben gross. Sicher kann der Augendurchmesser der Frösche nur dann gemessen werden, wenn das Auge aus seiner Höhle herausgenommen wird. Ebenso ist die Schnauzenspitze der Frösche, wie schon erwähnt, am Kopfskelett stark beweglich, sie kann stark vorgestossen und zurückgezogen werden, also bilden beide Objekte keine sicheren Ausgangspunkte für exakte Messungen.

Die Methode, die Beinlänge eines Frosches zu messen, indem man das Bein am Körper des Thieres entlang führt, bietet so viele Fehlerquellen allergröbster Art, dass geringe Divergenzen zwischen zwei Individuen, die auf diese Weise konstatirt sind, iiber die systematische Stellung der Individuen garnichts aussagen. Die Maasse werden ganz verschieden bei ein und demselben Thier, wenn es trächtig ist oder nicht, wenn es gut genährt oder abgemagert ist; ferner werden die Maasse vollständig verschieden sein, wenn das Thier mit gekrümmter Wirbelsäule gemessen wird, oder wenn es gerade gestreckt ist. Und in der That finde ich, dass scheinbare Divergenzen in der Gliedmaassenlänge der Rappien sich häufig sofort ausgleichen, wenn man die Wirbelsäule der Thiere gerade streckt und sie misst; unter diesen Umständen reicht bei allen erwachsenen Rappien das Tibio-tarsal-Gelenk am Körper entlang geführt bis zum Vorderrand des Auges oder nur ganz wenig über denselben hinaus. Bei jüngeren Thieren ist das Bein gewöhnlıch etwas kürzer, das ist aber ganz natïlich, da bei jüngeren Fröschen überhaupt die Hintergliedmaassen im Verhältniss zum Körper kürzer sind als bei alten Thieren; wie jeder erkennen kann, der das Wachsthum der Frösche verfolgt. Aus alledem folgt: geringe Divergenzen der Hintergliedmaassenlänge, welche zwei, zweifellos nahe verwandte Individuen zeigen, liefern noch keinen Beweis dafür, dass die Individuen als. Arten zu trennen sind.

Die Körperform der Frösche und speciell der Rappien ist zweifellos bei ein und demselben Thier ungemein variabel. Schlecht genährte erwachsene Thiere haben einen dïnnen, langgestreckten Leib und einen, im Verhältniss dazu, scheinbar sehr grossen und breiten Kopf. Etwas besser genährte Individuen haben die Form einer Acht, ihre Kopfbreite entspricht nun ungefähr ihrer Bauchbreite und erscheint im Verhältniss zum Körper mässig gross. Ueppig ernährte Individuen oder solche, welche vor der Begattung stehen, haben einen unförmig dicken, plumpen Leib, und ihr Kopf erscheint jetzt im Verhältniss zum Leib geradezu klein. Genaue Maasse in Rücksicht auf Kopfbreite und Gesammtkörper würde man vielleicht erhalten, wenn man bei den betreffenden Thieren die Koptbreite zwischen den Mundwinkeln messen und dann die Länge des gerade gestreckten Körpers - von der Schauzenspitze bis zum Ende des Sacrums gemessen - damit vergleichen würde. Aber auch diese Maasse würden für die Artbestimmung sehr nahe verwandter Individuen nicht ohne Redenken benutzbar sein, denn bei den Fröschen wächst bis ins Alter hinein die Wirbelsäule stärker als der Kopf, der bei den Fröschen schon von vornherein sehr gross angelegt wird, und daher verschieben sich bei älteren Thieren das Verhältniss der Kopfbreite zur Körperlänge zu Gunsten dèr Körperlänge. Also auch diese Maasse wären für Art-Bestimmungen nur innerhalb gewisser Variabilitätsgrenzen zulässig.

Bei Betrachtung der Hautcharaktere der Rappien kann man wohl von allen Hautfalten gänzlich absehen. Bei allen Fröschen ist die Haut so lose am Körper befestigt, dass sie je nach der Stellung des Thieres verschiedene Falten schlägt. So entsteht bei den Laubfröschen eine "Falte entlang der Wange", die über die Körpergelenke der Gliedmaassen hinweg bis zum After ziehen kann, 
wenn das Thier seinen Körper in eine Vertiefung eindrückt. Die »distinkte Falte um das Abdomen " entsteht bei unseren Laubfröschen, wenn das Thier Koth lassen will und während dieses Aktes. Da viele Thiere beim Abtödten in Spiritus aus Angst Koth entleeren oder sich zwischen bereits abgetödtete Thiere zwängen, so ist kein Wunder, dass bei manchen der in Spiritus getödteten Rappien Falten gefunden werden, die bei diesen Thieren sonst nur vorübergehend auftreten, im Spiritus aber durch Eiweissgerinnung »fixirt « worden sind.

Auch in Betreff der Hautdruisen finde ich bei allen von mir untersuchten Rappien keinen Unterschied. Dass die Drüsen bald etwas mehr, bald etwas weniger hervortreten, beruht darauf, dass die Haut bald mehr gerunzelt, bald glatt fixirt worden ist. Auch unsere Laubfrösche haben bald glatte, bald stark gerunzelte Haut. Es kann auch andererseits daher kommen, dass die Drüsen bei einigen Thieren gefüllt, bei anderen entleert sind. Keine der von mir untersuchten Rappien hat veine Haftscheibe« am Bauch. Manche von ihnen aber haben eine Körperhaltung, die eine solche Haftscheibe vortäuschen kann. Diese Thiere haben nämlich die Seiten des Körpers stark eingezogen, wobei der Rücken des Thieres gewöhnlich im Sacralgelenk stark winklich eingeknickt ist. Dies ist in Folge des Umstandes, dass die Abdominalmuskeln der Thiere, welche vom Becken schräg gegen den Brustgürtel ziehen, stark kontrahirt sind. Durch diese Kontraktion erzeugen sie zugleich zwei vorspringende Hautfalten an den Seiten des Bauches, zwischen welchen die Bauchhaut grubig einsinkt. Das sind die scheinbaren Ränder der Saugscheibe und diese Scheibe selbst, die besonders dann vorgetäuscht wird, wenn in der Grube ausserdem noch die Haut in viele Querfalten gelegt ist.

Eine solche Stellung nehmen übrigens Laubfrösche jedesmal dann ein, wenn sie ein grösseres Thier hinuntergewürgt haben und es nun durch Kompression des Leibes ersticken wollen.

Von den mir vorliegenden Rappien, deren Bauch eine derartige, voll ausgebildete Saugscheibenform hat, nehme ich an, dass sie kurz vor dem Absterben in. Spiritus Luft aus den Lungen ausgestossen haben, und nicht mehr die Kraft besassen, den Körper in die natürliche Form zurückzuführen.

Endlich muss ich noch mit einigen Worten auf die Schallblasen der Rappien eingehen. Die Schallblasen der männlichen Rappien sind denen unserer Laubfrösche ähnlich gestaltet, aber viel grösser und von viel festerer Hautkonsistenz. Ausserdem haben sie - wenigstens bei Rappia tettensis - eine ontogenetische Entwicklung seltsamster Art, und es ist daher nicht wunderbar, dass solche ontogenetische Entwicklungsstadien einer Rappienschallblase als specifische Charaktere gewisser Rappienarten beschrieben worden sind.

Bei Rappia tettensis, von welcher Form mir viele Männchen vorliegen, beginnt die Schallblase ihre ontogenetische Entwicklung als eine Art Querfalte an der Kehle des Thieres. Diese Falte wächst dann dadurch bestandig gegen den After hin fort, dass sich die Haut der Kehle des Thieres, soweit sie neben dem hinteren Ende der Schallblase liegt, und von ihr beim Wachsen überdeckt wird, zuerst unter ihr vorwölbt, dann an Konsistenz gewinnt und so zum Hinterende der Schallblase wird. Die Schallblase entsteht demnach als Querfalte an der Kehle des Männchens (Fig. H, I), dann wölbt sich an den beiden Enden dieser Falte die Kehlhaut nierenförmig vor $(\mathrm{H}, \mathrm{II})$, bildet sich später zur Schallblasenhaut um, wodurch die Blase nierenförmig wird (H, III) und oft spitze Ecken, zuweilen sogar in der Mitte ihres Hinterrandes eine Art Einkerbung zeigt, dann rundet sich die Schallblase auf Kosten der Kehlhaut eiförmig ab (H, IV) und wird zum Schluss zu einem so grossen Oval, dass sie im Maximum ihrer Ausbildung das ganze Schultergelenk des Thieres deckt $(\mathrm{H}, \mathrm{V})$.

Hat die Schallblase diese Entwicklung erreicht, dann ist ihre Haut in der Mitte sehr stark verdickt und dient sicher dazu, das Thier an glatten Gegen- 

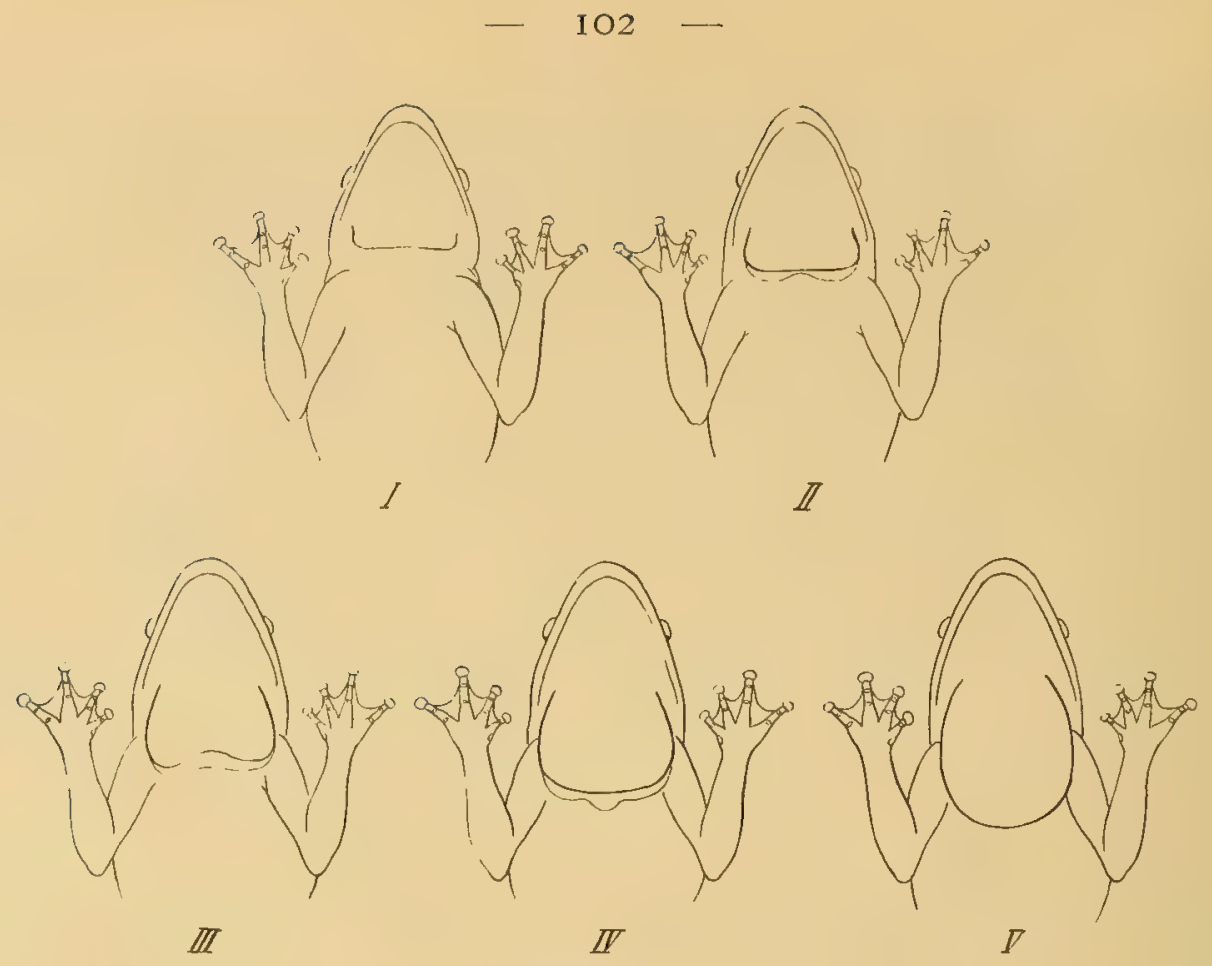

Fig. H.

ständen festzuhalten. Eine Haftscheibe - d. h. einen Apparat mit freien Rändern - hat diese Schallblase aber trotzdem nicht, höchstens ein Haftpolster.

$\mathrm{Ob}$ bei allen Rappienformen, welche mir vorliegen, die Schallblasenentwicklung in dieser Weise verläuft und bis zu demselben Endpunkt gelangt, konnte ich bisher aus Mangel an Material nicht konstatiren.

Es sind nunmehr alle anatomischen Charaktere durchgesprochen, welche für die Bestimmung der Rappienformen bisher in Anwendung gebracht wurden, und es hat sich gezeigt, dass von ihnen nur ganz wenige zu dem Zweck geeignet sind.

Nachdem ich mich hiervon überzeugt und den vergeblichen Versuch unternommen hatte, die Individuen nach diesen wenigen anatomischen Charakteren in Arten zu sondern, schlug ich den Weg ein, der ein besseres Resultat erwarten liess. Jedem Forscher, der eine grosse Zahl Rappien untersucht hat, fällt sofort auf, dass die ihm vorliegenden Individuen, abgesehen von zweifelhaften Formen, in eine grössere Anzahl sehr ausgesprochener Farbenvarietäten zerfallen. Es wird dies auch aus der Litteratur sofort klar, wo die meisten der beschriebenen Arten nichts anderes als Farbenvarietäten mit sehr charakteristischer Pigmentation sind. Farbenvarietäten sind natülicherweise keine Arten, sie stellen aber jedenfalls eine engere Gruppe von Individuen einer Art vor. Ich gruppirte nun die mir vorliegenden Individuen nach Farbenvarietäten, mit den ausgesprochensten Varietäten beginnend. Nachdem ich dies gethan hatte, legte ich mir die Frage vor: Stimmen die Individuen, welche meiner Ueberzeugung nach ein er Farbenvarietät anzugehören scheinen, in allen anatomischen Charakteren genau überein oder nicht?

Diese Frage ist sehr wichtig, denn lässt sich nachweisen, dass alle Individuen einer Farbenvarietät in allen ihren anatomischen Charakteren genau übereinstimmen, so ist kein Zweifel, dass die Individuen der Farbenvarietät nur einer Art angehören. Stimmen sie nicht in allen anatomischen Charakteren genau überein, so liegt die doppelte Möglichkeit vor, dass wir in den gleich gefäbten Individuen parallele Farbenvarietäten mehrerer Arten vor uns haben oder anatomisch variirende Individuen der Farbenvarietät einer Art. Das letztere wird dann der Fall sein, wenn sich nachweisen lässt, dass die Variabilität der anatomischen Charaktere 
innerhalb einer Farbenvarietät eine solche ist, wie sie bei Individuen einer Art vorkommen kann.

Die konsequente Durchfulhrung dieser Untersuchungsmethode, auf deren Nothwendigkeit schon Pfeffer hingewiesen hat, ergab sehr interessante Resultate, einnal über das Entstehen und die Fortentwicklung von Farbenvarietäten, zweitens über das Verhalten der Farbenvarietäten zu anatomischen Charakteren, drittens über die Rappien selbst.

Ehe ich mich den einzelnen Farbenvarietäten der Rappien-Gattung zuwende, will ich indess $\mathrm{zu}$ sčhildern suchen, wie Farbenvarietäten entstehen und sich fortbilden. Da ich hierbei eine fast unübersehbare Litteratur zu berücksichtigen habe, welche voll widersprechender Meinungen ist und ausserdem zeigt, dass die Autoren sich vielfach missverstanden haben, weil mancher von ihnen so ausgedehnte optische, physiologische und Litteraturkenntnisse bei seinen Lesern voraussetzte, dass diese ihm in seinen Auseinandersetzungen nicht folgen konnten, habe ich mich selbst genöthigt gesehen, gerade im optischen und physiologischen Theil meiner Auseinandersetzungen ausfuhhlicher zu sein, als es mir selbst erwünscht war. Sollte ich an einigen Stellen nach Ansicht des Lesers zu ausführlich geworden sein, verzeihe man es in Rücksicht auf meine Hoffnung, dass ich durch diese Auseinandersetzungen nicht nur eine sichere Grundlage fur meine eigenen Untersuchungen gewonnen habe, sondern auch für alle späteren Arbeiten, die über dieses schwierige Kapitel der Zoologie noch erscheinen werden. Ich gehe dann sofort auf die Rappien ein, welche "von unendlicher Variabilität in der Färbung ", wie Boulenger sagt, jene Gesetze in geradezu wunderbarer Weise illustriren.

Da sich Pigmentationsbilder nicht beschreiben lassen, habe ich mich entschlossen, eine unverhältnissmässig grosse Zahl von Individuen zeichnen zu lassen, in einer Anordnung, welche dem Beschauer gestattet, jede Farbenvarietät in ihrer Entwicklung und Fortbildung klar zu übersehen. Es sind dabei nur Individuen gezeichnet, die mir selbst vorgelegen haben. Auch sind natürlicherweise nur solche Individuen gezeichnet worden, welche das Entstehen und die Fortbildung einer Farbenvarietät klar erkennen lassen, oder solche, welche in dem mir vorliegenden Material die einzigen Vertreter einer Farbenvarietät waren. Zahlreiche andere Individuen, welche ebenfalls diesen Reihen angehören, habe ich nicht zeichnen lassen, obgleich sie es wohl verdienten; denn unter den von mir untersuchten circa 800 Individuen stimmt keins mit einem der anderen absolut genau in der Färbung überein. Jedes dieser Individuen gehört zwar einem bestimmten Formenkreis oder Pigmentationstypus an, hat aber ausserdem in diesem eine, wenn auch noch so geringe Individualität. Es bestätigt sich also auch hier das Gesetz: Bei belebten Naturgebilden giebt es keine Kongruenz der Form, nicht einmal Analogie im streng mathematischen Sinne des Wortes.

Die Tafel hat aber auch sonst noch ihre Berechtigung:

Noch nie sind auf einem einzigen Blatt so viele Rappienformen neben einander abgebildet worden, ferner enthält dieses Blatt alle Rappien-Arten, die von Peters beschrieben sind und deren Typen das Berliner Museum hat; mit Hilfe dieser Tafel und des Textes dïften sie mühelos nachzubestimmen sein. Drittens wird durch diese Tafel ein etwas intelligenter Sammler sofort im Stande sein zu erkennen, zu welcher der gezeichneten Gruppen eine von ihm gefangene Rappie gehört; er kann aus dieser Tafel beurtheilen, ob sein Fangobjekt von den gezeichneten Thieren in bemerkenswerther Weise verschieden ist, und er kann so unser Rappienmaterial olnne grosse Mühe vervollständigen, indem er die den Reihen noch fehlenden Glieder für das Museum sammelt, oder indem er den Reihen neue Zweige anfügt, oder indem er jene Aeste und Zweige der Tafel, welche noch keine Spitze haben, mit solchen versieht. 
Ich füge hier noch bei: Eine Reihe solcher Endglieder besitzt das Museum bereits, aber nicht alle sind in die Tafel aufgenommen worden; sie alle sind Individuen, welche kaum noch eine Spur einer Zeichnung aufweisen, oder die ganz ohne Zeichnung sind. Es wäre zwecklos gewesen, sie zu zeichnen, weil die Tafel alsdann nur ihre Umrisse enthalten hätte und an der Abbildung selbst demnach nichts zu sehen gewesen wäre. Gerade diese fast farblosen Thiere zu bestimmen, ist aber sehr schwer, weil hier fast nur anatomische Charaktere zu berücksichtigen sind; diese Thiere zeigen am besten, wie eng alle Rappien mit einander verbunden sind.

Die Abbildungen geben das Farbkleid der dargestellten Individuen peinlich genau, weniger genau ist der Bau der Individuen wiedergegeben, er ist fast immer aus dem Grunde etwas schematisirt, weil bei jedem Individuum auch die Farblagerung an den Oberlippenrändern und Körperseiten zu berücksichtigen war, und dies konnte nur erreicht werden, wenn das Thier etwas verbreitert gezeichnet wurde; auch durfte aus naheliegenden Gründen nicht zu viel Schatten in die Bilder gelegt werden. Trotz alledem aber ist in den Abbildungen auch noch die Körperform der Thiere annähernd gewahrt; es ist zu erkennen, ob das Thier langgestreckt oder plump, stumpf- oder spitzschnäuzig war. Die Abbildungen entsprechen daher allen Anforderungen, die man wissenschaftlich an sie stellen kann; die Tafel ist eben eine Musterleistung, wie sie von dem begabten Zeichner, der zugleich tüchtiger Zoologe ist, zu erwarten war.

Ehe ich zur Tafelerklärung übergehe, erst einige grundlegende Auseinandersetzungen über die dabei in Betracht kommenden Begriffe und Erscheinungen.

\section{Abschnitt I. Ueber die Begriffe: Farbe und Färbung, Farblage und Farbkleid.}

Farben sind diejenigen Aetherschwingungen, unter welchen ein Objekt dem Auge erscheint.

Jede der Spektralfarben: roth, gelb, grü, blau oder violett sind Aetherschwingungen von specifischer Wellenlänge und Geschwindigkeit.

Indem sich solche specifische Aetherwellen von der Lichtquelle gradlinig fortpflanzen, erzeugen sie Lichtstrahlen von specifischer Farbe.

Weiss ist keine Spektralfarbe; es ist das Gemisch aller Spektralfarben.

Schwarz ist der Mangel jeder Farbe.

Die Begriffe Farbe und Färbung sind fast identisch. Mit dem Namen Farbe "bezeichnet man das Subjekt der Farb-Erzeugung, mit dem Namen Färbung das Resultat seiner Thätigkeit.

Die Begriffe Farblage und Farblagerung bezeichnen die Art, wie Farben quantitativ und qualitativ in ihrem Verbreitungsbezirk vertheilt sind; der Begriff nimmt keine Rücksicht auf die Farben, welche in dem betreffenden Lager verwendet sind; es kann demnach ein und dasselbe Farblager in verschiedenen Farben aufgebaut sein. Der von mir vorgeschlagene Begriff "Farblagerung « ist identisch mit dem von anderen Autoren gebrauchten Wort: Zeichnung (der Thiere).

Das Farbkleid ist das Resultat der Zusammenwirkung von Färbung und Farblagerung.

\section{Abschnitt II. Die hier in Betracht kommenden optischen Gesetze.}

Nur Erleuchtungs, nicht Emissionsfarben spielen im thierischen Farbkleid eine Rolle und sind hier zu untersuchen.

Die Quelle all' dieser Erleuchtungsfarben ist in letzter Instanz das diffuse Sonnenlicht.

Der Bequemlichkeit wegen unterscheidet man unter ihnen in der Thierphysiologie: Lokal- und Strukturfarben. 
Lokalfarben sind diejenigen Farben, welche von einem Körper durch Farbenabsorption erzeugt werden und welche Ausfluss sind seiner chemischen Konstitution.

Strukturfarben nennt man diejenigen Farben, welche auf anderem Wege, z. B. durch Zerstreuung und Brechung des Lichtes, erzeugt werden, sei es ohne oder in Verbindung mit Absorptionsfarben.

\section{Abschnitt III. Grundlegende Gesetze der Optik.}

Weisse Lichtstrahlen, welche einen Körper treffen, werden von ihm entweder zurückgeworfen oder gebrochen.

Der gebrochene Lichtstrahl wird entweder verschluckt (absorbirt) oder durchzieht ungehindert den Körper (er wird von ihm ungehindert hindurchgelassen).

Die vom Körper zuriickgeworfenen Strahlen machen ihn dem Auge sichtbar.

Die vom Körper absorbirten Strahlen vermehren seine Aetherschwingungen.

Die den Körper ungehindert durchziehenden Strahlen machen ihn, sind sie gering an Zahl, durchscheinend; wenn ihn viele Strahlen durchziehen, wird er durchsichtig; gehen alle durch ihn hindurch, wird er aufgehcllt bis zur Unsichtbarkeit.

Zurückgeworfen werden die Lichtstrahlen entweder schon an der Körperperipherie oder sie dringen erst mehr oder weniger in den Körper ein und werden dann erst zurickgeworfen. Erzeugen sie beim Eindringen im Körper eine Lokalfarbe, so erscheint er bei ihrer Reflexion in dieser.

Die Art und Weise, wie ein Körper Lichtstrahlen zurückwirft, bestimmt ferner, ob er glänzend oder matt gesehen wird.

Wie Oppelt und Helmholtz bewiesen haben, entsteht Glanzempfindung in unserem Gehirn, wenn unsere beiden Augen unter ungleichen Lichteindrücken stehen. Darum wird ein Objekt weiss-glänzend von uns gesehen, wenn eins unserer Augen von ihm viel weisses Licht, das andere wenig oder gar keins erhält (wenn das eine Auge an ihm weisse, das andere schwarze Farbe sieht). Matt erscheint uns deshalb nur jenes Objekt, welches Lichtstrahlen gleichmäsig nach allen Seiten reflektirt, weil nur im gleichmïssig zerstreuten Licht beide Augen eines Beschaucrs gleichmäsisg durchleuchtet sind. Jeder Körper mit unregelmässiger Reflexion, d. h. jeder, von welchem das Licht in Strahlenbüscheln zerstreut wird, erscheint im Glanz, weil von ihm das eine Auge viel Licht, das andere wenig enthält.

\section{Lokalfarben.} absorbirt.

Jeder Körper erscheint in der Farbe oder in den Farben, die er nicht

Schwarz erscheint demnach der Körper, der alle Strahlen, die ilhn treffen, verschluckt.

Weiss derjenige Körper, der alle weissen Lichtstrahlen, die ihn treffen, unzerstreut reflektirt.

Wenn von einem Körper aus weissem Licht alle Spektralfarben bis auf eine verschluckt werden, gehört die Restfarbe zu den einfachen Lokalfarben.

Wenn von einem Körper aus weissem Licht nur eine Spektralfarbe verschluckt wird, können sich die nicht gebrauchten Farben zu einer Farbe vereinigen: es entsteht so eine gemischte Lokalfarbe.

Es kann also Rothfärbung dadurch entstehen, dass aus weissem Licht alle Farben bis auf Roth absorbirt sind, oder auch dadurch, dass aus weissem Licht nur grün, die Komplementärfarbe des Roth, absorbirt wird. In gleicher Weise sind Komplementärfarben: Blau und Orange, Violett und Gelb.

Je dichter ein Körper ist, desto intensiver ist seine Färbung. Auch dann, wenn ein und derselbe Lichtstrahl mehrere Male dasselbe Objekt passirt, wird 
dieses intensiver gefärbt, als ein gleiches Objekt, das nur einmal von gleichem Licht getroffen wird. So erscheint rothes Glas auf weissem Grund bei auffallendem Licht lebhafter gefärbt, als in reiner Luft bei gleichem Licht. Das von oben in die rothe Scheibe eintretende, dann von dem weissen Glas vollständig zuriickgeworfene Tageslicht passirt die rothe Scheibe zweimal und wird dadurch zur Farbenbildung besonders gut ausgenutzt.

Da es nur wenig Spektralfarben giebt, auch wenn Weiss und Schwarz als Farben hinzugerechnet werden, andererseits aber unzählige chemische Verbindungen vorhanden sind, deren jede gefärbt erscheint, so müssen Körper von oft sehr grosser Materialverschiedenheit dieselbe Färbung zeigen.

\section{Strukturfarben.}

Streng genommen muss man als Strukturfarbe schon jenes Weiss betrachten, welches als Weissglanz oder Mattweiss nicht aus dem Inneren eines Körpers, sondern von dessen Oberfläche durch Reflexion entsteht. Dies wird besonders klar, wenn ein Körper von Natur eine besondere Lokalfarbe zeigt, aber bei glatter Oberfläche oder durch Aufrauhung derselben die Lokalfarbe scheinbar verliert. So kann gefärbtes Glas mit facettirter Oberfläche unter Umständen weissglänzend sein, und wird seine Oberfläche angeätzt, wodurch auf ihr zahlreiche Spitzen entstehen, dann macht mit dem Fortschreiten der Aetzung die Lokalfarbe des Glases einer weissen Farbe Platz, welche ihre Entstehung verdankt der Lichtreflexion in den Spitzen der Glas-Oberfläche.

Sowie Spektralfarben durch Absorption entstehen können, so können sie auch sämmtlich entstehen als Strukturfarben und zwar auf vierfachem Weg: Bei der Brechung des Lichts, bei Lichtstrahlen-Interferenz, bei der Beugung des Lichts und bei Lichtreflexion aus trüben Medien.

Bei jeder Brechung des weissen Lichts findet zugleich eine farbige Zerstreuung desselben statt, da die verschieden farbigen Lichtstrahlen verschiedenes Brechungsvermögen haben und sich deshalb bei jeder Brechung von einander trennen müssen. Da indess Farben, welche einfacher oder doppelter Lichtbrechung ihre Entstehung verdanken, in der Haut der höheren Thiere nicht vorkommen, übergehe ich diese Art der Farbenbildung.

Interferenzfarben entstehen auf folgende Weise: Wie zwei Wasserwellen sich verstärken, wenn ihre Wellenberge aufeinandertreffen, sich schwächen oder aufheben, wenn ihr Wellenberg und Thal ineinanderfallen, so können auch Aetherwellen weisser Lichtstrahlen, welche einen gleichen Weg zurücklegen, sich gegenseitig verstärken, schwächen oder aufheben. Da die Aetherwellen weisser Lichtstrahlen verschiedene Farben repräsentiren, werden durch ihre Interferenz in dem Strahl verschiedene Farben ausgelöscht, andere verstärkt, und dadurch wandelt er sich zu einem Farbenstrahl um, welcher einfache oder gemischte Spektralfarben repräsentirt.

Unter den auf Interferenz der Lichtwellen beruhenden Erscheinungen spielen in der Thierphysiologie vor allem jene Farbenerscheinungen eine Rolle, welche sich zeigen bei Beleuchtung einer Substanz ohne Lokalfarbe, wenn dieselbe in einer sehr dünnen Schicht vorhanden ist und auf beiden Seiten von stärker oder schwächer lichtbrechenden Mitteln begrenzt wird. Beispiele derartiger Substanzen sind dünne Glasplättchen; die oben und unten von Luft umgeben sind. Das auf diese Plättchen fallende Licht wird an ihrer Oberfläche theils zurückgeworfen, theils hindurchgelassen. Der in ihr Inneres eintretende Lichtbetrag erleidet dann an der hinteren Glasplättchenwand eine zweite Spaltung, ein Theilbetrag geht durch die Wand in die untere Luftschicht hinaus, der andere wird zur Glasoberfläche zurückgeworfen und kann, wenn er dort hindurchgelassen ist, mit den von der Glasoberfläche zurückgeworfenen Strahlen interferiren, weil die unten und oben zurückgeworfenen Strahlen parallel laufen, also bei genügender 
Anzahl denselben Weg haben werden. $\mathrm{Ob}$ sie interferiren, hängt von der Länge der Lichtwellen und der Dicke der Glasschicht ab. Wenn für irgend eine Lichtstrahlengattung, z. B. für rothes Licht, zwischen der Länge der Aetherwellen und der Glasschicht ein solches Verhältniss stattfindet, dass die an der vorderen und hinteren Fläche der dünnen Schicht reflektirten Wellen bei ihrem Zusammentreffen sich in gleichen Schwingungszuständen befinden, sich also im vollsten Maasse verstärken, so wird für die übrigen Strahlengattungen, da ihre Wellenlänge von der des rothen Lichtes verschieden ist, diese Bedingung nicht in gleichem Maasse erfüllt sein, dieselben werden sich zum Theil weniger verstärken wie die rothen Strahlen, zum Theil ganz auslöschen, und die dünne Glasplättchenschicht wird folglich dem Auge des Beobachters in der Farbe der am meisten verstärkten Lichtstrahlen erscheinen, d. h. roth gefärbt sein. Solch' eine Bedingung für Rothfärbung wäre erfüllt, wenn die Plättchendicke gleich wäre einer rothen Lichtwellenlänge, dann würden bei der Interferenz der oben und unten reflektirten Lichtstrahlen die rothen Wellen einander genau decken und sich so zum Maximum verstärken.

Dass hier bei der Interferenz die Dicke der Glasplättchen eine Rolle spielt, wird sofort klar, wenn man Plättchen von verschiedener Dicke unter demselben Lichteinfluss vergleicht, dann zeigt das dickste Plättchen rothes Licht, weil dessen Wellenlänge die grösste ist, bei den dünneren Plättchen zeigen sich entsprechend der abnehmenden Plättchendicke nach der Reihe die übrigen Spektralfarben von Roth bis Violett, indem immer jene Farbe zur Lokalfarbe wird, deren Wellen sich am meisten verstärken. Die Intensität der jeweiligen Färbung solcher Plättchen hängt ausserdem wesentlich ab von der Differenz zwischen der Reflexionsfähigkeit der dünnen Schicht und der Substanz, welche sie umgiebt.

Interferenzfarben werden auch an Seifenblasen gesehen, deren dünne Seifenwasserschicht, wie die eben besprochenen Glasplättchen, an der Aussen- wie Innenseite von Luft umgeben ist. Die Farben wechseln hier, wenn die Blase grösser und dadurch ihre Haut dünner wird. Es zeigen aber ausserdem noch die verschiedenen Theile der Seifenblase verschiedene Farben, weil die Seifenhaut nicht uiberall dieselbe Stärke hat. Auf diese Weise entstehen an manchen Hautstellen zahlreiche Farben nebeneinander, die zu wechseln scheinen bei Veränderung des Seh-Winkels, unter den die Blase betrachtet wird (Schillerfarben). Dieselben Erscheinungen zeigen sich, wenn eine Luftblase zwischen Glashäutchen eingeschlossen ist und wenn in Krystallen von Gyps oder Kalkspath feine Risse auftreten. Schillerfarben von ganz besonderer Farbe aber zeigen sich, wenn eine Substanz eine streifige Struktur besitzt und genïgend düne Schichten derselben miteinander wechseln.

Strukturfarben, welche durch Beugung des Lichts entstehen.

Weisse Lichtstrahlen, welche auf die scharfe Kante eines undurchsichtigen Körpers treffen, erfahren eine Ablenkung von der geraden Richtung und gleichzeitig eine Zerstreuung, wodurch sie in Spektralfarben zerlegt werden.

Sind mehrere solche Kanten eng bei einander, so können die zerstreuten Aetherwellen interferiren, und es können so einfache, gemischte oder Schillerfarben auftreten. Die Schillerfarben zeigen sich dann, wenn die Zerstreuung des weissen Lichts eine so starke ist, dass die verstärkten unter den Interferenzfarben nicht mehr zu einer Kompositionsfarbe zusammenfliessen.

Aehnliche Farbenerscheinungen treten auf, wenn weisses Licht durch eine feine Oeffnung geht.

Auf Beugung des Lichts beruhende, sehr schöne Schillerfarben entstehen besonders dann, wenn Licht auf eine Oberfläche fällt, die eine grosse Zahl feiner Gruben trägt. Die Farben wechseln dann mit dem Einfallswinkel des Lichts und deshalb auch mit dem Gesichtswinkel, unter welchem die Platte betrachtet 
wird. Sie wechseln aber auch beständig, wenn man die Platte um ihren Mittelpunkt in der Horizontalebene rotirt.

Auf Beugung des Lichts beruhen die Farben, welche man im Sonnenlicht an Spinnweben und feinen Haaren bemerkt, ferner diejenigen, welche entstehen, wenn man durch feines Gewebe nach der Sonne sielt; auch das Farbenspiel, welches an den Flügeln mancher Insekten, an der Perlmutter, an Seidenzeugen, an abgestandenen Gläsern in reflektirtem Lichte auftritt, entsteht durch die Interferenz der Lichtstrahlen bei der Strahlenbrechung; Brewster z. B. wies nach, dass die Oberfläche der Perlmutter von sehr vielen feinen Furchen durchzogen ist, und indem er Plättchen von Perlmutter in Siegellack oder Wachs abdrückte, erhielt. dieses dieselben irisirenden Eigenschaften wie die Perlmutter.

Die Interferenzfarben, welche durch trübe Medien erzeugt werden, sind in der Thierphysiologie besonders wichtig, und gehe ich deshalb darauf etwas näher ein.

Sind viele kleine Körper von gleicher Lokalfarbe und von so geringer Grösse, dass sie mit blossem Auge als selbstständige Körperchen nicht mehr wahrgenommen werden können, in einem farblosen Medium gleichmässig vertheilt, so erscheint das Medium einheitlich gefärbt in der Farbe der in ihm enthaltenen Körperchen, und es gelten für ein solches Gemenge alle Gesetze, welche für Körper gelten, welche chemische Verbindungen sind und Lokalfarben besitzen.

Die Intensität dieser Färbung hängt natürlich von der Menge der farbigen Körperchen ab, welche in der farblosen Flüssigkeit enthalten sind.

Solche Doppelmedien werden trübe genannt.

Ein solches trübes Medium, umgeben von Luft, erscheint, wie schon erwähnt, in der Lolalfarbe des trïbenden Mediums. Ist dieses matt-weiss, erscheint das trube Medium ebenso; ist die trübende Substanz glänzend-weiss, so wird es auch das trübe Medium. Sein Glanz kann aber auch noch auf andere Weise entstehen.

Liegt ein trübes Medium auf einem matt-weissen, d. h. alles Licht unregelmässig zuriickwerfenden Medium, so erscheint es von viel intensiverer Lokalfarbe, als in der Umgebung von Luft. Liegt es auf einem weiss-glänzenden Grund, so erscheint es so glänzend in seiner Lokalfarbe, als wäre es selbst glänzend. Ist es z. B. gelb gefärbt und liegt auf einer weiss-glänzenden Platte, so zeigt es Goldglanz. Der Goldglanz entsteht hier, wie er künstlich an gewissen unechten Goldrahmen hervorgebracht wird, Rahmen, die man mit Blattsilber uberzieht, um zunächst den Metallglanz hervorzubringen, und dann mit einer dünnen Schicht von stark gefärbtem Firniss überstreicht, um das Weiss des Silbers in das Gelb des Goldes umzuwandeln.

Sind in trüben Medien mehrere Körper mit Lokalfarbe enthalten, so kann ein solches Medium auch zur Entstehung von Schillerfarben Veranlassung geben.

Wird ein trübes Medium durch Mischung zweier farbloser Substanzen von verschiedenem Brechungsvermögen erzeugt und vor einem dunkeln, annähernd schwarzen Grunde in auffallendem Licht betrachtet, so erscheint es blau oder bläulich-grau. (In durchfallendem Licht braun, gelb, orange oder roth.)

Je feiner das trübende Medium ist, desto intensiver ist diese Farbenerscheinung. Je grösser die trübenden Elemente sind, um so weniger schön und gesättigt, d. h. um so mehr. mit weiss oder grau gemischt wird das Blau des zurückgeworfenen Lichts, weil durch die grösseren Elemente mehr gelbes oder rothes Licht zurückgeworfen wird.

Man kann ausserdem in dem Blau sehr verschiedene Abstufungen unterscheiden, je nach der Dicke der truibenden Schicht, welche vor dem dunkeln Hintergrunde ausgebreitet ist. Am meisten gesättigt, aber auch am dunkelsten, d. h. am lichtärmsten, ist ein Medium, so lange die trübende Schicht dünn ist; je dichter die Schicht wird, um so heller, aber auch um so blasser erscheint das Medium und geht endlich in ein bläuliches Weiss über. 
Sind die trübenden Elemente in einem so gelagerten, farblosen trüben Medium ausserordentlich klein, so muss nicht Blau, sondern Violett als Farbe des auffallenden Lichtes zur Erscheinung kommen.

Grün kann auf diese Weise nicht zu Stande kommen, sondern, wie schon erwähnt, nur Bläulich-weiss. Ist dagegen das dem dunkeln Hintergrund vorgelagerte trübe Medium gelb, so wird die Farbe des auffallenden Lichts nicht blaul, sondern grün.

\section{Abschnitt III: Die Farben der thierischen Haut.}

Diejenigen Elemente der thierischen Haut, welche in ihr durch LichtstrahlenAbsorption Lokalfarben erzeugen, sind die Pigmente. Die Farben, welche durch sie in der Haut erzeugt werden, sind, wie alle Absorptionsfarben, die einfachen oder gemischten Aetherstrahlen, welche vom Pigment nicht verschluckt werden und deshalb in das Auge des Beschauers gelangen.

Krukenberg, neben Sorby und Macmum einer der wenigen Forscher, welche die thierischen Pigmente untersucht haben, unterscheidet gelbe, gelb-rothe, rothe (gewöhnlich diffuse) Pigmente und das grüne Turacoverdin als Pigmente der Fettfarbstoffe, Lipochrome, von dem schwarzen oder braunen Körperpigment, dem Melanin, dessen chemische Natur von ihm jedoch nicht festgestellt ist. Weisse Pigmente giebt es nach Krukenberg nicht; was man früher in Reptilien- und Amphibienhäuten dafür hielt, ist nach ihm und Anderen Niederschlag von Guanin.

Diesen zahlreichen „Pigmenten«, welche von Krukenberg nur als Bestandtheile der Vogelfedern und Vogeleischalen beschrieben worden sind, steht bei den Säugethieren, Reptilien und Amphibien sicher nur ein wirkliches HautPigment gegenüber, das körnige Melanin, welches in dicken Lagen schwarz oder schwarz-braun erscheint, in durchscheinenden Lagen braunfarbig ist, bei noch stärkerer Verdünnung zuweilen intensiv roth erscheint und bei stärkster Verdünnung röthlich-gelb oder gelb aussieht. Durch Neben- und Ueberlagerung in der Haut erzeugt es bei Reptilien und Amphibien alle übrigen Farbentöne der Haut als Strukturfarben.

Aber auch bei den Vögeln dürften viele der bisher für einfache chemische Verbindungen gehaltenen Federfarbstoffe solche einfachen chemischen Verbindungen nicht sein, ja vielleicht giebt es auch bei den Vögeln nur einen wirklichen Hautfarbstoff, das braune Pigment, aus folgenden Gründen:

Selbst das körnige braune Pigment, das Melanin, ist keine einfache chemische Verbindung, sondern besteht sicherlich, wie Ehrmann es bereits ausgesprochen hat, ähnlich dem Pigment der Pflanzen, aus einer protoplasmatischen Basis und aus der in ihr enthaltenen farbigen Substanz. Beweis dafur ist: es kann diese farbige Substanz aus ihrem Träger ausgezogen werden, ohne dass der Träger seine Form und Struktur verliert; es entsteht so eime Art durchsichtigen Pigments, Pigment ohne Farbe, wie es auch 2. B. in der Europäer-Haut normalerweise gefunden wird. Zweitens ist keiner der Stoffe, welche Krukenberg, als verschiedene Farbstoffe betrachtet, bisher chemisch rein dargestellt worden, sondern Krukenberg selbst hat nur nachgewiesen, dass sie spektroskopisch voneinander unterscheidbar sind. Das können sie aber auch dann sein, wenn sie Gemenge verschiedener Substanzen, oder wenn sie isomere Gebilde sind. Drittens, und das ist das Wichtigste: es lassen sich einige dieser „Pigmente " so leicht in andere umwandeln, dass in diesen Farbstoffen entweder Körper von sehr grosser Zersetzbarkeit und naher Verwandtschaft oder isomere Verbindungen zu erblicken sind. So wurde z. B. bereits der einzige bisher bekannte grüe Federfarbstoff, das Turacoverdin, in das bei denselben Vögeln vorkommende rothe Turacin allein durch Behandlung mit Luft und Feuchtigkeit verwandelt. Haben wir es hier thatsächlich mit einer chemischen Farbenänderung oder nur mit optischen Er- 
scheinungen, etwa mit einer Strukturänderung der Plasmabasis des Pigments zu thun, welche nun ihrerseits vielleicht mit Hilfe des eingelagerten Farbstoffs eine besondere Strukturfarbe erzeugt? - Das Letztere ist sicher der Fall bei folgenden Beobachtungen:

»Etwas Aehnliches wie die Umwandlung des Turacoverdins in Turacin habe ich, schreibt V. Haecker, Archiv. f. mikr. Anat. 1890. S. 79, in der Familie der Cotingiden gefunden. Wenn man die mit einem prachtvollen purpurrothen Farbstoff getränkten, aus einem Gefüge verhornter spindelförmiger Zellen bestehenden Fiedern I. Ordn. (rami) des Ampelis (Xipholena Glog.) pompodora L. mit etwa 25 prozentiger Schwefelsäure vorsichtig erwärmend belıandelt, so wird der purpurrothe Farbstoff in einen orangefarbenen bis gold-gelben überführt, indem zugleich die wesentlichen Träger des Farbstoffs, die Pigmentkörner, deutlich hervortreten. Bei stärkerer Erwärmung und mechanischer Einwirkung zerfällt die Hornsubstanz der Feder in ihre Elemente, d. h. eben in die spindelförmigen, gelben, körnerführenden Zellen.

》Wird dagegen 50-70prozentige Schwefelsäure angewandt, so wird der rothe Farbstoff von aussen nach innen langsam in einen grünen umgewandelt. Zugleich entweicht, wie dies bei gleicher Behandlung aller luftführenden Federn der Fall ist, aus den rudimentären Luftgängen der Fieder die Luft. Bei weiterer starker Erwärmung nimmt der grüne Ton einen bräunlichen Stich an und verschwindet allmählich.৫

In ähnlicher Weise kann der Farbstoff der dunkel-weinrothen Feder des zu den Coraciadae gestellten Eurylaemus javanicus Horst. bei Behandlung mit verdünnter Schwefelsäure in Orangefarbe und Gelb überführt werden, indem zugleich die Farbstoffkörner zum Vorschein kommen. (Ein Querschnitt zeigt, dass sie in der That Träger des rothen Farbstoffs sind.) Bei Anwendung einer stärkeren Koncentration kommt gleichfalls eine Umfärbung in ein allerdings wenig lebhaftes Griin zu Stande."

In beiden Fällen ist es zweifellos das braune, in ganz dünnen Lagen gelbe Melanin, welches infolge Strukturveränderung seiner. Plasmabasis (Sichtbarwerden der Körner) und seiner Umgebung eine scheinbare chemische Veränderung erleidet.

Mag dem sein, wie es will, bei den Reptilien und ebenso bei den Amphibien, auf deren Untersuchung es hier vorliegend ankommt, giebt es in der Haut, soweit meine Untersuchungen reichen, nur einen Farbstoff, das »braune "Melanin, und dieses erzeugt durch Wechsel der Quantität oder in Verbindung mit seiner Umgebung alle ubrigen Hautfarben als Strukturfarben. Dass diese Strukturfarben übrigens sowohl bei den Reptilien wie bei den Vogelfedern und bei den Amphibien in gleicher Weise entstehen, lehrt folgende Gegenüberstellung.

\section{Hautfarbe der kaltblütigen Wirbelthiere.}

Brücke war der erste, welcher sich mit der Entstehung des Farbwechsels der Thiere, der im wesentlichen auf Strukturfarbenbildung beruht, eingehend beschäftigte und der dieses Problem trotzdem so vollständig gelöst hat, dass die spätere Zeit an seinen Resultaten kaum etwas zu ändern fand.

Die Hauptresultate seiner Untersuchungen sind unter möglichster Berücksichtigung seiner eigenen Darstellung folgende:

I. Die Farben, welche ein Chamaeleon dilepis zu verschiedenen Zeiten zeigt, rühren nicht ausschliesslich von Pigmenten her, sondern beruhen im wesentlichen auf Interferenzerscheinungen.

2. Ein Theil dieser Interferenzerscheinungen wird von den Zellen der tiefen Schicht der Oberhaut nach dem Princip der dunnen Blättchen hervorgebracht. Es liegt nämlich beim Chamaeleon in der Tiefe der Epidermis eine Schicht platter polygonaler Zellen, welche lebhafte Interferenzfarben zeigen. Ihre Wände sind einander sehr genähert und enthalten Luft. Diese Luft ist die 
dünne, durch zweimalige Reflexion die Farben erzeugende Schicht. Die Interferenzzellen liegen oft mehrfach übereinander und kommen an allen Tuberkeln vor. Gewiss ist, dass sie der Epidermis angehören, und bei der Häutung theilweise mit abgestossen werden, denn unmittelbar nach der Häutung findet man in der Haut statt dieser schön gefärbten Interferenzschicht nur eine Lage von Zellen, die bei durchfallendem Lichte braun-gelb gefärbt sind. Die neue Interferenzschicht entsteht also später, und die Ausbildung der hohlen Zellen, aus denen sie besteht, hängt wahrscheinlich in eigenthümlicher Weise mit den mechanischen Verhältnissen des Wachsthums der Oberhaut zusammen.

Nur wenn das Thier sehr dunkel ist, treten übrigens die Farben dieser Zellen als Schillerfarben selbstständig hervor, die Haut zeigt dann zahlreiche glitzernde Punkte von verschiedener Farbe. Der Glanz dieser Farben, ihre grosse, auf einen engen Raum zusammengedrängte Mannigfaltigkeit machen es schon vor der Untersuchung des betreffenden Hautstücks wahrscheinlich, dass sie Interferenzfarben sind.

3. Diese Schillerfarben der Oberhaut der Chamaeleonen sind deshalb genetisch wesentlich verschieden von dem Oberflächenschiller der Schlangen, welcher z. B. an unsern einheimischen Nattern sehr leicht zu beobachten ist, und, wie der der irisirenden Knöpfe, durch parallele Furchen erzeugt wird, welche auf jeder Schlangenschuppe zu finden sind. (Die für die einzelnen Schlangen- und auch Eidechsenarten und selbst -Varietäten charakteristische jeweilige Anordnung der diese Furchen bildenden Leisten auf den Epidermis-Schuppen hat später Leydig sehr eingehend untersucht und geschildert.)

4. Auch die lebhafteren Farben der Frösche und Chamaeleonen, namentlich das schöne Grün der Laubfrösche, rühren, fährt Brücke fort, nicht von wahren Pigmenten - sondern von Interferenzzellen her: diese sind aber anders beschaffen als die eben beschriebenen der Chamaeleonen. Bei Hyla und den übrigen Fröschen breitet sich nämlich dort, wo die Haut grün ist, über schwarzen Pigmentzellen eine Schicht von Zellen aus, deren feinkörniger und wahrscheinlich krystallinischer Inhalt zu den prachtvollen Interferenzerscheinungen Veranlassung giebt, welchen die Thiere die schöne grüne Farbe, in welche sie gekleidet sind, sowie den Perlmutterglanz ihrer Flanken und Schenkel verdanken. Diese Zellen, welche die Hautfarbe mit Hilfe der unter ihnen liegenden schwarzen Pigmentzellen nach dem Princip der trüben Medien erzeugen und von Brücke fälschlich für »normale « Pigmentzellen angesehen wurden, sind beim Laubfrosch auf der Ruckseite des Körpers und der Glieder, wo sie, wie Pflastersteine, eine dicht neben der andern liegen, polygonal, auf der Bauchseite, wo sie weiter auseinander gerückt sind, sind sie vielfach verästelt, ganz so wie man dies so oft an schwarzen Pigmentzellen sieht. Die Farben sind in auffallendem Lichte meergrün, brillantgrün, blasses gelbgriin, falbes gelb und sogenannte Fleischfarbe d. h. ein mit viel weiss gemischtes Röthlichorange; in durchfallendem Licht röthlich-orange, roth, purpur, graublau und meergrün. An den schön grünen Theilen des Thieres kommen indess nur die ersten drei Farben vor, die beiden letzten findet man nur an den grauen oder weisslichen, perlmutterglänzenden Stellen.

5. Auch bei den Chamaeleonen liegt unter der Epidermis und in der Cutis ein weisses, theilweise gelbes, seltener orangefarbenes Pigment, das Milne Edwards bereits vor Briicke als pigment superficiel blanc, jaunàtre, grisâtre beschrieben hat. (Das weisse ist krystallinisches Guanin, das gelbe und orangefarbene verdüntes Melanin. Diese Pigmente liegen immer in Zellen, nicht, wie Brücke annahm, nur bei jungen Thieren.)

6. Unter und zwischen diesen weissen Pigmentzellen liegen auch bei den Chamaeleonen dunkle Pigmentzellen, deren zahlreiche verzweigte und dicht nebeneinander gestellte Ausläufer das weisse Pigment durchdringen und bis unter die Oberhaut gelangen. 
Das Pigment dieser dunklen Zellen ist im natürlichen Zustand immer nur schwarz und in diinnen Schichten mit brauner Farbe durchscheinend; dagegen wird es in Kali theilweise mit rother und violetter Farbe gelöst.

7. An den untersuchten Chamaeleonen kamen durchaus keine anderen Pigmente vor als die zwei genannten, und alle Farben der Thiere, insoweit sie nicht der Interferenzschicht der Epidermis angehörten, wurden von diesen Thieren durch verschiedenartige Superposition und Juxtaposition des weissen und braunen Pigments hervorgebracht. Selbst das bei diesen Thieren so vielfach abgestufte und häufig so schöne Grün entsteht nur dadurch, dass unter einer dünnen Schicht gelben oder gelbweissen Pigments unmittelbar das schwarze lag; ganz so wie in der Iris blauäugiger Menschen auch kein blaues Pigment vorkommt, sondern das Blau nur dadurch entsteht, das hinter dem weisslichen, durchscheinenden Gewebe schwarzes Pigment liegt. Auch bei anderen Eidechsen und bei den Schlangen werden blaue und grüe Tinten auf ganz ähnliche Weise erzeugt. Untersucht man z. B. eine grine Schuppe von Lacerta viridis, so findet man auf derselben zu unterst eine Lage von schwarzem und darüber eine dünne, durchscheinende von weissem oder gelb-weissem Pigment, sodass, wenn man die Epidermis wegnimmt, die Schuppe blau oder blaugrün erscheint, je nachdem das helle Pigment mehr weiss oder gelblich ist. Die Epidermis selbst ist mit weingelber Farbe durchscheinend und verwandelt somit das Blau oder Blaugrau in die schönste grasgrüne Farbe, mit welcher das Thier geziert ist.

8. Das dunkle Pigment bringt, wie Milne Edwards zuerst richtig bemerkt, den Farbenwechsel hervor, indem es sich bald der Oberfläche nähert, bald in die Tiefe zurïckgeht. Die Ausläufer der Pigmentzellen werden dabei nicht eingezogen, sondern von Pigment entleert. (Diese ausserordentlich feine Beobachtung Brücke's ist erst in neuester Zeit nach den Untersuchungen von Solger und Zimmermann in ihrem vollen Werth erkannt worden.)

Betrachten wir zuerst eine Hautstelle, deren helles Pigment rein weiss ist, so wird diese weiss erscheinen, sobald das schwarze Pigment so weit in die Tiefe zuriickgezogen ist, dass das helle daruber eine Schicht bildet, die dick genug ist, um undurchsichtig zu sein; sobald aber das schwarze Pigment sich der Obcrfläche nähert, so wird das Weiss in Blau-grau übergehen und endlich, wenn es ihr schon sehr nahe gekommen ist, einer violett-grauen Farbe Platz machen, welche am besten der sogenannten Neutraitinte (teinte neutre) unter den Aquarellfarben verglichen wird, wie man diese Farbe auch bei der mikroskopischen Untersuchung von Hautdurchschnitten überall da wahrnimmt, wo die diinnsten Schichten von rein weissem Pigment über dunkeln liegen. Je mehr aber das helle Pigment in seiner oberen Schicht gelb gefärbt ist, um so mehr wird die Erzeugung des Violett unmöglich werden, und je nach der Energie des Gelb werden Blaugrïn, Grün und Gelbgriin auftreten, welche natürlich wiederum mit der verschiedenen Dicke der hellen Schicht, welche über der dunkeln liegt, in Rücksicht auf Ton und Schattirung modifizirt werden. In der That ist es leicht, sich zu überzeugen, dass die Tuberkeln, an denen die blauen und violetten Töne entstehen, wenn sie ihre hellste Farbe annehmen, weiss werden, während diejenige, an welchen man die grinen wahrnimmt, nur bis zum Gelb verbleichen, und mit dem einfachen Mikroskope lassen sich die einzelnen Phasen des Farbenwechsels recht gut verfolgen.

Wir haben bis jetzt den Fall betrachtet, fährt Brücke fort, wo das schwarze Pigment gleichmässig gegen die Oberfläche vorrückt, es kommt aber auch vor, dass es in einigen Zellen ganz bis zur Oberfläche reicht (das heisst ohne daruber liegende Interferenzzellen ist. Ref.), während es in den dazwischen liegenden in die Tiefc zurückgezogen ist. Man hat dann eine weisse oder gelbe Fläche mit schwarzen Punkten, die aber so klein sind, dass sie das blosse Auge nicht als solche unterscheidet, sondern ihr Eindruck mit dem des Grundes vermischt ist. Je mehr diese Anordnung Raum gewinnt, um so mehr verlieren die Farben an 
ihrer Schönheit und machen dem neutralen oder schmutzig gelblichen Grau platz; dies sind die Farben durch Juxtaposition, welche die Mischungsfarben der beiden Pigmente darstellen, wähend bei dem früher betrachteten Falle der Superposition ganz neue Farben entstanden, welche durch blosse Mischung der Pigmente nicht erzielt werden können.

Wir haben aber noch einen zweiten Fall der Superposition zu betrachten, nämlich den, bei welchem das dunkle Pigment vor das helle tritt. Geschieht dies in solchen Massen, dass das dunkle eine undurchsichtige Schicht vor dem letzteren bildet, so wird die Hautstelle schwarz; so lange dies aber nicht der Fall ist, sondern das helle noch durch das dunkle hindurchwirkt, so entsteht, da das letztere mit brauner Farbe durchscheinend ist, die ganze Reihe der braunen Tinten, durch welche alle verschiedenen Farben des Thieres in Schwarz übergehen können. Ich habe endlich noch von einer blassen Fleischfarbe zu sprechen, welche ich an den Lateralflecken eines meiner Chamaeleonen beobachtete. Bei der Untersuchung dieser Hautstellen ergab es sich, dass das helle Pigment derselben theilweise ganz weiss, theilweise hoch orange gefärbt war. Weiss an der Oberfläche war es namentlich auf den Kuppen der grösseren Tuberkeln, orange an den Rändern und an den kleinen Tuberkeln. In einiger Entfernung wurden beide Farben nicht mehr als gesondert unterschieden und gaben als Mischung eben jene blasse Fleischfarbe. Diese Flecken konnten gleichfalls durch verschiedene graue und braune Nüancen, die theils durch Juxtaposition, theils durch Superposition entstanden, in Schwarz übergehen.

Eine Erweiterung erfuhren die Brücke'schen Angaben durch Untersuchungen, welche von Eberth und Leydig angestellt worden sind. Eberth, wclcher die optischen Auseinandersetzungen Brücke's durchaus missverstanden hat und deshalb noch einmal beweist, was Brücke bereits früher genau so bewiesen hat, beschreibt recht eingehend die grünen Hautpartien des Laubfrosches und weist darauf hin, dass bei Laubfröschen Pigment nur in der Lederhaut, nicht wie bei anderen Fröschen auch in der Epidermis gefunden wird, und beschreibt dann eingehender als Brücke, wie an den grünen Körperstellen der Laubfrösche über den wirklichen Pigmentzellen die gelben Interferenzzellen gelagert sind. „Diese Zellenlage, die nur durch die Oeffnungen der zahlreichen Hautdrüsen eine gröbere Unterbrechung erfährt, besteht aus rundlichen und polygonalen, nach Art eines I'lattenepithels angeordneten Zellen, die an intensiver gefärbten Hautstellen nur durch ganz schmale Spältchen voneinander getrennt werden.

¿Unter dieser Zellenlage finden sich zerstreute schwarz-braune oder ganz schwarz pigmentirte Zellen. Bald erscheinen sie als platte, rundliche und leicht eckige, bald als sternförmige Figuren. Bei hellen Thieren sind diese Gebilde sehr vollständig von den darüber gelegenen \%ellen bedeckt, sodass nur durch die schmalen, spaltförmigen Lücken der dunkle Inhalt zu Tage tritt. Bei dunkler Hautfarbe sind diese schwarzen Zellen mehr sternförmig, ihr Körper erscheint verkleinert, in viele Fortsätze verlängert. Die Spältchen zwischen den oberflächlichen Zellen sind jetzt in grösserer Zahl durch eine schwarze Substanz die Ausläufer der sternförmigen schwarzen Pigmentzellen - ausgefüllt. "

Das Pigment der Interferenzellen soll nach liberth ein gelbes " Fett « sein, und die einzelnen Interferen\%ellon unterscheiden sich, nach ihm, nur durch den verschiedenen Gehalt an Fetttröpfchen.

Während Brücke von den Interferenzzellen der Cutis nur angiebt, dass sie dort, wo sic vereinzelt liegen, wie l'igmentzellen verästclt sein können, sich also noch nicht die Frage vorgelegt hat, ob diese Zellen etwa wie Pigmentzellen kontraktil sind, hat liberth dicse frage zu beantworten gesucht und kam zu dem Schluss, dass sic alle, auch dic verästelten, nicht beweglichen Inhalt hätten, da er selbst auf direkte Versuche keine unwiderleglichen Beweise von ihrer Beweglichkeit erhalten habe. 
Dem widersprechen direkt die Untersuchungen, welche Leydig an Fischen, besonders am Bitterling, Rhodeus amarus, angestellt hat und welche zugleich ergaben, dass die Strukturfarben der Fischhaut in derselben Weise entstehen, wie die der Reptilien- und Amphibienhaut. Die betreffenden Ausführungen sind:*) »Pigment der Lederhaut beim Bitterling. An Pigment, welches ich während der Frühlingszeit untersuchte, unterscheidet man im Allgemeinen die grossen dunkeln Chromatophoren, zweitens kleine, goldgelbe Flecken, deren Elemente etwas an Fett erinnern, und drittens das schöne Roth, womit sich in genannter Zeit die Flossen schmücken und welches nur als eine Um- und Fortbildung des gelben Pigments anzusehen ist; endlich sind noch die guaninhaltigen Plättchen zugegen. «...

„Ueber die Zellen mit dem dunkeln Inhalt weg zieht in zusammenhängender Lage die Schicht der metallisch glänzenden Plättchen oder Flitterchen.

Vom letzterwähnten überdeckenden Pigment, silberigen Aussehens, (welches Guanin ist) kann es auf den ersten Blick scheinen, als ob dessen Elemente nicht durchaus innerhalb von Zellsubstanz lägen, sondern vielmehr frei ausgestreut wären. Allein das weitere Nachforschen befestigt uns doch in der Ueberzeugung, dass auch hier die Flitterchen allzeit von Cytoplasma umgeben sind: man vermag in Plättchengruppen, selbst solchen, welche stark in die Länge ausgezogen erscheinen, doch nicht selten den zur Zellsubstanz gehörigen Kernfleck aufzufinden."

»Und daran schliesst sich die fernere Betrachtung, dass das Plasma der die Flitterchen tragenden Zellen ebenso kontraktil sein muss, als es jenes der dunkeln, gelben und rothen Zellen ist. Zu dieser Annahme darf man kommen, wenn man die Farbentöne des absterbenden Fisches in ihren Veränderungen aufmerksam verfolgt, worüber ich schon anderwärts berichtet habe. (Blaufarbiger Wasserfrosch; Leuchtflecken der Ellritze, in Zool. Garten, 1892.) Hier steigert sich nämlich unter unseren Augen das prächtige Irisiren, namentlich an den Seiten des Leibes, und tritt ganz entschieden stärker hervor, als es am lebensfrischen Thier gesehen wird. In Erwägung der Strukturverhältnisse kann dies doch nur dadurch bewirkt werden, dass die Flitterchen durch die Kontraktilität des Plasmas, in welchem sie liegen, Verschiebungen und Aenderungen in ihrer Stellung erfahren.

»Dem Gesagten zufolge ist die Erscheinung des Farbenwechsels beim absterbenden Fisch als ein letztes Zucken der Zellsubstanz an der Peripherie des Körpers aufzufassen, gleichsam als ein letztes Aufflackern des Lebens. « -

Ich selbst kann Leydig nur beistimmen; mir liegt ein mikroskopisches Präparat von der glänzend weissen Binde vor, welche bei Rappia tettensis Petrs. über dem Auge entspringt und bis zum After verläuft. In dieser Binde sieht man fast nur rundliche Interferenzzellen, nur an einer Stelle findet man alle Uebergänge von der Form der rundlichen Interferenzzellen zu der strahlenförmig verästelter Zellen. Die Zellgruppe zeigt sehr deutlich, dass hier eine Anzahl ihrer Komponenten vor völliger Kontraktion erstarrt ist, während die anderen noch Zeit hatten, sich zu kontrahiren. Der Inhalt all' dieser Zellen ist aber durchaus nicht so sehr kontraktil, wie der echter Pigmentzellen. Selbst die Fortsätze der, unter diesen Zellen am meisten kontraktilen sind nur kurz und kaum verästelt, wie denn überhaupt diese Interferenzzellen viel kleiner und unentwickelter sind als die zugehörigen voll ausgebildeten Pigmentzellen; sie machen diesen gegenüber entschieden den Eindruck verkümmerter Zellen. -

\section{Haar- und Federfarben.}

Während bisher keine grösseren Arbeiten erschienen sind, welche über das Entstehen derFarben derSäugethierhaut und-Haare abhandeln, hat über dieFederfärbung

*) F. Leydig, Integument und Hautsinnesorgane der Knochenfische. Zoolog. Jahrbücher B. 8, Abth. für Anatomie, S. I9, 20 und 83 . 
$\mathrm{V}$. Haecker in ausgezeichneter Weise berichtet, und seine Arbeit ist deshalb hier zu berücksichtigen, weil in ihr zum ersten Mal über die Phylogenese der Strukturfarben abgehandelt wird. Aus seinen Untersuchungen ergiebt sich ausserdem, dass die Strukturfarben der Vogelfedern nach denseiben Principien entstehen, wie die der Reptilien-, Amphibien- und Fischhaut und zweitens, dass diese fixirten Strukturfarben genau so entstehen wie die, dem Farbwechsel unterworfenen. Ehe ich indess auf seine Untersuchungen eingehe, sei zuvor kurz erwähnt: Die Säugethiere und Vögel unterscheiden sich in Betreff der Hautfärbung im Allgemeinen von den Kriechthieren dadurch, dass bei ihnen die bei der Farberzeugung betheiligten Pigmente vorwiegend in der Epidermis liegen, während sie bei den Kriechthieren in der Cutis gefunden werden. Deshalb fand sie Haecker bei der Embryonalentwicklung der Feder in den tiefsten Schichten der Epidermis und an ihrer Grenzfläche gegen die Cutis in verzweigten Zellen, welche unter Umständen darüber liegende Epidermiszellen mit Netzen feiner Pigmentkörner umfassen. Bei einem zehntägigen Hühnchenembryo lagen sie zwischen den Zellen des Rete Malpighi mehr vereinzelt, bei einem Embryo von Gallinula chloropus bildeten sie in demselben Gewebe eine filzartig dichte Masse amöboider, schwarz-braun gefärbter Zellen und boten so eine deutliche Analogie zu den tief schwarzen Amöboïdzellen unter dem Rete malpighi der Reptilienhaut.

"In der ausgebildeten Feder«, schreibt Haecker, "liegt das Pigment bei brauner Färbung hauptsächlich in der Rindenschicht und in den Fiedern II. Ordnung (radii). Die Körner haben ovale, spindelförmige oder kreisrunde Gestalt und erlangen oft eine bedeutende Grösse. Die helleren rostbraunen Pigmente treten gewöhnlich in Form von kugeligen Körnern auf, welche zwischen den Hornhautschichten und in den Radius-Segmenten in perlschnurartigen, der Längsrichtung des betreffenden Orgäns folgenden Reihen angeordnet sind.

„Durch dichtes Auftreten der dunkelbraunen Pigmentkörner in der Rindenschicht und in den Fiedern II. Ordnung entsteht die Schwarzfärbung, während durch Zurücktreten der Pigmente aus den vorderen Theilen der Rinde und durch gleichzeitiges stärkeres Hervortretenlassen der metameren Anordnung des Pigments in den Fiedern II. Ordnung die Graufärbung erzielt wird. Eigentlich schwarze Pigmente sind selten, graue finden sich nirgends in den Vogelfedern; durch dichtgedrängtes Auftreten dunkelbrauner Pigmentkörner kann il vielen Fällen der Eindruck der Schwarzfärbung erzeugt werden; jede Isolirung eines Pigmentkorns giebt aber dann den wirklichen dunkelbraunen Ton des Pigments zu erkennen.

¿Vom phylogenetischen sowohl wie vom rein histologischen Gesichtspunkt aus schliesst sich der Graufärbung direkt die Blaufärbung an. Wenigstens sind durch das Auftreten der Graufärbung zwei von den Bedingungen für die Entstehung der Blaufärbung gegeben: die unpigmentirte Rindenschicht und die dichte Pigmentlage in den Markzellen. Die dritte Bedingung ist die zwischen beiden liegende Schicht dickwandiger, in der Oberflächenansicht mehr oder weniger polygonaler »Schirmzellen«. Schon Tatio hat in ihnen den Grund der Blaufärbung gefunden, ohne jedoch ihre feinere Struktur zu erkennen."

Genauer genommen, sind die Elemente der Blaufärbung folgende: "Epitrichium, pigmentlose Rindenschicht, eine Schicht regelmässiger lufterfüllter, dickwandiger, an den Wänden mit Poren versehener "Schirmzellen", dicke körnige oder fibrillöse pigmentirte Unterlage.《

Die hier von Haecker erwähnten "Schirmzellen", sind, wie man sofort erkennen wird, identisch mit den von Brücke beschriebenen über den schwarzen Chromatophoren liegenden sInterferenzzellen *

U'm die Bedeutung der verschiedenen Bestandtheile der erwahnten Zusammenstellung zu erkennen, hat Haecker verschiedene Versuche angestellt:

-Versuch A. Wird eine blaue Feder z. B. von Ampelis cotinga L. (Cotinga cayana Geoffr.) mit der Lnterseite auf den Objektträger geklebt und das Epitrichium, 
bezw. die hier nur schwach entwickelte Hornhaut (Rindensubstanz) vorsichtig weggeschabt, so ergiebt sich in auffallendem Licht folgendes Bild. Die hier bedeutend entwickelte Intercellularsubstanz der 》Schirmzellenschicht "erscheint in Folge des darunter liegenden dunklen Pigments dunkelbraun; die Oberfläche der Schirmzellen wirft blaues Licht zurück und zwar hauptsächlich am Rande, während in der mittleren Partie der Oberhaut das dunkle Pigment, welches darunter liegt, zur Geltung kommt.

"Versuch B. Bei der grünen Feder von Calyptomena viridis Raffl., welche die Schirmzellenstruktur zeigt, deren Rinde aber mit einem gelben Farbstoff getränkt ist, bewirkt die Entfernung eben dieser Rinde die Erscheinung, dass die darunter liegenden Schirmzellen blaues Licht zurückwerfen.

»Aus diesen und anderen Versuchen folgt: Dass die chemisch modifizirte Substanz der mit verdickten Zellwandungen versehenen typischen Schirmzellen (in geringerem Grade auch der übrigen Markzellen) die Eigenschaft hat, das blaue Licht zu reflektiren, das gelbe vorwiegend durchzulassen. Je dicker die Zellwandung ist, um so mehr tritt die Färbung hervor.

»Drei wesentliche Faktoren nun für das Zustandekommen der Blaufärbung sind somit, wie ich wiederhole:

I. Der Luftgehalt der Zellen.

2. Die verdickten Zellwände der Schirmzellen.

3. Die zahlreichen Poren der Zellwandung, welche sich in vielen Fällen konstatiren lassen.

»Bei Querschnitten zeigen nämlich nur diejenigen Zellen noch in ausgeprägter Weise die typische Färbung (blau im auffallenden, gelb im durchgehenden Licht), welche noch Luft enthalten. Sehr schön tritt dies namentlich bei Querschnitten durch die Federn von Cotinga hervor: überall, wo die Luft nicht durch das Einbettungsmittel verdrängt worden ist, $d$. h. wo sie den ganzen Zellraum und namentlich die zahlreichen Poren, welche besonders schön bei Cotinga sichtbar sind, durchdringt, tritt die Färbung hervor. Ist dagegen das Einbettungsmittel (venet. Terpentin, Glycerin) eingedrungen, so verschwindet die Färbung, während die Umrisse deutlicher hervortreten. In analoger Weise bewirkt die Behandlung mit verdünnter oder koncentrirter Schwefelsäure, welche bei Erwärmung die wenig widerstandsfähige Hornhaut sofort zerstört, ein Austreten der Luftblasen und damit ein Zurücktreten der Färbung.

»Es bleibt bei der Blaufärbung noch ein letzter Faktor zu berücksichtigen, die Pigmentlagerung. Ihren Einfluss zeigt am deutlichsten die Häherfeder. An den schwarzen Stellen sind die Schirmzellen noch nicht ausgebildet, die Wandungen zeigen gleiche Dicke, wie die der Markzellen, das Pigment erfüllt die Zellen; beim Uebergang zu den blauen Stellen treten die Pigmentkörner zurück, zuerst an die Hinterwand der Schirmzellen (dunkelblau), ' und allmählich dann aus den Schirmzellen ganz heraus (hellblau), während zugleich die Zellwandverdickung eintritt. In einzelnen Fällen wird schon durch Verschiedenheiten in der Höhe der Zelle ein Unterschied im Ton erzeugt, in dem ein um so helleres Blau zu Stande kommt, je höher die Zell-Lage ist; dieselbe Wirkung kann auch durch doppelte Zell-Lagen zu Stande kommen.

-Die Bedeutung der dunklen Pigmentlage ergiebt sich namentlich aus:

»Versuch D. Wird die Pitta-Feder wie in Versuch C präparirt und der Objektträger bei auffallendem Licht auf den dunklen Tisch des Mikroskops gelegt, so bleibt das Blau, wird er aber auf weisses Papier gelegt, so verschwindet die Blaufärbung, do h. das weisse Licht, welches vom Papier ausgesandt wird, löscht die blaue Lichtwirkung aus.

»Versuch E. Durch Behandlung mit Chlor wird die schwarz-braune Farbe des Pigments in Hell-braun oder Gelblich-braun überführt: die charakterstische Blaufärbung geht verloren. Die dunkle Pigmentlage schützt also das 
von den Schirmzellen reflektirte blaue Licht vor der Vermischung mit Lichtstrahlen anderer Wellenlängen, welche unterhalb der Schirmzellen-Schicht reflektirt werden können.*

Das Grün als Strukturfarbe kann nach Haecker auf folgende Weise zu Stande kommen:

». Entweder durch Tribung gelber Federn; so das Olivengrün unserer Singvögel. Die Fiedern I. O. der grünen Federn unserer Meisen z. B. zeigen eine nicht körnige gelbe Färbung der Rindensubstanz und der Wände der luftführenden Markzellen. Die Trübung zu Grün kommt zu Stande durch spärlichen braunen Farbstoff in den Luftzellen und durch die gefärbten Fiedern zweiter Ordnung.

》2. Die prachtvollen grünen Federn von Calyptomena viridis Raffl. haben vollkommen entwickelte Schirmzellen von gelb gefärbter Rindensubstanz überlagert. Der früher erwähnte Versuch beweist die Thatsächlichkeit des Zustandekommens des Grün auf diesem Wege.

»3. Tanagra lutea. Die gold-gelben glänzenden Federn des Bürzels enthalten die mit stark verdickten Zellwänden versehenen Markzellen, aber es fehlt die die blauen Strahlen isolirende Pigmentunterlage. Solange also diese gold-gelben Federn auf ihresgleichen zu liegen kommen, erscheinen sie mit der Farbe des gelben Farbstoffs; die hintersten aber, die auf den sammtschwarzen Schwanzfedern aufliegen, erscheinen grün, weil die durch die Schirmzellen und dunkle Unterlage zu Stande kommende Blaufärbung unter der gelben Rinde zu Stande kommt.

„Den gelben, gelb-rothen und rothen Färbungen liegen, schreibt Haecker weiter, stets Farbstoffe zu Grunde.

»Der Glanz bei gelben und rothen Federn tritt stets in Verbindung mit einer bedeutenden Entwicklung der verhornten Rindensubstanz unter gleichzeitiger Verkümmerung der luftführenden Markzellen und der Fiedern II. Ordnung auf. Der verhornte Theil ist also der reflektirend wirksame. Sehr schön kommt dies zur Geltung bei Phasianus pictus L. und verschiedenen Orioliden, so namentlich bei Oriolus regens Gaimard aus Neuholland. "

Ueber die Entstehung des Glanzes und der Färbung metallischer Fiedern II. Ordnung enthält sich Haecker des Urtheils, nach ihm beruhen sie wahrscheinlich auf Beugungserscheinungen, »denn«, wie er sagt, »selbst das z. B. bei Lamprocolius splendidus stark entwickelte Epitrichium der Fiedern II. Ordnung kann nicht herangezogen werden, um die Wirkung dünner Plättchen anzunehmen, wie dies durch Brücke geschehen ist. « -

\section{Andere Autoren und eigene Untersuchungen.}

Wo entsteht das Pigment?

Während man früher als selbstverständlich annahm, dass das körnige Pigment der Epidermis und Cutis in den Zellen selbst gebildet werde, haben sich bekanntlich eine Reihe von menschlichen Anatomen und besonders Pathologen unter Führung von Riehl, Ehrmann und Aeby dafür ausgesprochen, dass es aus dem Blutfarbstoff stamme, in Bindegewebszellen gebildet werde, die in der Nähe von Blutgefässen liegen, und dass es alsdann, sei es durch eine Kette festliegender Bindegewebszellen, sei es durch Wanderzellen in die Epidermis eingeschleppt werde, innerhalb welcher sich nunmehr die Epithelzellen mit ihm »mechanisch « belasten. " So entstand die Frage, welche in Schwalbe'scher Formulirung lautet: Haben wir Pigmentbildung im Epithel oder Pigmentübertragung auf das Epithel?

Die Lehre von der Pigmentübertragung auf das Epithel hat, so viel ich aus der Literatur ersehen kann, nur bei Medizinern und vor Allem bei menschlichen Pathologen Anhänger gefunden, ein Zoologe musste ihr von vornherein schon deshalb zweifelnd gegenüberstehen, weil ihm sofort einfallen wird, dass alle Thiere 
mit farblosem Blut ebenso gut und ebenso verschiedenartig pigmentirt sind, wie die Thiere mit rothem Blut, man denke nur an die mit geradezu wunderbarem Farbwechsel versehenen Cephalopoden, an die Schmetterlingsraupen u. s. w. Bei Thieren mit farblosem Blut kann aber schwerlich das Pigment aus rothem Blutfarbstoff gebildet werden; eine Thatsache, auf welche übrigens ein Pathologe, Elsässer, zuerst hingewiesen hat. Aber auch unter den Medizinern hat sich in neuester Zeit, besonders seit dem Vorgehen von Rieke, Schwalbe, Jarisch und Winkler mehr und mehr die Ueberzeugung Bahn gebrochen, dass das Pigment dort, wo es gefunden wird, auch entsteht, und die Lehre von der Pigmentübertragung auf das Epithel dürfte im Aussterben begriffen sein.

Rieke hat klar nachgewiesen, dass in den festliegenden Bindegewebszellen der menschlichen Choroidea die Pigmentbildung ohne Wanderzellen stattfindet, weil hier das Pigment zuerst feinkörnig, dann später grobkörniger in den Zellen selbst entsteht.

Schwalbe konstatirte bei seinen Untersuchungen über den Farbenwechsel winterweisser Thiere, »dass zu keiner Zeit des Jahres die Cutis oder das Unterhautbindegewebe ebensowenig wie die Haarpapille und der bindegewebige Haarbalg (bei den untersuchten Säugethieren) Pigment enthalten." Dagegen fand er beim Wiederauftreten des Pigments in den jungen Frühlingshaaren, »dass das Pigmentirte die Haarwurzeln der jungen gefärbten Frühlingsgeneration waren, deren die Papillen umfassende Bulbi als braune Knöpfchen, soweit sie den grösseren Grannenhaaren angehörten, schon mit unbewaffnetem Auge wahrgenommen werden konnten. Feine Längsschnitte durch Haare und Haut in diesem Stadium beseitigten jeden Zweifel. Nirgends waren in der Haut pigmentirte Zellen zu treffen, weder in der Cutis und der Haarpapille, noch in der Epidermis und den Wurzelscheiden. Pigmentirt war lediglich dass junge Haar und eine die Papillen-Oberfläche in drei Zellenschichten bedeckende Zone. Sogar die noch protoplasma-armen, den Hals der kegelförmigen langen Haarpapille umgebenden indifferenten Matrixzellen zeigten sich unpigmentirt." Also kann das Pigment hier nicht aus dem Bindegewebe stammen, sondern muss im Epithel selbst entstanden sein.

"Was nun die Art der Pigmentirung der drei Reihen junger Haarzellen betrifft, so besteht sie einfach darin, dass innerhalb des Zellkörpers feinste Pigmentkörnchen zur Ablagerung kommen, die rasch an Zahl und auch an Grösse zunehmen, aber immerhin sehr fein bleiben. Sie haben die Neigung, zu Klümpchen zusammen zu treten, in denen aber die einzelnen Körnchen deutlich zu erkennen sind."

Auch die Lehre von den "Wanderzellen«, welche das Pigment übertragen sollen, dürfte in ihrer alten Fassung nicht länger haltbar sein. Fragt man, welche Zellen die Pathologen für die pigmentverschleppenden Wanderzellen ansehen, so ist kein Zweifel, dass sie z. B. beim Frosch die in der Cutis liegenden pigmentirten, beweglichen Farbzellen, die sogenannten Chromatophoren meinen, und dass sie das Ausdehnen dieser Zellen und die Verlängerung ihrer Fortsätze für das Bestreben der Zellen halten, fortzukriechen. Nun ist aber durch die neueren Untersuchungen von Solger, Eberth und Zimmermann absolut sichergestellt, dass alle solche Chromatophoren festliegende Zellen sind, dass sie sich garnicht selbst, sondern dass nur ihr Inhalt sich zusammenzieht und ausdehnt, ihre Zellhaut dabei unbeweglich bleibt, und dass sie durch ein wunderbar feines und komplizirtes Netz von Nervenfasern umklammert werden und an ihren Platz gebannt sind. Wenn also diese Chromatophoren keine Wanderzellen sind, welches sind dann die Wanderzellen, die das Pigment verschleppen?

Vor Allem aber haben die Untersuchungen, welche Jarisch und Winkler an Froscheiern und Froschlarven anstellten, der Pigmenteinschleppungs-Hypothese den Todesstoss versetzt. Da beide Forscher in ihren Resultaten übereinstimmen 
und sich nur gegenseitig ergänzen, genügt es, wenn ich die Zusammenfassung der Winkler'schen Ergebnisse hier anführe, soweit sie hierher gehören:

$\nu \mathrm{I}$. Pigment findet sich schon in den frühesten Entwicklungsstadien des Eies, bereits vor der Einleitung des Furchungsprozesses.

»2. Die Bildung des Pigments während der Entwicklung des Embryos erfolgt durch eine Umwandlung der Dotterplättchen.

»3. Das Pigment findet sich in allen Keimblättern, aber im Ectoderm und Entoderm bedeutend stärker angehäuft als im Mesoderm.

》5. Jede Thätigkeit der Zellen, die zu einer neuen Bildungsform in den Embryonalanlagen führt, veranlasst auch eine Vermehrung des Pigments im Protoplasma.

\%. Die Pigmentbildung in den ersten Stadien kann mit der Umwandlung des Haemoglobins nicht zusammenhängen, weil in diesen Entwicklungsperioden noch keine Blutgefässe vorhanden sind.

»9. Das Pigment ist mit dem Keratohyalin nicht identisch." -

Winklers Untersuchungen erklären zugleich die Thatsache, welche so viele Pathologen veranlasst hat, die Hypothese von der Entstehung des Pigments aus dem Blutfarbstoff anzunehmen. "Sie stützen sich dabei, wie Kaposi sagt, auf die klinischen Thatsachen, dass Pigmentose und Hyperpigmentose in direkter Folge solcher Prozesse auftritt, welche mit reichlicherem Austritt von rothen Blutkörperchen aus den Gefässen einhergehen, das sind Hyperaemie, Entzündung und vascularisirte Neoplasie."

Nicht der »Austritt der Blutkörperchen « ist hier das Wesentliche - Blutaustritt dürfte übrigens bei vielen pathologischen Neubildungsprozessen überhaupt nicht stattfinden - sondern der Zufluss von überreichlichem Nährmaterial zu den Zellen, welche die Neubildung einleiten. Dieser Nährmittelzufluss regt die vorhandenen übernährten Zellen zur Theilung an und desgleichen die neugebildeten. Jede Thätigkeit der Zellen aber, welche zu einer neuen Bildungsform führt, veranlasst, wie Winkler bei den Embryonen der Froschlarven nachgewiesen hat, eine Vermehrung des Pigments im Protoplasma. Dieses Gesetz dürfte demnach auch für die mit Pigmentvermehrung verlaufenden pathologischen Neubildungen giltig sein, und auch die Thatsache, dass die Pigmentbildung gewöhnlich zuerst in den Zellen beginnt, welche um Blutgefässe (Capillaren) gelagert sind, spricht nicht mehr für die Blutbildung aus rothem Blutfarbstoff, sondern nur für jenes Winkler'sche Gesetz, denn diese Zellen sind es wohl, welche in einem bestimmten Zellkomplex an schnellsten und reichsten mit Nährstoffen versorgt werden.

Weitere Gründe für das Entstehen des Epidermispigments aus Blutfarbstoff sind bisher nicht beigebracht worden.

Auch die nachfolgenden Untersuchungen sprechen durchaus nicht dafür. -

Giebt es nur ein Pigment oder viele Pigmente?

Wenn man die Angaben einzelner Forscher nebeneinander stellt, so herrscht kein Zweifel, dass es bei den Wirbelthieren Pigmente von jeder Färbung mit Ausnahme der Violettfärbung giebt. So erklären Krukenberg und Haecker, dass in den Vogelfedern schwarze Pigmente, wenn auch selten, vorkommen. Blaues Pigment will Leydig beim Flusskrebs in 0,004 " langen Krystallen und feinen Punkten gefunden haben, ebenso beim Bitterling in dem stahlblauen Schwanzstreifen, den das Thier zur Begattungszeit aufweist. „Die mit Pigmentkörnchen vollgepfropften Zellen, von Gestalt rundlich oder zackig-ästig, haben bei durchgehendem Licht ein tief-schwarzes Aussehen. Fasst man aber vom lichteren Rand der Zelle her den Inhalt gut ins Auge, so zeigt sich, dass das einzelne Pigmentkörnchen nicht braun ist, sondern von tief-blauem, fast schwarz-blauem Farbenton. Auch dieses scheint krystallinisch zu sein «*) Grünes Pigment (Turaco-

") Leydig: Integument und Hautsinnesorg. Zool. Jahrb. r895, S. 20. 
verdin), giebt es nach Krukenberg in Vogelfedern. Braunes Pigment erwähnen alle Forscher. Ausserdem konstatirte Krukenberg rothes (Ararot, Turacin, Zoorubin und Zoonerythrin) in Vogelfedern, ebenso gelbes (Coriosulfurin) in der Tarsalhaut von Milvus regalis, und in Federn (Zoofulvin). Manche dieser Pigmente sind nach Krukenberg Fettfarbstoffe, andere Säuren, noch andere - so die braunen und schwarzen Melanine - beides nicht. Andere Forscher sprechen dagegen, oft nur mehr oder weniger verblümt, von nur einem Pigment, das in verschiedener Verdünnung oder als Strukturfärbung die anderen Farben erzeugt.

Ich selbst bin auf Grund sehr vieler Untersuchungen zu der Ueberzeugung gekommen, dass in der lebenden Reptilien- und Amphibienhaut wahrscheinlich nur ein Pigment vorhanden ist; dass aber, wenn mehrere derselben wirklich nachgewiesen werden können, diese unmittelbar und leicht auseinander hervorgehen, dass mit anderen Worten sie alle die Umwandlungsprodukte eines Urpigments sind. Als dieses Urpigment betrachte ich das bekannte braune Pigment der Haut, welches im Maximum der Häufung schwarz, bei sehr starker Verdünnung gelb, und unter besonderen Umständen roth erscheint. Blaue und grüne Pigmente treten meiner Ueberzeugung nach in der lebenden thierischen Haut nicht auf.

Ich verweise auf die folgenden Abschnitte dieses Kapitels, wo die Hauptgründe für meine Anschauung zu finden sind und füge hier noch einige hinzu: Nicht jeder Farbstoff, welcher einen Theil des Körpers färbt, ist ein Pigment, hier können Stoffwechselprodukte der Zellen, die mit einem Pigment garnichts zu thun haben, eine Rolle spielen. Dahin dürften auch alle Krystalle gehören, die einer Hautstelle eingelagert sind; denn, wie unter anderen Kaposi und Ehrmann ausgesprochen haben, ist das wirkliche Pigment stets ein diffuser Farbstoff, welcher entweder, wie alle Farbstoffe der Pflanze, in einen protoplasmatischen Farbstoffträger, eingebettet ist oder in Fettsubstanzen, welche, wie ich später begründen will, diese protoplasmatischen Farbstoffträger ersetzen können. Ein zweiter Grund gegen die Annahme mehrerer Pigmente ist: Alle Pigmente, welche Krukenberg beobachtet hat, hat er aus den abgestorbenen Vogelfedern oder aus den ebenso todten Vogeleierschaalen extrahirt. Haben diese Pigmente schon in der noch lebenden Feder eine Rolle gespielt, oder sind sie erst als Zersetzungsprodukte aus dem Urpigment beim Absterben der Feder entstanden? Bewiesen ist weder das eine noch das andere. Dass es Zersetzungsprodukte sein können lehrt Folgendes: Es ist bereits gelungen, das rothe Turacin der Vogelfedern einfach durch Behandlung mit Wasser und Wärme in das grüne Turacoverdin umzuwandeln; können nicht auf ähnliche Weise auch in der Natur grüne Farbstoffe aus rothen entstehen? Drittens: Alle Pigmente, welche Krukenberg und andere Forscher beschreiben, sind nur auf optischem Wege konstatirt worden, eine Reindarstellung eines derselben oder nur eine Isolirung derselben, wo sie gemeinsam vorkommen, ist bisher, wie Krukenberg selbst angiebt, nicht gelungen. Haben wir in all diesen "Pigmenten " nicht vielleicht Stoffgemenge vor uns, die grün oder roth erscheinen?

\section{Die Phylogenese der Hautfarben.}

Die Anordnung der Strukturfarben in nur einer Entwicklungsreihe ist nicht möglich, einmal deshalb, weil sie auf verschiedenen Wegen entstehen, und zweitens deshalb, weil unter Umständen eine von ihnen in eine andere umgewandelt werden kann und so die Möglichkeit gegeben ist, dass ein und dieselbe Strukturfarbe auf verschiedene Weise erzeugt werden kann.

Nothwendig sind für die Entstehung der Strukturfarben, darin stimme ich mit Haecker vollständig überein, die schwarzen Chromatophoren der Cutis, deren Inhalt zusammenziehbar ist und deren Farbe dadurch entsteht, dass in ihnen das gewöhnliche braune Hautpigment im Maximum angehäuft ist. Liegen diese Zellen unmittelbar unter der farblosen Epidermis, d. $h$. sind sie von keinen Inter- 
ferenzzellen überdeckt, so erscheint auch die von ihnen eingenommene Hautstelle schwarz gefärbt. Sind solche Hautstellen von einiger Ausdehnung und von intensiver Färbung, dann liegen in ihnen die schwarzen Pigmentzellen so dicht aneinander, dass sie eine Art Gewebe bilden, da ihre vielen Fortsätze sich gegenseitig innig berühren.

Aus schwarzen Hautstellen entstehen braun gefärbte einfach dann, wenn die schwarzen Chromatophoren einen Theil ihres Pigments verlieren und in Folge dessen gleichmässig braun gefärbt erscheinen. Die braune Farbe ist also eine Quantitätsfarbe. Hat man ein reicheres Thiermaterial zur Untersuchung, so kann man alle Stadien dieser Zellumfärbung am Objekt beobachten. Die Umfärbung beginnt in den äussersten Spitzen der Zweige der baumartig verästelten schwarzen Pigmentzellen, und schreitet von dort durch die Zweige und Aeste gegen das Zell-Lumen vor. Dann erst hellt sich auch der Binnenraum der Zellen auf, bis zum Schluss die ganze Zelle gleichmässig braun gefärbt erscheint. Man findet bei geeigneten Thieren all' diese Zellformen nebeneinander.

Das Braunwerden tiefschwarz gefärbter Chromatophoren kann man übrigens auch bei allen Reptilien und Amphibien konstatiren, welche längere Zeit in Spiritus gelegen haben. Der Spiritus zieht bei längerem Einwirken aus allen Pigmentzellen einen Theil des Farbstoffes aus, also auch aus den schwarzen, und die Zellen sind, wenn dies geschehen ist, nicht mehr schwarz sondern dunkelund später hellbraun. Wirkt der Spiritus sehr lange auf die Zellen ein, so können sie so stark aufgehellt werden, dass das Thier zum Schluss fuchsroth gefärbt erscheint.

Die Veränderung schwarzer Hautpartien zu grau gefärbten geschieht dadurch, dass eine Anzahl der in ihnen enthaltenen schwarzen Chromatophoren Rückbildung erleiden und zum Schluss verschwinden; an ihrer Stelle können Interferenzzellen auftreten. Diese liegen dann jedoch stets vereinzelt und weit voneinander entfernt, auch decken sie nie die übrig bleibenden schwarzen Pigmentzellen, sodass durch sie keine Strukturfarben erzeugt werden, wohl aber begünstigen sie das Grauwerden des Hautflecks, da der von ihnen ausgehende weisse Lichteindruck durch Vermischung mit dem von den schwarzen Zellen ausgehenden als Gesammitfarbe Grau ergiebt. Bei Lupenvergrösserung und unter dem Mikroskop erkennt man sehr deutlich in ergrauenden Hautpartien das Atrophiren einzelner Chromatophoren, sie sind viel kleiner als die intakt bleibenden, haben nur wenige und kurze Aeste und an denselben fast keine Zweige, während die intakt bleibenden ausser einem umfangreichen Körper sehr viele Aeste und von denselben nach allen Seiten dichtgedrängt ausstrahlende Zweige aufweisen; auch kann man in intensiv schwarzen Hautstellen durch Lupenvergrösserung die einzelnen schwarzen Zellen nicht erkennen, bei grauen dagegen erkennt man deutlich jede einzelne schwarze Zelle, sie liegen hier, durch Zwischenräume voneinander getrennt, annähernd gleich weit voneinander.

Während beim Entstehen der grauen Hautfarbe die Interferenzzellen nur einzeln auftreten, nicht aneinander stossen und die schwarzen Pigmentzellen nicht decken, entstehen sie bei der Umwandlung der schwarzen Körperstellen in violett, blau oder grün gefärbte in so grosser Zahl, dass sie dicht aneinander stossen und über den schwarzen Pigmentzellen völlig geschlossene Lagen bilden. Man erkennt dies sehr schön, wenn man unter dem Mikroskop ein grünes Froschhautstück nach Entfernung der Epidermis zuerst bei auffallendem Licht, dann bei durchfallendem Licht und zum Schluss von der Rückseite betrachtet. Bei auffallendem Licht sieht man nur die völlig geschlossene Lage der Interferenzzellen, nicht schwarze Pigmentzellen, höchstens drängen sich ganz vereinzelt Zweige derselben durch die Interferenzzellenschicht hindurch. Bei durchfallendem Licht schimmern die Pigmentzellen durch die Interferenzzellenschicht hindurch; man erkennt auch hierbei, dass sie ganz von jener Schicht überdeckt sind; betrachtet 
man dagegen das Hautstück von der Unterseite, so sieht man jede einzelne der getrennt liegenden schwarzen Pigmentzellen schon mit blossem Auge, sie liegen nun völlig frei auf der Interferenzzellenschicht, keine von ihnen ist (an ihrer Unterseite) von einer dieser Zellen überdeckt, ein Beweis dafür, dass die Interferenzzellen hier $z$ wischen Epidermis und schwarzen Pigmentzellen entstehen.

Sind die Interferenzzellen klein oder haben sie sehr feinkörnigen, farblostrüben Inhalt, so entsteht durch sie mit Hilfe des schwarzen Pigments violett als Strukturfarbe, sind sie gross- oder grobkörnig- farblos-trüben Inhalts, so erzeugen sie mit Hilfe des schwarzen Pigments blau als Strukturfarbe; ist ihr Inhalt gelb gefärbt, so erzeugen sie mit den untergelagerten schwarzen Zellen grün als Strukturfarbe.

Es ist nicht schwer einzusehen, dass diese Strukturfarben leicht ineinander übergehen können. Erlangen an violetten Körperstellen die Interferenzzellen grobkörnigeren Inhalt, so geht die violette Körperfärbung in Blau über, ebenso kann die blaue Strukturfarbe violett werden, wenn die Interferenzzellen der Blaufärbung sekundär aufgehellt werden. Verlieren die gelben Interferenzzellen, welche die Strukturfarbe Grün erzeugen, ihre Gelbfärbung, dann erwirbt die Körperstelle, der sie angehören, eine Blaufärbung und kann bei starkem Schwund des Interferenzzelleninhalts sogar in Violett übergehen. So werden die grünen Haut. stellen der Reptilien und Amphibien in Spiritus blau, weil der Spiritus aus ihren gelben Schirmzellen das Gelb auszieht. Beispiele: der Laubfrosch und Lacerta viridis. Liegen endlich in Interferenzzellen Guaninkrystalle in grösserer Menge, dann wird die von ihnen erzeugte Strukturfarbe metallglänzend.

\section{Ursachen der Hautfarben-Ausbildung.}

Zählt man an einem Hautstück von violetter oder grüner Strukturfarbe die Zahl der Interferenz- und Pigmentzellen und vergleicht das Zahlenergebniss mit dem, welches intensiv schwarz gefärbte Hautstellen desselben Thieres aufweisen, so findet man zuerst, dass in den strukturfarbigen Hautstellen die Zahl der Pigmentzellen viel geringer ist, als in den schwarzen Hautstellen. Es ergiebt sich zu zweit, dass in den intensiv schwarzen Hautstellen keine Interferenzzellen zu finden sind, in den strukturfarbigen dagegen um so mehr, und es lässt sich drittens nachweisen, dass in den strukturfarbigen Hautstellen die 'Zahl der Chromatophoren kleiner wird, wenn die Zahl der Interferenzzellen wächst. Lässt dieses gegensätzliche Verhalten der beiden Zellarten bereits auf einen gewissen Konkurrenzkampf der beiden Zellarten schliessen, so wird dies noch deutlicher, wenn man berücksichtigt, dass in strukturfarbigen Hautstellen die einzelnen Pigmentzellen in ihrer Entwicklung weit hinter denen der schwarzen Hautstellen zurückstehen. Die der schwarzen Hautstellen bilden einen mächtigen Körper mit zahlreichen Aesten, die in unübersehbares Gezweig auseinander strahlen; die Pigmentzellen der strukturfarbigen Körpertheile sehen dagegen wie kontrahirt aus, sind stets wenig ästig, die Aeste sind kurz und plump und kaum oder garnicht mit Zweigen versehen; ja es giebt zahlreiche unter ihnen, welche eigentlich nur noch plumpe, astlose Pigmentklumpen sind. Daraus folgt: Schwund der Chromatophoren und Vermehrung der Interferenzzellen gehen Hand in Hand.

Es entstehen nun die Fragen: Was sind die Interferenzzellen? bewirken sie die Rückbildung der Pigmentzellen oder wird durch Schwund der Pigmentzellen ihre Ausbildung begünstigt?

Die Interferenzzellen sind stets viel kleiner als die schwarzen Pigmentzellen, selbst sehr verkümmerte Pigmentzellen werden nur durch eine grosse Anzahl Interferenzzellen völlig verdeckt. Zweitens ist nachgewiesen worden, dass die Interferenzzellen selbstständige Bewegung haben, besonders dann, wenn sie vereinzelt liegen; dass sie sich zusammenziehen und ausdehnen können wie Pigmentzellen. Sie liegen drittens in der Lederhaut und können pigmentirt sein oder 
nicht. Ferner entstehen die ersten von ihnen zwischen den Aesten der schwindenden Pigmentzellen, und auch dann, wenn bereits viele von ihnen vorhanden sind, gruppiren sie sich stets so um die benachbarten Pigmentzellen, dass sie bei Häufung um dieselben den Eindruck von Weinbeeren machen, welche an einer verästelten Traube hängen. Aus all' dem schliesse ich, dass sie nicht voll entwickelte Pigmentzellen und Töchter jener Pigmentzellen sind, welche bei ihrem Entstehen Rückbildung erleiden, und erkläre mir die physiologischen Ursachen ihrer Entstehung und den Verlauf des ganzen Vorganges folgendermaassen: Werden die vollentwickelten schwarzen Chromatophoren durch eine der zahlreichen Ursachen, welche sie zur Kontraktion bringen (bei den Fröschen Licht, Wärme, Reibung u. s. w.), uiber ein bestimmtes Optimum hinaus beeinflusst, so gehen sie allmählich in einen der Reizstärke entsprechenden, mehr oder weniger vollständigen Kontraktionszustand über; ihr Körper wird dabei verdünnt, ihre Aeste und Zweige verschwinden entsprechend dem Reiz; auch verlieren sie, wie später nachgewiesen wird, dabei an Pigment. Dadurch werden sie nun aber zur Fortpflanzung besonders geeignet und angeregt, denn wie Zimmermann nachwies, pflanzen sich nur solche Pigmentzellen fort, welche wenig Pigment besitzen, und sie pflanzen sich nur dann fort, wenn sie vorher kontrahirt waren. Die so entstehenden Interferenzzellen rücken nun in die durch die Mutterzellenkontraktion entstandenen Gewebslücken ein; da aber durch die physiologischen Ursachen, welche ihr Entstehen aus den Mutterzellen begünstigen, die Mutterzellen selbst schon bis zur Rückbildung geschwächt werden, so kommen sie, da diese Ursachen auch auf sie einwirken, niemals zu voller Entwicklung: sie bleiben schwächlich und klein, bilden wenig oder keine Aeste aus und sind äusserst pigmentarm oder ganz pigmentlos.

Ich bin um so sicherer, dass die Interferenzzellen auf diese Weise entstehen, weil bereits Jarisch in der Froschepidermis eine ganz ähnliche ontogenetische Umbildung der Pigmentzellen direkt morphologisch beobachtet hat. In seiner ausgezeichneten Arbeit giebt er an, dass die Chromatophoren der Froschepidermis aus grossen runden Epidermiszellen dadurch entstehen, dass in diesen Zellen Vakuolenbildung eintritt, worauf die Zellhaut durch an Zahl und Grösse wachsende Nachbarzellen unregelmässig eingedrückt wird, ein Vorgang, der die Veranlassung giebt zur Ausbildung der zahireichen Aeste und Zweige der Chromatophoren. Wahrscheinlich handelt es sich auch bei diesen Vorgängen um einen Entwicklungsvorgang, genau dem entsprechend, welcher in der Cutis bei der Entstehung der Interferenzzellen zur Auslösung kommt, doch lässt sich das nicht so ohne Weiteres konstatiren, da die Abstammung der Nachbarzellen der Epidermis-Chromatophoren von Jarisch nicht festgestellt worden ist. Der Vorgang der Vakuolenbildung aber - nebenbei gesagt, ein glänzender Beweis für die Beobachtungsgabe des Entdeckers - lässt sich dadurch erklären, dass der Inhalt jener Zellen, wenn sie eine bestimmte Grosse erreicht haben (durch Lichteinwirkung auf die Zellen z. B.), kontrahirt wird, während die Wände der Zellen dieser Bewegung nicht folgen. Es ist das nicht wunderbar, da nach den schon erwähnten Untersuchungen von Zimmermann in allen Chromatophoren bei der Kontraktion nur der Zellinhalt kontrahirt wird, ohne dass die Zellwand seiner Bewegung folgt, das heisst aber nichts Anderes als: bei jeder derartigen Zellkontraktion entsteht in den kontrahirten Zellen Vakuolenbildung. Dass die Interferenzzellen verkümmerte Pigmentzellen sind, lehrt ausserdem noch ein Blick auf ihren Hauptinhalt: Sie besitzen entweder gelb-rothes oder gelbes Pigment, oder sind farblos; ihr Pigment liegt stets, wie schon von anderer Seite angedeutet ist, eingehüllt in Fett, während bei ihren Mutterzellen der Zellfarbstoff stets in eine Plasmahülle eingelagert ist; ferner sind viele von ihnen, besonders die farblosen, angefülit mit Guaninkrystallen. Das uberreiche Fett und Guanin in diesen Zellen beweisen aber ganz entschieden, dass die Zellen nicht normal ausgebildet 
sind, denn sowohl Fett wic Guanin sind "Zersetzungsprodukte des Zellinhalts, dic durch Störung des Stoffwechsels in den Zellen entstehen. (Fettige Entartung der Zellen ist eine häufige pathologische lirscheinung, und reichliche Anhäufung von Iarnstoffverbindungen findet man in \%ellen, deren Stoffwechsel gestört ist, Guanin speciell in den Fleischzellen bei Schweinegicht.)

Da das Pigment der Interferenzzellen stets in Fett eingelagert ist, das der Chromatophoren dagegen stets in einer Plasmahülle liegt, nehme ich an, dass in den Interferenzzellen nicht nur Konstitutionseiweiss, sondern auch die Plasmabasis des \%ellfarbstoffs fettig degenerirt ist. Eine Verschiedenheit des Pigments nehme ich aus später folgenden Grïnden nicht an; jedenfalls darf aus dem verschiedenen Verhalten dieser "Pigmente gegen Spiritus, Chloroform und Aether nicht, wie Krukenberg will, auf ihre chemische Verschiedenheit geschlossen werden. Die leichte Löslichkeit, welche der Interferenzzellfarbstoff in diesen Reagentien im (iegensatz zum l'igmentzellfarbstoff zeigt, der nicht einmal in kochendem Aether extrahirt werden kann, beruht einmal darauf, dass aus den Interferenzzellen nicht "Pigment", sondern das in den Zellen liegende, leicht lösliche Fett schnell ausgezogen wird, und da der Zellfarbstoff in diesem Fett liegt, wird er mechanisch mitgerissen und relativ schnell gelöst. Aus den Pigmentzellen zieht der Spiritus den Farbstoff viel schwerer aus, weil er die Plasma-Masse, in welcher der Farbstoff liegt, zur Gerinnung bringt und sich selbst dadurch den Zugang zum Farbstoff verspert. Bei langer Einwirkung auf die Pigmentzellen löst er aber, wie schon erwahnnt worden ist, auch von ihrem Farbstoff einen sehr beträchtlichen Theil.

Das führt mich nun zurück zu der Frage: sind die rothen und gelben Farbstoffe der Haut selbstständige chemische Individuen oder nur Verdünnungen des rostbraunen Melanin?

Zuerst ist leicht zu beweisen, dass die rothen und gelben Farbstoffe der Haut aus dem braunen Melanin entstehen. Hierfür liefert einen sehr einfachen und sicheren Beweis die Haut der Pelobates-fuscus-Larve. Die ganz schwarzen Larven dieser Thiere nehmen beim Uebergang auf das Land eine andere Färbung an; der grösste Theil ihrer gleichmässig schwarzen Rückenfäbung verblasst, und ihr Rücken erhält dadurch schwarze Flecken auf gelb-grauem Grund. Die Umbildung dicser 'Zeichnung ist eine sehr schnell verlaufende, sie ist in einigen Tagen vollendet, und das Thier ändert seine Färbung, man kann sagen, von Stunde zu Stunde. Zur Zeit, wenn die Larve das Wasser verlässt und dieser Umfärbungsprozess abgeschlossen ist, erschcinen wider Erwarten zahlreiche blutroth gefärbte Flecke in der Ruickenhaut des Thieres. Sie liegen an den Rändern der schwarzen Hautflecke und sind, wie mikroskopische Untersuchung lehrt, einzelne Chromatophoren der Haut, deren Pigmentnetz eine blutrothe Färbung annimmt. Man kann an manchen von ihnen die Umfärbung des Pigmentnetzes bis ins Detail verfolgen. Die Entstehung dieser Flecken ist eine relativ langsame, und sie verschwinden auch nur sehr allmählich, indem ihr Pigment aus Roth in Gelbfärbung übergeht. Wir haben hier also einen direkten Beweis dafür, dass das braune Pigment in rothes und gelbes übergeht.

In gleicher Weise entstehen aus braunem Pigment die rothen Ringe in der Ruickenhaut des Hylambates maculatus, und ferner die, auf dem Rücken der Phrynomantis bifasciata vorhandenen rothen Streifen und Flecke.

Ich hebe hier noch einmal besonders hervor, dass in allen diesen Fällen das rothe Pigment nicht in Interferenzzellen, sondern in den Chromatophoren cntwickelt wird. Interferenzzellen kommen bei dieser Farbzellenumbildung überhaupt nicht zur Ausbildung.

Vergleicht man nun genau die blutroth gefärbten Chromatophoren mit den braun und schwarz gefäbten desselben Thieres, so zeigt sich, dass die blutroth gefärbten zwar ebenso reich wie die schwarzen und braunen verästelt sind, dass sie aber im ganzen Bau und besonders in ihren Aesten und Zweigen einen viel 
zarteren und feineren Eindruck machen, als die braunen, deren Aeste und Zwcige stets etwas Massives und Plumpes haben; die rothen Zellen gehen dann später oft durch einfache Verfärbung ihres Pigments in hellgelb gefärbte Zellen über (Pelobates-Larven); daraus schliesse ich, dass die blutrothen Zcllon direkt aus braunen Zellen entstehen, indem sie eine geringe Verkimmerung erleiden und pigmentärmer werden, wodurch nicht nur ihre Zweige und Aeste, sondern auch ihr Körper durchscheinend wird, und dass sie beim Uebergang zur Gelbfarbung weiter verkimmern und noch pigmentärmer werden. Ihre intensiv rothe Färbung verdanken sie wohl nur dem Umstand, dass ihr braunes Pigment so vermindert ist, dass es viel Licht durch die Zelle hindurchgehen lässt; dieses Licht, das von Nachbargeweben reflektirt wird und weiss ist, verwandelt dann das Braun der Zellen durch Vernichtung des darin noch enthaltenen Schwarz in intensives Roth.

Dass in der That selbst die intensivste Rothfärbung der Reptilicn- und Amphibienhaut uberall dort, wo sie durch Farbstoffe hervorgerufen wird, wahrscheinlich nur einer bestimmten Lagerung des in den Chromatophoren enthaltenen braunen Pigments ihre Entstehung rerdankt, lehen indirekt cinige Reptilien, welehe beim Farbenwechsel dunkel gefärbte Körperpartien durch Kontraktion der darin enthaltenen Chromatophoren in voribergehend intensiv rothgefärbte umwandeln. Dahin gehören die bereits in dieser Arbeit erwähnten Chamacleo-dilepis-Individuen, dann Agama planiceps, deren Kopf bei jeder Erregung und im Tode, wie mir Herr Neumann schrieb, blutroth gefärbt erscheint; endlich Calotes versicolor, dessen dunkler Kopf und Rückenkamm bei Erregung des Thieres ebenfalls blutrothe Färbung annimmt.

Gelb gefärbt erscheinen alle Zellen von grosser Pigmentarmuth, sowohl die der Epidermis als der Cutis. Solche gelben Zellen entstehen ubrigens auch direkt aus braunen Pigmentzellen, behalten dann aber - im Gegensatz zu den ebenfalls aus braunen Pigmentzellen entstehenden rothen Zellen - die plumpe Form und Verästelung ihrer Mutterzellen bei.

Experimentelle Umfärbung der Amphibienhaut.

Es ist in den beiden vorigen Kapiteln dieses Abschnitts gezeigt worden, wie in der Froschhaut Strukturfarben entstehen und es ist bekannt, dass sie daselbst unter dem Einfluss äusserer Ursachen gegen den Willen des Thieres hervorgerufen werden können. Zu den äusseren Ursachen, welche die Chromatophoren des Thieres gegen dessen Willen zusammenziehen und ausdehnen können, gehören Licht, Wärme und Druck, auch mangelhafte und überreiche Ernährung der Haut haben Einfluss auf deren Farbkleid. All' diese äusseren Faktoren können, wenn sie gleichsinnig wirklich, ihren Einfluss auf das Farblkeid summiren, sie können sich aber auch bekämpfen und dadurch bei den Thieren Farbwechsel hervorrufen, welche schwer auf ihre äusseren Ursachen zurückzuführen sind. Da ich nun bereits durch erst kurz währende Experimente mit Wärme konstatiren konnte, dass das normale Farbkleid erwachsener Frösche durch diese äusseren Ursachen stark umgefärbt werden kann, da es das Bestreben zeigt, sich dem betreffenden Wärmemaximum und -minimum anzupassen, wird es sicher gelingen, durch fortgesetzte derartige Experimente Fröschen und besonders deren Larven völlig neue Farbkleider anzuzichten. Wie sich das Farbkleid der Thiere dabci umwandeln wird, könnte ich aus meinen Versuchen bereits andeuten, erwähne aber nur, dass es sproportional dem Reiz umgewandelt werden wird; also wahrscheinlich unter bestimmten Temperatureinwirkungen zum Schluss oder doch vorübergehend die Färbung fixiren wird, die es, wenn es Farbwechsel hat, unter dieser Temperatur vorübergehend anzunehmen gezwungen ist. Auf diese Weise wird es auch gelingen, Froschlarven nicht nur in der ontogrenetischen Entwicklung ihres Farbkleides aufzuhalten, sondern man wird sie auch über das, ihnen von der Vererbung angewiesene farbkleid-tadium weiter hinausetrangen kinnen. 
Auf die fundamentale Bedeutung derartiger Experimente darf wohl nicht weiter hingewiesen werden.

\section{Abschnitt IV: Phylogenese der Farbkleider.}

a. Theodor Eimer.

Theodor Eimer hat das sehr grosse Verdienst, der vergleichenden Anatomie ein neues Gebiet dadurch erschlossen zu haben, dass er zuerst in sehr ausgedehntem Maasse Untersuchungen über die Phylogenese der Farblagerung in der thierischen Haut angestellt hat. Und wenn auch manche unter seinen Schlüssen anfechtbar sind und von mir angefochten werden müssen, Niemand wird ihm absprechen, dass seine Untersuchungen gründlich und mustergiltig sind. Die Resultate seiner umfangreichen Arbeiten fasst er selbst in folgenden Worten zusammen:

"Alle Gebilde der Zeichnung sind auf drei Grundformen zurückzuführen: Längsstreifung, Fleckung und Querstreifung oder Tigerzeichnung.

"Die Längsstreifung ist diejenige Zeichnungsart, aus welcher die zwei anderen durch in ganz bestimmter Richtung fortgeschrittene resp. vorschreitende Umbildung sich entwickelt haben oder entwickeln. Und zwar ist es eine ganz bestimmte Anzahl von typisch gelagerten Längsstreifen, welche sich als ursprünglicher Ausgangspunkt aller Zeichnung erweist. Nichts ist zufällig in jener Umbildung, alles geschieht in strengster Gesetzmässigkeit, wie nach einem vorgeschriebenen Plan.

„Ueberall finden sich Arten, welche heute noch den ursprünglichen Typus einfacher Längsstreifung zeigen, andere sind gefleckt worden, andere getigert, dazwischen die verschiedenen Uebergangsformen. Früher oder später schwindet häufig alle Zeichnung. " (Die Thiere werden einfarbig oder farblos. Ref.)

Auch heute noch machen die Arten mit höherer Zeichnungsstufe im Verlauf ihrer individuellen Entwicklung die niederen in der Regel durch, d. h. getigerte Arten sind in der Jugend gefleckt und noch früher längsgestreift, manche ungezeichnete sind in der Jugend quergestreift, noch früher gefleckt, noch früher längsgestreift.

»Die Männchen gehen in der Zeichnung vor: männliche Präponderanz.

»Ausserdem zeigte sich, dass die Umbildung in ganz bestimmter Richtung am Körper geschieht: bei den Eidechsen von hinten nach vorn (postero-anteriore Entwicklung), sodass jedesmal neue Eigenschaften zuerst am hinteren Theil des Körpers auftreten, um dann von dort nach vorn über denselben sich auszubreiten. $\mathrm{Da}$ dieser Prozess immer von Neuem geschieht, so entsteht das Gesetz der wellenförmigen Entwicklung oder das Undulationsgesetz."

Für die Raubvögel stellte Eimer folgende Gesetze auf: „I) Das in der Jugend (abgesehen vom Dunenkleid, welches in der Regel meist ohne Zeichnung ist) Längszeichnung und blaue Grundfarbe vorherrschen; 2) dass sich beide beim Weibchen am längsten erhalten, während neue Eigenschaften zuerst beim Männchen und zwar bei älteren Männchen auftreten; 3) dass als solche neuen Eigenschaften erscheinen: a. Querstreifung, b. graue, graublaue und dunkel- oder rostbraune, auch schwarze Farbe. Ferner, dass die Querzeichnung zuerst, die neue Farbe später auftritt, endlich, dass beide eine Zeit lang zusammen bestehen können, dass aber zuerst die Zeichnung ganz schwindet."

Aus einer dritten Eimer'schen Arbeit: Die Artbildung und Verwandtschaft bei den Schmetterlingen, Jena 1889, hebe ich nur noch zwei Sätze hervor, die zur Vervollständigung und zum Verständniss des Vorigen nothwendig sind:

"Die Zeichnung ist eines der sichersten Mittel zur Erkenntniss der Verwandtschaftsbeziehungen. « Und:

"Bei der Feststellung der Verwandtschaftsbeziehungen gehe ich aus von der schwarzen oder dunklen Zeichnung, nicht von der hellen Grundfarbe. « - 
b. Franz Werner und Haecker.

Während Haecker mit seinen Ansichten über die thierische Zeichnung ganz auf Eimer'schem Boden steht, nimmt Franz Werner einen wesentlich anderen Standpunkt ein. Auch seine Ansichten citire ich möglichst im eigenen Gewand und schicke voraus, dass Werner nicht nur eine Einwanderung des Pigments in die Haut, sondern sogar eine Fortwanderung desselben in der Haut annimmt. Nach ihm kann also Pigment, welches einer bestimmten Hautstelle eingelagert ist, diese Stelle verlassen und sich an einer anderen niederlassen. Die Thatsache z. B., dass die schwarzen Salamander, wenn sie plötzlich in kaltes Wasser geworfen werden, ihre gleichmässig schwarze Färbung verlieren, indem sie dieselbe in schwarze Flecken auf etwas hellerem Grund verwandeln, erklärt er so: Bei dieser Umfärbung wandert das Pigment der heller werdenden Hautstellen in die dunkler werdenden Flecken hinein; kommen die Salamander dann wieder in wärmeres Wasser, dann fliesst, nach Werner, das ausgewanderte Pigment in sein altes Bett zurück.

Die Zeichnung der Thiere leitet er von einer irregulären Fleckenzeichnung (dunkle Flecken auf hellem Grund) ab; solche regellose Fleckenzeichnung tritt nach ihm bei allen Wirbelthierklassen und -Ordnungen als erstes (ontogenetisches und phylogenetisches) Stadium der Zeichnung auf. Als solche uralte, bei allen oder den meisten Reptilien und Amphibien homologe, primäre Flecken betrachtet er: die Inter- und Postocularzeichnung der Thiere, mindestens zwei Oberlippenflecken, dann einen Subocularstreifen und einen Nasenfleck.

Aus dieser Fleckenzeichnung entsteht nach Werner die primäre Längsstreifung dadurch, dass die Zwischenräume zwischen Flecken, welche in Längsreihen liegen, durch Pigment ausgefullt werden; während die primäre Querstreifung dadurch entsteht, dass Flecken, welche in Querlinien liegen, durch Zwischenlagerung von Pigment miteinander verbunden werden. Es kann diese Pigmenteinlagerung in die bisher farblosen Hautstellen so weit gehen, dass das Thier zum Schluss einfarbig wird (primäre Einfarbigkeit).

Diese Pigmenteinlagerung bei der Flecken- und Streifenverschmelzung geschieht nach Werner in zweierlei Weise: Entweder von beiden miteinander in Verbindung tretenden Flecken und Streifen gleichzeitig; es vergrössern sich die beiden Flecken oder Streifen (letztere natürlich der Breite nach) gegeneinander allmählich, bis sie aneinander stossen, oder die Verschmelzung von Längsstreifen geschieht durch gleichmässige Verdunkelung der Grundfarbe zwischen ihnen bis zur völligen Gleichheit derselben mit der Zeichnung. Es ist aber ausserdem, schreibt Werner, diese Verdunkelung der Grundfarbe eine sehr häufige Ursache entstehender sekundärer Einfarbigkeit der ganzen Oberseite des Thieres und deshalb interessant, weil diese Verdunkelung im Verlauf des individuellen Wachsthums, ja oft im Verlauf weniger Jahre an einem und demselben Thiere beobachtet werden kann.

Ausser der primären Zeichnung und Einfarbigkeit der Thiere unterscheidet Werner dann noch sekundäre Formen der Zeichnung. »Zunächst Flecke; sie können nur auf der Area primärer Längsstreifen entstehen und überschreiten dieselbe erst dann, wenn diese Streifen undeutlich geworden sind." „Durch Wanderung des Pigments nach den Rändern der Flecken und Streifen entstehen mehr oder weniger dunkle und breite Ränder, und die Mitte hellt sich entsprechend auf, dadurch können Ocellen entstehen (bei Fleckung) oder Theilung (bei Längsund Querstreifen, wodurch eine Vermehrung der Streifen entsteht, wenn die Mitte des Streifens der Grundfarbe ähnlich wird). Wird auch von ausserhalb der Zeichnung Pigment zur Bildung der dunkeln Ränder verwandt, so bekommt die Zeichnung ausserdem einen hellen Rand." -

Schon aus diesen Sätzen, noch mehr aber aus der Vorstellung, welche Werner von der Pigmentwanderung in der Haut hat, geht hervor, dass nach seiner Ansicht farblose Thiere durch Pigmenteinwanderung in die Haut zum 
Schluss gleichmässig schwarze Färbung erlangen können, dass aber auch andererseits schwarze Thiere durch P'igmentverlust bis zur Farblosigkeit verblassen können. Andere Aussprüche Werner's aber führen den Leser direkt zu der Vermuthung, der Autor nehme eigentlich an, dass die Haut jedes Thieres ein bestimmtes Pigmentquantum besitze, welches bei Thieren, deren Haut gleichmässig gefärbt ist, gleichmässig über die ganze Haut vertheilt ist, während es bei anderen Thieren ein Farbkleidmuster erzeugt, indem es bei ihnen an gewissen Körperseiten verschwindet und dafür an anderen um so mehr angehäuft wird. Die vorangehenden Kapitel dieser Arbeit dürten den Beweis enthalten, dass alle diese theoretischen Anschauungen über die Pigmentwanderung in der Haut mit den wirklichen Verhältnissen in Widerspruch stehen, denn dass Verschwinden des Pigments an gewissen Körperpartien beruht nicht darauf, dass hier Pigment auswandert, sondern es beruht auf Chromatophorenkontraktion und nachfolgender -degeneration und die Pigmentvermehrung an anderen Körperpartien beruht nicht auf Pigmenteinwanderung, sondern auf Chromatophorenexpansion und Wachsen derselben sowie auf Pigmentvermehrung in ihnen in Folge eigener Plasma-Thätigkeit der Chromatophore.

Andere Aussprüche Werner's, auf die ich später zurückkommen werde, sind:

»Bei der Längsstreifung wird die Grundfarbe um so stärker aufgehellt (bis auf weiss), je breiter die Streifen sind, je näher sie also aneinander riicken. "

„Die Zeichnung wird vom mütterlichen Thiere den Jungen so genau überliefert, dass sie bei ihnen am deutlichsten, vollständigsten und bis ins Alter höchstens gleich bleiben, aber sich weder vervollständigen noch verdeutlichen; die einzig mögliche Veränderung ist die Verschmelzung der Flecken zu Längsstreifen. Die Färbung jedoch kann sich im Alter bedeutend ändern. Die meisten Reptilien bilden im Aiter ihre Zeichnung mehr oder weniger vollständig zurück oder zeigen einfache Zeichnung, indem sie scheinbar ganz gleich gezeichnet sind, was als phylogenetisches Vorstadium der vollständigen Einfarbigkeit zu betrachten ist. «

"Jedenfalls hat noch kein Mensch die ontogenetische Entstehung von Flecken aus. Längsstreifen beobachten können, während ich das Gegentheil oft genug gesehen habe. Ich habe bestimmt konstatiren können, dass die Querstreifen des Tigers durch Verschmelzung einfacher runder Flecke (wie bei Cynailurus) entstehen."

Das post-anteriore Gesetz Eimer's erkennt Werner nicht an; ebenso wenig das Undulationsgesetz. „Das Schwanzende zeigt in sehr vielen Fällen ursprünglichere Verhältnisse in der Zeichnung als der übrige Rumpf, was den entwicklungsgeschichtlichen Lehrsatz, dass der vordere Theíl der Thiere in der Entwicklung dem hinteren vorauseilt, auch für die Phylogenese der Zeichnung bestätigt." -

c. Zenneck, Alfred Tylor, eigene Untersuchungen.

Die Ansichten Franz Werner's über die Pigmentwanderung in der thierischen Haut dürften durch die, am Anfang dieser Abhandlung besprochenen Forschungsergebnisse hinfallig geworden sein und damit ist dann auch seinen Ansichten über die Phylogenese der thierischen Farbkleidmuster der Boden entzogren. Dagegen hat seine Annahme, dass bei allen Wirbelthieren die Zeichnung ontogenetisch und phylogenetisch mit der Umbildung von dunkeln Flecken auf hellem Grunde beginnt, durch die Untersuchungen, welche Zenneck an Ringelnatterembryonen anstellte, eine wesentliche Stütze erhalten, wenn dies auch Zenneck, der in seinen Ansichten über die Phylogenese der Farbkleidmuster keine entschiedene Stellung einnimmt, nicht direkt ausgesprochen hat und eventuell nur von der Ringelnatter gelten lassen will. Zenneck fand, dass die Zeichnung der Ringelnatterembryonen mit Fleckbildung auf farblosem Grunde beginnt, dass diese Flecken in Längsreihen angelegt sind und später miteinander zu Längsstreifen verschmelzen können, und dass darauf erst die Zwischenräume zwischen den Streifen durch Pigment- 
einlagerung soweit ausgefuillt werden, wie sie bei erwachsenen Thieren überhaupt ausgefullt sind. Auf Grund seiner Untersuchungen verficht er alsdann den alten Satz, dass das Pigment, weil es in gewissen Fällen zuerst um die Blutgefässe herum zur Ausbildung kommt, durch die Blutgefässe in die Haut einwandere oder doch im Anschluss an sie in der Haut entstehe, denn »dass ein Zusammenhang zwischen den Gefässen und der Pigmentirung besteht, das dürfte nach dem Vorhergehenden unzweifelhaft sein «, und er scheint dabei der Ansicht zu sein, dass er der Entdecker der Thatsache ist, dass das Pigment in gewissen Fällen vorwiegend um die Blutgefässe herum abgelagert wird. Das Farbkleidmuster in der Haut der Ringelnatter aber soll nach ihm auf Grund seiner Untersuchungen deshalb ein regelmässiges sein, weil in dieser Haut die Blutgefässe, welche das Pigment erzeugen, regelmässig angeordnet sind.

Dass das Pigment oder besser die Pigmentfarbe nicht vom Blutfarbstoff und auch nicht von Blutgefässen abhängig ist, wird, wie bereits bewiesen wurde, direkt widerlegt durch die Untersuchungen von Zavisch und Winkler, welche an Froschembryonen bewiesen, dass in manchen Organismen bereits dann Pigment vorhanden ist und sich vermehrt, wenn in ihnen Blutgefasse und Blutfarbstoff noch nicht vorhanden sind.

Auch der Umstand, dass bei manchen Organismen pigmentirte Zellen aus verschiedenen Geweben koncentrisch um eine gemeinsame Blutbahn angeordnet sind, beweist nur, dass diese Zellen gemeinsam ernährt werden, nicht dass sie auch ihrem Inhalt oder ihrer Form nach, d. h. genetisch zusammenhängen. Eine Hauptarterie z. B. ernährt stets viele Gewebe verschiedenster Komposition, sie selbst aber durchfliesst dabei nicht die Gewebe, nimmt nicht Stoffe aus ihnen auf und transportirt sie fort, sondern sie ernährt alle von ihr abhängigen Gewebe durch Seitenäste, deren Strömung vom Hauptstrom abgezweigt wird und nicht mehr zu ihm wiederkehrt, sondern in die Venen verläuft. Der Stofftransport durch die Hauptarterie aus einem, von ihrem Stromgebiet abhängigen Gewebe ins andere, müsste demnach in seinem Beginn stets stromaufwärts gehen es giebt aber im Organismus keine Kräfte, welche einen derartigen Stofftransport bewerkstelligen können. Was aber für Hauptarterien gilt, gilt auch für alle Nebenarterien, auch sie ernähren nur die zu ihnen gehörigen Zellen und stellen keine Kommunikation zwischen ihnen her.

Dass die Gewebe unter Umständen koncentrisch um Blutbahnen gelagert sind, hängt von hydrodynamischen Gesetzen ab; kompakte Massen können nur von innen heraus gleichmässig und schnell ernährt werden, deshalb liegen z. B. auch die Knochenkörperchen koncentrisch um ihre Arterien.

Ganz besonders aber hebe ich hervor: Nicht die Blutgefässanordnung ist maassgebend für die Gewebsanordnung, sondern jede Gewebsanordnung erzeugt und beherrscht den zugehörigen Gefässverlauf. Jede Gewebswucherung ist das primäre, erst sekundär wachsen in sie Gefässe hinein. Regelmässige Farbkleidmuster haben daher auch regelmässigen Gefässverlauf; aber ihre Entstehungsursache ist er nicht. -

Es bleibt nunmehr nur noch die Frage zu erledigen: warum bilden sich bej den Embryonen gewöhnlich zuerst die schwarzen Hautflecken aus? Das hat in Folgendem seinen Grund. Es wurde schon früher darauf hingewiesen, dass in der Wirbelthierhaut Chromatophoren sehr verschiedener Qualitäten zu finden sind, neben Chromatophoren nämlich, welche ein Maximum von Pigment bilden, alle Formen derselben bis zu solchen mit einem Minimum von Pigment. Ausserdem ist schon wiederholt erwähnt worden, dass jene Chromatophoren, welche ein Maximum von Pigment fuhren, die grössten und leistungsfahig sten unter allen Hautchromatophoren sind, denn die Chromatophoren verhalten sich körperlich proportional ihrem Pigmentinhalt. Es ist nun wohl klar, dass selbst in dem Fall, wenn all' diese Chromatophoren gleichzeitig anfangen, Pigment zu bilden, 
dicjenigen unter ihnen, welche ausgebildet am grössten und pigmentbeladensten sind, am intensivsten und vielleicht am schnellsten Pigment bilden werden und deshalb zuerst von allen sichtbar werden. Aus solchen in jeder Beziehung vollkommenen Chromatophoren bestehen nun aber, wie ebenfalls schon wiederholt betont worden ist, die schwarzen Flecken der Haut. Es werden also bei den Wirbelthierembryonen im Hautfarbkleid deshalb die schwarzen Flecken am frühesten sichtbar, weil sie durch Chromatophoren gebildet werden, die in jeder Beziehung die vollkommensten Chromatophoren der Haut sind und welche ausserdem durch Schirmzellen nicht überdeckt werden.

Dass diese Flecke dann noch an grösseren Blutbahnen gelegen sind, kommt, wie auch noch einmal wiederholt werden mag, daher, dass ihre Chromatophoren intensiver ernährt werden müssen als alle anderen der betreffenden Haut. -

Durch Zenneck's Nachweis, dass bei den Ringelnatterembryonen die ontogenetische Ausbildung der Zeichnung mit Fleckbildung auf farblosem Grunde beginnt und dann in Längsstreifung übergeht, und durch Alfred Tylor's Nachweis, dass die dunkle Querstreifung gewisser Schweine ebenfalls durch dunkle Flecken vorgebildet wird, und durch die Beispiele, welche Werner selbst geliefert hat, scheint seine Ansicht, dass bei allen Thieren die Zeiclınung ontogenetisch und phylogenetisch mit schwarzer Fleckbildung auf hellem oder farblosem Grunde beginnt, gut bewiesen zu sein, und doch ist sie es nicht. Allerdings, bei einer sehr grossen Gruppe von Thieren entsteht und entwickelt sich die Zeichnung thatsächlich in dieser Weise; bei all' den Thieren nämlich, welche, um es vorweg zu sagen, ihre Entwicklung als »Em. bryonen ", d. h. so beginnen, dass sie im Beginn ihres Lebens in Eihüllen oder in den Mutterleib eingeschlossen sind; an diese Embryonen schliessen sich dann wohl noch sämmtliche Wirbelthierlarven an, welche in völligem Dunkel oder wenigstens in sehr lichtarmen Medien zur Entwicklung kommen. Dagegen giebt es eine sicher ebenso grosse Gruppe von Wirbelthieren, deren Ontogenese nicht mit Fleckenbildung, sondern mit Einfarbigkeit beginnt, und deren Zeichnung stets aus dieser Einfarbigkeit entsteht; es sind all' die Wirbelthiere, welche ihre Ontogenese im Tageslicht und als selbstständige »Larven « beginnen. Dazu gehören vor Allem die Froscharten mit sehr wenigen Ausnahmen und die weitaus meisten Urodelen. Schon in den Froscheiern liegt Pigment, wie Jarisch und Winkler nachgewiesen haben; und jede weitere Ausbildung der Froschlarven wird durch Ausbildung von Pigment begleitet, welches später sämmtliche Epidermis- und Cutiszellen füllt und die Larven bis zur Metamorphose oder bis nahe an dieselbe einfarbig dunkel und gewöhnlich tief schwarz erscheinen lässt. Aus diesen total gefärbten Larven entwickeln sich dann die ebenso stark oder weniger oder garnicht gefärbten erwachsenen Individuen. Merkwürdiger Weise hat weder Eimer, noch Werner, noch sonst einer unter den Forschern, welche Studien über die Phylogenese der thierischen Hautzeichnung unternahmen, diese höchst auffallige Thatsache berücksichtigt. Aus ihr ergiebt sich:

Weil Licht für die Ausbildung und Fortbıldung des Hautpigments einer der wichtigsten, ja vielleicht der wichtigste Faktor ist, ${ }^{, ;}$) deshalb leben alle »Embryonen unter Existenzbedingungen, welche die Hautfärbung unnöthig machen, und sie erwerben die Hautfärbung deshalb gewöhnlich erst kurz vor dem Ausschlüpfen aus dem Ei oder erst nach dem Ausschlüpfen aus demselben, und bemerkens-

*) Dass das Licht nicht nur indirekt, indem es die Chromatophoren beeinflusst, auf das Pigment einwirkt, sondern dass es auch direkte Beziehnngen zur Ausbildung der Pigmentfarbe hat, zeigte Poulton experimentell durch den Nachweiss, das bei Proteus anguineus, dem normaler Weise farblosen Höhlenbewohner, Hautfärbung auftritt, wenn das Thier längere Zeit am Tageslicht gehalten wird, und ferner bewies es auch Cunningham in folgender Weise experimentell: Junge Flundern sind an beiden Körperseiten gleichmässig pigmentirt. Bilden sie sich später asymetrisch um, so verliert ihre dem Boden zugekehrte Seite normaler Weise das Pigment; bei jungen Flundern aber, welche Cunningham in Gläsern zog, deren Boden aus Spiegelscheiben bestand, blieb sie pigmentirt. 
werther Veise, wenigstens bei den Reptilien, erst dann, wenn bercits ihre sonstigen Hautcharaktere, Schuppen z. B. und Anderes, völlig ausgebildet sind. An zahlreichen Beispielen habe ich dies konstatirt.

Wäre diese Ontogenese die Wiederholung der zugehörigen Phylogenese, dann ginge bei den Reptilien phylogenetisch die Schuppenbildung der lintstehung der Hautfärbung voraus, was wohl Niemand annehmen wird.

Ja selbst unter den Embryonen kann man einen noch sehr deutlichen Unterschied machen zwischen denen, welche sofort nach dem Verlassen des Eies oder Mutterleibes in das Tageslicht kommen, und denen, welche auch nach der Geburt im Dunkeln von ihren Eltern gepflegt und mit Nahrung versorgt werden. Die letzteren erwerben ihre definitive Färbung gewöhnlich noch später als die ersteren; denn wie schon Eimer erwähnt, sind z. B. die neugeborenen Raubvögel farblos im Dunenkleid, während dagegen die Jungen der Nestflüchter gewöhnlich ein gefärbtes Dunenkleid aufweisen können.

Alle »Larven", welche nach kurzem Eileben selbstständig im Tageslicht ihre Existenzbedingungen befriedigen müssen, besonders aber solche, welche schon ihre Eientwicklung im Tageslicht beginnen, erwerben wegen dieser Lebensweise viel früher ihre Hautfärbung als die Embryonen, und wenn sie, wie die Froschund Urodelenlarven, dabei noch viele Charaktere ihrer Ureltern rekapituliren, dann können wir wohl annehmen, dass ihre Farbkleid-Entstehung mehr phylogenetische Züge enthält als die der Embryonen.

Ich nehme deshalb an, dass das Farbkleid der Urwirbelthiere ihren ganzen Körper gleichmässig bedeckt hat und schwarzfarbig war, das letztere deshalb, weil bei allen Wirbelthierklassen sämmtliche Hautfarben aus Schwarz ihren Ursprung nehmen. Mit mir wird dies jeder Forscher annehmen müssen, der der Ueberzeugung ist, dass das Pigment nicht durch Einwanderung in die Haut, sondern in ihr selbst entsteht. Wenn es dort entsteht, dann müssen bei den Urwirbelthieren sämmtliche Hautpartien die Fähigkeit in sich gehabt haben, Pigment zu erzeugen, da noch jetzt zahllose Nachkommen dieser Urwirbelthiere ein den ganzen Körper deckendes Farbkleid tragen. Aus der Thatsache aber, dass auch heute noch sehr viele Wirbelthierarten ganz schwarze und bunt gefärbte Individuen neben einander beherbergen, und aus der zweiten Thatsache, dass bei den meisten Wirbelthierarten Melanismus auftreten kann, und aus der dritten Thatsache, dass die Färbung der Thiere so variabel ist, dass sie zur Artcharakterisirung nicht herangezogen werden darf, schliesse ich weiter, dass die meisten Wirbelthierarten mit universeller schwarzer Körperfärbung begonnen haben oder beginnen konnten. Dass wir viele sehr konstant und scheinbar unveränderlich gefärbte Arten besitzen, besagt gegen diese Annahme nichts, es beweist nur, dass die betreffenden Arten in der Gegenwart nicht mehr unter allen für sie erträglichen Lebensbedingungen zu leben gezwungen sind, dass mit anderen Worten ihr Verbreitungsbezirk ein engerer ist, als er ihrer Lebensfahigkeit nach sein dürfte. Aus all' diesen Gründen betrachte ich daher den Melanismus, wo er auftritt, als einen Rückschlag auf die Stammfarbe der Art. Bei den Thieren, welche als Larven über den ganzen Körper gleichmässig schwarz gefärbt sind, ist Melanismus demnach eine Hemmungsbildung, bei den Thieren dagegen, die ihn als Embryonen erwerben, ist er eine Art Ueberfärbung, erzeugt dadurch, dass einer oder alle Faktoren, welche die maximale Ausbildung des Pigments in den Hautstellen beguinstigen, auf das melanotisch werdende Individuum eingewirkt haben; denn die Färbung eines Thieres ist ungefär so variabel, wie jeder seiner Muskel; der in gewissen Grenzen an Leistungsfähigkeit und Ausbildung schnell ab. und zunehmen kann.

Mag man mit diesen Schluissen übereinstimmen oder nicht, jedenfalls ist so viel zweifellos festgestellt, dass bei fast allen Fröschen die ontogenetische Ent-

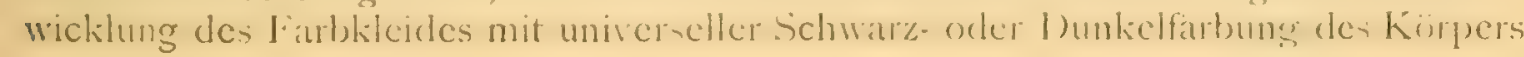


besinnt, was man durch J3enbachtung einheimischer und ausländischer Frösche jerler\%cit leicht konstatiren kann, und was auch durch zahlrciche Beispiele in dieser Arbeit und besonders schön durch die nachfolgende Rappienbeschreibung bewiesen wird.

Aber auch viele Individuen mit gemustertem Farbkleid und Embryonalcntwicklung lassen sehr deutlich erkennen, dass sie von Thieren abstammen, welche cin universelles schwarzes Farbkleid ihr eigen nannten; viele dieser Wirbel. thiere haben nämlich ein Jugend-Farbkleid, das viel weniger gemustert und viel dunkler ist als ihr definitives Kleid. Ja es ist bei manchen Arten das Jugendkleid einfach schwarz. Die Embryonen der meisten dieser Thiere erleiden also, sobald sie sich zu färben beginnen, eine Art Ueberfärbung der Haut, die dann beim Altern der Thiere wieder reduzirt wird. Das hat ubrigens Werner bereits erkannt und am prägnantesten in folgenden Worten ausgesprochen: »Die meisten Reptilien bilden im Alter ihre Zeichnung mehr weniger vollständig zurück oder zeigen einfache Zeichnung, indem ihre Schuppen ganz gleich gezeichnet sind. (Zool. Jahrb. I893, S. 382.)

\section{Abschnitt V. Farbkleider der Rappienhaut.}

\section{a. Einleitung.}

Vor Besprechung der Rappien will ich in Kürze einige Ausdrücke erklären, die ich in diesem Kapitel zu verwenden gezwungen bin.

Wie nachgewiesen wurde, haben die meisten Froschlarven, unter ihnen auch die der Rappien, ein den ganzen Körper überdeckendes Farbkleid von gleichmässig schwarzer Färbung. Während einige Frösche auch als erwachsene Individuen dasselbe beibehalten, alsdann also mit universellem Farbkleid und mit Urfärbung versehen sind, ändern es andere beim Uebergang aus dem Larven- ins Jugendstadium so um, dass bei ihnen an bestimmten Körperstellen ein Theil des ursprünglichen Hautpigments verloren geht und die Färbung des betreffenden Hautstuckes dadurch heller wird. Aus diesem Grunde nenne ich jede derartige Veränderung des Farbkleides ein Verblassen desselben.

Jedes Farbkleidverblassen findet an einer bestimmten Hautstelle statt und ist deshalb ein zonales; es findet zweitens zu einer bestimmten Zeit statt, ist deshalb ein chronales; und es findet drittens unter Wechsel der Färbung des Hautstiickes statt und ist deshalb ein chromales.

Das zonale Verblassen des Farblkleides kann sich entweder gleichmässig über den ganzen Körper des Thieres erstrecken und kann deshalb ein perisomatisches, oder, weil der Körper dabei nur eine Zone bildet, ein monozonales genannt werden, oder es findet nur an einem Theile des Körpers statt und heisst dann merisomatisch oder subzonal und kann allmählich bis zu einem polyzonalen gesteigert werden.

Bei jedem Verblassen, wenn es nicht perisomatisch ist, behalten Theile der Körperhaut die Urfärbung bei; ich nenne sie deshalb Restzonen und bezeichne die verblassten Körpertheile dementsprechend als Verblasszonen. Je nach ihrer Form bilden die Zonen alsdann Rest- und Verblassstreifen oder -Punkte oder sonstige Figuren. Ausserdem unterscheide ich Haupt- und Zwischenzonen und solche, die verwischt oder scharfrandig sind.

In Betreff der Ausbildung des Gesammtfarbkleides der Thiere wäre noch zu erwähnen: Jedes nicht universelle Farbkleid bildet ein Farbkleidmuster. Jedes dieser Farblkleidmuster entsteht aus einem universellen Farbkleid, aber nicht auf einmal, sondern durch langsame Entwicklung Schritt für Schritt, sodass es deshalb eine Phylogenese der Farbkleidmuster giebt. In den meisten fallen verlauft diesclbe folgendermaassen: Das Muster beginnt mit minimalen 
Anfängen, z. B. entstehen zuerst im schwarzen Grund nur wenig verblasste Hellflecken, die in Längsreihen angeordnet sind (Taf. V, Fig. 5 I u. folgende). Diese Flecke hellen sich später völlig auf und verwachsen zunächst durch Schwund jener Chromatophoren, welche sie trennen, zu hellen Längsstreifen. Später zerfallen dann noch die übrig gebliebenen Reststreifen in Punkte von schwarzer Farbe, die immer kleiner werden, bis zum Schluss das ganze Thier völlig entfärbt ist. Ich unterscheide deshalb bei der Phylogenese der meisten Wirbelthierfarbkleider ein Musterminimum, ein Aufsteigen des Musters, ein Muster optimum und einen Musterzerfall, der zum Schluss das Muster- und Farbkleid-Erlöschen bewirkt.

Von all den Individuen einer Froschart, welche danach streben, ein und dasselbe Farbkleidmuster zu seinem Extrem, do h. von seinen Anfängen an über das Optimum hinaus bis zu seinem Erlöschen auszubilden, kommen nur sehr wenige ontogenetisch bis zu diesem Extrem; die meisten machen schon auf einer der fruheren Stufen der betreffenden Farbklcidentwicklung Halt. Deshalb wird eine Reihe derartiger Individuen, richtig gruppirt, deutlich erkennen lassen, in welcher Weise das bei ihnen wrhandene larblkeid seine l'hylogenese von Anfang bis Ende durchläuft, wie das Tafel V ja zur Genüge zeigt.

Um für diese Individuenreihen, soweit sie die Phylogenese eines Farbkleidmusters repräsentiren, einen Namen $z u$ haben, der zugleich anzeigt, dass mit dem Namen keine Arten, sondern nur Varietäten bezeichnet werden, die sogar mehreren Arten angehören können, habe ich die Reihen nach folgendem Muster benannt: Rappiae x; series: trivittatae. Der Name sagt: Rappien von irgend welcher Art ( $\mathrm{x}$ bezeichnet in der Mathematik bekanntlich eine belicbige Zahl, hier eine beliebige Art), welche zu jener Varietätenreihe gehören, die durch drei Längsstreifen charakterisirt ist. Ich habe damn noch weiter bei jeder Individuenreihe, welche ein Farbleleidmuster phylesenctisch variirt, angegeluen, welche Individuen dieser Reihe aus dem mir vorlieesenden Material als Arten beschrichen worden sind und füge dieser Aufzählung nur die Schwimmhaut- und Kopfcharaktere der Arten hinzu. Die weitere Artbeschreibung kann ja bei den Artautoren selbst eingesehen werden. Weitere Bemerkungen über die Rappienarten findet man dann noch am Ende dieses Abschnitts zusammengestellt. -

\section{b. Ueber das Rappienfarbkleid.}

Alle Rappien beginnen ihre Farbkleidentwicklung aus gemeinsamer universeller Grundlage, d. h. als schwarze Larven. Diese erwerben, wie es scheint, ziemlich frühzeitig das Kleid der erwachsenen Individuen, das nach sehr verschiedenen Mustern angelegt wird. Den Mustern entsprechend können deshalb die erwachsenen Individuen in Reihen mit Nebenreihen geordnet werden, die alle einem bestimmten Extrem - der Farblosigkeit - zustreben. Die Individuen-Hauptreihen divergiren untereinander, während ihre Zweige - die Nebenreihen - konvergiren.

Unter allen von mir untersuchten erwachsenen Rappien giebt es streng genommen kein Thier, welches ein universelles Farbkleid und universelle Färbung besitzt, d. h. am ganzen Körper gleichmässig schwarz gefärbt ist; denn mit Ausnahme einer einzigen Form, Rappia fusciventris, haben alle von mir gesehenen Individuen dieser Art einen völlig entfäbten Bauch. Aber Rappia fusciventris hat trotzdem kein universelles Farbkleid, da an ihren Körperseiten je ein Verblassstreifen liegt, und noch weniger ist das Thier universell gefärbt. Man kann daher bei den Rappien eigentlich nur noch von einer Phylogenese des Farbkleide: der Oberseite sprechen und kann die Thiere dementsprechend in funf Hauptgruppen ordnen. 


\section{Gruppe I. Thiere an der Oberfläche gleichmässig verblassend.} reihen.

$\mathrm{Zu}$ dieser Gruppe gehört nur eine Individuenreihe mit zwei kurzen Neben-

\section{Reihe I: Rappiae x; series: unicolores (Taf. V, Fig. I-8).}

Die auf dem Rücken gleichmässig schwarz gefärbten Larven dieser Individuen werden später auf dem ganzen Rücken gleichmässig heller. Die Individuenreihe beginnt demnach ihre Fortentwicklung mit nur wenig verblassten, rauchschwarzen Thieren (Fig. I). Bei diesen Individuen liegen die schwarzen Chromatophoren so dicht aneinander, dass sie dem Thier eine durchaus einheitliche dunkle Färbung verleihen; Interferenzzellen besitzen die Thiere nicht oder nur in ganz geringer Zahl. Die extremeren Glieder der Reihe (Fig. 2-3) werden fortschreitend heller grau, weil ihr Rücken fortschreitend Chromatophoren verliert und zwar in so regelmässiger Vertheilung, dass keine seiner Partien von der Aufhellung besonders begünstigt wird. An die Stelle der atrophirenden Chromatophoren können Interferenzzellen treten. Dieselben liegen aber ohne Ausnahme in den Räumen zwischen den Chromatophoren, nirgends decken sie dieselben. Der Chromatophorenverlust der Thiere kann so weit gehen, dass sehr bald die erhaltenen Chromatophoren voneinander durch so ansehnliche Zwischenräume getrennt sind, dass schon mit blossem Auge jede einzelne derselben erkannt werden kann. Das Thier erscheint dann bei naher Betrachtung auf dem ganzen Rücken gleichmässig fein punktirt.

Wenn eine bestimmte Menge der Chromatophoren verschwunden ist, so erleiden die übrig bleibenden eine Umfärbung. Thre schwarze Farbe wandelt sich in schwarzbraun und braun, endlich in braungelb um. Braungelb ist das Vorstadium der Farblosigkeit. Die Umfärbung beginnt in den Ausläufern der Chromatophoren und rückt gegen ihr Centrum vor; sie beruht auf Pigmentschwund in den Zellen.

Thiere auf diesen extremen Entwicklungsstufen (Fig. 5 u. 6) haben sehr viele Interferenzzellen, die jede Chromatophore in einem dichten Kranz umstehen; aber auch hier noch liegen sie nicht auf den Chromatophoren, sondern nur $\mathrm{zw}$ ischen ihnen. Da sie entweder gelblich oder durch viel Guanin weiss gefärbt sind, so wird durch sie die ohnehin helle Farbe des Thieres noch erhöht.

Bei dieser Farbkleidentwicklung ist ausserdem noch sehr interessant, dass einzelne Vertreter derselben von der Hauptreihe dadurch abweichen, dass bei ihnen das Verblassen des Rückens, nachdem es bis zu einer bestimmten Aufhellung gleichmässig fortgeschritten ist, eine schwache Neigung zeigt, ungleichmässig zu werden. Ueber diese Anfänge kommt es indess nicht hinaus. So liegen mir rauchschwarze Individuen vor, deren Farbkleid bestrebt ist, auf hellerem Grunde umrandete Flecke auszubilden (Fig. 7).

Die Rückenpartien, welche bei diesen Individuen zu Flecken werden, sind stärker verblasst als der Rücken in seiner Gesammtheit, der ebenfalls heller geworden ist, während die Ränder der Flecke- die Färbung der Stammform beibehielten, d. h. rauchschwarz geblieben sind.

Dieses Individuum ist deshalb so hoch interessant, weil seine Flecke nach einem Muster angelegt sind, welches erst in einer anderen Rappienreihe vollendete Ausbildung erfährt (Fig. 65-7I). Jenes Individuum zeigt also schwache Konvergenz zu dieser Hauptreihe.

Ferner liegen mir zwei Individuen vor, bei welchen in dem sehr stark verblassten Rücken ein Hellstreifen angedeutet ist, der bis fast zum After hinunterläuft. Auch dieses Individuum zeigt die Tendenz, ein Farblileid auszubilden, das bei anderen Individuen, viel vollendeter entwickelt ist. 
Folgende im Berliner und Hamburger Museum vorhandene Individuen gehören hierher:

a) Schwimmhäute an Händen und Füssen gross, Schnauze abgerundet, Kopf scheinbar zusammengedrückt, oder ganze Schnauze deutlich mopskopfartig. Im Berliner und Hamburger Museum unter dem Artnamen: Rappia concolor Schleg.; 2 Individ. aus Acra, 3 aus Guinea (darunter Fig. 7); eines aus Massailand, G. A. Fischer S.; I aus Südwest-Nyansa, Stuhlmann S.; ' 4 aus Zanzibar, Moriz Tup. S. - Die Individuen würden nach Boulenger's Katalog sicher nicht als Rappia concolor bestimmt werden.

b) Schwimmhäute an Händen und Füssen klein, Schnauze dreieckig zugespitzt. Rappia zanzibarica Pfeff.; 2 Individ. von Zanzibar; 4 aus Bagamoyo, Fischer S. Eins der Thiere aus Bagamoyo zeigt deutliche Konvergenz gegen die Individuenreihe Fig. 66 bis 76.

\section{Gruppe II. Thiere auf der Oberfläche mit kleinen bis grossen Restflecken.}

Reihe I: Rappiae x; series: punctulatae (Taf. V, Fig. 9-II).

Die Reihe beginnt mit Individuen, welche auf dem Rücken nicht gleichmässig verblasst sind, sondern so, dass in ihrer vorwiegend gleichmässig aufgehellten Rückenzone zahlreiche Restpünktchen übrig geblieben sind. Diese winzig kleinen, rundlichen, schwarzen Flecke bestehen aus nur einer Chromatophore, welche beträchtlich gross und vielästig ist und von keiner Interferenzzelle überdeckt wird. Auch in der aufgehellten Zone des Rückens der Thiere sind zwar noch viele Chromatophoren vorhanden, sie aber sind winzige schwarze Pünktchen mit wenig oder keinen Aestchen und liegen unter einem so dichten Interferenzzellendach, dass nur noch einzelne ihrer Aestchen dieses Dach durchbrechen und bis zur Epidermis reichen.

Die Fortentwicklung der Individuenreihe ist folgende: Die Restpünktchen der Thiere werden andauernd kleiner, weil die ihnen zu Grunde liegenden intakten Chromatophoren zu atrophiren beginnen, indem sie sich stark kontrahiren und dadurch zu Klümpchen mit wenigen Fortsätzen degeneriren. Während ihres Degenerirens beginnen die Interferenzzellen auch auf sie hinaufzukriechen und decken sie schliesslich so, wie die schon früher degenerirten, welche in den von vorn herein aufgehellten Rückentheilen des Thieres liegen und nur noch mit einigen Fortsätzen das Schirmzellendach durchbrechen (Fig. . I ). Dieses sekundäre Chromatophoren-Degeneriren kann so weit gehen, dass der Rücken des Thieres gleichmässig aufgehellt wird. So entsteht an diesem Ast der Farbkleidentwicklung ein Individuum (Fig. IO), welches zwar durch seine gleichmässige Rückenfärbung gegen die Individuen der Concolor-Reihe (Fig. I-6) konvergirt, aber deshalb von ihnen abweicht, weil bei ihm die Schirmzellen über die Chromatophoren hinweggehen, was bei den Individuen der ConcolorReihe nie der Fall ist.

Noch deutlicher wird die nur scheinbare Konvergenz der beiden Reihen, wenn man ihre Färbung berücksichtigt. Die Individuen der Concolor-Reihe sind schwarz, rauchschwarz, braunschwarz, zum Schluss braun bis fahlgelb. Die bisher besprochenen Individuen der Punktatus-Reihe sind auf dem Rücken dunkel- (Fig. 9), oder hellgrün mit schwarzen Punkten (Fig. II), oder rein grün (Fig. IO).

Sehr interessant ist nun noch ein Seitenzweig der Punctatus-Reihe (Textfig. I), aus Thieren bestehend, welche bei vorwiegend gleichmässiger Rückenverblassung neben zahlreichen, sehr feinen, schwarzen Restpünktchen noch ebenso zahlreiche Hellflecken aufweisen; Hellflecken, welche in’ deutlichen Längsreihen angeordnet sind. 
Wegen dieser Hellflecken konvergiren die betreffenden Individuen gegen jene Rappiengruppe, welche von vornherein auf ihrem Rücken Hellflecken ausbilden. Die Hellflecken der hier vorliegenden Individuen sind im Leben citronengelb; sie bestehen aus gelben Interferenzzellen ohne Chromatophoren-Unterlage. Ein sehr grosses Individuum dieser Form steht unter dem Artnamen Rappia flavomaculatus A. D. im Hamburger Museum und stammt aus Abyssinien. Vier andere mir vorliegende Individuen, nach Anatomie und Zeichnung mit diesem genau übereinstimmend, wurden von Stuhlmann aus Bukoba gesandt.

Folgende von mir untersuchte Individuen gehören dieser Reihe an:

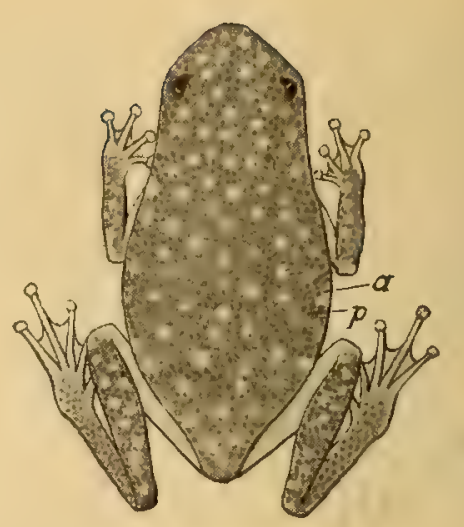

Fig. I.

a) Schwimmhaut an Händen und Füssen gross; Canthus rostralis deutlich, vorn abgestutzt, an den Seiten etwas eingedrückt; Maul mässig gross.

I. Taf. V, Fig. 9-II. Im Museum bisher ohne besonderen Namen. Zahlreiche Individuen aus Bukoba, Stuhlmann S.

2. Rappia flavomaculatus A.D., Hamburger Museum, Abyssinien; 4 Exemplare aus Bukoba.

b) Schwimmhaut an Händen und Füssen klein. Schnauze dreieckig zugespitzt. Der Beschreibung nach genau entsprechend der Rappia concolor des Boulenger'schen Katalogs, Hamburger Museum, ein Individuum von der Delagoa-Bai.

\section{Reihe II: Rappiae x; series: adspersae (Taf. V, Fig. I2-I6).}

Die Reihe beginnt mit Individuen, welche auf dem Rücken nicht gleichmässig verblasst sind, sondern so, dass in dem vorwiegend gleichmässig aufgehellten Rücken des Thieres zahlreiche Restfleckchen und -Pünktchen planlos verstreut sind. Die Restfleckchen bestehen aus einigen regellos nebeneinander liegenden Chromatophoren, haben deshalb meistens eine regellose Form und sehen nicht selten wie zerfressen aus. Die neben ihnen vorkommenden sehr zahlreichen Restpünktchen des Farbkleides bestehen aus nur einer grossen Chromatophore. Daneben findet man einzelne stark kontrahirte Chromatophoren, welche von einer dünnen Interferenzzellenlage überdeckt sind und deshalb im Spiritus bläulich angehauchte Hautpartien erzeugen; endlich findet man bei den Thieren auch noch Körperpartien, in welchen nur Interferenzzellen dicht gedrängt nebeneinander liegen, ohne Chromatophoren darunter. Lebend haben diese Thiere ausser den schwarzen Flecken und Pünktchen eine Grundfarbe, in welcher grüne und gelbe Partien regellos abwechseln.

Die Fortentwicklung der Reihe geschieht nun so, dass die schwarzen Flecken der Stammform beständig kleiner werden, und ein Theil ihrer Pünktchen verschwindet, weil die den Flecken und Pünktchen zu Grunde liegenden Chromatophoren in dauernden Kontraktionszustand übergehen und dann von Interferenzzellen überdeckt werden, während gleichzeitig ausserdem noch ein Theil der bereits überdeckten Chromatophoren ganz verschwindet. Es wächst also, wie in den beiden bisher besprochenen Reihen, auch in dieser das Grün und ganz besonders das Gelb auf Kosten des Schwarz, und schliesslich entstehen Individuen, welche im Spiritus fast rein weiss aussehen, lebend aber wahrscheinlich fahlgelb sind.

Die mir aus dieser Reihe vorliegenden Individuen haben ein und denselben anatomischen Bau, nämlich grosse Schwimmhäute, abgestumpfte Schnauze und ein mässig grosses Maul. 
Eins dieser Individuen heisst als Art: Rappia adspersa Ptrs.; Xinchoxo; Mus. N. 9176. - 3 Individuen stammen aus Bukoba, Stuhlmann S. - Die extremsten Individuen (Fig. I -16) sind in Sesse (West-Nyansa) von Stuhlmann gesammelt.

Reihe III: Rappiae x; series: punctatae (Taf. V, Fig. I8-I9).

Von dieser Reihe liegen mir nur drei Individuen vor, die auf dem Rücken vorwiegend gleichmässig verblasst sind und in dieser Grundfarbe eine grosse Anzahl rundlicher Flecke von mässiger Grösse besitzen. Diese Flecke sind alle etwas, aber nicht viel grösser als die grössten Flecke der Rappiae $\mathrm{x}$, series: adspersae.

Die Flecken bestehen aus Chromatophoren von schwarzem Körper mit dicken braunen Fortsätzen, die in grösserer Zahl - 6 bis Io - dicht nebeneinander liegen. Wegen dieser Chromatophorenfärbung sind die Flecke dunkelbraun, zuweilen fast schwarz. Die Rückengrundfarbe der Thiere ist rosenroth aus folgenden Gründen: In ihrem Bezirk liegen sehr zahlreiche einzelne Chromatophoren von geringer Grösse, welche nicht schwarz oder braun, sondern intensiv blutroth gefärbt sind. Es sind echte Chromatophoren, die in regelmässigen Abständen genau so gegen einander gelagert sind, wie die schwarzen Chromatophoren in dem rein grünen Farbkleid der einen früher beschriebenen Rappia x, var. punctata (Fig. IO). Sie unterscheiden sich von ihnen indess, wie alle rothen Chromatophoren von schwarzen, durch die grosse Zartheit ihres Körpers und ihrer Fortsätze. Sie sind übrigens alle von einer dichten Lage zum Theil stark guaninhaltiger Zellen überdeckt und erzeugen mit Hilfe derselben durch Farbendispersion die weinröthliche Grundfarbe des Thieres.

Ueber den dunkeln Chromatophoren des Thieres, welche dessen dunkle Flecken bilden, liegen, wie sonst, Interferenzzellen nicht, sie umlagern aber das Ausbreitungsgebiet der Flecken in dichtem Kranz, als wären sie bereit, sofort in dasselbe einzutreten, wenn ihnen durch anhaltende Kontraktion der Gegner die Möglichkeit dazu gegeben würde.

Die hier besprochenen Thiere sind ziemlich extreme Vertreter der Individuenreihe, $2 u$ welcher sie gehören, weil sie selbst stark verblasst, vorwiegend roth gefärbt sind. - Die Reihe dürfte mit grünen Individuen beginnen, welche schwarze Flecke von jener Grösse aufweisen, wie sie bei den vorliegenden Individuen vorhanden sind.

3 Individuen liegen mir vor - aus dem Hamburger Museum -, sie stammen aus Soyaux und tragen den Artnamen: Rappia nasuta Gray, stimmen mit dieser Art aber nur in der Färbung, nicht in der Schnauzenbildung überein, denn ihre Schnauze ist nicht zugespitzt, sondern abgestumpft und ihr Maul ist nicht klein sondern mässig gross. Ihre Hand- und Fussschwimmhäute sind gross.

\section{Reihe III: Rappiae x; series: guttatae (Taf. V, Fig. 25-35).}

Die Individuen dieser Reihe, von denen mir ungemein viele vorliegen, schliessen sich unmittelbar denen der vorigen Reihe an, sie weichen von ihnen eigentlich nur dadurch ab, dass ihre Restflecke durchweg grösser sind; docl dürfte noch mehr Vergleichsmaterial lehren, dass die beiden Reihen auch darin unmittelbar aneinander stossen.

Bei allen Individuen, die dieser Reihe angehören, sind über den Rücken schwarze Flecken in grosser Zahl so unregelmässig verstreut, dass die Flecken der einen Körperseite von denen der anderen wesentlich verschieden sind. Ausserdem sind sie so dicht gehäuft und so gross, dass bei all' diesen Thieren die Verblassstellen des Rückens als feine Maschen eines sehr hellen Nctzes zwischen ihnen eingezwängt sind. 
Die Individuen dieser Reihe sondern sich zuerst in zwei Abtheilungen. In solche, welche vorwiegend rundliche Flecken haben (Fig. 25-30), und in solche, deren Hauptflecken zwar abgerundet, aber langgestreckt sind (Fig. 3I-35). Die langgestreckten Flecken sind häufig von Ruickenlänge und dabei so angeordnet, dass bei dem betreffenden Thier nicht nur die Restflecken, sondern auch die Verblassstreifen annähernd Längslinien bilden. Diese Individuen sind deshalb Konvergenzformen gegen Rappien mit wirklichen Streifen, die später besprochen werden. Die Verblassstellen all dieser Thiere bestehen aus sehr dichten Schirmzellenlagen, die über Chromatophoren liegen, welche in einigen Verblassstellen noch leidlich erhalten und daher vielästig sind, in den meisten Verblassstellen aber nur noch schwarze, fast astlose Pünktchen darstellen.

Lebend haben die bisher besprochenen Individuen dieser Reihe tiefschwarze Flecke in grüner oder gelber Verblassfarbe. Grün sind all die Stellen ihres Rückens, welche in der Abbildung einen noch grauen Ton und als Objekt unter dem dichten Schirmzellendach noch leidlich erhaltene Chromatophoren aufweisen, gelb sind bei ihnen die Stellen, welche in der Abbildung rein weiss gehalten wurden und deren Chromatophoren zu Pünktchen degenerirt sind.

In beiden Abtheilungen dieser Farbkleid-Reihe verblassen die Restflecken entweder im Ganzen und gleichmässig, indem ihre Chromatophoren - zuerst in ihren Aesten, dann auch im Körper - an Pigment verlieren, wodurch die Flecke zum Schluss schön kastanienbraun werden, oder die Flecke verblassen so, dass sie sich in viele einzelne Pünktchen auflösen, die zum Schluss mehr oder weniger aufgehellt werden. Es geschieht, indem die Chromatophoren der Flecken sich fortschreitend kontrahiren und zum Schluss von Schirmzellen, die zuerst zwischen ihnen entstehen, ganz überdeckt werden. Auf diese Weise können die ganzen Flecke gleichmässig aufgehellt werden (Fig. 28-29), oder von innen heraus, sodass zum Schluss ihre weniger verblassenden Ränder schwarz gekörnte Linien bilden (Fig. 34), oder die Flecken können auf diese Weise von ihrer Peripherie aus eingeschmolzen werden und dabei dann, wenn es unregelmässig geschieht, in mehrere kleinere Flecken zerfallen.

Die auf diese Weise verblassenden Flecke gehen aus Schwarz in Dunkelgrau, dann in Dunkelgrün und zum Schluss in Gelb über, sie nehmen also sekundär die Farben der primären Verblassstellen an und vergrössern auf diese Weise auf ihre Kosten deren Verbreitungsgebiet: Unter den Chromatophoren der auf diese Weise verblassenden Flecke, welche auch beim Degeneriren normaler Weise schwarz bleiben, findet man ubrigens einzelne mit schwarzem Körper und braunen Aesten und hin und wieder eine ganz braune.

Ein sehr interessanter Zweig dieser Individuenreihe ist im Berliner Museum vertreten durch ein Individuum (Fig. 26), welches als "Farbenvarietät leoparda " bezeichnet werden kann. Das Thier hat in seinem Rückenfarbkleid runde Augenflecke - schwarze Flecke, die in der Mitte zu einem schönen Kastanienbraun aufgehellt sind -; sie liegen in netzförmigem Verblassmuster, dessen Maschen nur unmittelbar um die Augenflecke herum völlig aufgehellt sind, während sie in ihren mittleren Partien noch deutliche Reste ursprünglicher Dunkelfärbung aufweisen in Form von grauen Mittelzonen.

Lebend haben diese Thiere schwarze Augenflecke mit braunem Kern und gelber Umrandung, die in grünen Grund eingelagert sind.

Diese Leopardenform führt nun direkt hinüber $\mathrm{zu}$ einem anderen Zweig dieser Rappienreihe (Fig. 25), mir vorliegend in nur einem Individuum, dessen schwarze Flecke bereits verblasst sind, obgleich die Zwischenräume zwischen ihnen noch tief dunkel sind. Dieses Thier verblasst also auf einer sehr frühen Stufe der zugehörigen Farbkleid-Entwicklung und dürte lebend am ganzen Körper fleckenweise hell- und dunkelgrün gefärbt sein, auch besitzt es in seinem 
Rückenfarblkleid einige Pünktchen von intensiver Rothfärbung, bestehend aus einigen Chromatophoren von gleicher Färbung ohne Interferenzzellen-Ueberdachung.

Bei allen Individuen dieser Reihe ist die Schnauze abgestutzt und das Maul mässig gross, die Schwimmhäute an Händen und Füssen sind gleichfalls gross.

2 Individuen dieser Reihe, aus der Abtheilung mit runden Flecken, hat Peters als Rappia vermiculata beschrieben (Fig. 29 ist einer dieser Typen), sie stammen von Malange in Angola. Mus.-Nr. 10050, 9408. - Die zahlreichen Thiere aus beiden Abtheilungen, die mir vorlagen, stammen aus Sesse, West-Nyansa, Stuhlmann S.; die extremsten unter ihnen aus Bukoba, Stuhlmann S.; März 92. Die Leoparden-Form stammt aus Bukoba, Stuhlmann S. - Die Thiere mit rein braunen Restflecken auf gelbem Grunde fing Stuhlmann am Kagera-Ufer; 5. Februar I89I.

Reihe IV: Rappiae $\mathrm{x}$; series: striolatae (Taf. V, Fig. 2I-23).

Während die bisher besprochenen Vertreter dieser Gruppe entweder runde oder doch abgerundete Restflecke besitzen, haben die Individuen dieser Reihe Flecke in Form gewundener und zuweilen verästelter Strichelchen; daher der Name. Die Entwicklung der Reihe beginnt mit Individuen, welche in der Abbildung derartige schwarze Strichelchen auf grauem Grunde, in der Natur schwarze Strichelchen in grüner Verblassfarbe aufweisen. Die Fortentwicklung der Individuen geschieht dann so, dass auf ihrem Rücken entweder die Verblassfarbe auf Kosten der ursprünglichen Flecke zunimmt, indem sie in die Flecke - von deren Peripherie aus - eindringt (Fig. 22) und dieselben schliesslich ganz zerstören kann, so dass die Thiere dann rein grün werden, und von den rein grün gewordenen Punctatus-Formen nicht mehr zu unterscheiden sind. Bei dem anderen Zweige dieser Entwicklungsreihe (Fig. 23) hellt sich die Verblassfarbe des Rückens rings um die schwarzen Flecke durch Chromatophorenverlust und Interferenzzellenvermehrung sehr stark auf - d. h. sie geht in der Natur aus Grü in Gelb über, so dass dann Thiere entstehen, welche auf grünem Grund schwarze Flecke tragen, die gelb umrandet sind. Weiter habe ich bei dieser Reihe die FarblkleidEntwicklung nicht verfolgen können.

Ein Individuum dieser Reihe, entsprechend Fig. 2 I und aus Taita stammend, ist von Peters als Rappia striolata beschrieben worden; Hildebrandt S. Die angeblich rothe Farbe dieses sehr schlecht konservirten Stückes ist Farbe von Kautschuk, der im Spiritus der Sammelflasche aufgelöst war und wahrscheinlich als Flaschenverschluss diente.

Neuere Individuen stammen aus Bukoa, Stuhlmann S., März i 892. Schwimmhäute bei allen Individuen gross, Schnauze abgestumpft, Maul mässig gross.

\section{Reihe V: Rappiae x; series: striatae (Taf. V, Fig. 24).}

Zwei Individuen dieser Reihe liegen mir vor, sie haben Mittelstellung unter den Individuen, welche zu dieser Reihe gehören müssen. Sie haben Restflecke, die strichförmig, langgestreckt, stark gewunden sowie verästelt sind und in Verblasszonen liegen, deren um die Flecke herum liegende Theile stärker aufgehellt sind. In der Natur haben die Thiere schwarze Striche auf grünem Grunde, der um die Striche herum ins Gelbe spielt. Die Individuen bilden daher Parallelformen zu jenen Individuen der vorigen Reihe (Fig. 23), die genau so gefärbt sind, und unterscheiden sich von ihnen eigentlich nur dadurch, dass ihre StrichZeichnung viel gröber ist, was aber bewirkt, dass die Individuen grundverschieden aussehen. Von den beiden mir vorliegenden Individuen dieser Reihe hat das eine übrigens wesentlich schmälere Striche als das andere.

Beide Individuen, aus Bukoba stammend, durch Stuhlmann gesammeit, haben grosse Schwimmhaute, abgestutzte Schnauze und maissig grosses Maul. 
Reihe VI: Rappiae x; series: ocellatae-punctatae (Taf. V, Fig. 20).

Nur ein Individuum aus dieser sehr seltenen Individuenreihe liegt mir bisher vor. Das Thier hat über den ganzen Rücken verstreute, blutrothe Fleckchen von kreisrunder Form, bestehend aus einer geringen Anzahl zierlicher blutrother Chromatophoren, die nicht von Schirmzellen überdeckt sind. Das um sie herum liegende Verblassgebiet besteht - in der Abbildung - aus dunkeln Mittelzonen und hellen Rändern um die Flecke; die dunkeln Mittelzonen des Gebiets bestehen in der Natur aus noch gut erhaltenen, plump-ästigen, daher schwarzen Chromatophoren, die nahe aneinander liegen und von einer recht lockeren Schirmzellenlage überdeckt sind. Die kreisförmigen Gebiete um die rothen Flecke haben nur kugelförmige, schwarze Chromatophoren und darüber, sowie in den Zwischenräumen zwischen ihnen zahllose Interferenzzellen. Die Thiere haben also in der Natur blutrothe Flecke in gelber Umrandung auf grünem Grund.

Das Thier hat Verwandtschafts-Beziehungen zu gewissen Zweigen der Maculatus-Gruppe, so zu dem Individuum, das schon auf sehr früher Entwicklungsstufe Restflecken-Verblassung zeigt (Fig. 25) und auch zu der Leoparden-Form der Reihe. Würden bei der letzteren Form die ganzen Augenflecke braun werden, dann würde die Verwandtschaft der beiden Individuen noch mehr hervortreten, denn dann hätten die Individuen fast gleiche Färbung und nur Restflecken von verschiedener Grösse. Es ist wahrscheinlich, dass diese Ocellatus-PunctatusReihe später als Seitenzweig an die Punctatus-Reihe wird angeschlossen werden.

Es sei noch ausdrücklich darauf hingewiesen, dass diese Farbenvarietät nichts zu thun hat mit der Günther'schen Art Rappia ocellata.

Das Individuum stammt aus Balaibo am Duki-Ufer; Stuhlmann S.; 9. November I89I. Schauze abgestumpft, Maul mässig gross. Schwimmhaut an Händen und Füssen gross.

\section{Gruppe III. Farbkleidmuster der Körperoberfläche aus Verblassflecken entstehend. (Taf. IV, Fig. 36-7I).}

Die Chromatophoren dieser Rappiengruppe verhalten sich genau so, wie die der vorangehenden und ihr nachfolgenden. Während in all diesen Gruppen die Chromatophoren der Reststellen des Farbkleides sehr gross, vielästig, intensiv pigmentirt und von Interferenzzellen weder umringt noch überdacht sind, zeigen die der Verblassstellen Körper- und Pigment-Atrophie und zwar um so stärker, je heller die Hautstellen werden, denen sie eingelagert sind. Parallel ihrer Atrophie wächst dann die Zahl der Interferenzzellen. Zuerst liegen sie nur um die Chromatophoren herum, dann überdecken sie dieselben. Ich komme auf diese Verhältnisse nun nicht mehr zurück.

\section{a. Verblassflecken über die Körperoberseite regellos verstreut.}

\section{Reihe I: Rappiae x; series: densereticulatae (Taf. IV, Fig. 36-38).}

Verblassflecken ausserordentlich zahlreich und sehr klein, vorwiegend rund, über den ganzen Körper des Thieres unregelmässig verstreut. Das Restgebiet bildet deshalb eine Art plumpen, vielmaschigen Netzwerks (Fig. 36 und 38). Dieses Farbkleidmuster bildet sich fort, indem Theile des Restgebiets von den Hellflecken aus zerfressen werden, während sich zugleich andere Theile dieses Gebiets von innen heraus aufhellen, sodass zum Schluss bei den Thieren an manchen Körperstellen nur noch zahlreiche, vielfach verästelte Restfleckchen oder einzelne Restpunkte in farbloser Umgebung übrig bleiben.

Bei allen Vertretern dieser Reihe und dieser Gruppe beginnt die Aufhellung des Rückens an den Körperseiten d. h. vom Bauche aus. Dabei ist ausserdem 
noch zu bemerken: Auch die Hintergliedmaassen dieser Thiere haben in Bezug auf Färbung eine Ober- und Unterseite. Bei den meisten Rappien kann man nun beobachten, dass ihr Ober- und Unterschenkel dem Rücken in der Aufhellung weit voraus sind. Bei den meisten Individuen ist sogar der Oberschenkel bereits im Beginn der Farbkleidumbildung völlig aufgehellt, ihm folgt der Unterschenkel nach, dann erst der Rücken des Thieres. Man kann daher bei den meisten Rappien von der Unterschenkel-Oberseite ablesen, in welcher Weise bei ihnen später die Rückenaufhellung verlaufen wird. worden:

Aus dem mir vorliegenden Material dieser Reihe sind drei Arten beschrieben

a) Schwimmhäute an Händen und Füssen gross:

Erste Art: Rappia guttulata Günther, 2 Exempl., aus Libcria und Guinea. Bei einem Thier ist die Schnauze abgestumpft und das Maul mïsig gross. Bei einem anderen Thier ist das Maul - besonders unter den Augen - verbreitert, aber auch hier ist der Canthus abgestumpft.

Zweite Art: Rappia platycephala Pfeff,, 2 Individ., ein junges, ein altes. Schwimmhäute gross, Schnauze zugespitzt, aber hinter den Naslöchern etwas niedergedrückt, Maul mässig gross. Quillimane, Stuhlmann S.

b) Schwimmhäute an Händen und Füssen klein:

Rappia vermiculata Pfeff. Ein ganz junges Thier. Schnauze abgestumpft, Maul mässig gross. Zanzibar. (Taf. V, Fig. 34.)

Dass die Individuen Fig. 36, 37 und Fig. 38 derselben Farblkleidreihe angehören, ist auf der Tafel dadurch angedeutet, dass ihre Stammlinien am Grunde zusammenfliessen.

\section{Reihe II: Rappiae x; series: reticulatae (Taf. IV, Fig. 39 u. 44).}

Verblassflecken der Thiere rund oder oval, mässig gross. Restzeichnung ein schwarzes Netz. Bei dem vorliegenden Exemplar auf dem Rücken das Netz noch sehr vollständig. Die Weiterentwicklung des Netzes zeigen am Objekt die Körperseiten und die Unterschenkel-Oberseiten. Hier sind zahlreiche Verblassflecke miteinander verwachsen, sodass zumal an den Körperseiten nur noch Restpünktchen und vielfach gewundene Reststrichel zu sehen sind.

Das eine Individuum dieser Reihe, welches das Museum besitzt, stammt aus Elmine und trägt den Artnamen: Rappia reticulata Gthr. Schwimmhaut an Händen und Füissen gross. Maul mässigs, Schnauze vorn abgerundet, Canthus rostralis wenig hervortretend.

$\mathrm{Zu}$ dieser Gruppe gehört seinem Farbkleidmuster nach zweifellos auch ein Individuum, welches ich fälschlich in Tafel IV als Fig. 44 neben die folgende Reihe gestellt habe. Es besitzt ein Restnetz mit nur mässig grossen, ursprünglich ovalen Hellflecken, doch ist dies Netz bereits sehr defekt, weil viele seiner Maschen von den Verblassflecken aus völlig oder bis auf Restpunkte zerfressen sind. Man kann aber an den krausen, eingebuchteten Rändern der dadurch entstandenen grösseren Hellflecken noch sehr deutlich erkennen, wo die verschwundenen Xetzmaichen gelegen haben und dass die Netzliicken, als die Maschen noch unverletzt waren, oval und mässig gross gewesen sind. Das Thier stimmt übrigens anatomich genau mit den in $1 \ddot{i g}$. $65--66$ abgebildeten Individuen übercin, steht ihnen auch, wie man cicht, im Farbkleidmuster sehr nahe und seine Verblassflecken sind anfänglich sicher wie die dieser Formen gewesen, d. h. oval und mässig gross.

Dieses Thier weicht von dem vorigen anatomisch ab, hat kleine Schwimmhäute an Händen und Füssen, ein grosses Maul und eine etwas abgestutzte Schnauze mit nur wenig hervortretenden Rändern. I Individ., Usambara, wahrscheinlich Tanga; Reimer gesammelt. 
Reihe III: Rappiae x; series: laxereticulatae (Taf. IV, Fig. 40-43).

Verblassflecken am Rücken der Thiere sehr gross, abgerundet oder etwas eckig, dicht aneinander liegend. Restzeichnung ein weit- und dünnmaschiges Netz von schwarzer Färbung. Eine Reihe von Individuen, welche anatomisch genau übereinstimmen, liegen mir vor. Sie zeigen ihr Farbkleidmuster im Optimum und im Zerfall, der fast bis zum Abschluss fortschreitet. Auch bei diesen Thieren verblasst, wie bei den meisten Rappien, das Rückenfarbkleid von den Bauchseiten aus. Es werden daselbst sehr früh die Maschen des Restnetzes so arg zerfressen, dass schliesslich von ihnen nur noch schwarze Punkte und Linien übrig geblieben sind (Fig. 40). Auch sind bei dem eben erwähnten Thier bereits mehrere primitive Nackenverblassflecke nach Zerfall der zwischen ihnen liegenden Netzmaschen sehr innig vereint.

Bei Vertretern dieser Individuenreihe, die im Farbkleid noch extremer sind (Fig. 42), ist das Restnetz des Rückens völlig zerfetzt und in den übrig gebliebenen Fetzen sehr stark verblasst. Nur noch die Canthus rostralis-Ränder dieser Individuen behalten eine tief schwarze Färbung bei und bilden zwei aneinander stossende Praeocularstreifen.

Bei den extremsten Vertretern dieser Individuenreihe ist das ganze Farbkleid bis auf die dunkeln Praeocular-Streifen atrophirt.

Weiter geht bei dem mir vorliegenden Material das Verblassen dieses Farbkleidmusters nicht.

All diese Individuen stimmen anatomisch bis auf die Schnauzenform genau miteinander überein. Sie haben grosse Schwimmhäute an Händen und Füssen, ein mässig grosses Maul, aber eine variable Schnauze. Dieselbe erscheint bei einigen. Individuen dreieckig zugespitzt, bei anderen ist sie vorn etwas flach niedergedrückt, bei noch anderen ist sie vorn abgestutzt. Diese Individuen, wie überhaupt die mit Restnetzzeichnung versehenen, sind es, welche mich zwingen, anzunehmen, dass die Schnauzenform bei den Rappien noch recht variabel sei. Erst mehr Vergleichsmaterial und vielleicht nur Beobachtung lebender Thiere wird ergeben, ob diese Annahme berechtigt ist.

Zwei Arten vertreten im Hamburger und Berliner Museum dieses Farbkleidmuster: Rappia lagoensis Gthr. und Rappia guttata Schleg.

2 Individuen mit Farbkleidmuster-Optimum (Fig. 40-4I) liegen mir vor aus Accra (R. lag. d. Berliner Museums), eins mit verblassendem Muster (Fig. 42) aus Boutry (als Typ. von Rappia guttata Schleg. im Berliner Museum), 5 Individ. haben ein Farbkleid in maximaler Verblassung (Fig. 43), 3 aus Soyaux (als R. lag. im Hamburger Museum), eins aus Accra (als R. lag. im Berliner Museum), eins aus Kamerun (als Rappia guttata Schleg. im Berliner Museum).

\section{b. Verblassflecken in Längsreihen angeordnet.}

4 Individuenreihen gehören dieser Untergruppe an. Sie alle zeigen gleich gut das Entstehen von Hellstreifen aus Hellflecken, welche in Längsreihen angeordnet sind. Je nach der Zahl der bei ihnen auftretenden Verblassstreifen theile ich die Reihen ein.

\section{Reihe I: Rappiae x; series: trivittatae (Taf. IV, Fig. 45-49).}

Bei dieser Individuenreihe bilden die Verblassflecken drei Längsreihen. Die Verblassflecken sind in Spiritus intensiv weiss und bestehen aus punktförmigen Chromatophoren mit dichtestem Interferenzzellendach. Eine dieser Fleckenreihen läuft auf den Dornfortsätzen des Thieres entlang und wächst später zu einem hellen Medianstreifen aus, der von der Schnauzenspitze bis zum After reicht. Die 
bei den Thieren sonst noch vorhandenen Verblassflecken liegen in je einer Längsreihe hinter den Augen und bilden schliesslich durch Verwachsen je einen Postocularstreifen, der das zugehörige Auge am Hinterrand berührt und auch bis zum After reicht, wo er mit dem Medianstreifen verwachsen kann.

Bei manchen hierzu gehörigen Individuen haben die Postocularstreifen eine Fortsetzung in einem gleich hellen Praeocularstreifen, der vom Vorderrand des Auges über den Canthus rostralis entlang bis zur Schnauzenspitze zieht und dort mit dem Medianstreifen verwachsen kann. Ausserdem sendet bei den meisten Individuen der Postocularstreifen eine Ausbuchtung an die Augen-Oberseite auf das obere Augenlid.

Bei allen Vertretern dieser Reihe, welche mir vorlagen, sind ausserdem die an den Körperseiten unter den Postocularstreifen liegenden Restbezirke in schwarze Punkte zerfallen. In der hierdurch entstandenen Verblasszone sind jedoch die verkümmerten Chromatophoren von nur wenig Interferenzzellen umgeben. Die Haut der Thiere erscheint deshalb in dieser Zone glasig mit schwarzen Punkten, glasig wie die Bauchhaut. Nur hin und wieder treten auch in dieser Zone die Interferenzzellen zu kleinen weissen Flecken zusammen.

Sind bei diesen Thieren die Längsstreifen ausgebildet, so verblassen die zwischen ihnen liegenden schwarzen Reststreifen durch Chromatophorenatrophie und Interferenzzellenausbildung (Fig. 47 und 48).

Das letztgenannte Thier zeigt übrigens, dass das Gesammtverblassen des Rückens unter Umständen bereits eintreten kann, wenn der Medianstreifen noch nicht vollständig ausgebildet ist.

Einen Seitenzweig besitzt die Reihe in einem Individuum (Fig. 49), bei welchem zwar sehr deutlich die Tendenz vorwaltet drei Rücken-Verblassstreifen auszubilden, seine Medianfleckenreihe löst sich aber auf der Stirn in zwei nebeneinander liegende Flecken auf. Würde dieses Thier im Rückenverblassen fortschreiten, dann würde bei ihm wahrscheinlich eine vollständige Stim-Aufhellung eintreten, wie das bei Fröschen sehr häufig vorkommt.

7 Individuen dieser Reihe liegen mir vor, sie stimmen anatomisch genau überein, haben grosse Schwimmhäute an Händen und Füssen, ein mässig grosses Maul und eine Schnauze, die abgestumpft ist. Sie führen drei Artnamen.

Das im Farbkleid am wenigsten extreme Individuum (Fig. 45) ist bezéichnet als: Rappia marmorata Rapp., Marungu, Böhm S.; Mus.Nr. I0736.

Vier zeigen das Farbkleidmuster im Optimum (Fig. 46, 47) und haben den Artnamen: Rappia parallela Gthr., sind vom Kongo; Mus.-Nr. 8189.

Das Individuum mit dem Farbkleidmuster in Zerfall (Fig. 48) ist Rappia insignis Boc, aus Benguella und wurde dem Museum von Bocage geschenkt.

Das Individuum Fig. 49 war bisher unbestimmt und stammt aus Kawende, Wtangi Ubanja, P. Reichert S.; April I $885^{\circ}$

\section{Reihe II: Rappiae x; series: quinquestriatae (Taf. IV; Fig. 50 und Textfig. K. I).}

Von dieser Reihe liegt mir nur ein Individuum vor, welches auf der Körperoberseite fünf Verblass-Längsstreifen auszubilden strebt, von denen die drei auf seinem Rücken liegenden fertig sind, während die bei dem Thiere an den Oberkieferrändern und Körperseiten entlang laufenden erst ihr Vorbereitunessitadium zeigen d. h. aus solchen Hellflecken bestehen, welche bereits stark miteinander kommuniziren.

Auf dem Rücken dieses Thieres beginnen übrigens bereits die Reststreifen in ihrem mittleren Abschnitt zu verblassen. 
Nur ein Vertreter dieser Reihe liegt mir vor; er hat kleine Schwimmhäute an Händen und Füssen und eine zugespitzte Schnauze. Sein Tarsalgelenk reicht übrigens bis zum Auge, obgleich das Thier dickleibig, wahrscheinlich eiertragend ist. Es führt den Artnamen Rappia vittiger Ptrs.

\section{Reihe III: Rappiae x; series: septemstriatae (Taf. IV, Fig. 5I-59 und Textfig. K. 55).}

Es liegen mir so viele Träger dieses Farbkleidmusters vor, dass aus ihnen in Rücksicht auf das Farbkleidmuster nicht nur eine lückenlose Hauptreihe, sondern auch eine Anzahl Nebenreihen zusammengestellt werden konnten.

In ihrer Hauptreihe verläuft die Farbkleid-Entwicklung, wie in den vorangehenden Reihen: Aus kleinen runden Verblassflecken, die in Längsreihen hintereinander liegen und anfänglich erst halb aufgehellt sind (Fig. 5 I), entstehen durch Verschmelzung grössere langgezogene Flecke (Fig. 52, 53) und damit Thiere, welche immer entschiedener Längsstreifen auszubilden streben (Fig. 54, 55) und schliesslich ausbilden (Fig. 56).

Die Individuen, welche soweit gekommen sind, haben das von ihnen vertretene Farbkleidmuster im Optimum der Entwicklung; es sind bei ihnen 7 Längsstreifen voll ausgebildet: ein Medianstreifen, davon rechts und links je ein Rückenlängsstreifen, dann je einer, welcher durch das Auge zieht und schliesslich je einer, welcher am Oberkieferrand und an den Körperseiten zu finden ist. Im Farbkleidmuster-Optimum kommuniziren all' diese Hellstreifen an ihren Enden, während sie an der Schnauzenspitze erst dann miteinander in Verbindung treten, wenn das Farbkleidmuster stark verblasst ist (Fig. 58).

Nachdem dieses Farbkleidmuster bis zum Optimum ausgebildet worden ist, beginnt sein Zerfall, und zwar wie gewöhnlich in zweifacher Weise. Bei den Individuen, welche ich der Hauptreihe angliedere, schwindet es durch gleichmässiges Verblassen der bei den Thieren bisher noch vorhandenen Reststreifen (Fig. 57, 58), bis es schliesslich ganz erlischt (Fig. 59). Bei anderen Individuen werden die übrig gebliebenen Reststreifen von aussen und innen durch wachsende Verblassflecken zerfressen und zerfallen dadurch zuletzt in Restpunkte, die ebenfalls schwinden können.

Diese Individuenreihe ist ferner sehr reich an Vertretern, deren Farbkleidmuster eine Entwicklung erfährt, die wesentlich von jener abweicht, welche in ihrer Hauptreihe eine Rolle spielt. Bei einer Gruppe dieser Individuen (Fig. 60-62) verschmelzen z. B. nicht nur Hellflecken, welche einander in Längsreihen folgen, sondern auch solche, welche nebeneinander liegen, wodurch den Thieren die Möglichkeit genommen wird, tadellose Verblass-Längsstreifen auszubilden, denn es entstehen bei ihnen auf diese Weise lange verästelte Hellflecken, deren Ränder oft noch eingeschnürt sind und dann sehr deutlich erkennen lassen, aus wie viel primären Hellflecken der vergrösserte Hellfleck zusammengewachsen ist. Auch bei diesen Individuen können schliesslich die Restpartien gleichmässig verblassen, womit dann die Entwicklung dieses Seitenzweiges des Fünfstreifenmusters ihren Abschluss findet (Fig. 62).

Bei noch anderen Vertretern dieses Farbkleidmusters können die kleinen Hellflecken ihrer Vorgänger auf Kosten der umgebenden Restzonen so sehr wachsen, dass die mit einem solchen Farbkleidmuster begabten Individuen eine starke Annäherung an jene Rappien zeigen, welche früher als "laxereticulatae" beschrieben worden sind (Taf. IV, Fig. 40-43).

Endlich liegen mir auch noch solche Vertreter dieser Individuenreihe vor, welche zeigen, dass bereits die allerersten und alle etwas späteren Entwicklungsstadien dieses Längsstreifenmusters ohne weitere Fortbildung bis zum Erlöschen verblassen können. Jedes Farbkleidmuster, das viele Entwicklungsstadien durchläuft, kann 
also auf all seinen Entwicklungsstufen Halt machen und ohne Weiterentwicklung verblassen.

Die Individuen dieser Reihe, soweit sie mir vorliegen, stimmen miteinander anatomisch genau überein. Sie haben grosse Schwimmhäute an Händen und Füssen, eine abgestutzte Schnauze und ein mässig grosses Maul. Alle mit Ausnahme von vier gehören dem Hamburger Museum, stammen aus Quillimane und führen den Artnamen Rappia marmorata Gthr. Zwei Individuen dieser Reihe mit Farbkleidmuster im Optimum entsprechen Fig. 56, heissen Rappia taeniata Ptrs. und stammen aus Borror und vom Shire. Zwei andere Individuen, abgebildet auf Taf. IV, Fig. 6I und 62, hat Peters unter dem Artnamen Rappia variegata beschrieben; bei ihnen verwachsen auch Verblassflecken, die nebeneinander liegen. Die beiden Individuen stammen aus Quellimane.

Bei den Männchen dieser Reihe finde ich eine ontogenetische Schallblasenentwicklung, die genau jener entspricht, welche in Textfigur H von Rappia flavoviridis beschrieben worden ist.

All diese Individuen haben lebend schwarze Restzeichnung in grüner, dann gelber Verblassfarbe, bei manchen Individuen sind die Verblassstreifen nur in der Mitte gelb und an den Rändern grün, sie gehen so ohne Grenze in das Schwarz der Reststreifen über.

\section{Reihe IV: Rappiae x; series: substriatae (Taf. IV, Fig. 65-76).}

Dieses Farbkleidmuster beginnt seine Entwicklung mit 9 Längsreihen kleiner runder Verblassflecken, welche in eine Restzone von tief schwarzer Färbung eingebettet sind (Fig. 65, 66). Sie sind eigentlich dazu bestimmt, 9 Längsstreifen auszubilden, was sich darin zeigt, dass bei einzelnen Individuen der Reihe einzelne dieser Streifen zum Theil oder fast ganz ausgebildet werden. Daneben verschmelzen aber selbst bei diesen Individuen auch solche Verblassflecke miteinander, welche nicht hinter-, sondern nebeneinander liegen. Jedenfalls erreicht das betreffende Farbkleidmuster niemals sein Streifenoptimum, sondern es beginnt sehr frühzeitig zu verblassen, indem am Rücken der Thiere die schwarze Restzone von innen heraus aufgehellt wird und zwar so stark, dass sie schliesslich die Färbung der in ihr liegenden ursprünglichen Verblassflecken ausbildet und mit ihnen untrennbar verschmilzt. Durch dieses Verblassen der Restzone entstehen auf dem Rücken der Thiere zuerst Verblassflecken, die in einer halbhellen Rückengrundfarbe gelegen und tief schwarz umrandet sind (in Fig. 66 am After, in Fig. 72 und 73 am ganzen Rücken). Der Verblassfleckenrand verliert später andauernd an Umfang und Farbenintensität und erlischt schliesslich ganz, sodass dann die sekundären und primären Verblassstellen des Thieres ineinander fliessen.

Die Hauptvertreter dieses Farbkleidmusters verblassen auf diese Weise zuerst am hinteren Körperende, dann auch in der Mitte des Rückens, und es bleibt bei ihnen zum Schluss nur noch eine eigenthümliche Kopfzeichnung zurück, welche aus den Schenkeln zweier Supraocular-Hellstreifen besteht, die tief schwarz umrandet sind und bei einigen Individuen sogar noch aus primitiven Verblassflecken zusammengesetzt sind, die bei anderen mehr oder weniger verwachsen. Bei allen Individuen der Hauptreihe sind diese Supraocularstreifen an der Nasenspitze vereint. Sie reichen beim Beginn des Farbkleidmuster-Zerfalls bis zur Körpermitte (Fig. 68), verkürzen sich dann aber schnell (Fig. 69) bis von ihnen schliesslich nur noch Reste vorhanden sind, die über den Augenrand des Thieres nicht wesentlich herabreichen (Fig. 7I).

Weiteres Verblassen dieser Individuenhauptreihe habe ich noch nicht konstatiren können.

Ein Seitenzweig dieser Entwicklung zeigt das Farbkleidmuster-Verblassen in etwas anderer Form (Fig. 72, 73). Hier spielen beim Aufhellen der Rückenrest- 
zone die Supraocular-Hellflecken keine andere Rolle als die anderen RückenVerblassflecken, von denen beim sekundären Rückenverblassen eine Anzahl sehr lange erhalten bleiben, während die am unteren Ende der Supraocularstreifen liegenden schon früher verschwinden. Noch sonderbarer ist bei anderen Seiten\%wcigen dieser Farbkleidentwicklung das Verhalten der Rückenzeichnung (Fïg. 74, 75, 76). Gemeinsam ist diesen Individuen, dass bei ihnen die helle Supraocularbinde bedeutend verbreitert wird, weil Verblassflecken, die neben ihr liegen, mit ihr verwachsen. Auf solche Weise entsteht in Fig. 74 ein sehr breites, helles Subocularband, das mit seinen Windungen und Ausbuchtungen fast den ganzen Rücken des Thieres deckt; und in Fig. 75 ist auf diese Weise die ganze Stirn des Thieres aufgehellt.

Die in den Supraocularstreifen dieser Thiere liegenden schwarzen Pünktchen sind die letzten Reste ursprünglicher Fleckenränder.

Die diesem Farbkleidmuster angehörigen Individuen zerfallen anatomisch in zwei Gruppen:

a) Schwimmhaut an Händen und Füssen gross. Schnauze abgestumpft, Maul mässig gross.

2 Individ. von Peters unter dem Artnamen: Rappia argus beschrieben. Eins aus Borror (Fig. 72), Ptrs. S., Mus.-Nr. 4807; das andere von der Zanzibarküste (Fig. 73), Hildebrandt S., Mus.-Nr. 7967.

b) Schwimmhaut an Händen und Füssen klein. Maul gross, Schnauze scheinbar zugespitzt; es kommt daher, weil der Zwischenkiefer fast horizontal liegt und die Kopfzeichnung über die Naslöcher hinweggeht.

Ein Individ. als Rappia concolor Hall. beschrieben. Matschie, Sitzber. Gesell. nat. Fr. Berlin I 892 , S. 99; die anderen ohne Artbezeichnung. Zehn aus Usambara (wahrscheinlich Tanga), Reimer S.; eins aus Dar es Salaam, von Stuhlmann gesammelt.

Bei allen Individuen sind im Leben die Flecken gelb, ihre Ränder schwarz. Die Restzone ihres Rückens verblasst aus Schwarz zu Braun und dann zu Gelb.

\section{Gruppe IV. Mit Verblassstreifen beginnend.}

Reihe I: Rappiae $x$, series lineatae (Taf. IV, Fig. 77-83; dieselben Figuren in Textfigur $\mathrm{K}, 77-83$ ).

Die dieser Gruppe angehörigen Individuen fasse ich in nur eine Reihe zusammen, obgleich sie in den Details ihrer Farbkleidmuster so weit auseinander weichen, dass sie, wenn mehr Vergleichsmaterial zusammengetragen sein wird, in mehrere Reihen zerfallen werden.

Die Vertreter dieser Gruppe stimmen darin mit denen der vorigen überein, dass bei ihnen das universelle Oberkörperfarbkleid der Larven unter Ausbildung von Längsstreifen verblasst; sie unterscheiden sich aber von den Vertretern der vorigen Gruppe sofort dadurch, dass erstens ihr ganzes Rückenfeld an dieser Verblassung theil nimmt, weshalb bei ihnen streng genommen keine wirklichen Reststreifen vorhanden sind, sondern nur mehr oder weniger helle Verblassstreifen. Sie unterscheiden sich ferner von den Vertretern der vorigen Gruppe dadurch, dass bei ihnen diese Längsstreifen nicht durch Hellflecke vorgebildet werden, sondern von vornherein in ihrem ganzen Verlauf gleichmässig verblassen. Nachträglich können dann auch bei ihnen in dem Gebiet eines halbhellen Verblassstreifens wirkliche Verblassflecke entstehen (Textfig. K, 79). Diese können später wachsen und dadurch Thiere erzeugen, welche schliesslich sehr ausgesprochene Konvergenzformen $z u$ den siebenstreifigen Individuen der vorigen Gruppe bilden (Textfig. K, 80 und 8I). 

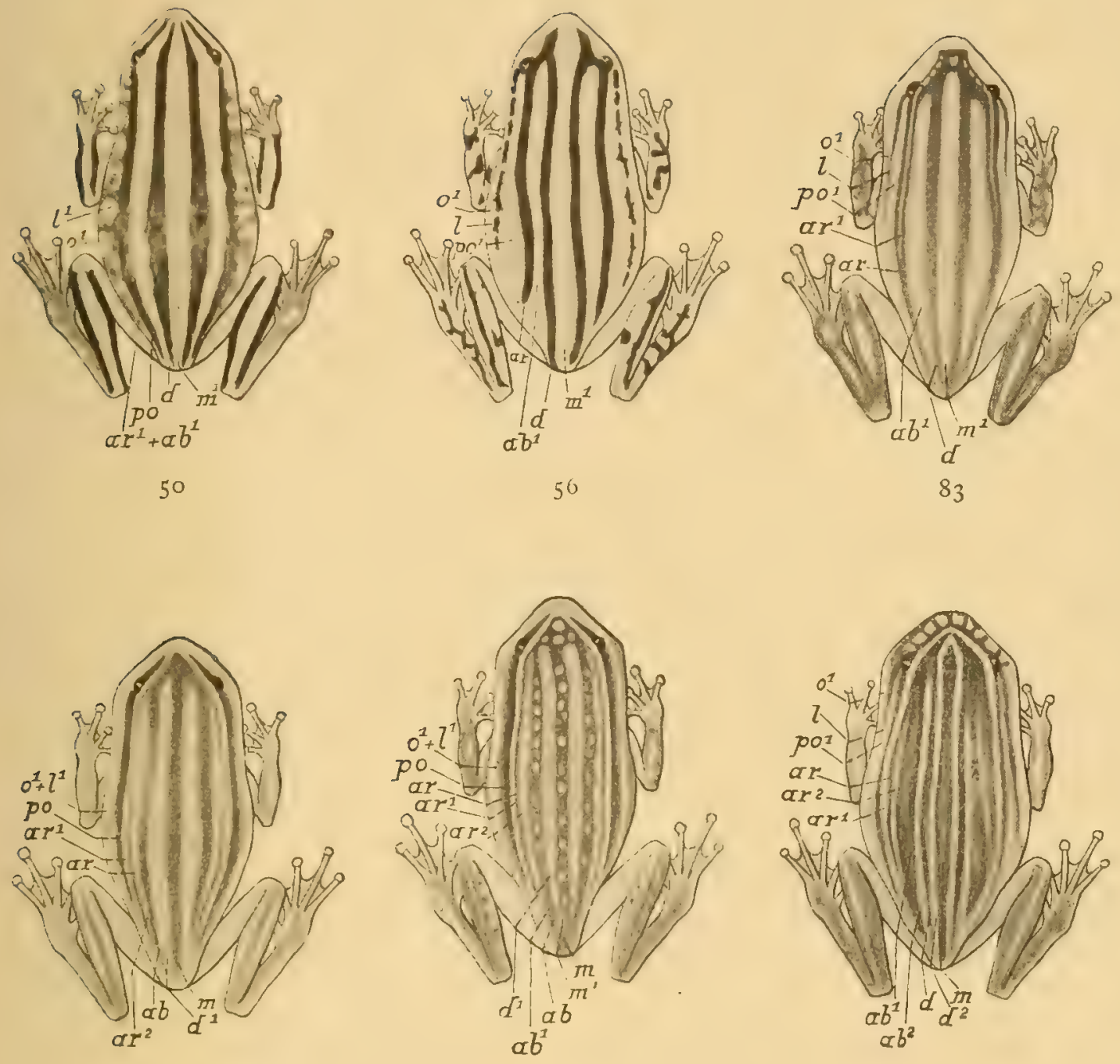

77

79

82

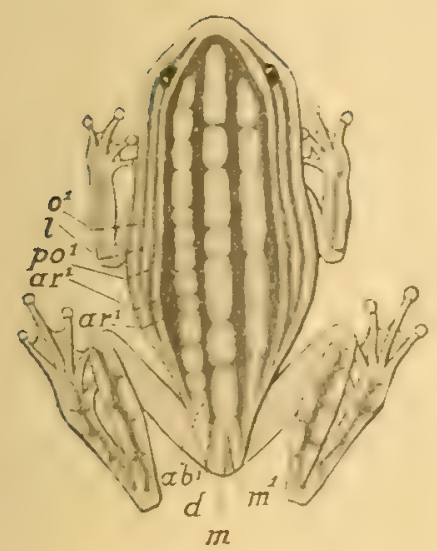

so

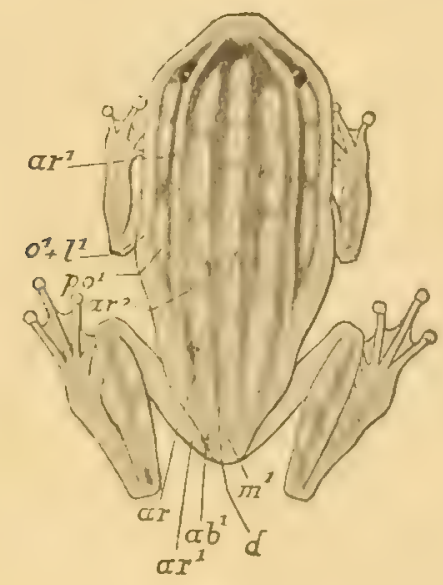

SI

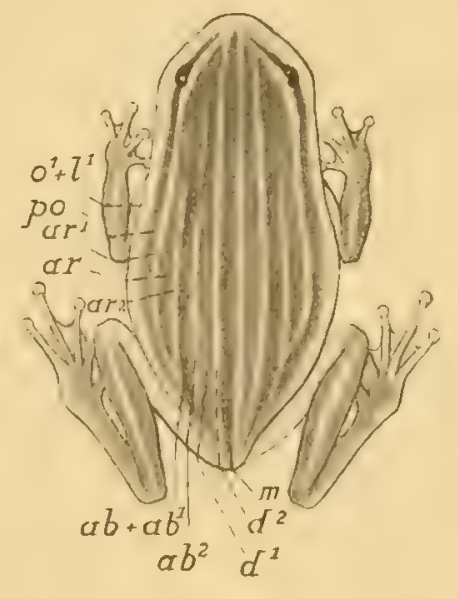

78

Fig. K. 
Gemeinsam ist allen Individuen dieser Gruppe ausserdem, dass bei ihnen an jeder Körperseite ein Hellstreifen mehr oder weniger ausgebildet ist, welcher über das obere Augenlid hinwegzieht und zwar so, dass er das Auge unmittelbar berührt (Textfig. $K$, ar). Derselbe ist übrigens homolog dem entsprechend gelegenen Hauptstreifen der Substriatus-Reihe.

Die Individuen dieser Verblassstreifengruppe zerfallen der Färbung nach in zwei Untergruppen: In solche, bei denen durch das Auge ein Hellstreifen geht (Fig. 80-83) und in solche, bei welchen dessen Stelle ein Verblassstreifen einnimmt (Fig. 77-79).

Die Individuen dieser Gruppe sind besonders wichtig deshalb, weil sie unter allen Rappien die meisten Längsstreifen aufweisen und weil man mit ihrer Hilfe bereits besprochene Formen noch eingehender vergleichen kann.

Dem Leser dieser Farbkleid-Untersuchungen wird es bereits aufgefallen sein, dass bei der vorigen Individuengruppe in den verschiedenen Farbkleidmustern Hellstreifen ausgebildet werden, die denen der benachbarten Muster fast nie homolog sind. Dies wird noch deutlicher, wenn man Typen der vorigen Gruppe miteinander und dann mit denen der vorliegenden Gruppe vergleicht; z. B. zuerst Fig. 50 und 56 miteinander (am besten in Textfigur $\mathrm{K}$ ) und dann mit Fig. 83 ebendaselbst. Bei jedem der ersten beiden Individuen (50 und 56) findet man alsdann in der Rückenmitte einen völlig aufgehellten Medianstreifen ( $\mathrm{m}$ ), welche Streifen wegen ihrer Lage und annähernd gleichen Breitenausdehnung mit Recht für homolog zu halten sind. Dann aber geht bei der Fünfstreifen-Form (Fig. 50) ein Reststreif (pr) durch das Auge, bei der Siebenstreifen-Form (56) dagegen ein Hellstreifen (pr). Beide stimmen in ihrer Lage und Ausdehnung ganz genau überein, in der Färbung dagegen sind sie grundverschieden, sie sind demnach nicht homologe sondern analoge Bildungen. Sehen wir nun von den Hellstreifen ab, welche bei beiden Thieren an den Oberkiefern und Körperseiten entlanglaufen und vergleichen statt dessen jene Verblass-Längsstreifen, welche bei beiden auf dem Rücken neben dem Medianstreifen hinziehen (Fig. $56 a b^{1}$, Fig. $50 a r^{1}+a b^{1}$ ) so ist leicht einzusehen, dass dieselben nicht völlig homolog sind, denn der eine von ihnen ist sehr breit und reicht bis an das Auge, der andere dagegen ist schmal und wird vom Auge durch einen voll ausgebildeten Reststreifen getrennt. Dass sie nicht streng homolog sind, lehrt ausserdem Textfig. $K, 83$. Wir sehen in ihr eine Form, die in all' ihren Charakteren der eben besprochenen Siebenstreifenform (Fig. 56) genau entspricht. Sie hat auf dem Rücken einen hellen Medianstreifen $(\mathrm{m})$, einen hellen Streifen durch das Auge (pr), den hellen Oberkieferstreifen (o) der anderen Form, der vom vorigen durch einen Reststreifen (1) getrennt wird; ferner hat dieses Thier auch einen hellen Rückenstreifen (ab), der durch einen schwarzen Streifen (ar) von seinem Auge fern gehalten wird. In diesem Reststreifen aber liegt bei ihr ein in Ausbildung begriffener Verblassstreifen $\left(a r^{1}\right)$, welcher bei der Siebenstreifenform garnicht vorhanden ist. Vergleicht man nunmehr die beiden Hellstreifen $\left(\mathrm{ar}^{1}\right.$ und $\mathrm{ab}^{1}$ ) dieser Form (83) mit dem einen Hellstreifen $\left(a r^{1}+a b^{1}\right)$ der Fünfstreifenform (50), so ergiebt sich sofort, dass beide Hellstreifen der einen Form in dem einen der anderen Form enthalten sind; und man erkennt hieraus: Man darf bei Vergleichung zweier Farbkleidmuster nur solche Streifen und Flecken für homolog halten, welche am Körper der verglichenen Thiere ganz gleich gelegen sind. Und man erkennt ferner, dass die verschieden-streifigen Farbkleidmuster der vorigen Rappiengruppe genetisch völlig unabhängig voneinander sind, da die mehr-streifige Form nicht eine Fortbildung der weniger-streifigen ist.

Fragt man nun, wieviel Hellstreifen können bei einer Rappia im Maximum entstehen, so ergiebt eine Vergleichung aller mir vorliegenden Vertreter dieser Lineatus-Reihe folgendes:

Es zerfällt bei jeder schwarz gefärbten Rappie die Körperoberseite in eine Anzalıl schwarzer Längsstreifen, welche in Hellstreifen umgebildet werden können. 
An einer Hälfte der Körperoberscite, vom Bauchanfang bis zu den I)ornfortsatzen der WVirbel gezählt, sind es folgende: Ein Oberlippenstreif (o), ein unterer Augenstreif (1), ein mittlerer Augenstreif (po), ein oberer Augenstreif (ar), ein äusserer Rückenstreif (ab), ein innerer Rückenstreif (d) und der Medianstreif (m), also im ganzen 7. Da von diesen Streifen 6 jeder Körperseiten-Hälfte angehören und nur der Medianstreifen einfach ist, so würde das Thier auf der Körperoberseite, wenn all seine erwähnten Bezirke in ihrer Mitte Verblassstreifen aubilden würden, deren 13 haben.

Die so entstandenen Verblassstreifen bezeichne ich nach den Zonen, in welchen sie entstehen, als Oberlippenverblassstreifen u. s. w. und in der Abbildung mit $o^{1}, 1^{1}$, po ${ }^{1}$ u. S. w. bis $\mathrm{m}^{1}$.

Aber mit der Ausbildung dieser Verblassstreifen ist die bei den Rappien mögliche Maximalzahl der Verblass-Lüngsstreifen noch nicht erreicht, denn es können bei den extremsten Thieren auf jeder Hälfte der Körperoberseite nicht nur in den Verblassbezirken, sondern auch noch $\mathrm{z}$ wischen ihnen Verblassstreifen entstehen. Einer z. B. zwischen dem Medianstreifen und dem inneren Rückenstreifen (in den Figuren als $d^{2}$ ), der zweite zwischen innerem und äusserem Rückenstreifen $\left(a b^{2}\right)$ und ein dritter zwischen dem äusseren Rückenstreifen und dem oberen Augenstreifen $\left(a r^{2}\right)$; macht zusammen für beide Körperseiten 6 und mit den bisher nachgewiesenen I3 zusammen 19. Es können demnach bei einer Rappie an der Körperoberflache im Maximum 19 Verblassstreifen entstehen. Natürlich ist dabei Voraussetzung, dass sie in der Verblassung nicht alle gleich weit fortgeschritten sind, sondern höchstens, wie in der Lineatus-Reihe, als halbhelle, helle und volle Verblassstreifen abwechseln; denn wären alle gleich weit in der Verfärbung entwickelt, dann würden sie Individuen erzeugen, welche über die ganze Körperoberfläche gleichmässig entfärbt wären.

Unter den mir vorliegenden Rappien der Lineatus-Reihe sind solche, "welche diesem Streifenmaximum sehr nahe kommen. Das in Fig. 82 abgebildete Individuum hat z. B. I 6 mehr oder weniger ausgebildete Hellstreifen, und das in Fig. 78 abgebildete hat ebenfalls 16 , die aber nur zum Theil mit denen des vorigen Individuums übereinstimmen.

Das Nähere über die einzelnen Vertreter dieses Farbkleidmusters ergiebt die Textfigur $\mathrm{K}$ durch die in ihr enthaltene genaue Bezeichnung der bei den Individuen vorkommenden Streifen.

\section{Gruppe V. Individuen, zuerst auf dem Rücken verblassend, und deshalb an den Seiten der Körperoberfläche mit Restzonen.}

Reihe I: Rappiae x; series: laterostriatae (Taf. IV, Fig. 84-II8).

Während alle bisher besprochenen Rappien so verblassen, dass ihre ganze Körperoberieite an der I Ier-tellung des Farbkleidmuster; betheiligt ist, verblasit bei den vorliegenden Individuen (Fig. 84) an der Körperoberseite zuerst der Rücken, und zwar in so grosser Ausdehnung, dass seine Verblasszone noch die (iebicte der oberen Augen-treifen mit umfisst; dagegen bleiben anfang - die Seiten der Thiere vom mittleren Augenstreifen an bis zum Oberkieferrand und Bauchanfang unversehrt, d. h. tief schwarz. Von dieser Urform des Farbkleidmusters, von einem Thier also mit sehr wenig aber gleichmässig aufgehelltem (dunkelbraunem) Rücken und tief ichwaren Scitenstreifen, der durch das Ause rieht und bis zum Oberkieferrand und Bauchanfang hinab reicht, gehen alle iibrigen Farbkleidmuster dieser Gruppe aus (in Fig. 84 ist der dunkle Seitenstreif des Thieres leider zu schmal angegeben, erst bei weiteren Veränderungen dieses Farbkleidmusters kann er, wie in der Fïsur, zu einem reinen mittleren Augenutreifen recluzirt werden). 
Die zahlreichen Individuen, welche dieses Farbkleidmuster weiter fortbilden, weichen sofort in eine Anzahl gleichwerthiger Reihen auseinander.

Zuerst entsteht eine Individuenreihe mit Abzweigungen, bei welcher das angegebene Farbkleidmuster ohne wesentliche Fortbildung verblasst. Der Rücken dieser Individuen (Taf. IV, Fig. 85, 86) wird dabei fortschreitend heller, gleichzeitig verblasst ihr schwarzer Seitenstreifen vom Oberlippenrand und Bauchanfang aus, sodass er schliesslich zu einem mittleren Augenstreifen reduzirt ist, darauf verblasst er auch von seinem Hinterende aus, wobei er unter Umständen in Restflecke zerfallen kann. Bald entstehen so Thiere, bei welchen er nur noch am Canthus rostralis und kurz hinter dem Auge in starker Aufhellung sichtbar ist. Schliesslich werden die Thiere völlig entfärbt und erscheinen in Spiritus gelblich-weiss oder rein weiss wie weisses Handschuhleder. In Natur wird ihr Rücken und dann auch der Seitenstreif nacheinander schwarz-braun, grün-braun, grïn, gelb und zum Schluss weiss-gelb (fahlgelb).

An dieser Individuenreihe habe ich nachträglich noch zwei Nebenreihen beobachtet, eine, bei welcher das Rückenverblassen anfänglich nicht ganz gleichmässig verläuft. Bei ihren Vertretern verblasst auf dem Rücken eine sehr feine Linie, welche dem schwarzen Seitenstreifen oben anliegt, etwas friher als der übrige Rückentheil; es entsteht bei ihnen dadurch eine Andeutung eines oberen Augenverblassstreifens, doch kommt derselbe niemals zu wirklicher Ausbildung. Ausserdem kann bei manchen von diesen Thieren ein unterer Augenverblassstreifen angedeutet werden. Die Individuen nähern sich dadurch anderen, welche später besprochen werden und diese Streifen in vorzüglicher Ausbildung besitzen. Später hellt sich dann auch ihre ganze Körperoberseite völlig auf.

Der andere Zweig dieser Reile verblasst so, dass von der ursprünglich sehr dunklen Rückenfärbung ein Stückchen erhalten bleibt, welches auch bei unseren Laubfröschen vorkommt und als Lendenschleife bezeichnet wird. Auch diese Thiere können ähnlich wie die der vorigen Nebenreihe verblassen, d. h. mit Andeutung eines oberen Augenstreifens, es entstehen so aus ihnen Individuen, welche genau so gezeichnet und gefärbt sind wie unsere Laubfrösche.

All diese Individuen stimmen anatomisch genau miteinander überein, sie haben grosse Schwimmhäute an Händen und Füssen, eine abgestumpfte Schnauze und mässig grosses Maul. (Bei einem Individuum allerdings finde ich zwischen dem dritten und vierten Zeh im Schwimmhautrand eine Einkerbung, welche deutlich zeigt, dass die Schwimmhaut kleiner zu werden strebt.)

Eins dieser Individuen, mit der Färbung unseres Laubfrosches, ist von Bocage als Typ. seiner Art: Rappia dombecnsis dem Museum überwiesen worden. Stammt aus Dombe. Mus.-Nr. 6465. Ein Thier mit genau demselben Farbkleidmuster stammt aus Chinchoxo. Mus.-Nr. 9173. Ein drittes aus Port Natal ist Eigenthum des Hamburger Museums.

Drei der Hauptreihe angehörige Individuen stammen aus Radem in Kavirondo, wo sie Oscar Neumann im Februar I894 auf Kandelaber-Euphorbien gesammelt hat. Eins mit demselben Farbkleidmuster stammt von der Delagoa-Bai und gehört dem Hamburger Museum an.

Schon die Vertreter dieses Farbkleidmusters zeigen eine eigenthümliche anatomische Divergenz. Diejenigen unter ihnen, welche dunkel gefärbt sind, haben eine glatte Rückenhaut. Je heller die Thiere werden, desto mehr treten auf ihrem Rücken die Druisen wulstig hervor, bis sie bei den ganz entfärbten Individuen in der eigenthümlich rauhen und anscheinend sehr dicken Haut sehr deutlich sichtbar sind. Man kann deshalb annehmen, dass die Drüsen der Thiere in dem Maasse an Ausbildung gewinnen, wie ihre Haut entfärbt wird. Hierfur spricht manches, so der Umstand, dass die Entfärbung dieser Thiere, wie ihre Lebensweise vermuthen lässt, in Folge intensiver Beleuchtung stattfindet. Die stärkere Ausbildung der Drüsen würde dann den Nutzen haben, dass die Thiere 
durch starkere Schleimabsonderung besser vor dem Vertrocknen geschitzt witren. Es ist aber auch möglich, dass bei den ganz entfärbten Individuen die Drüsen nur stärker hervortreten als bei den dunkel gefärbten. Eine dritte Möglichkeit ist aber ausserdem, dass die Thiere deshalb eine Haut haben, die so druisig erscheint, weil sie so schlecht ernährt sind; denn alle entfärbten Thiere, die mir vorliegen, sind klein und auffällig schlecht ernährt.

Die zweite Individuenreihe, welche das Urfarbkleid dieser Gruppe weiter fortbildet, entsteht dadurch (Fig. 9I), dass in dem gleichmässig schwarzen Seitenstreifen des Urthieres weisse Verblassflecken auftreten, später in Querrichtung zunehmen, dabei zum Theil miteinander verwachsen und so die Seitenstreifen völlig durchbrechen. Aus den schwarzen Seitenstreifen werden so grosse verästelte schwarze Flecke, welche in weisser Verblassfarbe liegen.

Die Fortentwicklung dieses Farbkleidmusters habe ich erst in neuester Zeit festgestellt und daher nicht in Tafel V abbilden lassen können. Sie ist folgende: Während der Rücken sich immer mehr aufhellt und in Spiritus aus Schwarzbraun in Oliv-braun übergeht, verschwinden an den Körperseiten des Thieres dic schwarzen Flecken mehr und mehr, indem sie entweder von weissen Flecken noch stärker zernagt werden oder indem sie von innen heraus verblassen. Die lintwicklung dieses Farbkleidmusters schreitet dann so lange fort, bis das Thier in Spiritus an der ganzen Körperoberseite gelb-weiss und rein weiss geworden ist.

Die Individuen dieser Reihe unterscheiden sich anatomisch in garnichts von denen der vorigen, mit welchen sie übrigens zusammenwohnen. Auch hier sind die Individuen mit dunkler Färbung glatt, während die mit rein weisser Färbung auf dem Ruicken drüsige Erhebungen zeigen.

Die extremsten unter ihnen tragen den Artnamen: Rappia granulata Ptrs. 2 Individuen aus Tette, Peters Sammler, Mus.-Nr. 4811. Ebenso extrem sind 3 Exemplare aus Kakoma, von Böhm gesammelt. - 2 weniger extreme Individuen stammen aus Chinchoxo, Mus.-Nr.9173. Das am wenigsten extreme Thier (Fig, 2) stammt aus Massai-Nyika und ist von Oscar Neumann gesammelt.

Die dritte Individuenreihe, welche dieses Farbkleidmuster fortbildet (Fig. 87-90), weicht nur dadurch von der zweiten ab, dass bei ihr die schwarzen Flecken, welche durch Zerfall des schwarzen Seitenstreifens entstehen, viel kleiner sind. Nach der Art dieses Zerfalls gabelt sich dann die Reihe in zwei Ausläufer. Bei den Vertretern des einen von ihnen (Fig. 87-89) entstehen so aus dem schwarzen Scitenstreifen urspringlich zwei Reihen schwar\%er Restflecke, cinc obere und eine untere, von denen später zuerst die obere ganz verblasst (Fig. 89), dann auch die untere, sodass die Thiere schliesslich, weil mittlerweile auch ihr Rücken ganz aufgehellt wird, in Spiritus rein weiss gefärbt erscheinen, in Natur weiss-gelb. Bei den Vertretern des anderen Ausläufers der Reihe zerfällt der schwarze Seitenstreifen in viele verästelte Querstrichelchen, also in sehr kleine Flecken, die später, wenn der Rücken des Thieres ganz aufgehellt ist, ebenfalls ganz verschwinden.

Anatomisch stimmen die Vertreter der Reihe genau miteinander überein. Sie haben grosse Schwimmhäute an Händen und Füssen, eine abgestumpfte Schnauze und mässig grosses Maul. Sonst aber sind die des zweiten Ausläufers der Reilie sehr viel grösser als die des ersten; die letzten sind also wahrscheinlich junge oder in der Entwicklung zurückgebliebene Thiere.

Das eine Individuum, entsprechend Fig. 89, ist als Rappia marginata Ptrs. beschrieben worden und stammt aus Macanga am Pomfefluss; Mus.-Nr. 4806. Zahlreiche gleichartige Exemplare sandte Böhm aus Kakoma.

Individuen, entsprechend Fig. 90, sandte Büttner aus Togo und Baumann aus der Gras-Savanne bei Tongbe im Togogebiet.

Von der vierten Individuenreihe, welche das Urfarbkleid dieser Gruppe auf besondere Weise fortbildet, liegen mir so viele Vertreter vor, dass sie ein

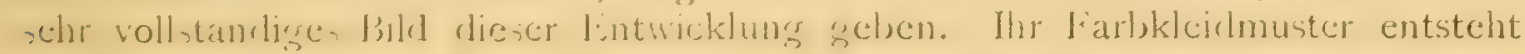


dadurch, dass der Rücken der Thiere nicht im ganzen Umfang gleichmässig verblasst, sondern einen oberen Augenverblassstreifen auszubilden strebt, der durch eine Reihe selbstständiger weisser Verblassflecken angelegt wird (Fig. 92), die dann bei anderen Thieren in einen weissen Verblassstreifen zusammenfliessen, der von ihrer Schnauze bis zum After reicht und durch seine gewöhnlich noch eingekerbten Ränder (Fig. 93) deutlich erkennen lässt, dass er aus Flecken entstanden ist. Gleichzeitig wird bei diesen Thieren der schwarze Seitenstreifen von seiner Bauchseite aus reduzirt, wobei einzelne Verblassflecken, die in ihm entstehen, mitwirken können, doch treten dieselben nie zu einem unteren Verblassstreifen zusammen.

Wenn das Farbkleidmuster dieses Optimum erreicht hat, verblasst es gewöhnlich so, dass es ohne weitere Veränderung vom Hinterende des Thieres aus aufgehellt wird (Fig. 93 und 94). Mir liegen jedoch ausserdem noch vier Individuen vor, deren schwarze Augenstreifen denen der Fig. 93 und 94 entsprechen, deren Rücken aber bereits so stark aufgehellt ist wie der obere Augenverblassstreifen jener Thiere, die in Fig. 93 und 94 abgebildet sind. Den vier Individuen scheint deshalb ein oberer Augenverblassstreifen zu fehlen, während er in Wirklichkeit nur nachträglich verschwunden ist. Bei noch anderen Vertretern dieser Individuenreihe verblasst die mittlere Rückenzone zum Schluss nicht gleichmässig. Es entstehen so Individuen, bei welchen die mittlere Rückenzone durch Restpunkte eingefasst ist (Fig. 96); andere Individuen erwerben dadurch auf ihrer mittleren Rückenzone eine halbdunkle Restzeichnung, die von einer helleren Verblasszone eingeschlossen wird und bis an den oberen Augenverblassstreifen reicht.

Anatomisch stimmen alle Vertreter dieses Farbkleidmusters in den hier berücksichtigten Charakteren genau überein. Sie haben an den Händen kleine Schwimmhäute; an den Füssen zeigen sie ein eigenthümliches Schwanken in der Ausbildung der Schwimmhäute. Viele haben daselbst grosse Schwimmhäute, andere zeigen deutlich die Tendenz, an den Füssen kleine Schwimmhäute auszubilden; manche haben sogar zwischen dem fünften und vierten Zeh grosse, zwischen den anderen Zehen kleine oder fast kleine Schwimmhäute. Bei allen ist die Schnauze zugespitzt und das Maul mässig gross.

Die als Vertreter dieser Individuenreihe in Taf. IV, Fig. 92-97 abgebildeten Individuen führen im Berliner Museum den Artnamen Rappia betsileo Grand., alle stammen aus Madagaskar. Hierzu kommen die fün extrem entfärbten Individuen von Rappia betsileo aus dem Hamburger Museum. Ihr Rücken ist so hell wie ihr oberer Augenverblassstreifen. Sie gehen also noch über Fig. 94 und 95 hinaus.

Genau dasselbe Farbkleidmuster entwickeln dann auch die im Berliner Museum unter dem Namen Rappia horstocki Schleg. vorhandenen Individuen. 3 Exemplare stammen vom Kap der guten Hoffnung, Mus.-Nr. 306r, 4 aus Misahöh in Togo; sie sind dort von Baumann auf Pflanzen in Waldlichtungen gefunden worden.

Die fünfte und letzte Individuenreihe, welche das Urfarbkleid der Gruppe fortbildet, liegt mir in sehr vielen Exemplaren vor. Ihr Farbkleidmuster entsteht dadurch, dass in dem anfänglich gleichmässig verblassten Rücken der Thiere ein oberer Augenverblassstreifen in Flecken angelegt und dann voll ausgebildet wird, während gleichzeitig im unteren Theil ihres schwarzen Seitenstreifens ein zweiter Verblassstreifen in Flecken angelegt wird und durch Zusammenfliessen derselben zur Ausbildung kommt (Taf. IV, Fig. 98 und 99). Der untere der beiden Streifen wird als unterer Augenverblassstreifen angelegt, dehnt sich aber bald auch in die Oberlippenzone aus. Ist dieses Farbkleidmuster im Optimum ausgebildet (Fig. IOO), dann zeigen die Individuen einen schwarzen Augenstreifen, der oben und unten von einem breiten hellen Längsstreifen eingefasst wird. Das Farbkleidmuster 
schwindet dann bei der Hauptreihe der Individuen (Fig. IOI und IO2), indem es ohne weitere Fortbildung vom hinteren Ende des Thieres aus so stark wie die Verblassstreifen aufgehellt wird. Bei anderen Thieren verblasst zuerst der schwarze Augendurchquerstreifen soweit, dass er die Färbung des Rückens annimmt, dann wird entweder der obere oder untere Augenverblassstreifen noch intensiver weiss, während die ganze sonstige Oberseite des Thieres so aufgehellt wird, dass sie die Färbung des nicht veränderten zweiten Verblassstreifens annimmt. Es entstehen alsdann Individuen, deren ganze Oberseite sehr hell und einfarbig ist, und welche entweder nur den oberen oder nur den unteren Augenverblassstreifen beibehalten. (Die Figuren Taf. V, I03-IO5 und I06- IO8, welche diese Entwicklung darstellen sollen, sind durchaus verfehlt.)

Diese Individuenreihe ist sehr reich an Seitenzweigen. Schon von dem ersten Vertreter dieses Farbkleidmusters (Fig. 98), zweigen sich zwei Seitenreihen ab. Bei der ersten (Fig. III) wird ausser den zwei bisher besprochenen Verblassstreifen ein dritter als Augenstreifen in Flecken angelegt. Bei der zweiten Seitenreihe sendet, wie man sieht (Fig. 109), der obere Augen. verblassstreifen in den schwarzen Augenstreifen Ausläufer hinein, die ihn schliesslich ganz zerfressen, ja sie wachsen sogar bis in die schwarzen Partien der unteren Augenzone hinein, deren Verblassstreifen erst in Punkten angelegt ist.

Von jenem Vertreter dieses Farbkleidmusters (Fig. 99), welcher schon einen voll entwickelten oberen Augenverblassstreifen hat, während sein unterer erst in Punkten angelegt ist, zweigen sich Individuen ab, deren mittlere Rückenzone ungleichmässig verblasst und so eine Restzeichnung ausbildet (Fig. II 2 und II3). Bei einem von diesen Individuen wird diese Restzeichnung sogar durch Verblasslinien umrandet (Fig. I I3).

Von jenem Vertreter dieses Farbkleidmusters, bei welchem beide Augenverblassstreifen voll ausgebildet sind (Fig. 100), zweigen sich endlich Individuen $a b$, bei welchen die Rückenmittelzone ebenfalls ungleichmässig verblasst, sodass in dieser entweder tief dunkle Restpünktchen und -Schleifen übrig bleiben (Fig. II4 und I I5) oder ein Reststreifen (Fig. I I6), der bei weiterer Entwicklung sogar von zwei hellen Verblassstreifen flankirt werden kann (Fig. II7).

Alle Individuen dieser Reihe stimmen anatomisch überein: Schwimmhaut an den Händen klein, an den Füssen schwankend, bald gross, bald verkleinert. Schnauze wohl bei allen spitz.

Individuen Fig. 98- I I als Rappia picturata Schleg. im Berliner Museum. Individuen gleich Fig. IOO-IO2 als Rappia fimbriata B. e. P. im Berliner Museum. Typ. aus Gowe Limbareni, die anderen aus Bukoba, Stuhlmann S.

Die Individuen mit nur oberen Augenverblassstreifen, sonst gleichmässig hell gefärbter Körperoberseite gehören zur Art: Rappia flavoviridis Ptrs. Typ: I Individuum aus Boror, Peters S.; Mus.-Nr. 663I. I Individuum aus Tette, Peters S.; Mus.-Nr. 48I2 (war ursprünglich Typ von Rappia tettensis). I Individuum, Quillimane, Stuhlmann S., dem Hamburger Museum gehörend. I Individuum, Cabaceira, Peters S., Mus.-Nr. 6632. I Individuum, Korogwe, Stuhlmann S. I 5 Individuen, Böhm S., Kakoma. - Diese Art kann übrigens auch als eine Farbenvarietät der Rappia horstocki angesehen werden. - 2 Individuen mit nur unterem Augenverblassstreifen, sonst gleichmässig hell gefärbt auf der ganzen Oberseite; Stuhlmann S., Bukoba.

I Individuum gleich Fig. I12, Misahöh in Togo, Baumann S.

I Individuum gleich Fig. I I4, Bukoba, Stuhlmann S.

I Individuum gleich Fig. I I , Bukoba, Stuhlmann S.

Je I Individuum gleich Fig. Ir6 und I 7 , Bukoba, Stuhlmann S.

I Individuum gleich Fig. II3, Togo, Baumann S.

Das Individuum Fig. I I 8 , welches Peters als Rappia nitidula beschrieben hat, gehört nicht, wie man leicht einsehen wird, dem eben besprochenen Farb- 
kleidmuster an, denn es hat nur einen ganz wenig angedeuteten oberen Augenverblassstreifen und keinen wirklich voll ausgebildeten unteren Augenstreifen. Es gehört dem Farbkleidmuster nach zur dritten Reihe dieser Gruppe und zwar an den Anfang des ersten Endastes derselben, steht also vor Fig. 87. Grinde dafür sind: Es ist bei ihm der schwarze Seitenstreifen durch einen fast ganz ausgebildeten Verblassstreifen, welcher das Auge durchquert, in zwei Hälften getheilt, in eine untere und eine obere. Seine untere Hälfte ist ausserdem bereits völlig in einzelne Restpunkte zerfallen, während seine obere Hälfte bei einigen Thieren Durchbrechung zeigt. Sein Farbkleidmuster ist also im Grunde das Vorstadium für dasjenige, welches Fig. 87 zeigt, Ein zweiter Vertreter dieser »Art«, welcher mir vorliegt, zeigt übrigens eine noch weniger durchbrochene obere Hälfte des ursprünglichen schwarzen Seitenstreifens.

Nur im Farbkleidmuster, aber nicht anatomisch stimmen übrigens diese beiden Individuen mit den vorher besprochenen der dritten Reihe uberein, denn sie haben kleine Schwimmhäute an den Händen und fast kleine an den Füssen; ausserdem ist ihre Schnauze spitz.

Typ aus Yoruba, I Individuum, Mus.-Nr. 7729. Das zweite Individuum stammt aus Misahöh in Togo, Baumann S. -

\section{Anhang.}

Rappia glandicolor, Peters, 2 Individuen, Typen, aus Taita, unterscheidet sich nur durch die Grösse von Rappia granulosa, Peters, wie das schon Boulenger angegeben hat. -

Rappia fusciventris, Peters, weicht nur dadurch von Rappia fuscigula ab, dass bei ihr der ganze Bauch dunkelbraun pigmentirt ist. -

Rappia acutirostris, Peters, 2 Individuen, aus Kamerun, steht anatomisch und dem Farblkleidmuster nach auf dem Standpunkt der Fig. 97 und ist eine Rappia horstocki. -

\section{Abschnitt VI. Rückblick auf das Vorige.}

a. Die Phylogenese der Farbkleidmuster.

Die Urfärbung der Rappien ist schwarz. Das Urfarbkleid derselben ist ein universelles, den ganzen Körper deckendes. Dieses schwarze universelle Farbkleid ist der Ausgangspunkt für alle Farbkleidmuster, welche von Rappien sonst noch getragen werden. Nachdem all diese Farbkleidmuster je ein Entwicklungsoptimum passirt haben, zerfallen sie und streben ein und demselben Extrem: ihrem gänzlichen Erlöschen zu. Also aus Individuen, die, wie man mit Recht sagen kann, in ihrer Haut alle Farbkleidmuster und Hautfarben vereinigen (denn nur deshalb sind sie universell und schwarz gefärbt), entstehen auf zahllosen Wegen andere Individuen, deren Haut ein Farbkleid- und Farben-Minimum ausbildet, d. h. völlig entfärbt wird.

Durch die Art, in welcher bei den Rappien Farbkleidmuster entstehen und vergehen, liefern sie einen vorzüglichen Beweis zu. Gunsten des von mir gefundenen Descendenzgesetzes«, wie ich das in den Ergänzungsheften des anatomischen Anzeigers 1894, S. 5, entwickelte 》Zoophyletische Entwicklungsgeset\% " von jetzt ab zu nennen bitte.

Wie dort nachgewiesen ist, giebt es Organe und in letzter Instanz auch Individuen, welche mit einem Maximum von Fähigkeiten ausgestaltet sind; aus jedem von ihnen entwickeln sich zahlreiche Organ- und Individuenreihen, von denen jede nur wenige oder gar nur eine Fähigkeit ihrer Stammeltern kultivirt und fort- 
bildet; ihre anderen Fähigkeiten verkiimmern durch Nichtgebrauch bis zur Atrophic. Diese Reihen, welche in gemeinsamen Eltern wurzeln, weichen daher um so mehr auseinander, je extremer ihre Vertreter werden. Ihren Abschluss finden sie in Individiuen, welche trotz sonstiger Divergenz das gemeinsam haben, dass sie alle extrem einem Minimum von Fähigkeiten angepasst sind.

Das Hautfarbkleid-Minimum ist null, sein Maximum ist ein universelles schwarzes Farbkleid. Die Beziehungen zwischen dem Descendenzgesetz und den Farbkleid-Variationen der Rappiengattung sind jetzt wohl deutlich genug präcisirt.

$\mathrm{Zu}$ den Farbkleidmustern, d. h. zu den sekundär entstandenen Farbkleidern gehören bei allen Reptilien und Amphibien nicht nur die längsstreifigen Farbkleider, sondern auch die, welche auf farblosem oder halb hellem Grunde schwarze Flecke aufweisen. Beide sind daher nicht Ausgangspunkte für alle anderen Farbkleider, wie das Eimer und.Werner angenommen haben. Die "Zeichnung « der Thiere ist von ihrer »Färbung " nicht zu trennen; die Farben der Haut und die Farbkleidmuster gehören untrennbar zusammen.

Kann ich also Eimer's Anschauung, dass die Streifenzeichnung das Urfarbkleid der Amphibien- und Reptilienhaut sei, nicht zu der meinen machen, so kann ich ebenso wenig sein Gesetz der post-anterioren Farbkleidentwicklung und noch weniger sein Undulationsgesetz bestätigen. Es giebt, wie nachgewiesen wurde, sowohl Reptilien wie Amphibien, bei welchen der Kopf dem Körper in der Farbkleidentwicklung vorauseilt, indem er dabei zuweilen ganz selbstständige Entwicklung einschlägt. Allerdings, bei recht vielen Amphibien und Reptilien verblasst das Farbkleid der Körperoberseite von seinem Ende und von seinen Bauchseiten aus, bei anderen verblasst es dagegen vom Rücken aus.

Bei den Thieren, bei welchen das Farbkleid der Körperoberfläche von seinem Ende und von seinen Bauchseiten aus verblasst, bleiben am Kopf eine Anzahl von Restflecken gewöhnlich sehr lange erhalten (Postocularstreifen, Praeocularstreifen, Frontal- und Occipitalflecke Werner's). Diese Hautflecke hielt Werner auf Grund seiner Anschauung von der Farbkleidentwicklung für phylogenetisch sehr alt, während sie in Wirklichkeit als die bei jenen Thieren am spätesten verschwindenden Reste des Urfarbkleides angesehen werden müssen und phylogenetisch nicht älter sind als alle anderen rein schwarzen Flecken der Haut. Durch ihr von Werner nachgewiesenes sehr häufiges Alleinauftreten zeigen sie zugleich, dass bei vielen Thieren das Farbkleid von hinten und unten gegen den Kopf hin verblasst.

Aus den Farbkleidmustern allein darf nicht auf die Verwandtschaft von Individuen seschlowen werlen, denn gleiche Jarbkleidmuter kimnen bei anatomisch verschiedenen Individuen auftreten und zwar nicht nur bei Individuen, welche ihrer anatomischen Charaktere wegen als Arten voneinander zu trennen sind, sondern sogar bei Individuen, die zu verschiedenen Familien gehören (Rappia dombeensis Boc., Hyla arborea L.). Bei ein und derselben Art können aber andererseits wiederum so viele Farbkleidmuster auftreten, dass deshalb Farbkleidunterschiede nur Varietätscharaktere darstellen.

\section{b. Entstehungsursachen der Hautfarbkleidmuster.}

Die Hautfarben entstehen, wie nachgewiesen wurde, als Reaktionen der Chromatophoren auf solche äusseren Einflüsse, welche konstant werdende Umbildungen der Chromatophroren und elazu gchörge Intwicklunstorsenge (Interferenzzellenbildung) hervorrufen. Solche äusseren Einflusse sind Licht, Wärme, Druck und Ernährung (normale, mangelhafte, überreiche). Wirkt eine dieser äusseren Ursachen stärker oder schwächer als bisher auf ein universelles Farbkleid so ein, dass alle seine Theile von gleichem Reiz getroffen werden, so muss sich das betreffende Farbkleid zu einem universellen, anders gefärbten 
umwandeln. Werden aber die äusseren Einflüsse nur für einen Theil des bisher universellen Farbkleides verändert, so muss das Individuum sein universelles Farbkleid verlieren und ein Farbkleidmuster ausbilden. Die Farbkleidmuster der Amphibien- und Reptilienhaut (und in letzter Instanz aller Wirbelthierhäute) sind also Anpassungen des Hautfarbkleides an äussere Einflüsse, die es verändern können, und welche die verschiedenen Hautstellen mit verschiedener Intensität treffen. Die Veränderung des Farbkleides geschieht bei genügender Dauer der Beeinflussung proportional dem Reiz.

Es ist mir bereits gelungen, für einen Theil der Haut-Farbkleidmuster nachzuweisen, durch welche äusseren Ursachen sie hervorgerufen werden können. Die betreffenden Studien sind indess noch nicht abgeschlossen. So wurde ja bereits früher in dieser Arbeit darauf hingewiesen, dass bei allen Thieren, welche nur mit dem Kopf aus Löchern schauend auf Beute lauern, der Kopf ein intensiveres Verblassen zeigt als der Rumpf. Bei den Thieren, welche frei im Tageslicht leben, aber die Gewohnheit haben, sich vorwiegend an bestimmten Stellen ihres Wohngebietes und daselbst in bestimmten Lagen und Stellungen aufzuhalten, werden Muster, welche durch Schatten und Spalten der sie umgebenden Gegenstände auf ihrer Haut erzeugt werden, zum Schluss als Farbkleidmuster fixirt. Es gelingt ja bekanntlich, wie schon Brïcke nachwies, auf der Chamaeleonhaut ein gewünschtes Farbkleidmuster vorübergehend zu erzeugen, wenn man auf diese Haut das Sonnenlicht durch eine entsprechende Schablone längere Zeit einwirken lässt. - Beim Entstehen der Flecke, besonders aber der Augenflecke, spielen wahrscheinlich Wassertropfen eine grosse Rolle. - Der Reibung auf dem Boden verdankt der Bauch der meisten Kriechthiere seine Farblosigkeit u. s. W.

Weder der Blutgefäss-, noch einer besonderen Nervenvertheilung in der Haut verdankt ein Farbkleidmuster seine Entstehung. Jede einzelne Chromatophore wird innervirt und $\mathrm{zu}$ jeder Chromatophore führt ein Blutgefäss. Jedes Farbkleidmuster hat deshalb allerdings seine eigenartige Nerven- und Blutgefässanordnung, doch ist dieselbe nicht die Ursache, sondern die Folge der Ausbildung eines besonderen Farbkleidmusters. Man darf nur die zahllosen Farbkleidmuster ansehen, die in einer Gattung (bei Rappia z. B.) möglich sind, und wird sofort erkennen, dass es keine für die Färbung prädisponirten Hautstellen geben kann.

\section{c. Wieviel Rappienarten giebt es in dem untersuchten Material?}

Diese Frage kann ich noch nicht beantworten, aus dem einfachen Grunde, weil das Material, welches ich untersuchen konnte, zu ihrer Lösung noch nicht genügt und ich nicht warten kann, bis es vervollständigt worden ist. Jedenfalls ist die Zahl der Arten nicht gross. Zusammenzuziehen sind vor Allem die »Arten«, welche, ohne anatomisch voneinander abzuweichen, ein und dassel.be Farbkleidmuster variiren. Aber auch viele Individuenreihen, die verschiedene Farbkleidmuster variiren, ohne anatomisch verschieden zu sein, gehören zusammen.

Sobald die von mir aus Afrika erwarteten Rappiensendungen eingetroffen sind und ich das Rappienmaterial gesehen habe, welches die Hauptmuseen Europas beherbergen, komme ich in einer besonderen Arbeit auf diese Frage zurück.

\section{Megalixalus fornassini (Bianc.)}

Sansibar; 2 Individ.; J. Kirk S.; Boul., Cat. Bat. S. I 30.

Sansibar; I4 Individ.; Hildebrandt S.; Peters als Hyperolius dorsalis. Mus.-Nro. I0094. 
Sansibar; 3 Individ.; Hildebrandt S.

Tanga in Usambara; I Individ.; Neumann S.

Kingani, grosse Fälle; I Individ.; Stuhlmann S.; I8. Aug. I888; Pfeffer in Stuhlmann I888, S. 3I.

Mhonda in Unguu; I Individ.; StuhlmannS.; 7. Sept. I888; Pfeffer in Stuhlmann I888, S. 3I.

Dar es Salaam; I Erw., 2 Junge, I Larve; Stuhlmann S.; 1895.

Lake Nyassa; I Individ. 우 J J. Kirk S.; Boul. Cat. Bat., S. I 30.

Süd-Ufer des Victoria Nyansa; Emin Pascha S.; Boulenger, Ann. Mag. I 890, S. 93.

Bei der Larve fällt auf: die dunkle Zeichnung sowie die runde Pupille.

\section{Megalixalus leptosomus, Ptrs.}

Megalixalus stuhlmanni Pfeff.; Pfeffer in Stuhlmann X (I892) S. 9.

Sansibar-Insel; 26 Individ.; Stuhlmann S.; 6. Sept. I 888.

Tanga in Usambara; 2 Individ.; Neumann S.

Undussuma; 2 Individ.; Stuhlmann S.; I6. Nov. I89I; Auf Bananen.

Fundort unbekannt; 2 Individ.; Sammler unbekannt.

Die Art ist variabel in der Färbung, die Variabilität entspricht der des Megalixalus fornassini (Bianc.).

Zwischen Megalixalus leptosomus Ptrs. und Megalixalus stuhlmanni Pfeffer (beide Typen habe ich untersucht) finde ich nur Farbenunterschiede; die Art stuhlmanni wird sich daher nicht aufrecht erhalten lassen.

„Die im Spiritus weissen Streifen auf dem Rücken der Thiere sind nach Stuhlmann im Leben silberweiss. «

\section{Cassina senegalensis (D. e. B.)}

Massai-Niyka; 3 Individ.; Oscar Neumann S.; Juni I 893.

Dar es Salaam; 6 Individ.; Stuhlmann S.; I894.

Das eine Individuum dieser Art, welches noch den Larvenschwanz besitzt, ist auf dem Rücken einfarbig schwarz gefarbt, an seiner Oberlippe aber und an den Körperseiten zeigt es Verblass-Stellen; ein Beweis dafür, dass auch bei dieser Art das definitive Farbkleid durch mässiges Verblassen grösserer Körperpartien aus schwarzem Larvenkleid entsteht.

\section{Hylambates anchietae, Boc.}

Wald bei Magila und in Usegua; 3 Individ.; Stuhlmann S.; Mai 1893. Vernelegiudé westlich vom Albert Nyansa; I Individ.; Stuhlmann S.; 23. Dez, I89I.

Hell-grau-braun mit brauner Zeichnung.

\section{Hylambates maculatus, A. D.}

Sansibar; 3 Individ, $\nmid$ u. $\delta$; Kirk S.; Boul., Cat. Bat. S. I34.

Sansibar; 4 Individ.; Stuhlmann S.; 6. Aug. 1888; Pfeffer in Stuhlmann X, S. 32 .

Sansibar; I Individ.; Stuhlmann S.; I5. Aug. I888; Pfeffer in Stuhlmann X, S. 32 .

Sansibarinsel; 2 Individ.; v. d. Decken S.; Peters, Decken. S. I8.

Sansibar; 5 Larven; Hildebrandt S.; Mus.-Nro. 8Iog. 
Sansibarküste; 5 Individ.; Hildebrandt S.; Mus.-Nro. I0079.

Sansibarkuiste; 6 Individ.; Hildebrandt S.; Mus.-Nro. 8005.

Dar es Salaam; 4 Erwachsene, 5 Larven; Stuhlmann S.; I 894.

Larven tiefschwarz, daraus entstehen die Erwachsenen mit schwarzen Flecken in rothen Ringen auf dunkelgrauem Grund.

\section{Hylambatus aubryi (A. D.)}

Derema am Pangani in Usambara; 3 Individ.; Conradt S.

Derema in Usambara; 5 Junge; Conradt S.; I6. Sept. I89I.

Buloa bei Tanga; 5 Erwachsene; G. Eismann S.; 1895.

Buloa bei Tanga; 9 Junge; G. Eismann S.; I895.

Bei dieser Art ist die individuelle Umfärbung einzelner Vertreter eine sehr weit gehende:

Die juingsten mir vorliegenden Vertreter der Art (Taf. V, Fig. I), welche eben das (zweifellos schwarze) Larvenstadium überwunden haben, was daran zu erkennen ist, dass ein Theil von ihnen noch ein deutliches Schwanzrudiment trägt, haben alle dieselbe Färbung: In einem feinen Netzwerk schwarzer Färbung liegen zahllose verästelte und gewundene Verblassflecken von in Spiritus blauschwarzer Färbung. Doch ist die blau-schwarze Färbung, wie man bei Lupenbetrachtung ersieht, keine einheitliche, weil in den Flecken noch zahlreiche Pünktchen von schwarzer Farbe (d. h. zahllose Chromatophoren) verstreut liegen. Auch ist bereits unter diesen jungen Thieren sowohl die Ausbildung des Netzwerks wie die Färbung der eingestreuten Verblassflecken eine verschiedene. Bei den primitivst gefärbten ist das Netzwerk noch über den ganzen Rücken zusammenhängend, daneben finde ich Thiere (Taf. V, Fig. 2), deren Netzwerk so vollständig von den Verblassflecken zerrissen ist, dass es fast nur noch aus einzelnen verästelten Punkten besteht. Die einzelnen Verblassflecken der Thiere können dabei mehr oder weniger dunkel gefärbt sein, entsprechend der Menge der Chromatophoren, die in ihnen liegen, während bei anderen Thieren die Rückenflecken so stark aufgehellt sind, dass die »Hauptfarbe dieser Thiere nicht mehr schwarz, sondern entschieden hellgrau-blau ist.

Bei zahlreichen, nicht bei allen, unter diessen mir vorliegenden jungen Thieren geht aber an gewissen Körperpartien die Aufhellung der Flecken und ihre Vergrösserung auf Kosten der umgebenden Primärfärbung noch weiter fort. Bei diesen Thieren treten milchweisse Flecken am ganzen Schnauzenrand oder am Schnauzenrand und an den Körperseiten entlang, besonders aber am ganzen Oberschenkel, an der Fusswurzel und an den Zehen auf. Die Flecken sind hier so gross, dass dadurch Oberschenkel und Fuss der Thiere weiss gebändert erscheinen.

Einige mir vorliegende erwachsene Individuen. haben diese Färbung der jungen Thiere fast ganz behalten, und habe ich solche mit weissen Flecken am Oberkieferrand, solche mit weissen Flecken auch an den Körperseiten und solche ganz ohne diese Flecken.

Auf dem Rücken der Thiere verläuft diese totale Entfärbung gewisser Partien nicht so rapid wie die geschilderte weisse Fleckenbildung an den Körperseiten gewisser Individuen, daher treten auch auf dem Rücken der total verblassenden Thiere noch Uebergangsfarben auf. Zuerst wird hier das restirende Netzwerk der Schwarzfärbung auf zahllose Pünktchen reduzirt; so dass zum Schluss auf dem ganzen Rücken der Thiere schwarze Flecke von einiger Grösse nicht mehr zu finden sind und derselbe deshalb einfarbig grau-blau gefärbt erscheint. Nunmehr verblassen grössere zusammenhängende Partien dieser sekundär entstandenen, universellen Rückenfärbung dadurch, dass die in ihr enthaltenen Chromatophoren eine Verminderung ihres Pigments erfahren und dadurch aus schwarzer Färbung in braune übergehen. So entstehen Thiere, in deren brauner Rückenhauptfärbung restirende grau-blaue Flatschen liegen (ähnlich Taf. V, Fig. 3). Das sind die erwachsenen 
Thiere, welche den jungen Thieren in der Färbung noch relativ nahe stehen und welche ich bereits oben erwähnt habe. Das weitere Verschwinden der Chromatophoren in den grau-blauen Flatschen, wodurch auch diese Flatschen allmählich ganz verschwinden, und der Pigmentschwund in allen Chromatophoren welche erhalten bleiben, kann so weit fortschreiten, bis die Thiere auf dem Rücken als Haupt- oder alleinige Färbung ein helles Lederbraun zeigen d. h. bis bei ihnen alle restirenden Pigmentzellen braun gefärbt sind.

Früher schon, als dieser Prozess beendet ist, doch bei verschiedenen Individuen auf sehr verschiedenen Entwicklungsstadien, ja selbst bei noch ganz dunkel gefärbten Jungen, können aber ausserdem noch einzelne Ruickenstellen völlig pigmentlos werden (Taf. V, Fig. 3). Die pigmentlosen Stellen sind zuerst punktförmig klein und natürlich in Spiritus weiss. Viele von ihnen dehnen sich indess bald $\mathrm{zu}$ riesigen Flatschen aus, indem sie sowohl auf Kosten der benachbarten Hauptfärbung wachsen als auch sekundär miteinander vereinigt werden (so entstehen Thiere wie Taf. V, Fig. 4), und zum Schluss kann dann diese Fleckbildung so weit fortschreiten, dass das ganze Thier (in Spiritus) fast oder ganz weiss gefarbt erscheint. Zwei von solchen total entfärbten Thieren liegen mir vor.

In der Natur verläuft die Umfärbung der Thiere in einer anderen Farbenfolge, weil ihr Verblassen mit der Ausbildung von gelben Interferenzzellen beginnt, die schwarzen Thiere werden dadurch zu dunkelgrünen mit schwarzen Flecken, dann zu dunkelgrünen ohne schwarze Flecke, dann zu braun-grünen mit dunkelgrünen Flecken, dann zu solchen mit bratıner Hauptfärbung. Die auf dem Rücken einzelner Individuen entstehenden, im Spiritus weissen Flecken sind in Natur nicht weiss sondern citronengelb, sodass die völlig verblassten Individuen citronengelb gefärbt sind. Diese Naturfarbe der Individuen konstatirte ich an frisch ins Museum geschickten, noch nicht vom Spiritus angegriffenen Vertretern der Art.

\section{Hylambates argenteus, Pfeff.}

Sumpf südlich der Stadt Bagamoyo; I Individ.; Stthlmann S.; 28. Juli 1888; Pfeffer in Stuhlmann X, S. 32 mit Beschreibung.

\section{Familie: Engystomatidae.}

\section{Phrynomantis bifasciata (Sm.)}

Tanga in Usambara; Io Individ.; Oscar Neumann S.; darunter ein Individuum mit Fleckenreihen an der Seite statt Längsbänder.

Bagamoyo; I Individ.; Fischer S.

Nguru-Berge; 2 Individ.; G. A. Fischer S.; Mus.-Nro. I0663.

Usaramo; 3 Individ.; Stuhlmann S.

Kakoma; eine Abbildung; Böhm S.

Kokotoni; I Individ.; Stuhlmann S.; 29. Sept. I88s. Ein Stuick der Var. A. Boulenger's, mit zwei röthlich-gelben Längsbändern und ebenso gefärbtem Steissfleck.

Kokotoni; 2 Individ.; Stuhlmann S.; 24. Okt. I 889; Pfeffer in Stuhlmann $\mathrm{X}$, S. 34. „Var. B. Boulenger, bei denen der Charakter der schwarz- und weissen Längsstreifung nicht gut zu erkennen ist. "

Ohne Fundort; I Individ.; Stuhlmann S.; Pfeffer in Stuhlmann X, S. 34. ¿Var. B. Boulenger's, mit ausgesprochener schwarz- und weisser Längsbänderung zwischen den beiden Hauptbändern. Diese Zeichnung entsteht dadurch, dass sich vom Nacken bis zum Steissfleck zwei breite Längsbänder ziehen, die in sich schwarz liniirt sind." Die Form führt in der Färbung hinüber zur nächsten Art.

Böhm schreibt: „Phrynomantis bifasciatus findet man zur Regenzeit in nassen Feldern. « 


\section{Phrynomantis microps, Ptrs.}

Mkero-Sumpf in Massai-Nyika; 5 Junge; Oscar Neumann S.

Mkero-Sumpf in Massai-Nyika; I4 Larven; Oscar Neumann S.; Boulenger als Phrynomantis-Larven bestimmt, daher wahrscheinlich zu dieser Art gehörig.

\section{Breviceps verrucosus, Rapp.}

Buloa bei Tanga; 2 Individ.; G. Eismann S.; 1895.

\section{Breviceps mossambicus, Ptrs.}

Magila; I Individ.; Oscar Neumann S.; 5. Mai I893; Mus.-Nro. I I 162. Rubugwe; I Individ.; Stuhlmann S.; 23. Aug. I 890.

\section{Hemisus sudanense, Steind.}

Tanga in Usambara; 4 Individ.; O. Neumann S. X, S. 35 .

Kihengo, Ost-Unguu; 4 Individ.; Stuhlmann S.; Pfeffer in Stuhlmann

Kakoma; 3 Individ.; Böhm S.

Kawende; Katani M buga; I Individ.; P. Reichard S.; April 1885.

Ohne näheren Fundort; 4 Individ.; Stuhlmann S.

Böhm bemerkt dazu: »Diese sonderbare Art mit kleinem spitzen Kopf und kräftigen Extremitäten kann, trotz des sehr gedrungenen Körperbaues, doch ziemlich hohe und weite Sätze machen. Nur selten, während der Regenzeit, im Felde getroffen. «

\section{Familie: Bufonidae.}

\section{Bufo regularis, Reuss}

Buloa bei Tanga in Usambara; 6 Individ.; G. Eismann S.; 20. Aug. I895. Derema in Usambara; 2 Individ., jung und alt; Conradt S.; Matschie, Gesell. nat. Freunde, Berlin.

Usambara; I Individ.; Reimer S.; I894.

Usambara (Cisterne Ambone bei Tanga); I Individ.; Oscar Neumann S. Usegua (am Ufer des Rukagura); I Individ.; Stuhlmann S.; 27. Sept. I888; Pfeffer in Stuhlmann; X, S. 35. $\mathrm{X}, \mathrm{S} .35$.

Mhonda; 3 Individ.; Stuhlmann S.; 6. Okt. 1888; Pfeffer, Stuhlmann

Dar es Salaam; 2 Individ.; Stuhlmann S.; I89I u. I894.

Marangu im Kilima-Ndjaro; I Individ.; Volkens S.; Bemerkung dazu unten.

Morogoro auf dem Wege nach Mpapwa.

Rubugua in Unyamwesi; I Individ; Stuhlmann S.; 23. Aug. I890.

Kakoma; II junge, 2 alte; Böhm S.; Bemerkung dazu unten.

Kafuro (Karagwe), I350 m hoch; I Individ,; Stuhlmann S.; 5. März I89I.

Bukoba; 4 Individ.; Stuhlmann S.; Jan. I89I; März I892.

Huri-Fähre? I Individ., schlecht.; Stuhlmann S.; 28. Sept. I89r.

Ohne näheren Fundort; 2 Individ.; Stuhlmann S.

Volkens bemerkt: „Die Kröte ist im Kilima-Ndjaro häufig an Bächen und Wasserleitungen des Kulturlandes. Schreit Abends laut. « Das letztere dürfte nicht richtig sein. 
Böhm unterscheidet zwei Krötenarten in Ostafrika: „Eine, deren Hinterschenkel oben schön roth sind, wie schon Günther angiebt. Diese häufigste Kröte kommt Abends aus ihren tiefen Löchern an Brunnen und Gräben zum Vorschein, wo sie auf zwei Noten abwechselnd ruft. Streift von dort durch die Felder. Die zweite Art mit rothen Tuberkeln. Die Jungen mit hellem Rückenstreif. Legt Anfang Febr. ihre zwei Eierschnüre ab. Leider sind die grossen eingesammelten Exemplare dieser Art verdorben."

Was Böhm für zwei ostafrikanische Krötenarten hält, sind zwei Varietäten der Bufo regularis, die sich genau so voneinander unterscheiden, wie die Varietät Bufo carens var. carens Smitl von Bufo carens var. vertebralis Smith. Die eine Varietät (entsprechend vertebralis) ist formlos wie unsere Kröte und über den ganzen Körper mit gleich grossen Drüsen besät. Gefärbt ist sie im Alter schmutzig grau mit dunkeln Flecken und Streifen.

Die andere Form (carens) hat einen deutlich gegen die Körperseiten abgesetzten, flach ausgebreiteten hellen Rücken, der eingefasst ist durch eine schwarze Binde, die rom Auge zur Vorderseite des Hüftgelenks streicht. Vom Auge zieht ein weisser Streif zur Mitte des Mundes und ein mit demselben zusammenhängender gleichgefärbter zur Vorderseite des Mundes. Die auf dem Rückenfelde in der Mitte und nach dem Kopf hin gelegenen Drüsen sind klein, dagegen die nahe dem Oberschenkel gelegenen sehr gross.

Was Böhm über die Färbung seiner beiden Arten sagt, dürfte berechtigt sein für gewisse Altersstufen der beiden Varietäten: Die Entwicklung der Rückenfärbung verläuft in beiden Varietäten ähnlich wie die der Bufo calamita: Aus den schwarzen Larven werden beim Uebergange auf das Land durch Verblassen netzartig zu:ammenhängender Rückenpartien gelb-graue Junge mit dunkeln Flecken, dann nimmt die Abfärbung der Thiere weiter zu und zwar dadurch, dass aus noch erhaltenen dunkeln Chromatophoren blutrothe entstehen, sodass nunmehr bei den Thieren schwarze und blutrothe Flecke in gelb-grauer Oberkörperfarbe liegen. Bei ihrem weiteren Wachsthum verschwinden die rothen Flecke in Folge weiteren Pigmentschwunds in ihren Chromatophoren, ebenso verschwinden viele schwarze Flecke, die Thiere werden dadurch mehr und mehr gelb-grau.

Es ist wahrscheinlich, dass die beiden Varietäten in der Ausbildung der rothen Flecke gewisse Unterschiede zeigen, da sie ja überhaupt abweichend voneinander gefärbt sind; wenigstens fand ich bei halberwachsenen Individuen der carens-Form keine rothe Oberschenkelflecke, dagegen die von Böhm erwähnten srothen Tuberkeln«. Bei halberwachsenen Individuen der plumpen, formlosen Varietät fand ich jene rothen Oberschenkelflecke, allerdings auch sehr zahlreiche rothe Rückenflecke, vorwiegend hier in der Nachbarschaft der Tuberkeln.

Dass nur die Jungen der einen Varietät in der Rückenlinie einen weissen Streifen haben, ist ein Irrthum Böhms. Mir liegen völlig Erwachsene beider Varietäten vor, die diese weissen Rückenstreifen haben; der Rückenstreif ist also auch kein Jugendcharakter der Individuen.

\section{Bufo carens, Sm.}

Usaramo; I Individ.; Stuhlmann S.

Bukoba; I Individ.; Stuhlmann S.; Jan. oder März 1892.

Das Thier aus Usaramo ist die Var. vertebralis Smith, das andere die Var. carens Smith.

\section{Bufo steindachneri, Pfeff.}

Kihengo; I Individ.; Stulılmann S.; 12. Sept. 1888. Pfeffer in Stuhlmann $\mathrm{X}$, S. 35 , mit Artbeschreibung. 


\section{Subordnung: Aglossa.}

\section{Familie 1.: Dactylethridae.}

\section{Xenopus mülleri, Ptrs.}

Sansibar; I Individ, Sir J. Kirk S.; Boul., Cat. Bat. S. 458.

Sansibar; Sumpf bei Kibueni; 6 ganz junge; Stuhlmann S.; 2. Mai I 888. Pfeffer in Stuhlmann X, S. 36.

Sansibar; I7 Larven; Stuhlmann S.; 27. Mai I $88 S$

Sansibar; I Individ.; Stuhlmann S.; I2. Juli I 888

Sansibarinsel; I Individ.; Stuhlmann S.; 6. August 1888

Sansibarinsel; 7 Larven; Stuhlmann S.; 6. August I 888

Sansibarsumpf; 3 Larven; Stuhlmann S.; 6. August I 888

Sansibar; 19 Larven, I alt; Stuhlmann S.; I 5. Juni i 889

Pfeffer

in Stuhlmann X, S. 36 .

3I. Mai I 888 .

Bueniriff südlich von Sansibar; I Individ.; Stuhlmann S.; 3. August I 889.

Sansibarküste; 6 Individ.; Hildebrandt S.; Mus.-Nro. 8590.

Tanga in Usambara; 4 Individ.; Oscar Neumann S.

Dar es Salaam; alle Entwicklungsstadien (I 8 Larven, 4 Junge, 4 Erwachsene); Stuhlmann S.; I 895 .

Dar es Salaam; 6 Individ.; Stuhlmann S.; I 894.

Sumpf östlich von Irangi; 3 Individ.; Oscar Neumann S.

Kakoma; 9 Individ.; Böhm S.

Kakoma; alle Entwicklungsstadien; Böhm S.

Kawendi, Katani Mbuga; 2 Individ.; Paul Reichard S.; 1885.

Bukoba; I Individ.; Stuhlmann S.; Februar I 892.

Böhm schreibt über diese Art: "In allen Teichen und Tümpeln, so auch in den Brunnengruben der Ortschaften häufig und zur Regenzeit in den Feldern, Abends bis in die Gehöfte und Häuser kommend. - Wo das Wasser zur Trockenzeit ganz versagt, gräbt sich die Krallenkröte gleich anderen Amphibien und kleinen Siluriden in den Schlamm ein und verfällt hier in Torpor. Trotz ihres plumpen Körperbaues vermögen sie mit den kräftigen Hinterextremitäten stark ausschnellend weite Sätze zu machen. Mit ihren Nägeln können sie ganz ordentlich kratzen.

Die junge Brut findet man vom ersten Regen an in allen Tümpeln. Mitte Mai haben viele Larven noch dicke, walzenartige Köpfe, lange Bartfäden und unverkürzten Ruderschwanz. Am 26. März die ersten mit hervorbrechenden hinteren Extremitäten, am I9. April solche mit vier vollständigen Füssen; dieselben tragen noch immer ihren kolossalen Fischkopf und die langen Tentakeln. Ihr Ruicken war bereits dunkel marmorirt. Obgleich mir ein »dorsal-disk «nicht deutlich geworden, möchte ich doch Silurana tropicalis Gray (Proc. zool. Soc. I 864 p. 45 ff.) mit diesen Larven für identisch halten.

Bei den Thieren aus Irangi sind die unter den Augen befindlichen Zäpfchen nicht so lang, wie der Augendurchmesser.

Thiere aus Kakoma: Diese drei Exemplare sind sehr interessant, weil bei ihnen allen genau in der Mitte zwischen den Choanen Zahnspuren zu finden sind. Das eine besitzt drei deutlich entwickelte Zähne, das andere eine, wie es scheint, in zwei Partien gesonderte Kauplatte, beim dritten und grössten Thier sind auf der Platte die Zähne kaum angedeutet.

Von den Dar es Salaam-Exemplaren haben 2 keine, 3 entwickelte Palatinzähne. 


\section{Xenopus laevis (Daud.)}

Bukoba; I Individ; Stuhlmann S.; Februar I892.

Kafuro (Karagwe); 3 Individ.; Stuhlmann S.; IO. März I89I; I350 m über dem Meere.

Alle 4 Individuen entsprechen genau dieser Art, denn sie haben den kleinen Metatarsaltuberkel und die winzigen Zäpfchen unter den Augen.

Oben oliv, unten weiss mit grauen Flecken, Schenkel unten rostroth.

\section{Xenopus boettgeri n. sp.}

Ituri-Fähre bei Wandesoma; I Individ, Stuhlmann S.; IS9I.

Finger mit halber Schwimmhaut; Zehen nur $3 / 4$ Schwimmhaut; Nas. löchernach vorngerichtet; das ganze Thier durch spitze Tuberkeln rauh.

Am nächsten stehend Xenopus calcaratus. Kopf klein; Schnauze kurz, abgerundet, ohne Canthus rostralis; Naslöcher direkt nach vorn gerichtet; Augen nach oben, klein, ihr Durchmesser $I^{1} / 3$ mal enthalten im Oberlippenrand vom Auge bis zur Schnautzenspitze; Stirnbreite zwischen den Augen circa $2^{1} / 4 \mathrm{mal}$ so gross wie der Augendurchmesser; oberes Augenlid auf eine blosse Hautfalte reduzirt; Finger schlank, zugespitzt, nicht gleich an Grösse: die beiden äusseren grösser als die inneren; mit halber Schwimmhaut. Zehen sehr ungleich, die dritte die längste, dann die vierte, dann die zweite und erste; nur Dreiviertel-Schwimmhaut; die drei inneren mit schwarzen Krallen. Die Hintergliedmaassen vorwärts am Körper entlang geführt, reichen mit dem Tarsusmetatarsus-Gelenk genau bis zum Auge. Der äussere und innere Metatarsus sind durch eine tiefe Grube voneinander ge-

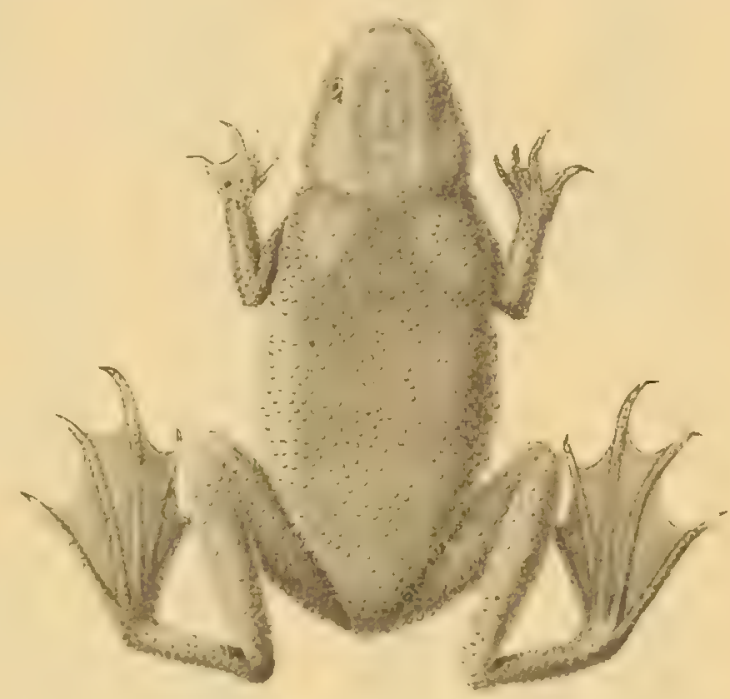

Fig. L. trennt. Haut rauh durch sehr viele Stacheln; besonders an den Körperseiten Stacheln von verschiedener Grösse und dann je ein grosser Stachel umgeben von einem Kranz kleiner; am kleinsten die Stacheln des Kopfes und des Rückens, am grössten die der Seiten und besonders die der Hintergliedmaassen, wo sie sogar die Zehen bis an die Spitzen bedecken. Die bei den anderen Xenopusarten an den Seiten liegenden, fast parallelen Rillen fehlen.

Oben und unten braun-schwarz, unten an vielen Stellen heller als am Rücken.

\section{Ordnung: Gymnophiona.}

\section{Familie: Coeciliidae.}

\section{Hypogeophis güntheri, Blgr.}

Sansibar; I Individ., alt.; J. E. Parisch S.; Boul., Cat. of Batr. sal., S. 97. Sansibar; 6 Individ., jung.; J. Kirk S.; Boul., Cat. of Batr. sal., S. 97. Sansibar; I Individ., jung.; J. Kirk S.; Mus.-Nro. 10407. 


\section{Scolecomorphus kirki, Blgr.}

Wahrscheinlich Nähe des Tanganyika-Sees; I Individ.; J. Kirk S.; Boulenger, Ann. Mag. nat. hist. 1883 , S. 48 mit Artbeschreibung.

\section{Bdellophis vittatus Blgr.}

Usambara; I Individ.; Linnaea Berlin S.; Boulenger, Proceed. zool. Soc. London, 1895, S. 412.

Buloa bei Tanga in Usambara; 2 Individ.; G. Eismann S.; 1895.

\section{Boulengerula boulengeri n. g., n. sp.}

Usambara; 5 Individ.; Gustav Eismann S.; I 895. (Boulenger bestimmt.)

Diese Coeliengattung steht zwischen den Gattungen Gegenophis und Scolecomorphus ( 5 und 16 der von Boulenger gegebenen Synopsis, P. Z. S. I 895 , p. 403), denn bei ihr berihren sich, wie bei Gegenophis die Parietalia und Squamosa, dagegen haben sie, wie Scolecomorphus, nur eine einzige Reihe von Zähnen im Unterkiefer.

Die Gattungsdiagnose ist demnach: Squamosum in Kontakt mit dem Parietale. Im Unterkiefer eine einzige Zahnreihe. Augen überdacht. Tentakel konisch, ausstreckbar, gleich weit vom Nasloch und der Kiefersymphyse entfernt. Keine Schuppen.

Die Artdiagnose ist: I32 Leibesringel. Färbung: Blaugrau, der Rücken gewöhnlich dunkler als der Bauch. Länge: $23,5 \mathrm{~cm}$.

\section{Figurenerklärung.}

Taf. I: Farbleidmuster der Art Lygodactylus picturatus Ptrs.

II, Fig. I-2: Pachydactylus boulengeri n. spec.

» 3: Chamaeleon sphaeropholis Rchw.

4: Kopf des Chamaeleon fischeri Rchw.

5: Chamaeleon temporalis Mtsch.

6: Chamaeleon spinosus Mtsch.

7: Rhampholeon brevicaudatus Misch.

8: Kopf des Chamaeleon deremensis Mtsch.

9: Kopf des Chamaeleon taitensis Steind.

III: Kopflappen-Beschilderung bei vier Individuen von Chamaeleon dilepis Leach.

IV: Farbkleidmuster der Gattung Rappia.

V, Fig. I-4: Vier Hylambates aubryi (A. D.) $3+4=$ mula frde thish

" " " 5-I4: Farbkleider der Körperober-und Unterseite bei Homalosoma.

Textfig. A: Querschnitt durch die Rückenschale von Stenothaerus sinuatus.

B: Vier Kopfzeichnungen von Zonurus tropidosternum Cope.

C: Durchschnitte durch Chamaeleonhörner.

D: Beide Kopfseiten einer Chlorophis irregularis (Leach.).

E: Beide Kopfseiten eines Ramphiophis rostratus.

F: Vomerzähne bei vier Rana bravanus Ptrs.

G: Schwimmhäute an Händen und Füssen bei Rappia.

$\mathrm{H}$ : Schallblasenentwicklung bei Rappia flavoviridis.

I: Rappia flavomaculata (A. D.).

K: Farblkleider von Rappien, entsprechen Taf. IV, Fig. 50, 56 u. 77-83.

I.: Xenopus boettgeri n. spec. 


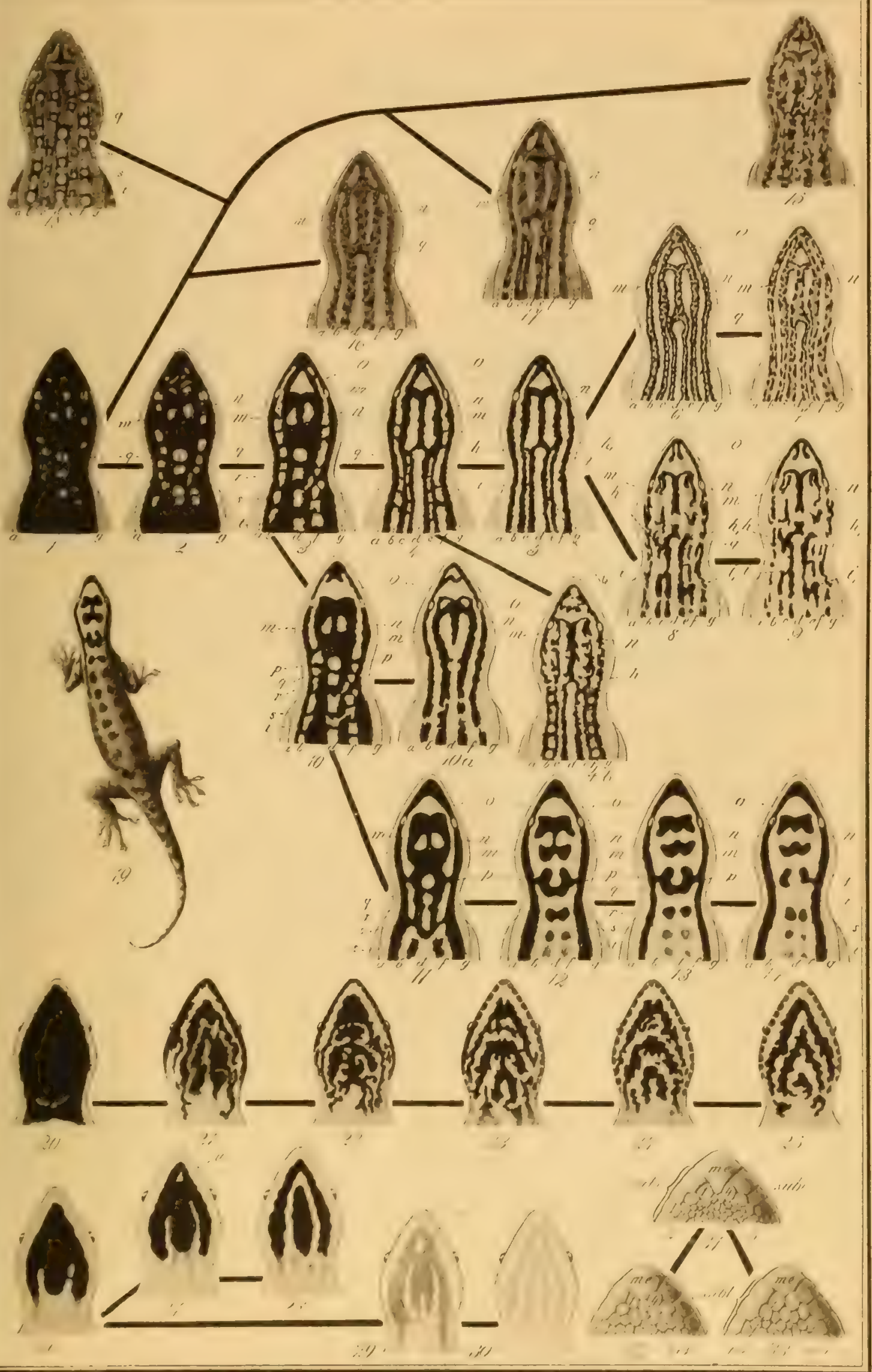

Ew. H. Rübsaamen del. 



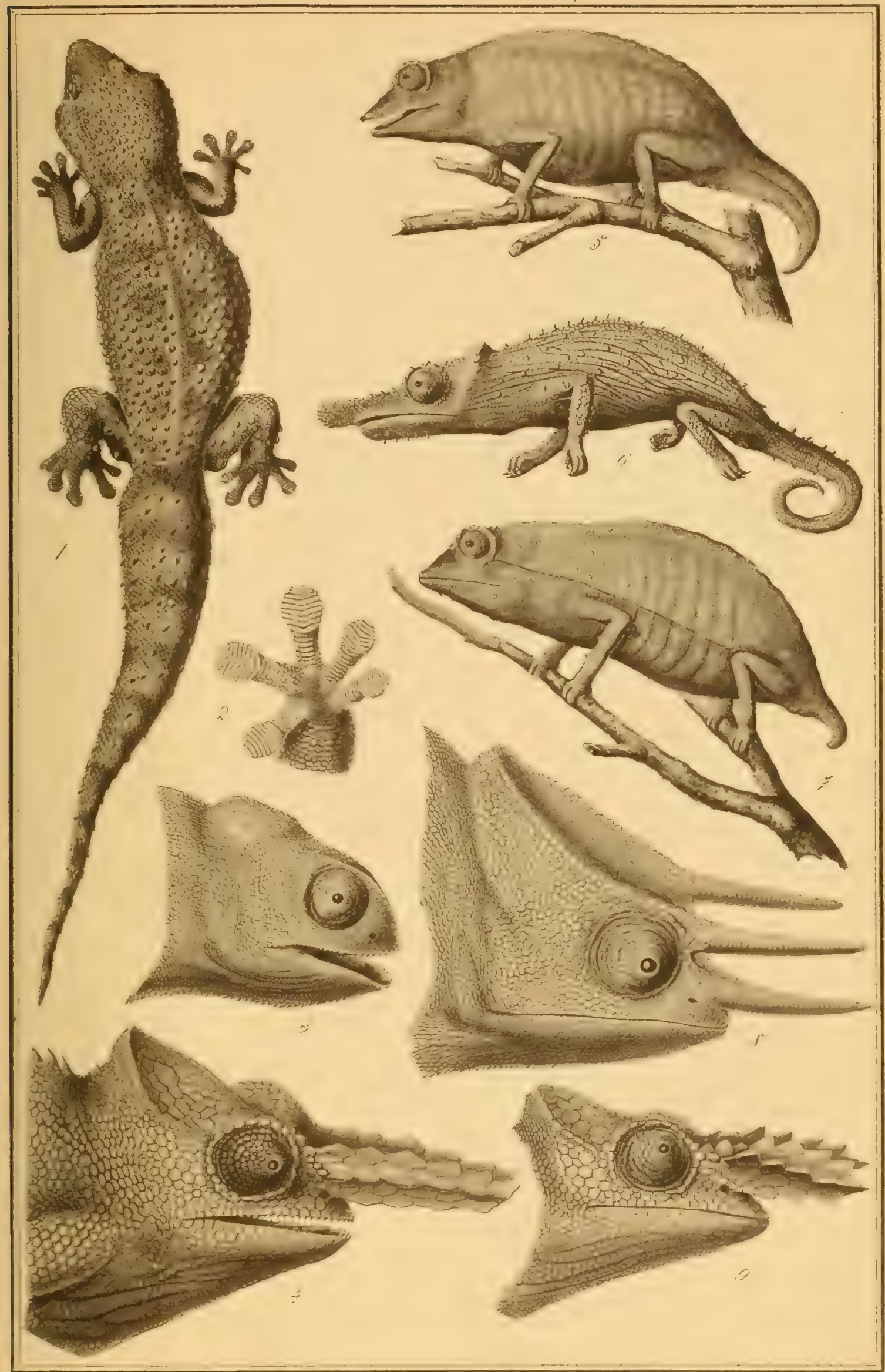

Er. H. Rübsaamen del. 



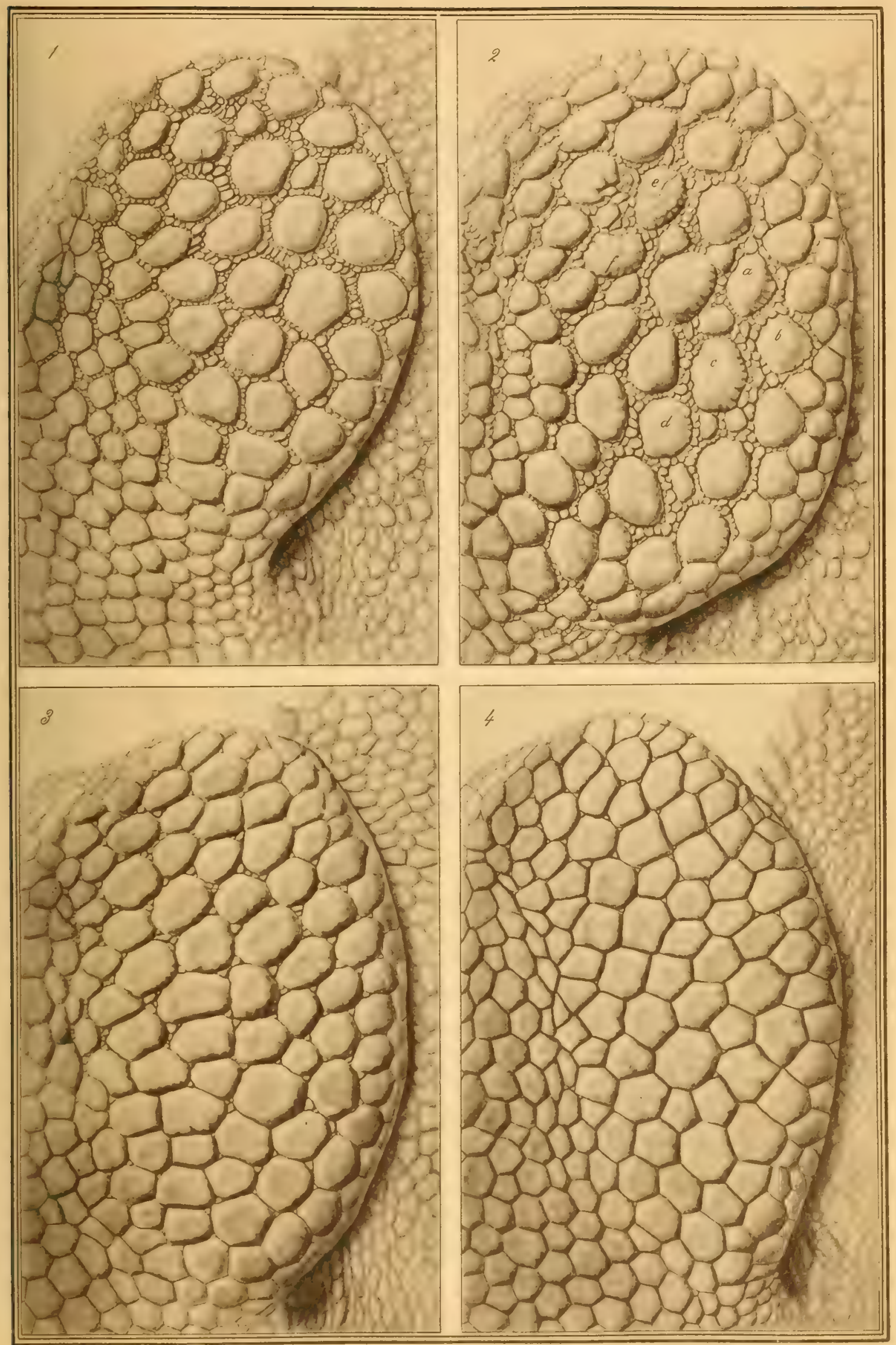

Ew. H. Rübsaamen del. 





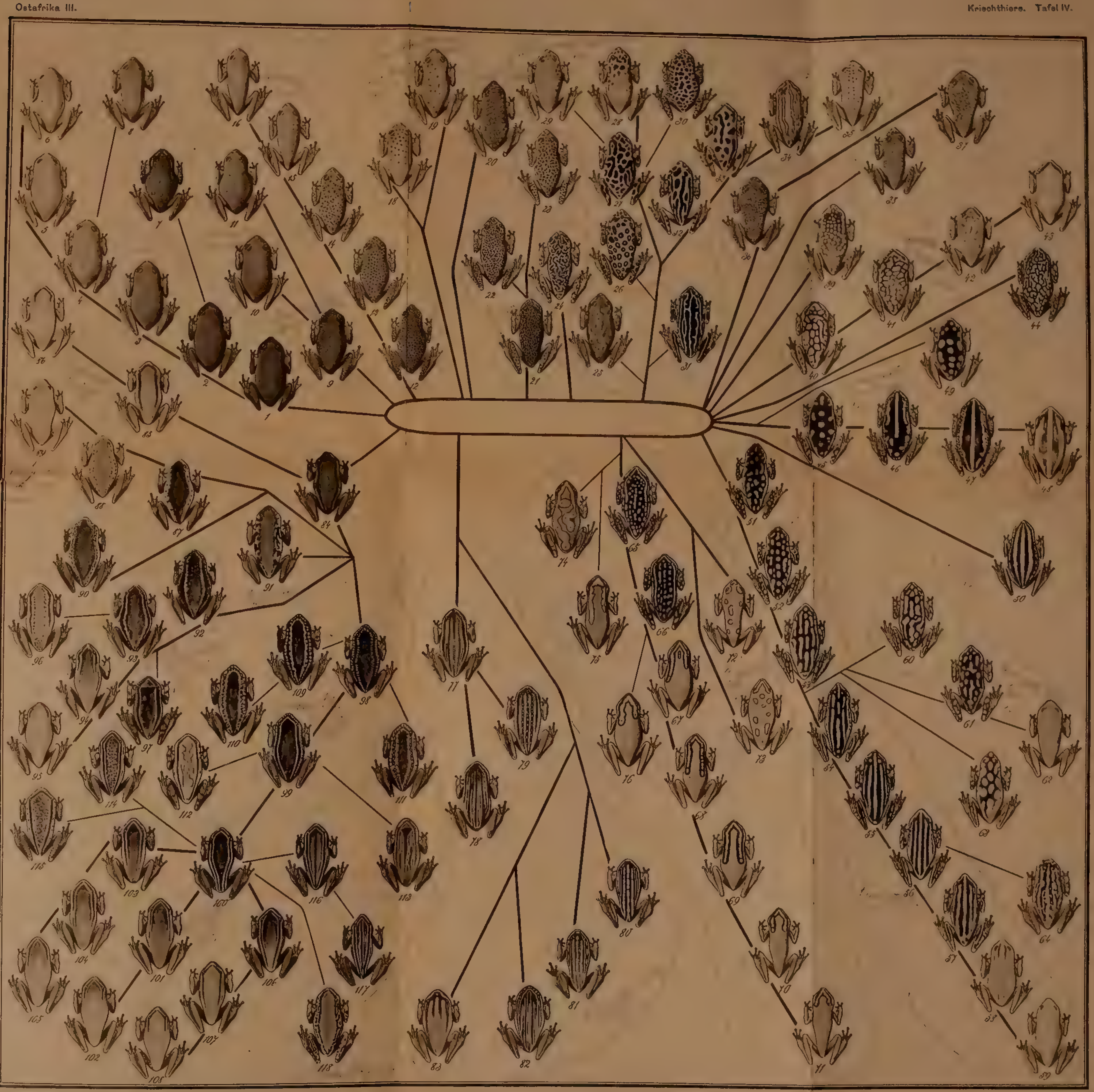

Ew. H. Rilbsaamen del. 



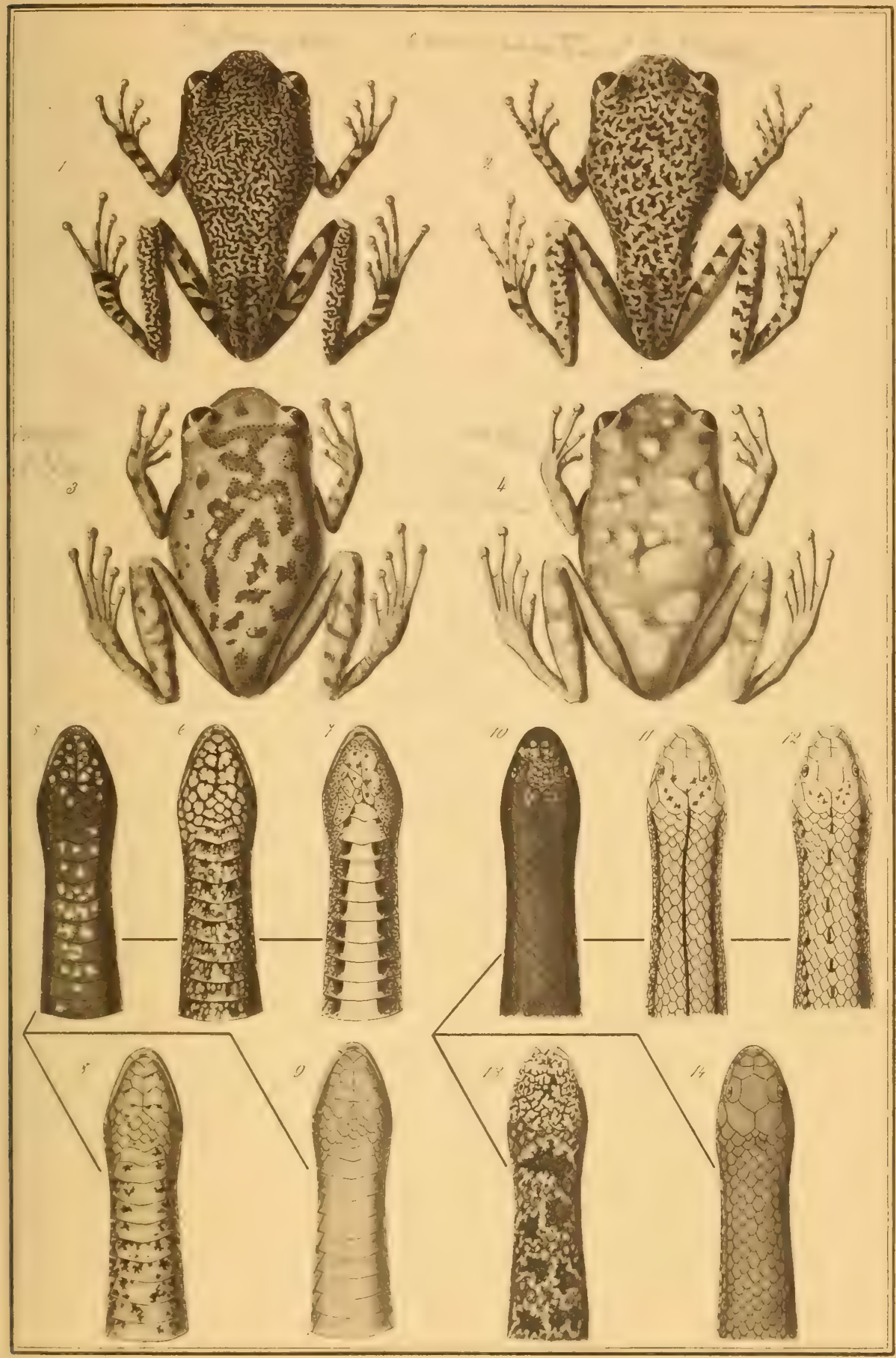

Ew. H. Ruibsaamen del. 





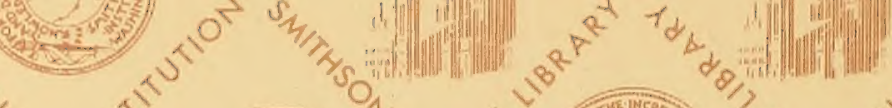

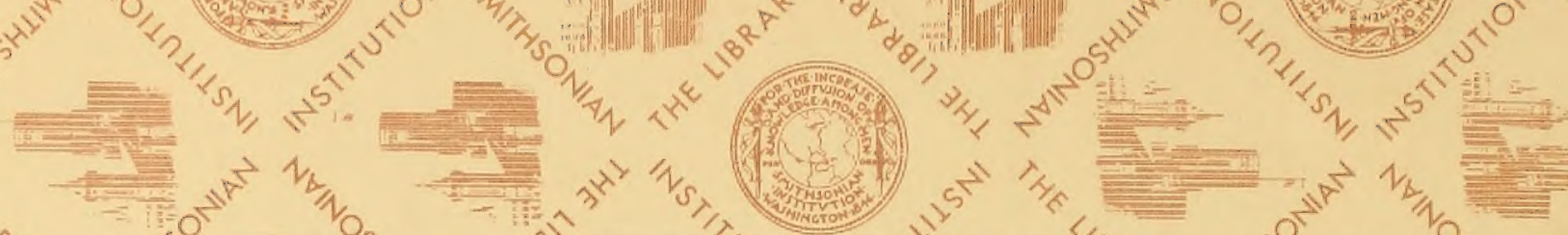

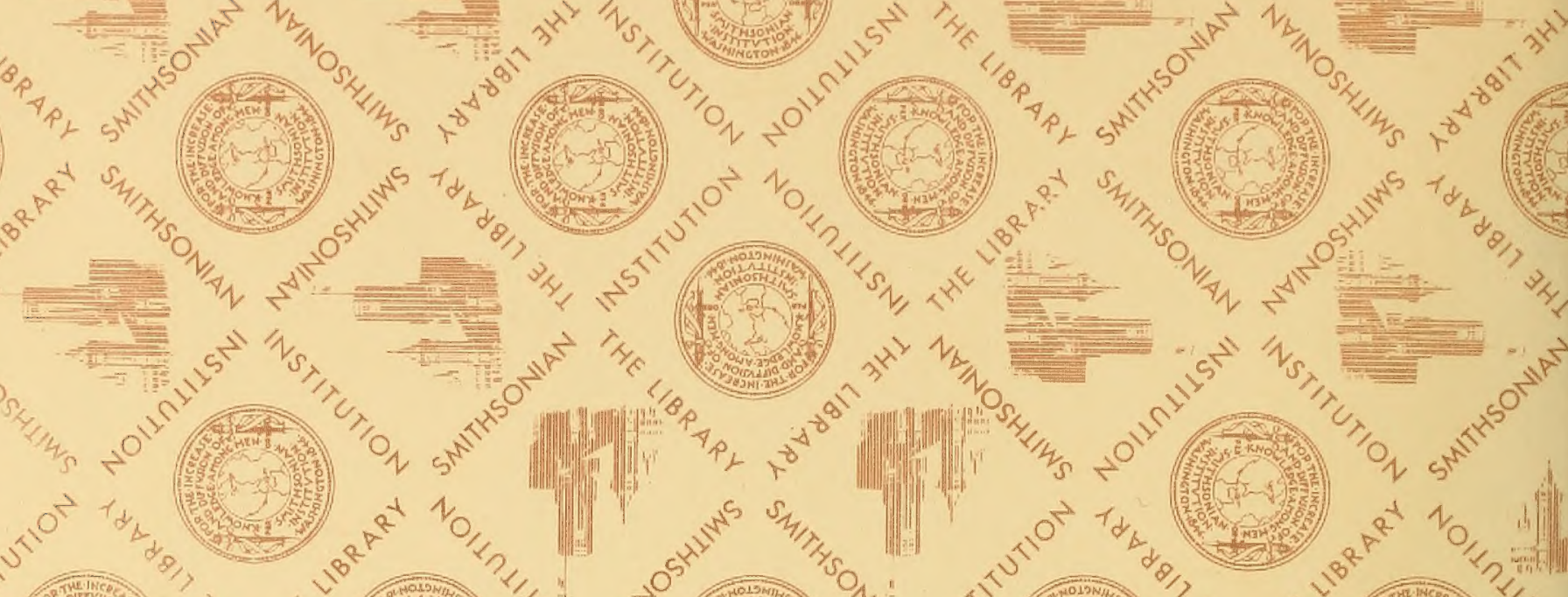

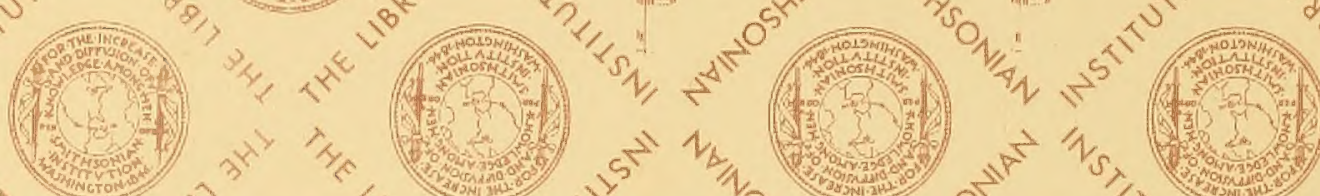

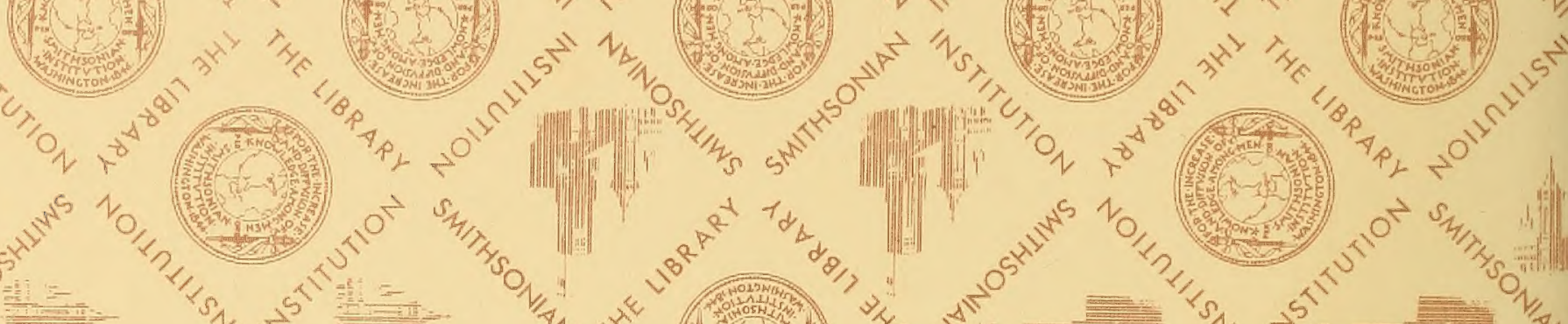

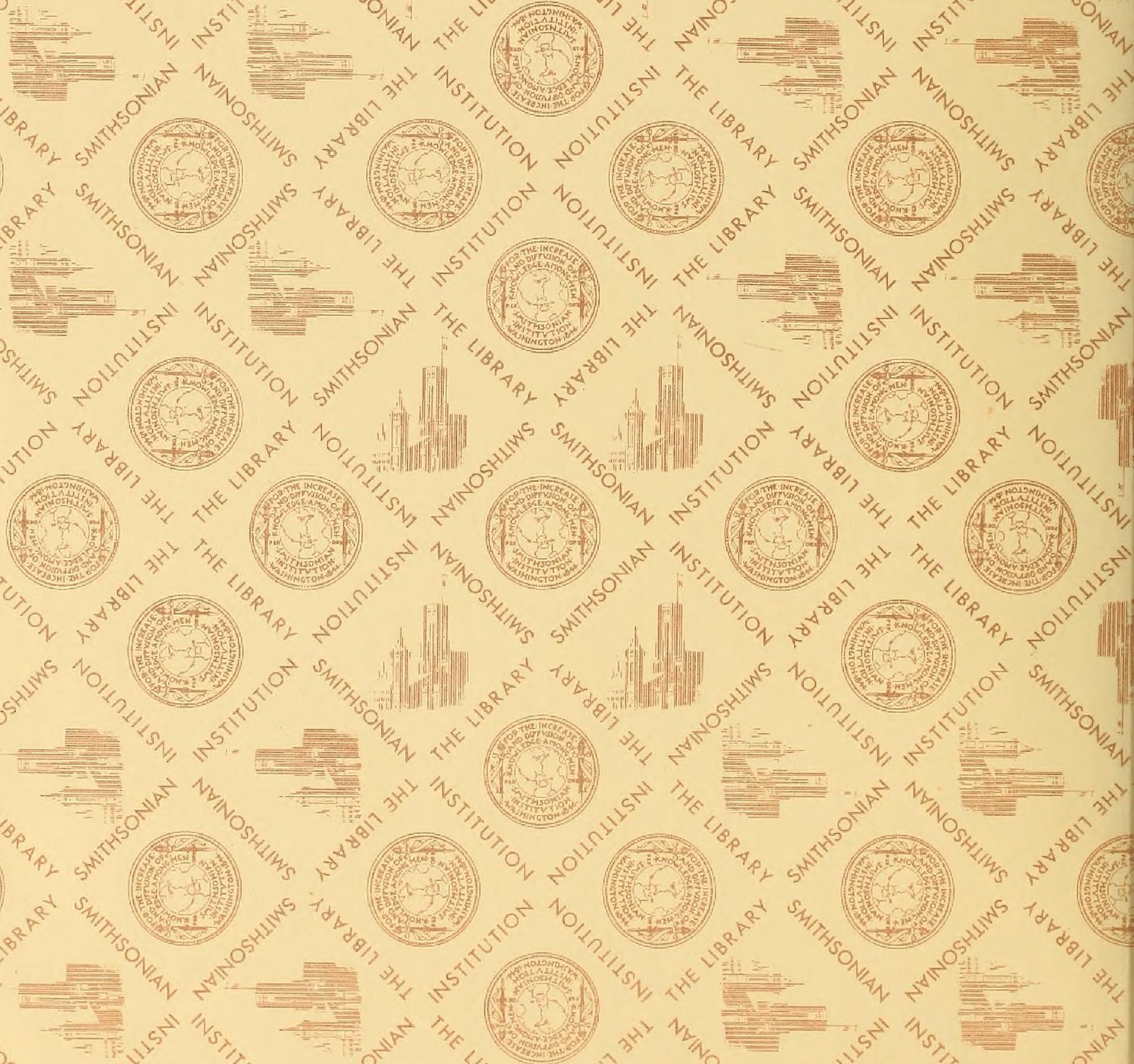

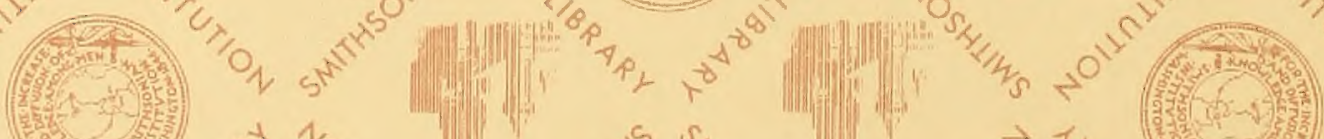



SMITHSONIAN INSTITUTION LIBRARIES 